URBAN PLAY AND THE PLAYABLE CITY: A CRITICAL PERSPECTIVE

EDITED BY: Yoram Chisik, Ben Schouten, Mattia Thibault and Anton Nijholt PUBLISHED IN: Frontiers in Computer Science and Frontiers in Psychology

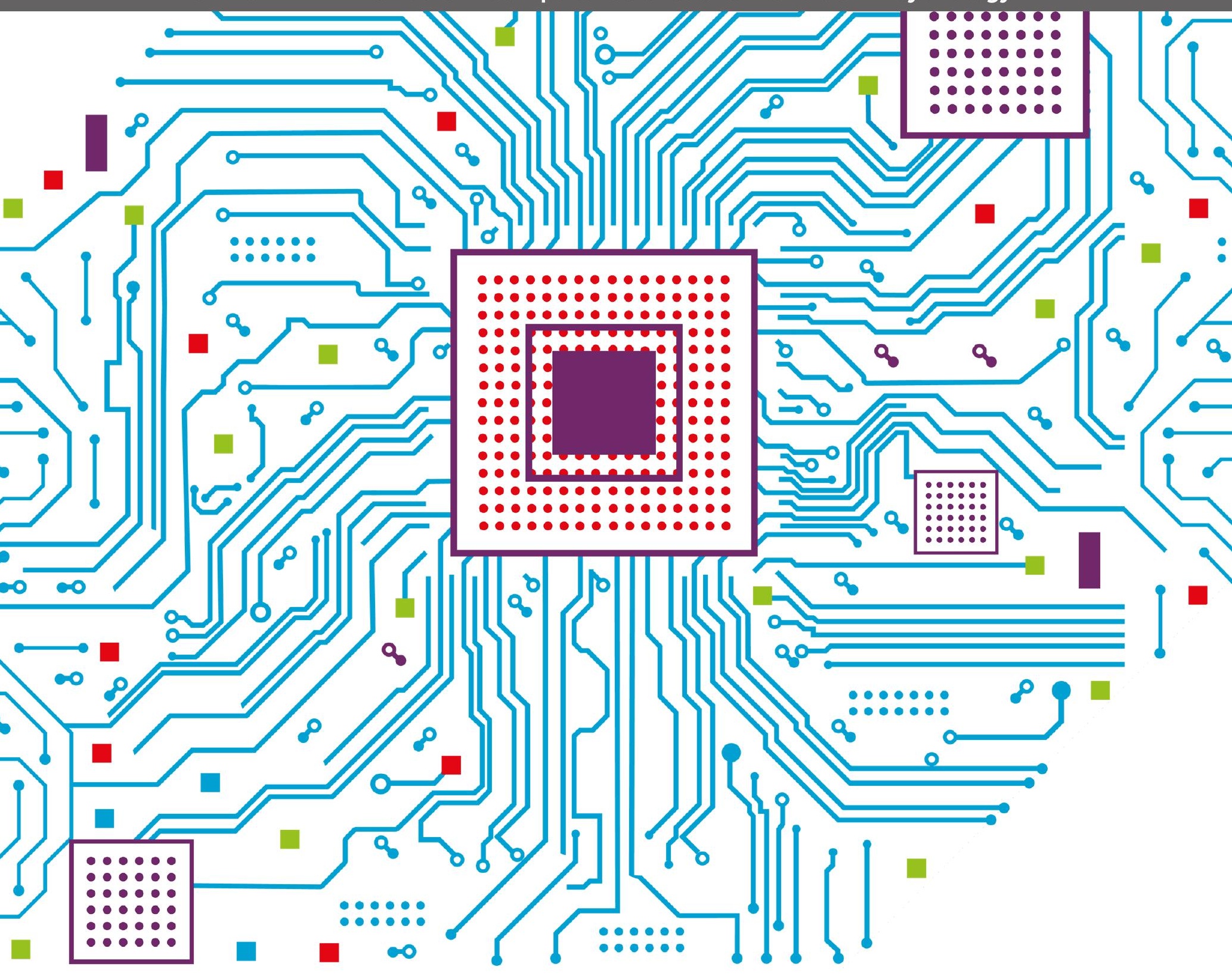




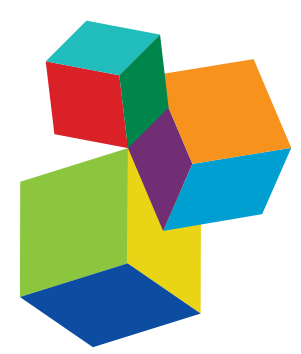

Frontiers eBook Copyright Statement

The copyright in the text of individual articles in this eBook is the property of their respective authors or their respective institutions or funders. The copyright in graphics and images within each article may be subject to copyright of other parties. In both cases this is subject to a license granted to Frontiers.

The compilation of articles constituting this eBook is the property of Frontiers.

Each article within this eBook, and the eBook itself, are published under the most recent version of the Creative Commons CC-BY licence. The version current at the date of publication of this eBook is CC-BY 4.0. If the CC-BY licence is updated, the licence granted by Frontiers is automatically updated to the new version.

When exercising any right under the CC-BY licence, Frontiers must be attributed as the original publisher of the article or eBook, as applicable.

Authors have the responsibility of ensuring that any graphics or other materials which are the property of others may be included in the

CC-BY licence, but this should be checked before relying on the

CC-BY licence to reproduce those materials. Any copyright notices relating to those materials must be complied with.

Copyright and source acknowledgement notices may not be removed and must be displayed in any copy, derivative work or partial copy which includes the elements in question.

All copyright, and all rights therein, are protected by national and international copyright laws. The above represents a summary only.

For further information please read Frontiers' Conditions for Website

Use and Copyright Statement, and the applicable CC-BY licence.

ISSN 1664-8714

ISBN 978-2-88974-422-0

DOI 10.3389/978-2-88974-422-0

\section{About Frontiers}

Frontiers is more than just an open-access publisher of scholarly articles: it is a pioneering approach to the world of academia, radically improving the way scholarly research is managed. The grand vision of Frontiers is a world where all people have an equal opportunity to seek, share and generate knowledge. Frontiers provides immediate and permanent online open access to all its publications, but this alone is not enough to realize our grand goals.

\section{Frontiers Journal Series}

The Frontiers Journal Series is a multi-tier and interdisciplinary set of open-access, online journals, promising a paradigm shift from the current review, selection and dissemination processes in academic publishing. All Frontiers journals are driven by researchers for researchers; therefore, they constitute a service to the scholarly community. At the same time, the Frontiers Journal Series operates on a revolutionary invention, the tiered publishing system, initially addressing specific communities of scholars, and gradually climbing up to broader public understanding, thus serving the interests of the lay society, too.

\section{Dedication to Quality}

Each Frontiers article is a landmark of the highest quality, thanks to genuinely collaborative interactions between authors and review editors, who include some of the world's best academicians. Research must be certified by peers before entering a stream of knowledge that may eventually reach the public - and shape society; therefore, Frontiers only applies the most rigorous and unbiased reviews.

Frontiers revolutionizes research publishing by freely delivering the most outstanding research, evaluated with no bias from both the academic and social point of view. By applying the most advanced information technologies, Frontiers is catapulting scholarly publishing into a new generation.

\section{What are Frontiers Research Topics?}

Frontiers Research Topics are very popular trademarks of the Frontiers Journals Series: they are collections of at least ten articles, all centered on a particular subject. With their unique mix of varied contributions from Original Research to Review Articles, Frontiers Research Topics unify the most influential researchers, the latest key findings and historical advances in a hot research area! Find out more on how to host your own Frontiers Research Topic or contribute to one as an author by contacting the Frontiers Editorial Office: frontiersin.org/about/contact 


\section{URBAN PLAY AND THE PLAYABLE CITY: A CRITICAL PERSPECTIVE}

Topic Editors:

Yoram Chisik, Independent researcher, Israel

Ben Schouten, Eindhoven University of Technology, Netherlands

Mattia Thibault, Tampere University, Finland

Anton Nijholt, University of Twente, Netherlands

Citation: Chisik, Y., Schouten, B., Thibault, M., Nijholt, A., eds. (2022). Urban Play and the Playable City: A Critical Perspective. Lausanne: Frontiers Media SA. doi: 10.3389/978-2-88974-422-0 


\section{Table of Contents}

04 Editorial: Urban Play and the Playable City: A Critical Perspective Yoram Chisik, Anton Nijholt, Ben Schouten and Mattia Thibault

07 A Planning Game Over a Map: Playing Cards and Moving Bits to Collaboratively Plan a City

Micael Sousa

19 Together We Can Make It Work! Toward a Design Framework for Inclusive and Participatory City-Making of Playable Cities

Geertje Slingerland, Stephan Lukosch, Mariëlle den Hengst, Caroline Nevejan and Frances Brazier

35 Urban (Digital) Play and Right to the City: A Critical Perspective Eunice Castro Seixas

40 Urban Play as Catalyst for Social Wellbeing Post-Pandemic Troy Innocent and Quentin Stevens

43 The Participant Journey Map: Understanding the Design of Interactive Augmented Play Spaces

Danica Mast, Sanne I. de Vries, Joost Broekens and Fons J. Verbeek

62 Catch the Bus: Probing Other-Than-Human Perspectives in Design Research Viktor Bedö

72 Interactive Urban Play to Encourage Active Mobility: Usability Study of a Web-Based Augmented Reality Application

Michael Oduor and Timo Perälä

84 Adventure Mode: A Speculative Rideshare Design

Stephanie Sherman, Ash Eliza Smith, Deborah Forster and Colleen Emmenegger

90 To Play and To Be Played: Exploring the Design of Urban Machines for Playful Placemaking

Louis Chew, Luke Hespanhol and Lian Loke 


\title{
Editorial: Urban Play and the Playable City: A Critical Perspective
}

\author{
Yoram Chisik ${ }^{1}$, Anton Nijholt ${ }^{2 *}$, Ben Schouten ${ }^{3}$ and Mattia Thibault ${ }^{4}$ \\ ${ }^{1}$ Independent Researcher, Haifa, Israel, ${ }^{2}$ Human Media Interaction, University of Twente, Enschede, Netherlands, \\ ${ }^{3}$ Department of Industrial Design, Eindhoven University of Technology, Eindhoven, Netherlands, ${ }^{4}$ Gamification Group, \\ Tampere University, Tampere, Finland
}

Keywords: playable cities, smart cities, urban games, urban design, human-computer interaction

\author{
Editorial on the Research Topic
}

Urban Play and the Playable City: A Critical Perspective

\section{INTRODUCTION}

Cities by their very nature are utilitarian creations built to support both the physical and symbolic needs of the communities that built and inhabit them and are capable of representing the societies and cultures that they host. However, the nature of the urban environment and its affordances is such that it easily invites play in both its construction (architecture) and the different kinds of interactions that take place within its confines. While cities, by design, offer opportunities for structured and unstructured play in the playgrounds, ball courts, and game boards constructed by municipalities, at the same time, they often host more spontaneous games and playful activities that repurpose or harness the city infrastructure and bend it to their own-playful-logic. These have a rather wide range. They include traditional games, such as hide and seek, treasure hunting, or tag, that harness the physical features of the immediate surroundings of the players and that can be augmented through technology with applications such as Picoo (Picoo, 2021) or within larger projects such as in geocaching (O’Hara, 2008).

They also include playful activities that are oriented toward the community inhabiting such

Edited and reviewed by: Kaleem Siddiqi,

McGill University, Canada

*Correspondence: Anton Nijholt a.nijholt@utwente.nl

Specialty section: This article was submitted to Human-Media Interaction, a section of the journal

Frontiers in Computer Science

Received: 31 October 2021 Accepted: 09 December 2021 Published: 11 January 2022

Citation:

Chisik Y, Nijholt A, Schouten B and Thibault M (2022) Editorial: Urban Play and the Playable City: A Critical

Front. Comput. Sci. 3:806494 doi: 10.3389/fcomp.2021.806494 spaces and related to forms of territorialization, such as Parkour (Ameel and Tani, 2012), of political activism, as in flash mobs, and of interaction with the community through games such as Massively Multiplayer Soba, which builds on the concept of a treasure hunt to challenge players to engage and interact with the local community in a particular area of a city (Flanagan, 2010). They also encompass location-based games, that very often take place exactly in urban spaces, such as Pokémon Go, and that use the entire city as their playground (Hjorth and Richardson, 2017).

Apart from entertainment, these forms of play can serve multiple purposes. During the first phase of social distancing and quarantine due to the COVID-19 pandemic, for example, urban play became an important factor of resilience, with playful activities concentrating on spaces such as windows, balconies, and rooftops (Thibault and Baer, 2021).

Urban play can even go beyond the use of the spaces of the city and include their design, offering a possibility to discuss and plan through stories and roleplay, issues that matter to local communities (Schouten et al., 2019). A noteworthy example is Play the City (Tan, 2017) a roleplaying game for collaborative decision-making on new housing projects, infrastructure, or social cohesion amongst others (Schouten et al., 2017). What all these games and activities have in common is that they happen outside the traditional cultural boundaries reserved to play, and creatively "invade" new spaces-both physical and digital. Recently, the notion of the playable city has emerged as a counterpoint to the "smart city" whereby the array of sensors and actuators that enable smart city infrastructure can be harnessed to create novel interactions and playful experiences within the 
city - by lending an ear to trees, giving a voice to park benches, stairs, and garbage cans, or reviving the shadows that pass in the night-thereby enabling a host of new interactions and experiences and raising new challenges and concerns about distraction and duplicity (Nijholt, 2016, 2019).

In this Research Topic, we compare and contrast the various forms of play that occur in urban environments or are dedicated to their design and planning, with the notion of the playable city. In a playable city, the sensors, actuators, and digital communication networks that form the backbone of smart city infrastructure are used to create novel interfaces and interventions intended to inject fun and playfulness into the urban environment, both as a simple source of pleasure and as a means of facilitating and fostering urban and social interactions.

\section{CONTRIBUTIONS}

This Research Topic will include nine peer-reviewed papers of which five are dedicated to original research, two are perspectives, one is a comparative analysis, and the last is an opinion piece. These articles are collectively dedicated to various themes and perspectives. The contributions focus on different forms of play (ranging from playing cards to parkour) and technologies (including AR, smart benches, and transportation) and engage the concept of playable cities from different angles.

Sousa explores the use of board game mechanics as a means of sparking discussion and ideation in urban planning co-design sessions. The paper describes the rationale behind the approach and the game design process through which the author and a group of students at the University of Coimbra shaped an initial idea into a collaborative design methodology that can be adapted to the specific needs of disparate design inquiries and planning scenarios.

In their paper Slingerland et al. define a framework for inclusive and participatory city-making from a bottom-up perspective aligning all possible stakeholders. The framework is based on several interviews with community officers and a real case of a new housing project called Bouwlust (Desire to Build). It emphasizes playfulness, community building, inclusiveness, and sustainability. To set design requirements for participatory city-making projects it suggests and defines four activities: connecting with the neighborhood, identifying key stakeholders, data gathering and analysis, and reflection.

Innocent and Stevens argue in an opinion paper, that the COVID-19 pandemic created an opportunity to reimagine city life, the function of public spaces, and urban planning policies. They give examples of urban play and recreational activities during the pandemic, reflective walking and the rediscovery of local neighborhoods, and public art projects that comply with social distancing constraints. Creativity and social life were challenged and were able to adapt to such constraints. Taking Melbourne (Australia) as a model, they posit that responses to COVID-19 should lead to the transforming of public spaces and the re-allocation of urban spaces for play, socialization, and social well-being.
Chew et al. explore the notion of play as place-making by examining the role smart street furniture can play in the design and evolution of future urban landscapes. By using smart benches as a benchmark, they speculate on how technology (playful and otherwise) can be used to not only augment the experiences of those living in urban environments but also to augment the fabric of the city itself by imbuing what until now have been static elements with life and agency of their own.

Bedö introduces a public transport design project that explores similarities between autonomous buses and their users. In this (extension of) a Catch the Bus project, the perspective of an autonomous bus, that is, a non-human, is introduced. The project aims at exploring how, playfully, people, traffic, and autonomous busses engage with each other. It is an exploratory design research approach that decenters from the human perspective and instead focuses on the (non-human) autonomous bus's perspective. What is it like to navigate traffic as a bus? The author concludes that the combination of playfulness, merging the real and fictive, and shifting away from one's perspective to an otherwise inaccessible perspective, is the basis of the epistemological export for design exploration.

In her perspective piece, Seixas looks at studies on the use of urban play for promoting the right to the city with a critical eye. The author offers a short review of studies on urban play that share the idea that play has an intrinsic social value. Confronting this idea with the radical work of Henri Lefebvre, Seixas argues that not all forms of play are necessarily beneficial for citizens and communities and contends that some could instead be used to promote commercialized forms of leisure or to increase urban entrepreneurialism. In the conclusion, the author then suggests that, while the right to play is indeed important, urban play advocates should also explore the citizens' right not to play in the city.

Mast et al. contributed a paper on the positive effects of so-called Augmented Play Spaces, public environments for playful interaction within the city, through a Participant Journey Map consisting of interviews of experts and previous design projects as well as research. The PJM focuses on six transitional play states: "Transit," "Awareness," "Interest," "Intention to participate," "Participation/Play," and "Intention to stop." The Participant Journey Map provides insight into people's engagement with interactive augmented play spaces and the influential factors facilitating their journey, including design recommendations on how to improve the engagement with such interactive playgrounds.

Oduor and Perälä, present their pilot study for a locationbased urban game tested in the city of Oulu, Finland which aimed to promote physical activity in urban public areas through the use of Augmented Reality (AR). The game encouraged players to bike and walk across Oulu to 30 different checkpoints where AR instructions would guide them in a workout session with the public facilities available in the city. A follow-up questionnaire helped the authors to identify the strengths of their app, as well as informed the next steps of development. The conclusions highlight how such experimentations can be useful to explore how to combine the built environment with AR technology to encourage urban exploration, interactions, and active mobility. 
In a perspective article by Sherman et al., we find an example of speculative design (design fiction) (Dunne and Raby, 2013). A speculative rideshare design is proposed that in addition to features that aim at trust and efficiency (route optimization, communication between autonomous vehicles) has an 'Adventure Mode' that rather aims at providing an entertaining rideshare experience. In this mode, the rider can enter some preferences but the journey and destination will be given a playful interpretation. This offers a way of moving through the city, seeing unexpected places, having chance encounters with strangers, and adding playability to the smart city.

\section{CONCLUSIONS}

The picture emerging from the contributions to this Research Topic, with its wide range and different approaches, is one that highlights the potential and pervasiveness of play and games in contemporary cities. While play has always been an essential part of urban life, our contributors show how the technological development within the urban environment appears to go hand in hand with playful uses and "misuses" of technology for play's sake. If the urban environment is becoming increasingly filled with sensors and actuators, AI, and augmentations, all these are susceptible to be reappropriated, overturned, and repurposed to realize their playful potential.

In parallel, our contributors also make a good case for a contemporary social understanding of play that perceives it as

\section{REFERENCES}

Ameel, L., and Tani, S. (2012). Parkour: Creating Loose Spaces? Geografiska Annaler: Series B, Human Geography, Vol. 94. London: Taylor and Francis. $17-30$.

Dunne, A., and Raby, F. (2013). Speculative Everything: Design, Fiction, and Social Dreaming. Cambridge, MA: The MIT Press.

Flanagan, M. (2010). "Creating critical play," in Artists Re-Thinking Games, eds R. Catlow, M. Garrett, and C. Morgana (Liverpool: Liverpool University Press), 49-53.

Hjorth, L., and Richardson, I. (2017). Pokémon GO: Mobile media play, place-making, and the digital wayfarer. Mobile Med. Commun. 5, 3-14. doi: $10.1177 / 2050157916680015$

Nijholt, A. (ed.). (2016). Playable Cities: The City as a Digital Playground. Series: Gaming Media and Social Effects. Singapore: Springer.

Nijholt, A. (ed.). (2019). Making Smart Cities More Playable. Exploring Playable Cities. Gaming Media and Social Effects Series. Singapore: Springer Nature.

O'Hara, K. (2008). "Understanding geocaching practices and motivations," in Proceedings of the SIGCHI Conference on Human Factors in Computing Systems (New York: Association for Computing Machinery (ACM)), 1177-1186.

Picoo (2021). Available online at: https://www.picoo.com/en/ (accessed October 31, 2021).

Schouten, B., Ferri, G., de Lange, M., and Millenaar, K. (2017). "Games as strong concepts for city-making," in Playable Cities, ed A. Nijholt (Singapore: Springer), 23-45.

Schouten, B., van der Spek, E., Harmsen, D., and Bartholomeus, E. (2019). "Chapter 12: The playful scientist: stimulating playful communities for science a possible response to many of the issues related to city design, management, and life. Several aspects of urban existence are being "gamified" starting with planning and including mobility and logistics as well as social well-being and community building.

As the world becomes ever more urbanized, cities incorporate more and more technological novelties, and play becomes increasingly more influential in our culture, research on playable cities is becoming more and more relevant. And as the challenges faced by cities seem to become greater with time, the need for novel, critical, and creating approaches on how we could use the potential of play to improve urban life, foster sustainability, consolidate resilient and inclusive communities becomes even more urgent. We hope the ideas and methods presented in this volume will spark further thoughts and translate into novel actions by urban dwellers, designers, planners, and policymakers to the benefit of us all.

\section{AUTHOR CONTRIBUTIONS}

All authors contributed equally to the article and approved the submitted version.

\section{FUNDING}

This project has received funding from the Academy of Finland-funded Centre of Excellence in Game Culture Studies (Grant No. 312395).

practice," in The Playful Citizen, eds R. Glas, S. Lammes, M. Lange, J. Raessens, and I. Vries (Amsterdam: Amsterdam University Press), 235-254.

Tan, E. (2017). Play the City. Rotterdam: Games Informing the Urban Development, Jap Sam Books.

Thibault, M., and Baer, M. F. (2021). "Urban gamification during lockdown and social isolation-from the teddy bear challenge to window expeditions," in 5th International GamiFIN Conference, GamiFIN 2021, Vol. 2883 (Aachen: CEUR Workshop Proceedings), 130-139.

Conflict of Interest: The authors declare that the research was conducted in the absence of any commercial or financial relationships that could be construed as a potential conflict of interest.

Publisher's Note: All claims expressed in this article are solely those of the authors and do not necessarily represent those of their affiliated organizations, or those of the publisher, the editors and the reviewers. Any product that may be evaluated in this article, or claim that may be made by its manufacturer, is not guaranteed or endorsed by the publisher.

Copyright $\odot 2022$ Chisik, Nijholt, Schouten and Thibault. This is an open-access article distributed under the terms of the Creative Commons Attribution License (CC $B Y)$. The use, distribution or reproduction in other forums is permitted, provided the original author(s) and the copyright owner(s) are credited and that the original publication in this journal is cited, in accordance with accepted academic practice. No use, distribution or reproduction is permitted which does not comply with these terms. 
OPEN ACCESS

Edited by:

Yoram Chisik,

University of Madeira, Portugal

Reviewed by:

Carlos Vaz De Carvalho,

Polytechnic Institute of Porto, Portugal

Tonguc Ibrahim Sezen,

Teesside University, United Kingdom

*Correspondence:

Micael Sousa

micaelssousa@gmail.com

Specialty section:

This article was submitted to

Human-Media Interaction,

a section of the journal

Frontiers in Computer Science

Received: 07 April 2020

Accepted: 22 July 2020

Published: 04 September 2020

Citation:

Sousa M (2020) A Planning Game

Over a Map: Playing Cards and

Moving Bits to Collaboratively Plan a

City. Front. Comput. Sci. 2:37.

doi: 10.3389/fcomp.2020.00037

\section{A Planning Game Over a Map: Playing Cards and Moving Bits to Collaboratively Plan a City}

\author{
Micael Sousa* \\ CITTA, Department of Civil Engineering, University of Coimbra, Coimbra, Portugal
}

Rational systemic planning and collaborative planning seem to be two conflicting approaches in spatial planning practice and research. However, some authors are trying to make them compliant through new approaches that are more human centered. Applying games to planning processes can be one of many solutions to consider. This article describes the process of developing an analog game session and the first test of this serious board game approach. This game approach began with modern board game design elements as a starting design base and was adapted for further developments in game-based planning processes, following the methods of serious games through the adaptation of the design, play, experience framework. The purpose of this game session is to create a simple and flexible tool to train students and future planners for the use of games in the development of collaborative urban planning processes, contributing to filling the gap created by the absence of simple and flexible games to use in daily planning practices.

Keywords: collaborative planning, serious games, board games, tabletop games, urban games

\section{INTRODUCTION}

Creating a game is not an easy process. Developing a serious game to apply to educational purposes or to be used as a support for participative and collaborative planning processes, in which budget, time constraints, or even expert skills are lacking (Ampatzidou et al., 2018), can be even harder (Crookall, 2010). The collaborative planning approach in the spatial planning field of research aims to include as many stakeholders as possible in the processes to deliver better plans suited to individual and community needs (Healey, 1997). A long debate pitting rational systemic planning in opposition to collaborative planning seems to be fading as the main authors try to establish some bridges between them (Innes and Booher, 2018).

The intent of this research is to contribute to developing new game approaches that address this tendency toward integration between rational systemic approaches and collaborative planning ones. This was done through the use of analog tabletop/board games, tested during a practical lecture with civil engineering students in a class on regional and urban planning. The game exercise consisted of two different games that happened in a sequence over the same map of the city. The two games had very different components and game mechanics although they formed a logical sequence and were played over the same map.

The first game was designed to establish some common knowledge and communication among players, which is essential to the start of a collaborative process (Healey, 1997). The second game implemented a concrete planning process, based on a game model, in which players could manipulate the urban environment. 
The main objective of this experiment was to provide an example of a prototype, inspired by commonly known modern board game mechanics, that can serve as a practical implementation for daily use. Planning students, teachers, and practitioners following this approach, supported by the design, play, experience (DPE) framework (Winn, 2009), should be able to use games inspired by these methods for their public participation and collaboration processes.

Analog games were tested in this session because they are easier to construct and adapt while naturally fostering collaboration among users (Zagal et al., 2006; Xu et al., 2011; Rogerson and Gibbs, 2018; Rogerson et al., 2018). These games can fill the gap identified by Ampatzidou et al. (2018), in which planning practitioners recognize the potential of games but say that they do not have the resources and knowledge to use them in their daily work.

\section{METHODOLOGY}

The practical, direct objective of the testing session was to create a flexible and simple game dynamic to apply in a class with a $2 \mathrm{~h}$ duration. The game dynamic considered the importance of game mechanics (Järvinen, 2008; Sicart, 2008) in an approach related to the DPE model used for serious game processes (Winn, 2009), in which the game designer creates a playful dynamic system to generate experiences through the use of game mechanics, considered more broadly. In this game experience, there was the need to do some adaptation related to the analog nature of the game and to the need to include a facilitator.

Although the potential of game mechanics is known for serious games (Michael and Chen, 2006; Dörner et al., 2016), the specific game mechanics present in modern board games are not yet fully explored and established in the literature as the recent work from Engelstein and Shalev (2019) shows. The innovations of modern board games, mostly Eurogames, and their main game mechanic typologies and distinctive game play (Woods, 2012) are yet to be explored for practical usage in academic literature (Sousa and Bernardo, 2019).

The inspiration to conduct this new game approach for a planning game over a map began with the City Game experience, first developed by Tan and Portugali (2012), following the complexity theory, according to which individual agents could collaboratively plan, with minimal rules, a coherent urban design. This game approach was tested during the 18th meeting of AESOP: Games for Cities, and it also employed some notions of money management to create restrictions and force players to collaborate by combining their budgets to build the desired projects.

To go deeper into the simulation dimension, game-design elements from modern board games were used, allowing the building of the game approach dynamic over a satellite map retrieved from Google Maps (www.google.pt/maps) at a scale of 1:2000. The game Spyfall (Ushan, 2014) helped to build a common understanding of the urban territory-in this case, the city of Leiria in Portugal. Then, after this first game, a new game, developed especially for this session, was played over the same map. This second game was inspired by the game mechanics of Town Center (Viard, 2014) and City Game (Tan and Portugali, 2012). This last game pretended to establish a collaborative game approach to plan land uses; transport infrastructures; and the economic balance between public services, employment, housing, commercial activities, and the reduction of pollution and negative social impacts from land-use interactions in the city. The use of a printed Google map allowed the adaptation of the game approach to any given territory.

Before the experiment, a pretest was given to the players, documenting the participants' previous experience with games, serious games, and board games in general. After the game dynamic, including the debriefing, players were asked to document the final game experience. The data gathered in the two inquiries followed the Mayer et al. (2014) framework, mostly addressing the experience during game play, the complexity of the game, game flow, immersion, fun, and satisfaction with the learning and simulation process. The intent of the data collection was to understand the previous experience players had with games and their reaction to the game dynamic of the play dimension of the DPE framework (Winn, 2009) as it was considered in the prototype testing (see Figure 1). The debriefing process followed Lederman's (1992) prescriptions with a facilitator offering an overview of the game play and fostering players' self-analysis and collective understanding of the game experiments.

\section{THE RATIONALITY THROUGH COLLABORATION IN PLANNING}

From a rational, systemic, traditional point of view in planning, planners should deliver planning solutions based on mathematical modeling and previsions about housing, transportation, facilities, and other needs for collective land use (Taylor, 1998). With these given options, politicians should decide according to what they believe is in the public interest. As democracies strengthen and their tendency to be more participative models the lack of shared decision making, including citizens and stakeholders, became unacceptable (Innes and Booher, 2018). The rational approach seems to be incapable of addressing the complexities of contemporary societies, in which indifferent solutions fail to properly address people's needs (Healey, 1997). The way to solve the problems of coexistence in today's multicultural societies that are globalized and with free, active citizens appears to be through direct broad participation and co-creation. Nonetheless, the rational, systematic approach is still essential to provide information and make coherent plans (Allmendinger, 2017) even in collaborative approaches.

Several movements providing alternatives to more participative and collaborative solutions in planning have emerged, mostly since the 1980s (Margerum, 2002). Four main influences can be identified:

- The rational communication premise from Habermas (1981), considering that individual demands could be rational if communicated with equality and truth and based on facts and information. 


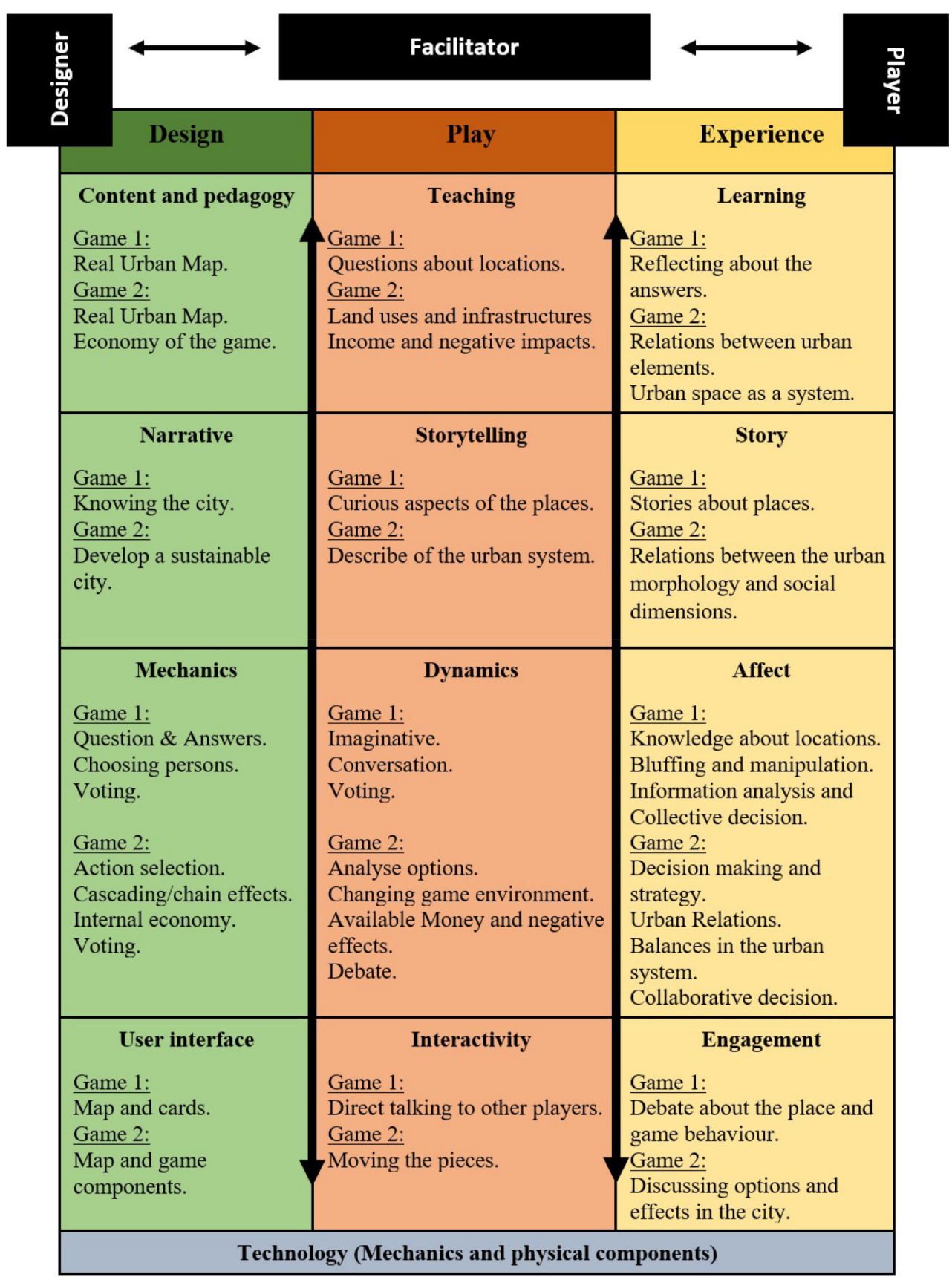

FIGURE 1 | DPE framework adapted to the serious game process of analog games.

- The network society effect in the age of information, which allows citizens to live in parallel societies outside territorial restrictions (Castells, 1996).

- Structuralism, according to Giddens (1984), departing from the notion that agents are influenced by structures and can influence structures to some degree.

- The theory of complexity, following Portugali (2016), approaches include complex systems in which conscious agents plan while participating in incomprehensible and complex collective planning dynamics on higher scales.

These influences inspired many different approaches and testing of new methods. The most common is the collaborative planning process, in which planners act as facilitators, engaging with citizens and stakeholders and providing arenas for free discussion and co-creation, supported by technical knowledge and following some established rules, guidelines, and theoretical influences as 
previously quoted. However, the rational, systemic approach is not compatible with these dynamics based on focus groups, non-linear processes, and other similar methodologies.

Innes and Booher (1996) assume that role-playing games could be a solution to create engaging methods for generating discussion related to the planning topics of a concrete planning problem. Tan (2016) started role-playing in the "generative city game" experiments, concluding that the games required more elements to reach systemic simulation. Resources, real restrictions, and visual modeling helped in the understanding of planning problems and provided more coherent plans through the game-planning approach.

Departing from this acknowledges an alternative approach, which followed modern board game design elements, was tested through a sequence of two games. The first game had minor adaptations to generate a common ground for players, allowing them to know the territory and themselves first. The second game, inspired by cube placement mechanics, created a strategic and fully collaborative simple planning process, generating an urban solution. The game's elements of design and their playable dimensions and experience generation are expressed in Figure 1.

\section{MODERN BOARD GAMES}

Board game design has somehow continued to evolve in the shadow of digital games over recent years. However, some authors consider that we are living in a golden age of board game culture and industry (Booth, 2015; Arnaudo, 2018). Although this is highly questionable, the proliferation of new games and gaming communities all over the world is a fact, which is related to hobby board game design trends, known as modern board games (Sousa and Bernardo, 2019).

Since the 1980s, the board games created and played mainly in Germany defined a new type of product: Eurogames (Woods, 2012). These games updated the design standards in a way that has influenced worldwide game production since the start of the 21st century (Donovan, 2017). Departing from the Eurogame board games' unique elements, new board games, done professionally and innovatively, are influenced by them, also supporting new solutions for serious game purposes. Eurogames provide balanced games that can engage adults with innovative and elegant game mechanics, low luck dependence, controlled gameplay duration, and game systems that can provide medium-weight-complexity models to simulate reality (Woods, 2012). Considering these characteristics, adding to the knowledge that board games provide intrinsic collaborative forms of play (Zagal et al., 2006), the materiality of the game systems provide multiple forms of fun and help the learning process (Xu et al., 2011), and playing a board game is a voluntary act of collective learning, a new game solution was tested in a lecture on regional and urban planning. As Parlett (2018) says, the new games transferred the game dynamics from the board to the players, which suits collaborative planning approaches.
The elegance of the Eurogames' mechanics, which are able to simulate realities while maintaining a playful and engaging dynamic with simplicity and reduced game play (Woods, 2012) is tested in the explored prototype. The exploration of these design features has not yet been fully explored in gaming and the serious gaming literature (Sousa and Bernardo, 2019).

\section{DEVELOPING THE GAME APPROACH EXPERIENCE}

Castronova and Knowles (2015) argue that creating a new game is difficult, and it is easier to use and adapt existing commercial games to generate serious game solutions. Following this suggestion, some well-known board games were tested and adapted to create a planning experiment. In addition, considering that any game can be adapted to be a serious game (Dörner et al., 2016), the selected games were modified to simulate a small urban planning process. Taking into account that a serious game is a game used to deliver other objectives besides fun (Michael and Chen, 2006; Winn, 2009) while maintaining the fun of it, the proposed game approach was constructed to help students in civil engineering from the Polytechnic of Leiria to understand the collaborative planning approach and how it could be implemented through games. To achieve this, two commercial board games were adapted to create the game solution learning tool, which also considered the City Game (Tan and Portugali, 2012) tests.

In a serious game approach, the balance between simulation and playfulness is difficult to achieve, which reinforces the need to profit from established modern board game designs, mostly from Eurogames. Departing from well-tested games, this experiment intended to offer an example for planning practitioners, showing how they can reduce the complexity of developing new game approaches from scratch. It is a pragmatic way to respond to the lack of simple and ready-to-use game tools for planning (Ampatzidou et al., 2018).

The game experiment had a total duration of $2 \mathrm{~h}$. Initially, for $40 \mathrm{~min}$, the students played an adapted version of Spyfall over a Leiria city map, using Post-its to signal the names of the locations. As in the original game, players received random sets of cards that determined their roles. The first game was played in a competitive way although it was played in teams. Instead of the illustrated original cards, the locations and cards were marked with numbers (see Figure 2).

The second game consisted of a city building game with cubes, cardboard, and rope. The game mechanics were inspired by Town Center. However, many modifications were done to simulate different land usage, facilities, green parks, public transport lines, the economy, and pollution. This game was fully cooperative (see Figures 3-5).

The experiment ended with a debriefing process (Lederman, 1992) regarding the planning results, discussing the model created collaboratively by the students during gameplay, starting from a general overview conducted by the facilitator, continuing to the self-evaluation of each player's actions in the game and 


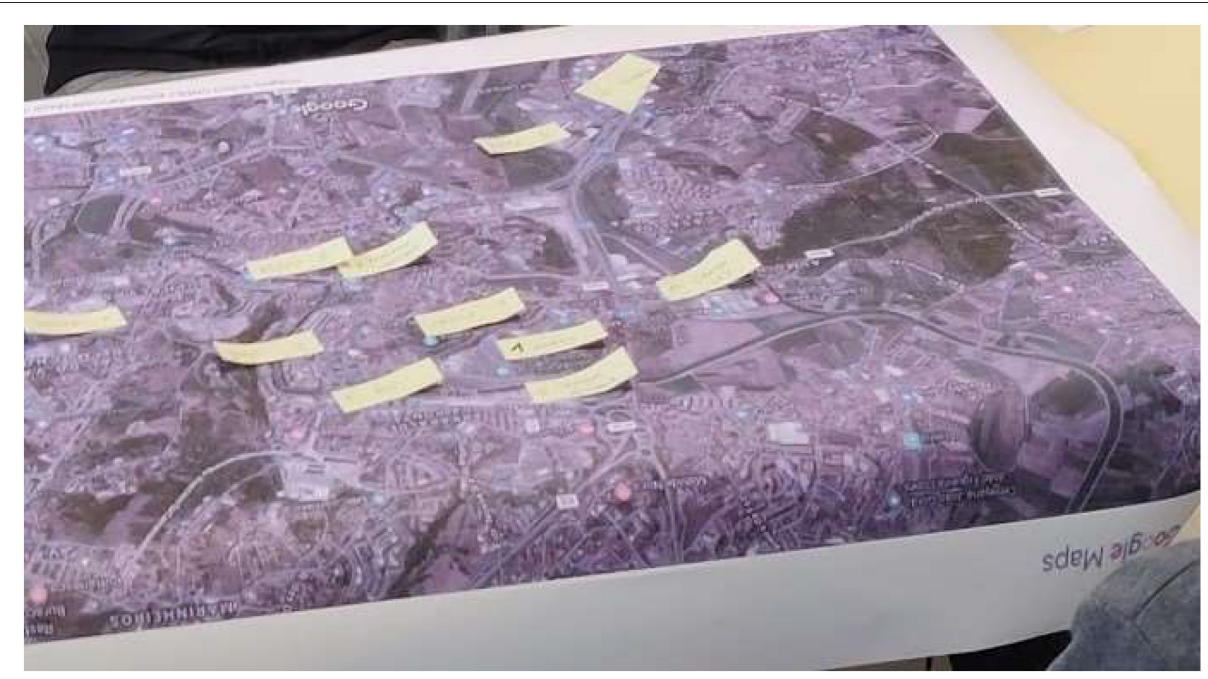

FIGURE 2 | Game play of the first game.

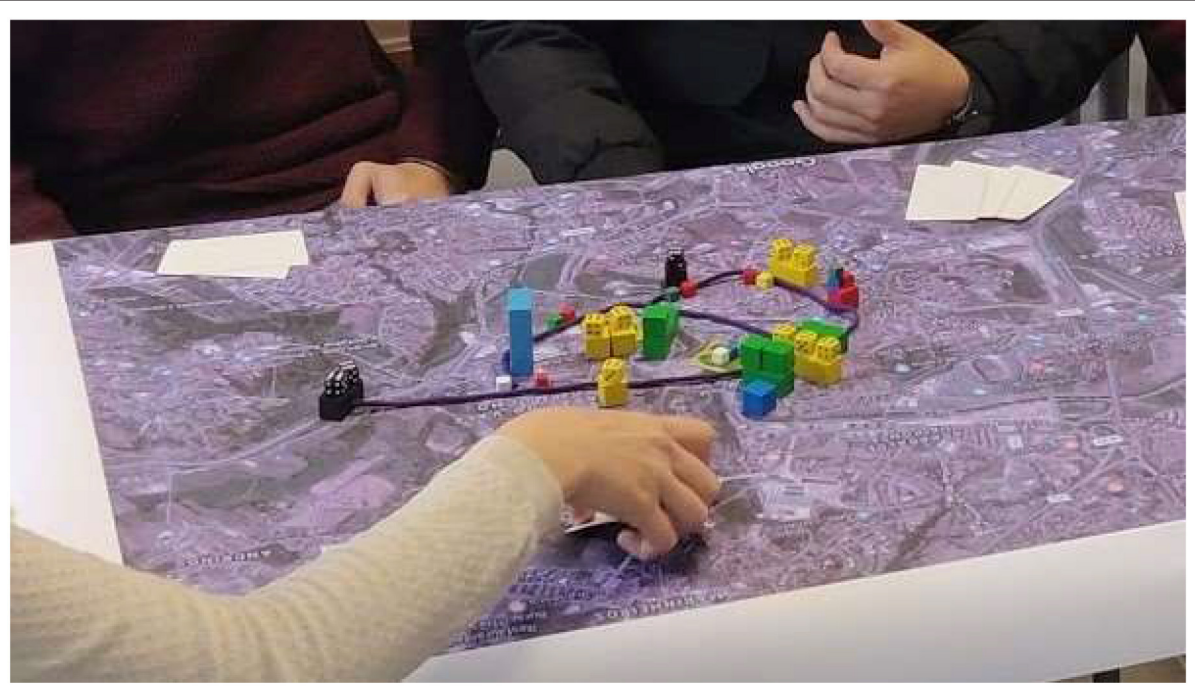

FIGURE 3 | Game play of the second game.

their consequences, and ending in a collaborative conclusion about the game learning outputs. This was done by the game creator, who acted as a facilitator during the entire session, helping players to understand the rules and taking notes to address in the debriefing process. This final step is of great importance because, as Crookall (2010) mentions, the debriefing can be more important than the game itself to establish a serious game.

The games sought to address a real case study and not only an abstract urban landscape. The game design elements from modern board games provided the components and mechanics to establish the game system. The final model, constructed during the second game, should provide a clear understanding of the players' decisions and their interactive effects. However, the real board was missing. The solution rested in using a printed plan from Google Maps with an approximate scale of 1:2000 to serve as the game's common board. This enabled the simulation of land use typologies for the city of Leiria, which was the real city being addressed in the lecture. This scale allowed the use of colored cubes sized approximately $1.5 \mathrm{~cm}$ per edge, which is a component from Town Center and fit the natural block scale of the morphology of the city. It also permitted sticking small Postits $(1 \mathrm{~cm} \times 4 \mathrm{~cm})$ on which were written the names of the places for the first game, related to Spyfall.

\section{GAMES THAT INSPIRED THE APPROACH}

The game session was divided into two separate games that were connected by the main objectives regarding how to develop collaborative approaches and develop a simple, sustainable, 


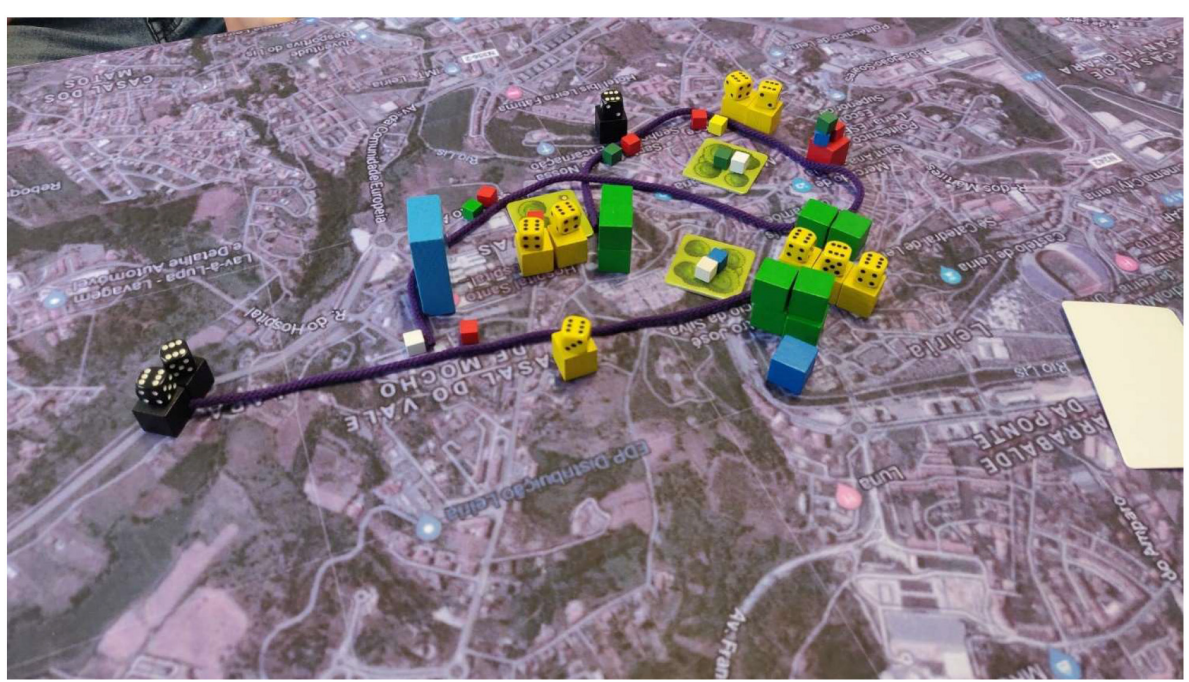

FIGURE 4 | Final visual result from the second game (south view).

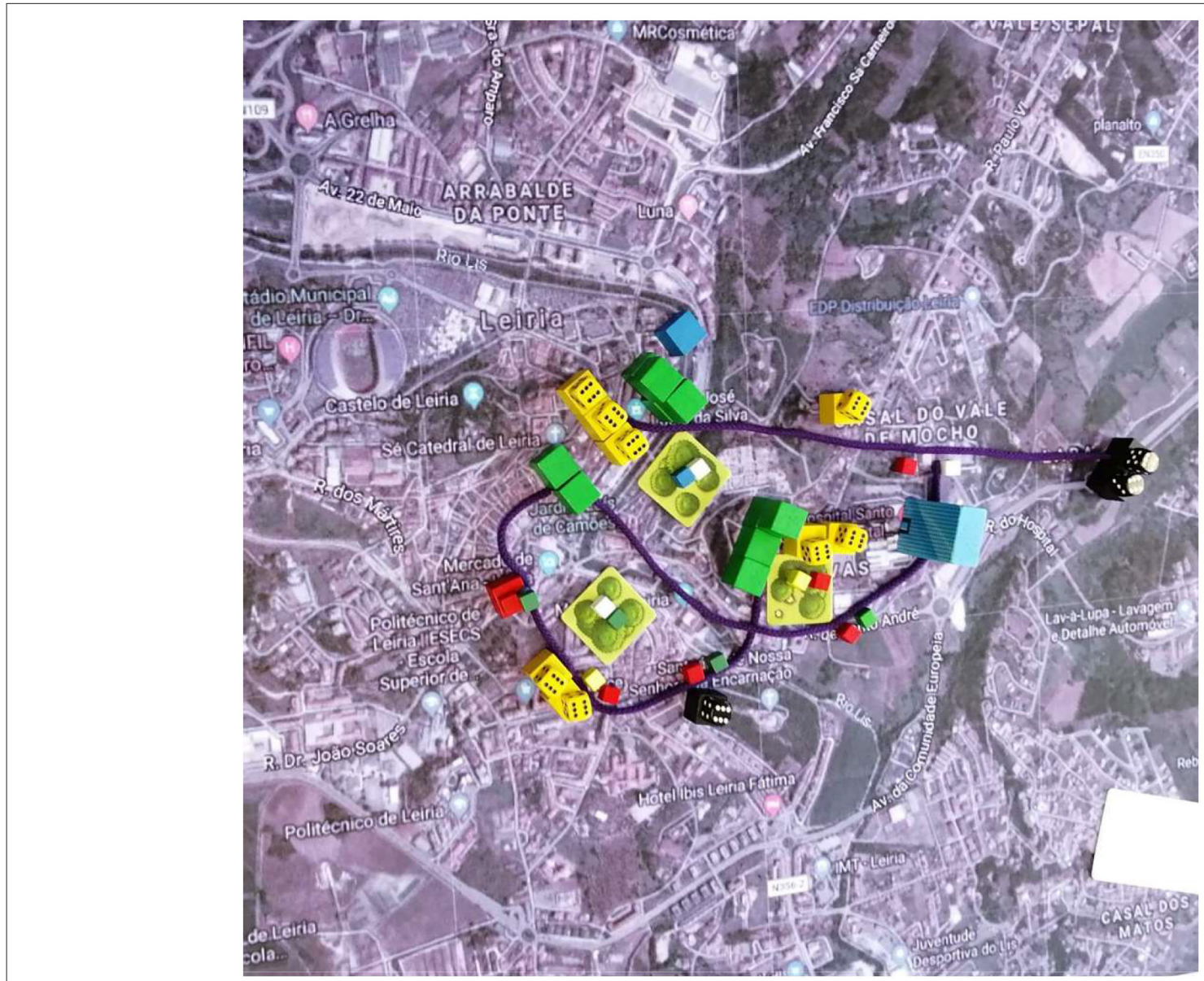

FIGURE 5 | Final visual result from the second game (East View). 
urban model through games. The two games were inspired by several other games, by their mechanics to activate the game system, and their consequent dynamics and experiences related to land knowledge and to the possibility of building a simple, interactive city model. Physical components from several other games were also used to express a meaningful relationship to the reality they intend to represent to players during the game state.

The City Game (Tan and Portugali, 2012) inspired the second game, in particular the freedom to play any game component in turn-based game sequences in which blocking was not allowed. The City Game version tested during the 18th meeting of AESOP, developed by Sara Encarnação and her team from the Nova University of Lisbon, was vital for the definition of the actions table (see Table 1).

Spyfall (Ushan, 2014) consists of a party game of bluffing and deceiving and in which roles are randomly determined in each play. In a game of Spyfall, there are two teams competing: the spy who needs to guess the correct location and the team of the remaining players who know what role they have and ignore the roles of all the other players. The accusing of the spy occurs through voting. The roles are determined by cards that must be kept secret except from the owner. The locations are represented on a large composite map in the center of the table with the same images appearing on the cards representing the player's roles apart from the spy. The adaptation to the serious game experience consisted of using the Google Map of the city of Leiria, first allowing players to choose 12 locations and identifying them with numbers and names marked in Post-its over the map. The numbers on the map matched the cards, which were stacked in small decks. This adaptation maintained the essence of the original game and the fun of it while players created common knowledge about the city. The objective of identifying the spy and the correct location in the city in only $5 \mathrm{~min}$ was done through direct "yes" or "no" questions about each place. To accuse a player of being the spy, a vote needed to be approved by the majority. This created a brief deliberation process. The game used the question mechanics in a deterministic way to generate information players could work with. The absence of random effects within the question mechanics was influenced by Eurogame deterministic designs.
The influence of Town Center (Viard, 2014) in the second game was less than that from Spyfall for the first game although the game mechanic of piling and automatically generating effects from the proximity of neighbor cubes and components was important. This allowed the production of an organically growing simulation model. The big cubes used to simulate land use and facilities came originally from Town Center game except for the hospital and parks. The main mechanic brought from modern board games was the cube placement and the cascading automatic effects in the economy of the game (Engelstein and Shalev, 2019).

The game components in the first game were all handmade. To create the second game, more components were needed. The strings came from String Railways (Hayashi, 2009), the small cubes from Rajas of the Ganges (Brand and Brand, 2017), the dice from Panamax (D'Orey et al., 2014), the green parks from Agricola Farmers of the Moor (Rosenberg, 2018), and the hospital from Suburbia's (Alspach, 2012) first player marker. The coins to simulate the money came from Villagers (Gaarder, 2019).

\section{GENERATING THE CITY MODEL TO PLAN THE CITY THROUGH COLLABORATION}

The first game has already been explained, being very close to the original game of Spyfall, but the second part was very different. This second game, inspired by the City Game and Town Center, was also played over the Google satellite map of Leiria (scale of $1: 2000$ ), having only this component in common with the first one. Players started with 3 money units and played in a sequence of turns, forced to pick a game component that simulated a landuse license in the city, a public facility, a green park, or public transport line to put on the map. Some of these options had monetary costs; others generated revenue to the city common budget as some pollution/negative social impacts (see Table 1).

As can be observed in Table $\mathbf{1}$, there is a lot of simplification in the costs and the effects. The game should be simple so that it can be played almost instantaneously. This was only possible because the facilitator continuously explained the game during the session, clarifying the options and consequences to players.

TABLE 1 | Available actions to players during the second game.

\begin{tabular}{|c|c|c|c|c|}
\hline Actions & $\begin{array}{l}\text { Cost to build } \\
\text { (money units) }\end{array}$ & $\begin{array}{l}\text { Profit generation } \\
\text { (money units) }\end{array}$ & $\begin{array}{l}\text { Pollution/social } \\
\text { negative impacts }\end{array}$ & Available quantity \\
\hline Housing unit (green large cube) & 0 & 0 & +1 & 24 \\
\hline $\begin{array}{l}\text { Commercial/light industry/services unit (green } \\
\text { yellow cube) }\end{array}$ & 0 & $+1 \times$ Surround housing unit & +1 & 8 \\
\hline Heavy industry unit (black large cube) & 0 & $\begin{array}{l}+3+1 \times \text { Surrounding } \\
\text { commercial unit }\end{array}$ & $3+1 \times$ Surrounding unit & 4 \\
\hline Green park unit (cardboard tile) & -4 & 0 & -2 & 4 \\
\hline Police/Fire department unit (red large cube) & -10 & 0 & -3 & 2 \\
\hline School unit (blue large cube) & -20 & 0 & -4 & 2 \\
\hline Hospital unit (suburbia player markers) & -30 & 0 & -6 & 1 \\
\hline Public transport line unit & -5 & 0 & -2 & 4 \\
\hline
\end{tabular}


The values in Table $\mathbf{1}$ were obtained through a spreadsheet, balancing the positive and negative inputs and outputs. In this way, sustainable growth could be achieved, but only if the players balanced their actions, generating money, and choosing actions to reduce the negative effects as soon as they had the required money. Players could not pass because they were always forced to choose something to build. The free actions generated negative impacts, and the ones able to reduce these impacts were expensive, only activating their benefits for the surrounding areas. This city building game exercise was done through collaboration, generating discussion, and debate for each individual decision. When players proposed to use the common city budget to place an expensive facility, a vote was called. The players only had three personal money units, which was not enough to build any of the actions that reduced the negative impacts, essential to achieve the game objectives. To build them, they needed to use the common city budget. The inspiration for this limitation came from the City Game tested during the 18th meeting of AESOP, and the economic systems from Eurogame mechanics (Woods, 2012) were transposed to a spreadsheet.

The pollution and social negative impacts were represented by small cubes, placed near the building that generated them. Colored dice marked the profit from commercial/services and industry cubes and were limited to 6 for each one. This limit established the balance of the game system, determining available components and options to achieve a sustainable city. In this manner, growing the city should be possible while also controlling the piling of the negative cubes throughout gameplay in a clear and representative way. The negative cubes, when absorbed by the positive effects of the facilities, parks, and public transport lines, were placed atop those components to represent that they had exhausted their positive capacity of absorption. The public transport lines made any buildings near and along them to be considered as adjacent.

The game session, considering the two games, is expressed in Figure 1, according to the adaptation of the DPE framework (Winn, 2009) to an analog serious game. In this adaptation, developed by the author of this experiment, there was the need to add the facilitator role because analog serious games have the need to be explained to players and the debriefing part of the experiment needed to be conducted. The technology, in this case, is the mechanics and game components. The DPE adaptation was organized considering the two games in each of the flows:

- learning (content and pedagogy, teaching, and learning);

- storytelling (narrative, storytelling, and story);

- game play (mechanics, dynamics, and affects);

- user experience (user interface, interactivity, and engagement).

From these flows, in a summarized way, the design intended to generate a play experience in which players could learn more about the urban space (first game) and act over it by changing the urban system in a collaborative way to achieve sustainability (second game). The facilitator acted as a mediator between the designer and player, being present during play to observe the experiences. This knowledge plays a major role in supporting the debriefing process.
TABLE 2 | Gaming preferences from players.

\begin{tabular}{lccccc}
\hline $\begin{array}{l}\text { Player's game } \\
\text { preferences } \\
\text { (classification } \\
\text { from 1 to 5) }\end{array}$ & $\begin{array}{c}\text { Do not } \\
\text { like (1) }\end{array}$ & $\begin{array}{c}\text { Avoid } \\
\text { play (2) }\end{array}$ & $\begin{array}{c}\text { May } \\
\text { play (3) }\end{array}$ & $\begin{array}{c}\text { Like to } \\
\text { play (4) }\end{array}$ & $\begin{array}{c}\text { Like to play } \\
\text { a lot (5) }\end{array}$ \\
\hline Analog games & 0 & 0 & 1 & 4 & 1 \\
Sports & 0 & 0 & 1 & 1 & 4 \\
Digital games & 0 & 0 & 1 & 3 & 2 \\
Traditional games & 0 & 0 & 3 & 3 & 0 \\
\hline
\end{tabular}

\section{DATA COLLECTION}

The quantitative direct data was collected with inquiries before and after the games. The observation was done by the facilitator and recorded in a small report during game play, which was useful to the debriefing process.

Six students participated in the whole gaming session $(n=$ 6). The inquiries had yes/no questions and a 5-point Likert scale to measure preferences and perceptions from players. In Table 2, the players' game preferences are shown, highlighting the strongest preference for digital games and a massive appreciation of sports. Although a small number of players participated in the experiment, modern board games are usually played from 2 to 6 players (Woods, 2012; Rogerson and Gibbs, 2018). This type of small group is common in focus groups and other group working and collaboration techniques (Bishop, 2015).

Only one student answered saying that he had never participated in a learning or training session with games. Half of the students ignored the existence of modern board games, but they admitted playing games at least once per week. One player admitted playing every day, and one several times per day. Just one of the students played once per month. We can say the students were interested in games and played regularly.

Table 3 reveals the low levels of anxiety and frustration and the high levels of immersion, motivation, and fun felt during gameplay. Students also highlighted their ability to be flexible and adapt themselves to the game and other players' interactions, considering also that the level of challenge was recorded as high although the difficulty was average. The observation from the facilitator corroborates these perceptions.

Concerning the serious game effects, players considered the experience to be positive, referring to the seriousness of game applications, skill and knowledge testing, surprise, and the fun side of the games played. Only when asked if analog games could perform better than digital games as learning experiences and simulations did the answers reveal values apart from 4 ("a lot") to 5 ("totally/always") although 4 of the students considered that an analog game could be "totally/always" better than digital games to fulfill the objective of implementing a collaborative planning playable process. This may be surprising and may be biased because the students answered just after playing analog games. All this data is available in Table 4.

The inquiries before and after the games had one recurrent question: "How would you classify the learning and simulation 
TABLE 3 | Experiences and perceptions during game play of the gaming session.

\begin{tabular}{lccccc}
\hline $\begin{array}{l}\text { Experiences and } \\
\text { perceptions during } \\
\text { gameplay (classification } \\
\text { from 1 to 5) }\end{array}$ & $\begin{array}{c}\text { Nothing } \\
\text { (1) }\end{array}$ & $\begin{array}{c}\text { A bit } \\
\text { (2) }\end{array}$ & $\begin{array}{c}\text { Moderately A lot } \\
\text { (3) }\end{array}$ & $\begin{array}{c}\text { Totally } \\
\text { (4) }\end{array}$ \\
\hline Fun & & & & & \\
Difficulty & 0 & 0 & 0 & 2 & 4 \\
Immersion & 0 & 1 & 3 & 1 & 1 \\
Challenge & 0 & 0 & 0 & 3 & 3 \\
Anxiety & 0 & 0 & 2 & 1 & 3 \\
Adaptation ability & 1 & 3 & 2 & 0 & 0 \\
Surprise & 0 & 0 & 1 & 4 & 1 \\
Empathy among players & 0 & 0 & 2 & 2 & 2 \\
Frustration & 0 & 0 & 0 & 3 & 3 \\
Motivation & 3 & 3 & 0 & 0 & 0 \\
& 0 & 0 & 1 & 2 & 3 \\
\hline
\end{tabular}

TABLE 4 | Questions about the serious game dimensions of the tested games.

\begin{tabular}{lccccc}
\hline $\begin{array}{l}\text { Questions about } \\
\text { the seriousness of } \\
\text { the games and } \\
\text { future applications } \\
\text { (classification 1 to 5) }\end{array}$ & $\begin{array}{c}\text { Nothing/ } \\
\text { No (1) }\end{array}$ & $\begin{array}{c}\text { A bit } \\
\text { (2) }\end{array}$ & $\begin{array}{c}\text { Moderately A lot } \\
\text { (3) }\end{array}$ & $\begin{array}{c}\text { Totally/ } \\
\text { always (5) }\end{array}$ \\
\hline $\begin{array}{l}\text { It was possible to test skill } \\
\text { and knowledge in the } \\
\text { game? }\end{array}$ & 0 & 0 & 0 & 3 & 3 \\
$\begin{array}{l}\text { Games could be applied to } \\
\text { other contexts and cases? }\end{array}$ & 0 & 0 & 0 & 2 & 4 \\
$\begin{array}{l}\text { Games fulfilled the serious } \\
\text { objectives? }\end{array}$ & 0 & 0 & 0 & 3 & 3 \\
$\begin{array}{l}\text { Would you play these } \\
\text { games just for fun? }\end{array}$ & 0 & 0 & 0 & 2 & 4 \\
$\begin{array}{l}\text { Were you surprised with the } \\
\text { game approach? }\end{array}$ & 0 & 0 & 0 & 2 & 4 \\
$\begin{array}{l}\text { Analog games can provide } \\
\text { better experiences and } \\
\text { simulations solutions than } \\
\text { digital games? }\end{array}$ & 0 & 0 & & & \\
\hline
\end{tabular}

potential of games?" The results are expressed in Table 4. Four players improved their perception of the potential of serious uses of games for learning and training to the maximum classification.

\section{RESULTS DISCUSSION}

\section{Board Game Results}

The first game established the communication and required empathy that helped players passing to the negotiation and cocreating of the second game although it was a competitive game played in teams: spy vs. all other players (see Figure 2). Players wanted to play more; however, the second game needed more time and only $2 \mathrm{~h}$ were available.

Players cooperatively played the second game (see Figure 3). Each player received 3 money units, and Table 1 was visible to all players during gameplay. Individual turns happened in a clockwise sequence without the possibility to pass because the city should continue to grow. This rule intended to address the thematic objective of sustainable urban growth. The map served as guidance, but it was not mandatory to follow the road systems although the river and hills should be considered. Nevertheless, players felt influenced by the represented morphologies.

The 6 players played a total of 30 turns, each one taking 5 turns. In the game, they used (see Figure 4)

- 10 housing cubes (green);

- 8 commercial/services cubes (yellow);

- 3 industries (black);

- 3 green parks (green token);

- 1 school (blue cube);

- 1 police office (red cube);

- 1 hospital (tall blue building);

- 3 public transport lines.

These options resulted in an income to the city budget of 75 money units, considering the contribution from the commercial/services and industry cubes, all taken to the maximum revenue capacity, represented by the 6 face-value dice at the top of each cube (see Figure 4). Each time a player proposed to use the common city budget, a vote was called. Only one time was the voting negative because players previously discussed each vote. All the used buildings that reduced pollution and negative social impacts cost 87 money units in total. Although the players' decisions produced only 75 units of revenue, they used their personal money to help build those facilities. In the end, only 2 players remained with some personal money: one player with 1 money unit and another with 2. The city budget had 3 money units remaining. However, at the end of the game, 2 cubes representing pollution and negative social impacts persisted on the board. All the other cubes were removed but put near the components that reduced them, so players could keep track of the ones remaining and the capacity of the buildings/components to absorb negative impacts.

During the second game, students started to do some parallel role-play, creating a narrative for the housing zones. Players naturally started to go beyond the symbology and meaning of the components as expected in the DPE adapted model (see Figure 1). For example, the housing zone near the hospital, between the 3 parks and with a direct public transport line, was considered to be the expensive habitational zone of the city, and the one most to the right was the poorer area, where residents lived packed together and in the periphery (see Figure 4).

\section{Inquiries and Observation Results}

Players enjoyed the games (see Table 3) with low levels of anxiety, low frustration, and high levels of fun and motivation. Players wanted to continue playing, but there was no more time available. Their opinion about the potential of learning and simulations though games increased greatly at the end of the experiment (see Table 5). When trying to make some correlation, although the data is small $(n=6)$, the correlation between the preference for digital games and the perception of the added value of analog games over digital games $(0,56)$ is higher than the correlation 
TABLE 5 | Players perceptions about the potential of serious games.

\begin{tabular}{lccccc}
\hline $\begin{array}{l}\text { Players classification } \\
\text { the learning and } \\
\text { simulation potential } \\
\text { of games }\end{array}$ & $\begin{array}{c}\text { Nothing/ } \\
\text { No (1) }\end{array}$ & $\begin{array}{c}\text { A bit } \\
\text { (2) }\end{array}$ & $\begin{array}{c}\text { Moderately A lot } \\
\text { (3) }\end{array}$ & $\begin{array}{c}\text { Totally/ } \\
\text { (4) } \\
\text { always } \\
\text { (5) }\end{array}$ \\
\hline $\begin{array}{l}\text { Before the games } \\
\text { After the games }\end{array}$ & 0 & 0 & 0 & 5 & 1 \\
\hline
\end{tabular}

between the preference for analog games and the perception of the added value of board games over digital games $(0,17)$.

Through direct observation by the facilitator, some information was gathered in the observation notes about the experience. Players had little doubts about the games during gameplay, and those players who understood the game faster explained to other players the decisions they could make and the expected impacts on the game systems. This rule enforcing helped the collaboration process. These interactions allowed the fast pace of the game with little downtime, and due to the small number of participators, all players were engaged in playing the game. No reports of smartphone use or parallel talk were reported during game play $(2 \mathrm{~h})$.

\section{CONCLUSIONS}

The application and adaptation of the DPE framework helped to define the game session, the objectives for each game, and their relationships. Also, considering the role of the facilitator as an actor who knew the design objectives, helped players to participate in the game experience and to achieve the desired goals by themselves. The implemented design, in its multiple flows, created a game play that players enjoyed. The game results (see Figures 2, 4) express the debate about the urban map in the first game and the collaborative decision making that generated a coherent new urban model during the second game.

Players entered the game without knowing what to expect. They felt engaged, considering the results from the inquiries (see Table 3), in loco observations and the result of the city model (see Figures 4, 5). The first game contributed to understanding and share knowledge about the territory, empowering students through the question mechanic. The second game allowed students to discuss and implement, in a collaborative way, general guidelines and ideas to plan the city, receiving realtime feedback from the chain/cascading mechanics of the cube placement. No downtime between plays and turns was registered. The decisions were proposed by the active player, but all others participated with their opinions and easily contributed by giving their money to build expensive buildings and facilities. There was no record of non-collaboration or game disengagement in general (only one call to vote in nine failed), enforcing the notion that a city model can be planned collaboratively with few rules despite it being important to generate the debate and the consensus-building to activate and profit from the cube placement and cascading effects in the city economy.
The debriefing moment was fast and easily supported by the second game results, materialized in the game model itself, which acted as examples to remember decisions and the process of urban growth. By playing the second game, players expressed the potential for this game system to help deliver general guidelines to plan the urban space. This model helped the facilitator to address the subjects of sustainable growth and the urban interactions of land use, facilities, and infrastructure. The discussion with students happened through the game itself as mentioned with moments of collective reflection and decisions that allowed the continual growth of the city, generating income, and progressively reducing negative outcomes through gameplay. In the final debriefing, the students agreed that they could have reduced all the negative outcomes if they did not focus mainly on the income although only two negative cubes remained on the map (see Figures 4, 5). This was used during debriefing as a metaphor for the prevalence of efficiency models that mainly promote the economic outputs in most plans. The game system engaged the player to the point that narratives emerged naturally. Players enjoyed and established meaning for the game dynamics, which is proof of success for general game design objectives (Salen and Zimmerman, 2004) and, in this case, of a serious game (Winn, 2009) to promote participation in a playable planning process. It can be concluded that the game achieved its serious objectives because players played in collaboration, discussing every play from the first and only collectively rejecting action. The objectives of sustainability were also reached due to the existence of only two negative cubes remaining on the board while having a positive money surplus for the city's common budget.

This experiment showed it is feasible to implement a serious game experience to simulate a simple urban model, using modern board game components and mechanics to establish collaborative planning, following the DPE adapted framework. The use of the printed Google Map and the simple spreadsheet is flexible enough to simulate simple planning game approaches and compliant with modern board game mechanics. Students did not know the lecture would be done with games; they just knew it was about collaborative planning. This promises to be an approach with the potential for usage in other planning processes, profiting from the innovation and flexibility of these new game designs and the continuous development of serious game frameworks.

\section{GAPS AND FUTURE DEVELOPMENTS}

Although the second game seems balanced with a tight economy between the costs of the actions and their positive and negative outputs, more testing should be done to truly balance it in all situations. Nonetheless, the results seem promising, showing that applying innovative mechanics and other design elements from modern board games, supported by a simple spreadsheet table, can help players understand the economy of the game in a fun way. The game system can be played over a map, opening possible new adaptations to other, different, urban realities.

With one play, it was possible to plan a new urban solution, but the continuous plays of the game by the same players 
improved the relationship with cost and effects, just like the knowledge of the played city map.

The application of the DPE framework proved to be useful, and the possibility of adaptation opens new paths for future uses of analog serious games. This approach provides more tangible design support to non-game designers who may want to start a serious game-planning process.

Some difficulties in understanding the proximity effects during game play were felt. In future tests, some transparent reference grid with squares or hexagons should be used over the map, assisting in reading the neighboring land units, the shapes, places to put the cubes, and the distances between all game components. The design of war games and Eurogames maps, with their hexagonal shapes, could help improve this. The capacity of the public transport lines should also be defined and marked on the board, for example, their precise length.

The effects of over-concentration should also be considered and produce extra negative outputs. This was obvious to players through the narrative they created. Players also understood the effects of the heavy industry location. They used the public transport lines to put it away from housing but connected to it and to the commercial/services to generate the expected income.

The tracking of income through the dice was efficient, easily related to the source of the revenue due to the color of the cubes above them although limiting it to 6 units (the pips of the D6 dice). In the future, other types of dice can be used, easily increasing the pip value to 20 if necessary (with the D20 used in role-playing games).

In future tests, some formal role play should be introduced because players showed a natural will to establish narratives associated with the city morphology. This could transform the game into a semi-cooperative game, having different roles and some hidden victory conditions to every player, simulating in this way stakeholders' and citizens' behavior as well as hidden agendas in a participative and collaborative planning process. This could be easily done by giving different profile cards to each

\section{REFERENCES}

Allmendinger, P. (2017). Planning theory. London: Macmillan International Higher Education. doi: 10.1057/978-0-230-38004-2

Alspach, T. (2012). Suburbia. Board game. Bézier games.

Ampatzidou, C., Gugerell, K., Constantinescu, T., Devisch, O., Jauschneg, M., and Ber-ger, M. (2018). All work and no play? Facilitating serious games and gamified applications in participatory urban planning and governance. Urban Plan. 3, 34-46. doi: 10.17645/up.v3i1.1261

Arnaudo, M. (2018). Storytelling in the Modern Board Game: Narrative Trends From the Late 1960s to Today. Jefferson, MO: McFarland.

Bishop, J. (2015). The Craft of Collaborative Planning: People Working Together to Shape Creative and Sustainable Places. New york, NY: Routledge. doi: $10.4324 / 9781315732848$

Booth, P. (2015). Game Play: Paratextuality in Contemporary Board Games. New York, NY: Blooms-bury.

Brand, I., and Brand, M. (2017). Rajas of the Ganges. Huch!.

Castells, M. (1996). "The rise of the network society" in The Information Age: Economy, society and culture. Vol 1. Cambridge, MA: Blackwell. player. More testing with more students and other city maps is also important for future developments that now are possible following this approach.

Another possible development consists of using digital technology and devices to read the game components' disposition and automatically generate information about the component's interactions.

\section{DATA AVAILABILITY STATEMENT}

The raw data supporting the conclusions of this article will be made available by the authors, without undue reservation.

\section{ETHICS STATEMENT}

Ethical review and approval was not required for the study on human participants in accordance with the local legislation and institutional requirements. The patients/participants provided their written informed consent to participate in this study.

\section{AUTHOR CONTRIBUTIONS}

The author confirms being the sole contributor of this work and has approved it for publication.

\section{FUNDING}

The author would like to thank Fundação para a Ciência e a Tecnologia (FCT), the Portuguese funding agency that supported this research under the grant PD/BD/146491/2019.

\section{ACKNOWLEDGMENTS}

The author would like to thank Professor João Pedro Silva for revising the paper and allowing the experimental class and Professor António Pais Antunes for being the author's Ph.D. thesis supervisor.

Castronova, E., and Knowles, I. (2015). Modding board games into serious games: the case of Climate Policy. Int. J Serious Games 2, 41-62.

Crookall, D. (2010). Serious games, debriefing, and simulation/gaming as a discipline. Simul. Gaming 41, 898-920. doi: 10.1177/10468781103 90784

Donovan, T. (2017). It's All a Game: The History of Board Games from Monopoly to Settlers of Catan. New York, NY: St. Martin's Press.

D'Orey, G., Soledade, P., and Sentieiro, N. (2014). Panamax. Board game. MESAboardgames.

Dörner, R., Göbel, S., Effelsberg, W., and Wiemeyer, J., (eds.). (2016). Serious Games: Foundations, Concepts and Practice. Springer. doi: 10.1007/978-3-319-40612-1

Engelstein, J., and Shalev, I. (2019). Building Blocks of Tabletop Game Design: An Encyclopedia of Mechanisms. London: Routledge; CRC Press. doi: 10.1201/978042943 0701

Gaarder, H. (2019). Villagers. Board game. Sinister Fish Games.

Giddens, A. (1984). The Constitution of Society. Berkeley, CA: University of California Press. 
Habermas, J. (1981). The Theory of Communicative Action: Reason and the Rationalization of Society. Boston, MA: Beacon Press.

Hayashi, H. (2009). String Railway. Board game. Okazu brand.

Healey, P. (1997). Collaborative Planning: Shaping Places in Fragmented Societies. New York, NY: Macmillan International Higher Education. doi: 10.1007/978-1-349-25538-2

Innes, J. E., and Booher, D. E. (1996). Consensus building as role playing and bricolage: toward a theory of collaborative planning. J. Am. Plan. Assoc. 66, 9-26. doi: 10.1080/01944369908976031

Innes, J. E., and Booher, D. E. (2018). Planning with Complexity: An Introduction to Collaborative Rationality for Public Policy. London, New York, NY: Routledge. doi: 10.4324/9781315147949

Järvinen, A. (2008). Games Without Frontiers: Theories and Methods for Game Studies and Design. Tampere: Tampere University Press.

Lederman, L. C. (1992). Debriefing: toward a systematic assessment of theory and practice. Simul. gaming 23, 145-160. doi: 10.1177/10468781922 32003

Margerum, R. D. (2002). Collaborative planning: building consensus and building a distinct model for practice. J. plan. educ. res. 21, 237-253. doi: 10.1177/0739456X0202100302

Mayer, I., Bekebrede, G., Harteveld, C., Warmelink, H., Zhou, Q., van Ruijven, T., et al. (2014). The research and evaluation of serious games: toward a comprehensive methodology. Br. J. Educ. Tech. 45, 502-527. doi: 10.1111/bjet.12067

Michael, D., and Chen, S. (2006). Serious Games: Games that Educate, Train, and Inform. Boston, MA: Thomson Course Technology.

Parlett, D. S. (2018). Parlett's History of Board Games: the Updated Edition of The Ox-ford History of Board Games. Bratt: Echo Point Books and Media.

Portugali, J. (2016). "What makes cities complex?" in Complexity, Cognition, Urban Planning and Design (Cham: Springer), 3-19. doi: 10.1007/978-3-319-32653-5_1

Rogerson, M. J., and Gibbs, M. (2018). Finding time for tabletop: board game play and parenting. Games Cult. 13, 280-300. doi: 10.1177/15554120166 56324

Rogerson, M. J., Gibbs, M. R., and Smith, W. (2018). “Cooperating to compete: the mutuality of cooperation and competition in boardgame play," in proceedings of the 2018 CHI Conference on Human Factors in Computing Systems (Montreal, QC). doi: 10.1145/3173574.3173767

Rosenberg, U. (2018). Agricola: Farmers of the Moor. Board game. Lookout games.
Salen, K., and Zimmerman, E. (2004). Rules of Play: Game Design Fundamentals. London, UK: MIT Press.

Sicart, M. (2008). Defining game mechanics. Game Studies, 8. Available online at: http://gamestudies.org/0802/articles/sicart?viewType=Print\&viewClass=Print

Sousa, M., and Bernardo, E. (2019). "Back in the game," In International Conference on Videogame Sciences and Arts (Cham: Springer), 72-85. doi: 10.1007/978-3-030-37983-4_6

Tan, E. (2016). "The evolution of city gaming," in Complexity, Cognition, Urban Planning and Design. In Post-Proceedings of the 2 nd Delft International Conference, eds J. Portugali, and E. Stolk (Springer). doi: 10.1007/978-3-319-32653-5_15

Tan, E., and Portugali, J. (2012). “The responsive city design game," in Complexity Theories of Cities have come of Age (Berlin; Heidelberg: Springer), 369-390. doi: 10.1007/978-3-642-24544-2_20

Taylor, N. (1998). Urban Planning Theory Since 1945. London, UK: Sage.

Ushan, S. (2014). Spyfall. Board game. Hobby World.

Viard, A. (2014). Town Centre. Board game. LudiCreations.

Winn, B. M. (2009). “The design, play, and experience framework," in Handbook of Research on Effective Electronic Gaming in Education (IGI Global), 1010-1024. doi: 10.4018/978-1-59904-808-6.ch058

Woods, S. (2012). Eurogames: The Design, Culture and Play of Modern European Board Games. Jefferson, MO: McFarland.

Xu, Y., Barba, E., Radu, I., Gandy, M., and MacIntyre, B. (2011). "Chores are fun: understanding social play in board games for digital tabletop game design," in DiGRA Conference.

Zagal, J. P., Rick, J., and Hsi, I. (2006). Collaborative games: lessons learned from board games. Simul. Gaming 37, 24-40. doi: 10.1177/1046878105282279

Conflict of Interest: The author declares that the research was conducted in the absence of any commercial or financial relationships that could be construed as a potential conflict of interest.

Copyright (c) 2020 Sousa. This is an open-access article distributed under the terms of the Creative Commons Attribution License (CC BY). The use, distribution or reproduction in other forums is permitted, provided the original author(s) and the copyright owner(s) are credited and that the original publication in this journal is cited, in accordance with accepted academic practice. No use, distribution or reproduction is permitted which does not comply with these terms. 
OPEN ACCESS

Edited by:

Anton Nijholt,

University of Twente, Netherlands

Reviewed by:

Micael Silva Sousa, University of Coimbra, Portugal

Marco Romano,

University of Salerno, Italy

*Correspondence:

Geertje Slingerland

g.slingerland@tudelft.nl

Specialty section

This article was submitted to

Human-Media Interaction,

a section of the journal

Frontiers in Computer Science

Received: 30 August 2020

Accepted: 28 October 2020

Published: 21 December 2020

Citation:

Slingerland G, Lukosch S, Hengst Md,

Nevejan C and Brazier F (2020)

Together We Can Make It Work!

Toward a Design Framework for

Inclusive and Participatory

City-Making of Playable Cities.

Front. Comput. Sci. 2:600654.

doi: $10.3389 /$ fcomp. 2020.600654

\section{Together We Can Make It Work! Toward a Design Framework for Inclusive and Participatory City-Making of Playable Cities}

\author{
Geertje Slingerland ${ }^{1 *}$, Stephan Lukosch ${ }^{2}$, Mariëlle den Hengst ${ }^{3}$, Caroline Nevejan ${ }^{4}$ and \\ Frances Brazier $^{1}$ \\ ${ }^{1}$ Systems Engineering, Delft University of Technology, Delft, Netherlands, ${ }^{2}$ Human Interface Technology (HIT) Lab NZ, \\ University of Canterbury, Christchurch, New Zealand, ${ }^{3}$ Real-Time Intelligence Lab, Dutch Police, The Hague, Netherlands, \\ ${ }^{4}$ Cultural Sociology, University of Amsterdam, Amsterdam, Netherlands
}

Making it work together can be challenging when various stakeholders are involved. Given the context of neighborhoods and cities specifically, stakeholders values and interests are not always aligned. In these settings, to construct long-term and sustaining participatory city-making projects, to make it work together, is demanding. To address this challenge, this paper proposes a design framework for inclusive and participatory city-making. This framework is inspired by the playable city perspective in that it endorses an open, exploratory, and interactive mindset of city actors. An extensive literature review on approaches taken for playful and participatory interventions in local communities provides the foundations for the framework. The review brings forward four pillars on which the framework is grounded and four activities for exploration of the design space for participatory city-making. A case study from The Hague (NL) is used to demonstrate how the framework can be applied to design and analyze processes in which city stakeholders together make it work. The case study analysis complements the framework with various research methods to support researchers, urban planners, and designers to engage with all city stakeholders to create playful and participatory interventions, which are inclusive and meaningful for the local community. The research contributions of this paper are the proposed framework and informed suggestions on how this framework in practice assists city stakeholders to together make it work.

Keywords: design framework, participatory design, playable city, neighborhoods, design spaces, city-making

\section{INTRODUCTION}

Active citizenship, self-organization, and engagement are high on the agenda of governments worldwide (Kleinhans et al., 2015; Certomà et al., 2017). Engaging citizens in city-making has time and again shown to have positive outcomes on city life in terms of increased trust in government (Cooper et al., 2006) and raised community cohesion (Gaventa, 2004). Citizens are motivated to participate in shaping their environments (Juujärvi and Pesso, 2013; Mulder, 2015) and are more and more included as partners in co-creation of their cities (Dörk and Monteye, 2011; de Lange and de Waal, 2013). Contemporary cities ultimately strive to be designed with contributions of many 
different city stakeholders (Schroeter, 2012; Fredericks et al., 2015; Golsteijn et al., 2016; Custers et al., 2020; Palacin et al., 2020), often embracing the notion of a smart city with a technology-push in city-making (Nam and Pardo, 2011; Nijholt, 2017).

Although the technology in top-down smart city design regularly focuses on making city life more efficient (Nam and Pardo, 2011), Playable City (Nijholt, 2017) design focuses on the use of smart city technology to engage citizens with their physical space to increase participation in their neighborhood community (Nijholt, 2020). (Serious) Games (Schouten et al., 2017) have successfully been used as a talking tool to facilitate discussion between different stakeholders (Tan and Portugali, 2012) or to include citizens in city-making (Stokes, 2020). Citizens can play an urban planning game to experience decisions and considerations that city planners have to make (Ashtari and de Lange, 2019). Another successful approach has been to place playful interventions in neighborhoods to gather citizen input on city life (Golsteijn et al., 2016; Claes and Moere, 2017; Claes et al., 2017), create discussion on local issues (Schroeter, 2012; Wouters et al., 2014; Hespanhol et al., 2015), or explore alternate designs of the physical space (Fredericks et al., 2015; Golsteijn et al., 2016; Custers et al., 2020). Consideration of the technological, social, and physical structure and networks between people, and of the city, are key to the design of such interventions (Brazier and Nevejan, 2014). These structures and networks define the design space to be considered by all city stakeholders in participatory design of a Playable City.

For people, social and physical, and online and offline realities merge into one experience and understanding of the world (Nevejan, 2007; Nevejan et al., 2018). A clear need exists to include the perspectives of all stakeholders in city-making (Juujärvi and Pesso, 2013; Harding et al., 2015) and the Playable City provides a promising perspective, as it aims to exploit the physical, digital, and social layers of the city to foster citizen engagement (Stokes, 2020). This paper combines insights from these fields to develop a design framework to foster collaboration between stakeholders and integrate digital and physical forms of participation. This framework fills the gap of a city-making design approach in which all stakeholders are able to contribute and their input is equally valued (Harding et al., 2015). Bringing these perspectives together creates a complete picture of a neighborhood with its social and physical structure and networks (Schroeter, 2012; Innocent, 2018). This paper focuses primarily on the physical and social structure of and networks in the neighborhood, as these elements provide starting points for a design that supports presence and trust between city actors (Nevejan and Brazier, 2015a,b). When playful interventions are informed by these social structures and networks, they will better suit the local context and answer the wishes and needs of a neighborhood's inhabitants (Schroeter, 2012; Hespanhol et al., 2015; Cila et al., 2016; Stokes, 2020).

While the importance of including the local community and stakeholders is widely acknowledged, it remains a challenge how to organize such processes (Leminen et al., 2012; Harding et al., 2015; Stokes, 2020). This paper addresses this challenge by developing a framework for inclusive and participatory citymaking. The next section further elaborates the gap addressed in this paper: namely the need for a participatory design process in which stakeholders can jointly explore their playable city. A literature review follows and provides the basis for the design framework. This framework distinguishes four types of activities with which to engage all stakeholders in the exploration of the design space of their playable city. Next, the framework is applied to a case-study in Bouwlust, a neighborhood in The Hague (NL), where citizens and professionals are looking for ways to work together to improve liveability and safety. Insights from this case study shed light on the applicability of specific methods for the four types of activities in the framework. The final section of this paper discusses insights from this practical application and directions for future research.

\section{RELATED WORK}

The notion of the Playable City was introduced as a novel perspective on the city: one that is playful, open, exploratory, interactive, and participatory. While several books (e.g., Nijholt, 2017, 2020; Stokes, 2020) and many research articles have been published on this playful perspective, the field is still developing and exploring the notion of a Playable City (Nijholt, 2017, p. 6), its contribution to current thinking (Nijholt, 2017, p. 9), and how the success of Playable Cities can be evaluated (Fisher and Hornecker, 2017; Nijholt, 2017, p. 17). In other words, much work is being (and has still to be) done. Earlier work introduced the notion of playgrounds; physical places in the city where citizens interact on the streets in fun, open, and spontaneous ways (Slingerland et al., 2019a, 2020b). These playful environments, potentially mediated by technology, were designed to create safe spaces for citizens to explore, experience, and reflect on city life (Ferreira et al., 2017). In these spaces, citizens need to trust each other and experience each other's presence (Brazier and Nevejan, 2014; Harding et al., 2015).

To be successful at fostering participation, these spaces need to be designed to embrace the technological, physical, and social aspects of the city (Brazier and Nevejan, 2014). The use of technology in the city seems to become more apparent now that many cities label their city as "smart" (Nijholt, 2017). Technology also plays an important role to mediate the Playable City. Researchers question who should design and use this technology, hence the Playable City (Nijholt, 2017, p. 3). While some research focuses on processes to engage and co-create with city professionals (Tan and Portugali, 2012; Ashtari and de Lange, 2019), other research specifically studies how citizens can be mobilized around local issues to explore possible solutions (Disalvo et al., 2009; Crivellaro et al., 2015; Voida et al., 2015; Innocent, 2018). When local governments design these technologies on their own, citizens have little influence on the design and outcome (Erete, 2015; Le Dantec and Fox, 2015). Technologies created from bottom up, on the other hand, need city resources to scale and sustain (De Koning et al., 2018). Both streams acknowledge that citizens as well as neighborhood professionals, such as community police officers or community 
workers, possess unique knowledge about the neighborhood and have a solitary perspective on what would be an appropriate intervention (Bowles and Gintis, 2002; Nelson and Baldwin, 2002; Erete, 2015; Cila et al., 2016; Chisholm et al., 2020; Custers et al., 2020). Very few interventions are nevertheless the result of joint efforts between these different neighborhood stakeholders (Harding et al., 2015; De Koning et al., 2018) or focus on a long-term transition (De Koning et al., 2017).

Meanwhile, the whole social, physical, and technological structure of a neighborhood needs to be taken into account to reconsider roles and responsibilities when city actors work together (Nevejan and Brazier, 2015a,b; Golsteijn et al., 2016). Research into living labs provides some insight into how city stakeholders can co-create and which different roles apply (Leminen et al., 2012; Mulder, 2012; Nyström et al., 2014). While this is a good start, living labs are often focused on innovation of public services (Mulder, 2012; Leminen, 2013), not necessarily concerning play or interventions for the urban space. An exception is the work of Juujärvi and Pesso (2013) on urban living labs that takes the neighborhood as the place for developing local solutions. Their work describes how four city actors (civil servants, educational institutions, local firms, and citizens) contribute to urban living labs, and concludes that new methods of co-creation need to be developed (Juujärvi and Pesso, 2013). Research on living labs in general put forward the question of how participation is best facilitated within those labs and how all stakeholders can be included (Leminen et al., 2012; Leminen, 2013; Puerari et al., 2018).

The question remains how a Playable City can be cocreated in collaboration with all city stakeholders, resulting in an engaging and empowering participatory place to live. Prior work argues for the need of city actors for increased transparency, influence, and exchange when working together on city-making (De Koning et al., 2018). To our knowledge, current literature lacks overarching guidelines or frameworks for participatory design processes in which multiple stakeholders jointly explore their playable city. Therefore, this paper addresses the following research question: How can all stakeholders be included in exploring the design space of their playable city? The method to answer this question is explained below, after which a framework is presented from literature insights.

\section{METHODS}

The research question is answered by building theory based on a literature study and a case study. The literature study concludes with a design framework that is further grounded by case study research in The Hague (NL).

\subsection{Literature Study}

The literature study was performed by selecting and reviewing papers on urban (playful) interventions from the fields of human-computer interaction and participatory design. The review focuses on generating insights on how multiple stakeholders can jointly explore the design space of their (playable) city. This analysis uses the structure proposed by Hansen et al. (2019), who view participatory design processes through the lens of program theory. For each paper, the following elements are identified: which (co-)design and research activities were used during the research, which actors were included, what was their level of involvement [resonating with mechanisms from Hansen et al. (2019)], and which type of effect the research evoked. The types of effect are categorized as outputs, outcomes, and/or impact. Examples of effects that are categorized as output are design requirements or evaluation results; examples of outcomes are participants gaining new competence or identifying new ways of working; finally, an example of achieved impact is when long-term networks are created or the research results in democratic influence (Hansen et al., 2019). Papers were selected for the review based on the following three criteria: (1) the paper describes an intervention aiming to include citizen opinion; (2) one or multiple actors is involved in the design and/or evaluation of the intervention; (3) the paper describes enough detail of the design and/or evaluation process such that the activities, actors, level of involvement, and effects can be analyzed. The insights of the literature study are integrated in a design framework for participatory city-making presented below in section 5 .

\subsection{Case Study}

To demonstrate and further understand how this framework can guide designing inclusive processes with city stakeholders, the framework is used to analyze a research project that was executed in Bouwlust, a neighborhood in The Hague (NL). The study setup is an embedded, single-case study design, as just one neighborhood is studied and several units of analysis are involved (varying from Bouwlust as a whole to individual citizens) (Yin, 2003). The research in The Hague provides both a unique and representative case. It is unique due to the research setting in which a large variety of methods were used, both digital and face-to-face, to engage different city stakeholders. This unique setting is of interest, even as a single case (Yin, 2003). At the same time, the case is representative because the liveability and safety challenges with which Bouwlust is faced are common for urban socially mixed neighborhoods. Representative cases are relevant to study everyday situations and the resulting insights are assumed to be explanatory for situations in other similar neighborhoods (Yin, 2003). Due to these specific characteristics, this case was selected and found suitable to further inform the theory built from the literature study.

\subsection{Framework Analysis}

The Bouwlust case was analyzed by first collecting all available documentation and data on the research project. These were reports and slide decks used to present the research to stakeholders, transcripts, and survey data which were collected during the research, and the project website ${ }^{1}$ that was used to keep local actors informed about the research. The last three authors of this paper were involved in the research project in Bouwlust and hence their experiences also informed the analysis. Each of the research methods used in Bouwlust were described as a first step in the analysis. Following, the first author made an initial analysis by reflecting on the contribution of each of

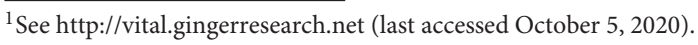


the methods to the aims of the four activities in the framework and determining to which extent the methods fit the four pillars. As a result, the methods were sorted and mapped on each of the activities to which they contributed. This initial outcome was discussed among all authors and further iterated by adding reflections and experiences of the other authors, leading toward the analysis presented in section 6 .

\section{LITERATURE STUDY}

Fourteen papers were selected from the literature search and included in the analysis as shown in Table 1. They are analyzed using the structure explained before, considering which Activities, Actors, Level of involvement, and Effects are described in the papers.

\subsection{Activities}

A common activity mentioned in all papers is identification of a topic that is of interest to the community involved that is used to mobilize people to participate. In some cases, this so-called matter of concern (Bjögvinsson et al., 2012) is already known to the researchers because of previous engagement with a community (e.g., Vlachokyriakos et al., 2014). In other cases, researchers start with field work to identify a matter of concern for the local community. Researchers explore the area with field visits, desk research, and interviews to discover a topic of concern for the local community and for which they can be mobilized. For example, Crivellaro et al. (2015) started with desk research on the city and then moved into the neighborhoods to contact locals, build relationships, identify issues, and involve professional stakeholders to move forward in addressing those issues. Fieldwork to connect with the context and community is an essential activity in this type of research (Slingerland et al., 2020a).

After the essential fieldwork, different paths unfold depending on the interest and purpose of the research. Four papers test an existing participation tool using the identified matter of concern (e.g., Schroeter, 2012; Valkanova et al., 2014; Fredericks et al., 2015). The main activities then comprise field user tests and focus groups to discuss the results. Other papers (e.g., Hosio et al., 2012; Wouters et al., 2014; Harding et al., 2015; Cila et al., 2016; Claes et al., 2017) deploy co-design activities with city stakeholders before implementing and testing an installation. Playful approaches are introduced as part of the co-design to create an open and creative mindset of the engaged partners. Hespanhol et al. (2015) consider play to be an essential aspect of eliciting community engagement and Brandt (2006) mentions it explicitly as a framework for participation. One step further is to include stakeholders in the evaluation as well (e.g., Aoki et al., 2009; Harding et al., 2015; Parraagudelo et al., 2018; Custers et al., 2020), for them to be able to continue the design process independent of the researchers. Play and games can be used to support these processes, and help stakeholders understand different perspectives (Ashtari and de Lange, 2019).

\subsection{Actors and Their Level of Involvement}

The extent to which a city community, either citizens or professional, are involved in the research and design varies considerably between papers. In five papers (Schroeter, 2012; Valkanova et al., 2014; Vlachokyriakos et al., 2014; Fredericks et al., 2015; Golsteijn et al., 2016), citizens are only involved as testers and professional actors are consulted for the context and content. In the cases of Fredericks et al. (2015) and Golsteijn et al. (2016), the performance installations were designed by the researchers, and citizens tested them during the field study. The (playful) installations gather citizen input on a specific topic. In some cases, researchers feed these results back to the local organization with whom they partnered (Fredericks et al., 2015; Golsteijn et al., 2016). Citizens often do not receive feedback on what happened with their input, although they do express this need (Vlachokyriakos et al., 2014; Hespanhol et al., 2015).

In five papers (Hosio et al., 2012; Wouters et al., 2014; Harding et al., 2015; Claes and Moere, 2017; Custers et al., 2020), local organizations and citizens are involved as co-designers of a citymaking intervention. For example, Hosio et al. (2012) organized several sessions with youngsters to collect requirements for an installation and social networking service to engage youth in city-making. The youth and youth organization were involved in the design process and gave feedback after using the resulting design. Custers et al. (2020) applied a similar approach named "Experimental Evaluation," in which city stakeholders collectively design, implement, and evaluate improvements for the city. This process not only focuses on co-producing interventions, but also on establishing collective learning with all stakeholders.

\subsection{Effects}

The effects these projects can have are categorized into three different levels: output, outcome, and impact. Seven papers remain in the output level, producing insights for designing participation tools. In these cases, the feedback citizens provided in the installation is shared and discussed with the local organization, and in some cases is sometimes visible to citizens themselves. Researchers also reflect with co-design participants on the outcome of the intervention (Hosio et al., 2012). The results are focused on how the installation enabled citizens to participate (Valkanova et al., 2014). Two papers also produce outcomes as a result of the co-design: actors learn new skills and develop competences.

Five paper show examples of participatory processes with effects on the level of impact (Aoki et al., 2009; Crivellaro et al., 2015; Harding et al., 2015; Parraagudelo et al., 2018; Custers et al., 2020). The research of Parraagudelo et al. (2018), for example, has a strong people-centered focus and started with ethnographic work in Colombia to get in contact with community organizations. They slowly built up relationships with formal institutions as well and aimed to help these organizations to co-design on the streets to advance the community. These papers focus on community empowerment and researchers act as facilitators to provide citizens and professionals with the tools and skills to collaborate, identify and discuss local issues, and work toward solutions. Such focus on building capacity and mutual learning is an essential aspect in 
TABLE 1 | Fourteen research projects are analyzed to understand how stakeholders are involved to jointly explore city-making.

\begin{tabular}{|c|c|c|c|c|}
\hline Paper & Activities & Actors & Level of involvement & Effect(s) \\
\hline Schroeter (2012) & $\begin{array}{l}\text { Field user tests, focus } \\
\text { groups }\end{array}$ & $\begin{array}{l}\text { Urban planners, citizens, } \\
\text { researchers }\end{array}$ & Citizens as testers & Output \\
\hline $\begin{array}{l}\text { Fredericks et al. } \\
\text { (2015) }\end{array}$ & Field user tests, focus group & $\begin{array}{l}\text { Representatives of local } \\
\text { government, citizens, } \\
\text { researchers }\end{array}$ & Citizens as testers & Output \\
\hline $\begin{array}{l}\text { Golsteijn et al. } \\
\text { (2016) }\end{array}$ & $\begin{array}{l}\text { Design of intervention, Field } \\
\text { user test }\end{array}$ & $\begin{array}{l}\text { Local government, citizens, } \\
\text { researchers }\end{array}$ & Citizens as testers & Output \\
\hline Hosio et al. (2012) & $\begin{array}{l}\text { Focus groups, prototype } \\
\text { design, field user tests, } \\
\text { feedback sessions }\end{array}$ & $\begin{array}{l}\text { Youth workers, youth, } \\
\text { researchers }\end{array}$ & Actors are consulted & Output, outcome \\
\hline $\begin{array}{l}\text { Harding et al. } \\
\text { (2015) }\end{array}$ & $\begin{array}{l}\text { Stakeholder workshops, } \\
\text { iterative co-design, field } \\
\text { user tests, focus groups }\end{array}$ & $\begin{array}{l}\text { Citizens, private workers, } \\
\text { local government, } \\
\text { researchers }\end{array}$ & Actors as informants & Output, outcome, impact \\
\hline Aoki et al. (2009) & $\begin{array}{l}\text { Ethnographic work, } \\
\text { workshop, system design, } \\
\text { deployment }\end{array}$ & $\begin{array}{l}\text { Consultants, citizens, urban } \\
\text { planners, NGOs, } \\
\text { researchers }\end{array}$ & $\begin{array}{l}\text { Actors as informants and } \\
\text { data collectors }\end{array}$ & Output, outcome, impact \\
\hline $\begin{array}{l}\text { Parraagudelo et al. } \\
\text { (2018) }\end{array}$ & $\begin{array}{l}\text { Creative activities and } \\
\text { workshops }\end{array}$ & $\begin{array}{l}\text { Grassroots communities, } \\
\text { researchers }\end{array}$ & $\begin{array}{l}\text { Communities drive the } \\
\text { research }\end{array}$ & Output, outcome, impact \\
\hline $\begin{array}{l}\text { Vlachokyriakos } \\
\text { et al. (2014) }\end{array}$ & Field user tests & $\begin{array}{l}\text { Citizens, grassroots, } \\
\text { researchers }\end{array}$ & Citizens as testers & Output \\
\hline $\begin{array}{l}\text { Valkanova et al. } \\
\text { (2014) }\end{array}$ & Field user tests & Citizens, researchers & Citizens as testers & Output \\
\hline
\end{tabular}

participatory design work (Bo Andersen et al., 2015; Halskov and Hansen, 2015).

\subsection{Take-Aways Toward the Framework}

The literature informs the design framework presented in the next section. The first take-away from the literature review is that all papers report on activities to get to know the local context and to connect with key actors. As shown in Table $\mathbf{1}$ and the analysis, there are significant differences in the extent to which citizens and other stakeholders are involved in city-making processes and the effects these projects have on the local community.

Some papers show examples of participatory processes in which different stakeholders are brought together, treated equally, and given influence on the design process (e.g., Aoki et al., 2009; Crivellaro et al., 2015; Parraagudelo et al., 2018; Custers et al., 2020). These papers affect the community at the level of impact: the local community engages in new relationships and practices, and researchers aim for the community to selfsustain these collaborations. In these cases, the focus of the activities is to facilitate the collaboration process between all actors. This explicitly entails including the stakeholders in the evaluation of these processes and to collectively reflect on the outcomes and next steps.

\section{A DESIGN FRAMEWORK FOR PARTICIPATORY CITY-MAKING}

Based on insights from the literature discussed above, the design framework is proposed as depicted in Figure 1. Four types of activities researchers can deploy to explore the design space of a participatory playable city are grounded in four pillars.

\subsection{Framework Foundation: Pillars for Participatory Playable City-Making}

The literature review was structured around "activities," "actors," "level of involvement," and "effects," providing the foundation for the four pillars of the framework. The pillars are presented in a random order, and they are all of equal importance: 


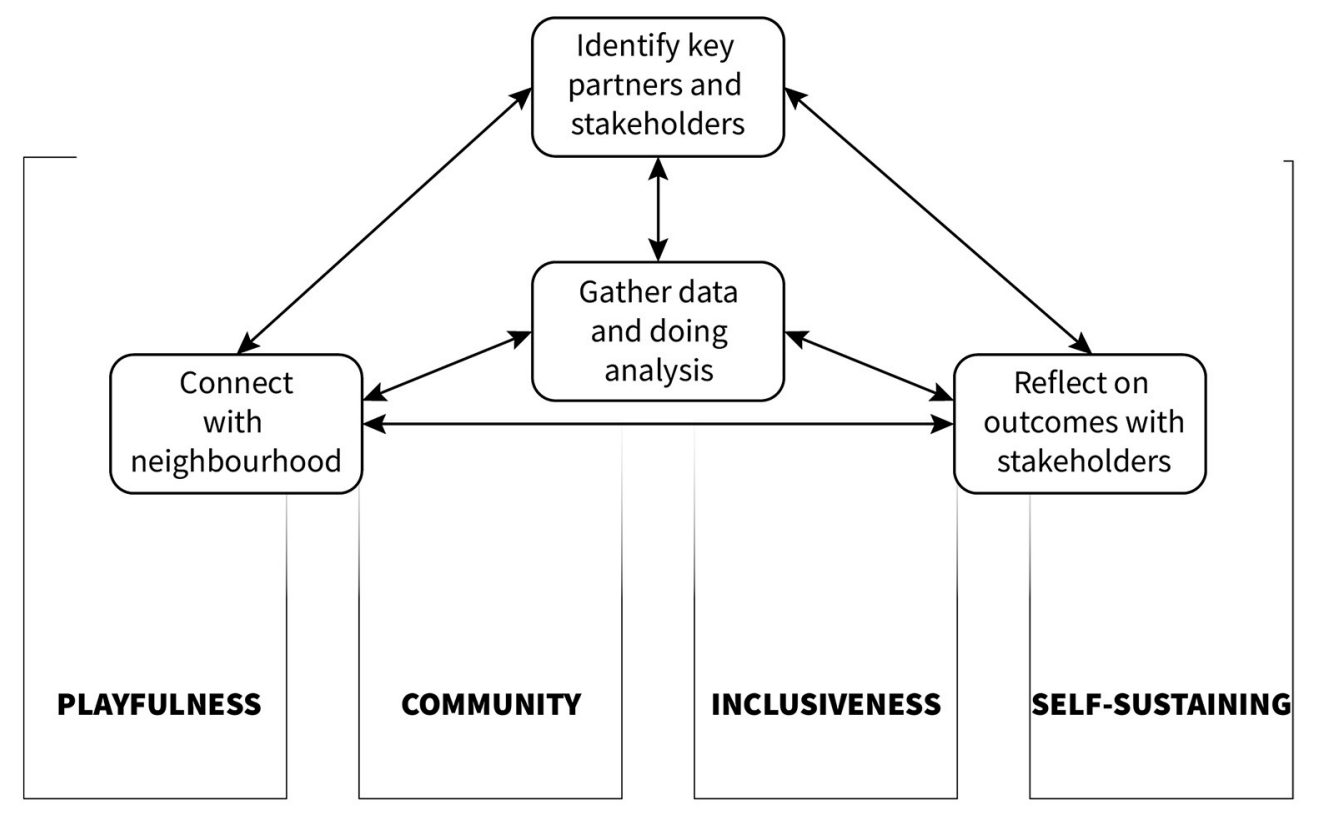

FIGURE 1 | The design framework proposed in this paper comprises four activities grounded on four pillars.

- The first pillar is Playfulness, directly related to "Activities." A playful mindset and setting during (research) activities enable open discussions and exploration between stakeholders.

- The second pillar is Community, directly related to the "Actors" involved, highlighting the central position of local community and context.

- The third pillar is Inclusiveness, directly related to "level of involvement." Analysis on the "level of involvement" indicated that all actors should be involved and treated equally, and be able to influence the design process.

- The fourth pillar is Self-sustaining, directly related to "Effects." Analysis of "Effects" showed that a focus on building community capacity enables local actors to continue the initiated design process and related discussions.

\subsection{Framework Content: Activities to Explore the Design Space of the Playable City}

The activities analyzed in the literature review are condensed to four activities for inclusive and participatory city-making in the framework (see the boxes in Figure 1):

- Connect with the neighborhood: The purpose of this activity is to understand the social, physical, and technological structure of, and the networks within an area. Becoming familiar with the local context also provides input to identify key partners, build relationships with them, and understand how outcomes of the research can be best brought back to the local community for reflection and evaluation. Methods in this activity include, for example, desk research, observations, neighborhood walks, and interviews.
- Identify key partners and stakeholders: In this activity, key partners and stakeholders are identified in terms of playable city design. Examples of potential partners and stakeholders are local enterprises, police officers, community centers, and grassroots communities because of their perspective on what a playable city should be. Field work is a method to execute this activity: starting by approaching obvious partners and interviewing them to create an overview of social structures and networks within a neighborhood. During such field work, researchers become further acquainted with the area, start to build relationships, and identify opportunities for reflection and discussion on the intermediate outcomes.

- Gather data and doing analysis: This activity is placed in the middle in Figure $\mathbf{1}$ because it is considered to be the core activity in this framework. Building relationships with all stakeholders is essential to be able to create a fruitful participatory process to design playable cities. The methods used in this activity to collect data should contribute to relationships between city stakeholders and the researchers, but also relationships between the various stakeholders themselves. In this activity, methods include interviews, focus groups, workshops, and prototyping to explore the roles and responsibilities of each stakeholder in the city. The results of this activity are input for the other three.

- Reflect on outcomes with stakeholders: To create a continuous and sustaining participatory practice between city stakeholders, outcomes of the design processes should be made visible and accessible for the community to reflect and discuss. This activity ensures that this happens, making use of physical and digital options to increase accessibility for as many people as possible not only when outcomes are communicated, but also thereafter. Methods and tools used in this activity 
can be prototypes, interactive installations, digital platforms, and workshops. Communicating the outcomes, making them accessible, and reflecting on them will also contribute to the other activities, possibly triggering new activities.

The order of the activities presented above is not necessarily the order in which they need to be executed: each activity contributes to the other activities and depending on the research aims and resources, multiple iterations of activities may be involved. As shown in Figure 1, these activities are grounded on the four pillars. Communities and inclusiveness play a central role: activities always include stakeholders. Activities should be playful and aim for outcomes that can be self-sustained by the local community. As mentioned before, all activities should consider the technological, social, and physical structures of, and networks within, the local context in design space exploration. This means for the connect with the neighborhood activity, for example, looking at digital platforms the local community uses, such as Facebook groups (technological layer), considering the formal and informal (citizen) groups and initiatives (social layer), and analyzing the physical environment of the local context (physical layer). While these activities in the framework seem to be separate entities, they inform each other as reflected by the arrows between them. As explained below, activities can be fulfilled by multiple methods: interviews can, for example, both be used to become acquainted with a neighborhood as well as to identify key partners and stakeholders.

The next part of this paper uses this framework to analyze the case study presented below. The aim of this analysis is to acquire further understanding of the applicability of the framework, in particular in the applicability of research methods used in each activity. The value of the outcomes of the activities and the extent to which they fulfill the four pillars this framework are evaluated.

\section{CASE STUDY: PLAYABLE BOUWLUST}

The case selected for this paper is a research project that explored the design space for liveability and safety in a participatory process in a neighborhood in The Hague (NL). The local government and police of The Hague identified the neighborhood of Bouwlust as one with a low level of citizen participation for which a new approach was needed. The liveability and safety issues with which citizens are confronted include drug abuse, litter, and youth gangs. Several initiatives have been started in the past by both the local government, the police and citizens to address these issues, often initiated and executed by one of these actors, often for a designated period of time. The research programme this paper analyzes was initiated by these parties to together explore options for inclusive participation to address liveability and safety issues. A research team of Delft University of Technology was invited in this context to, jointly with citizens and other partners, explore the design space of participation in Bouwlust. These methods are outlined in the next section after which the contribution of the methods in each activity is analyzed.

\subsection{Case Study Methods}

To identify the design space for participation, key actors, their relationships, and their view on participation were explored using eight different methods explained below.

\subsubsection{Artistic Research}

Architect Afaina de Jong ${ }^{2}$ made an architectural visual analysis of the neighborhood. At different moments during the week she visited Bouwlust and took photographs of the physical environment and the buildings. The architect walked through the neighborhood and explored if and how the physical environment supports social interaction and community building. The architect used the YUTPA framework (Nevejan, 2009) to do her architectural and artistic analyses. YUTPA is the acronym for "being with You in Unity of Time, Place and Action." The YUTPA framework has been developed to analyze trade-offs in presence design and facilitate discussion about different presence configurations (Nevejan and Brazier, 2015a). To this purpose, each presence design is analyzed along four dimensions: time, place, action, and relation (Nevejan and Brazier, 2011). Different underlying factors are specified for each dimension. The YUTPA dimensions resonate well with the need to acquire insight into the physical (dimensions place and time) and social (dimensions relation and action) structure of and networks within Bouwlust. This framework has also been used in other settings (e.g., Nevejan and Brazier, 2012) to understand the design space for participation. In Bouwlust, the YUTPA analysis, for example, revealed that there are many green areas, such as small parks and playgrounds, but that those are rarely used. Such insights were documented by the architect using photographs taken, and notes made, during the site visits.

\subsubsection{Desk Research}

For desk research, the team relied highly on municipal documentation, such as urban district plans, safety, and security reports, and neighborhood monitors. The municipality provided reports with evaluations of different participation initiatives that had been performed in the past. The police provided crime reports on, for example, burglaries, robberies, and (domestic) violence. Furthermore, the results of two surveys were provided, one of liveability and safety issues according to the citizens, and one on the digital means available to the citizens. The researchers themselves also analyzed several citizen participation initiatives they found on the internet through, for example, Facebook accounts of the neighborhood and of the community police officer.

\subsubsection{Neighborhood Mapping}

Two student groups from three different universities following an MSc programme on Responsible Innovation engaged in a mapping exercise in Bouwlust. They visited Bouwlust for 2 days and asked citizens to map places in the neighborhood where they feel happy. The collected locations and stories of citizens were put on an interactive digital map by the students for everyone to access.

\footnotetext{
${ }^{2}$ Afaina was part of the research team.
} 


\subsubsection{Interviews With Community Officers}

One of the first engagements with the community of Bouwlust were interviews held with five community professionals (four community police officers, one community worker). They played an important role in building up rapport with citizens in Bouwlust. The interviews were semi-structured and focused on three main topics. The first topic was the tasks of the police officer and community worker: their daily routines, which tasks lead to a good feeling (under which circumstances) and which ones cause frustration (under what circumstances). The second topic concerned the interaction and collaboration between professional partners, within the police force and outside with, for example, the Municipality and housing associations with questions, such as How do you negotiate and tune activities? How do you support each other? How do you receive and show appreciation? The third topic was about the way interaction and collaboration with citizens was organized, and its importance with questions, such as How do you interact with citizens? What is important in your work for citizens?

\subsubsection{Citizen Questionnaire and Interviews}

Following the interviews with community professionals, a questionnaire and semi-structured interview guide were developed to address the perspective of citizens. Again, the YUTPA framework (Nevejan, 2009) was used to structure and analyze the interviews with citizens. The questionnaire included one question for each of the factors underlying the four dimensions of the YUTPA framework, resulting in a questionnaire with 16 questions in total. For example, the "duration of engagement" factor was translated to the question "How long do you live here?" The factor "body sense" resulted in the question "Do you feel connected with the people in the neighborhood?" A question about the factor "reciprocity" was rephrased as "Do people help each other in this neighborhood?" As a final example, the "role" factor was translated to the question "Are you as a citizen important for actions that happen in the neighborhood?" The questionnaire addressed the social infrastructure in Bouwlust, to which extent citizens enjoy living in Bouwlust, whether they can take responsibility for the neighborhood, and how much they feel they can collaborate with other citizens or community professionals. Each question required an answer on a scale of 1 (hardly) to 10 (very much).

In a similar vain were questions formulated for the semistructured interview, using the YUTPA framework, to trigger the respondents to express their experiences of living and participating in the neighborhood. Citizens were informed about the research project and the option to participate, by leaflets that researchers distributed in the neighborhood, in physical mailboxes. These leaflets also offered the option for citizens to go to a website and answer some questions, instead of having a physical interview. The researchers set themselves up in a mobile unit for a few days near the shopping center in Bouwlust and approached citizens on the street inviting them to either fill out the questionnaire on paper or to participate in a more elaborate interview. This setting is shown in Figure 2. In total, 22 citizens participated in the physical interview that resulted in rich qualitative stories and experiences of citizens to complement the questionnaire outcomes. The questionnaire was filled in by 72 citizens.

\subsubsection{Citizen Focus Groups}

Participants for the citizen focus groups were recruited by visiting locations where citizens come together and approaching citizens to participate. For the focus groups, primary schools were visited to invite mothers to discuss their situations with the researchers. The researchers also visited the community center to talk to other citizens. In total 11 persons participated in the discussions. The topics addressed, and questions asked, were similar to the semi-structured interviews with citizens in the mobile unit.

\subsubsection{Installation}

To understand which circumstances in Bouwlust (e.g., emerging safety issues) could foster citizens to connect with each other and community professionals, an installation was setup for 2 days in the neighborhood, 1 day close to a mosque, and 1 day near the shopping center. This installation confronted citizens with specific circumstances, for example an increase of burglaries, and researchers asked citizens to respond, in terms of whom they would contact and in what way (face-to-face, email, phone, etc.). The answers provided by citizens gave further insight into the social structure of, and networks within Bouwlust and the possibilities to build and extend relationships between the various stakeholders.

\subsubsection{Design Workshop}

As a final activity, a design workshop was organized in which citizens and community police officers discussed the outcomes of the other activities and explored design options for Bouwlust. Twelve citizens, two community police officers, and a community worker gathered on an evening in the community center to co-design solutions for the three problems most frequently addressed in earlier activities: loiterers, litter, and burglaries. The participants were triggered to think of solutions from three perspectives, from the perspective of the most likely responsible stakeholder, such as the police or city council, from the perspective of social institutions, such as schools, mosques, health care, and shops, and from the perspective of physical and digital installations, such as apps, sensors, and street light. Solutions varied from larger garbage bins, improving locks on houses, via social influencing through school, church and mosque, understanding what loiterers need, to digital apps to report and inform citizens and government, and placing cameras and sensors at crucial places.

\subsection{Results of Case Study Analysis}

This section analyzes and outlines to what extent the methods helped to fulfill the aim of each of the activities, grounded on the four pillars. An overview of this analysis is shown in Figure 3. It depicts the relation between the research methods used during this case study and the activities of the earlier proposed design framework.

\subsubsection{Connect With the Neighborhood}

The aim of this activity is to acquire insight into the social, physical, and technological structure of the neighborhood. Initial 

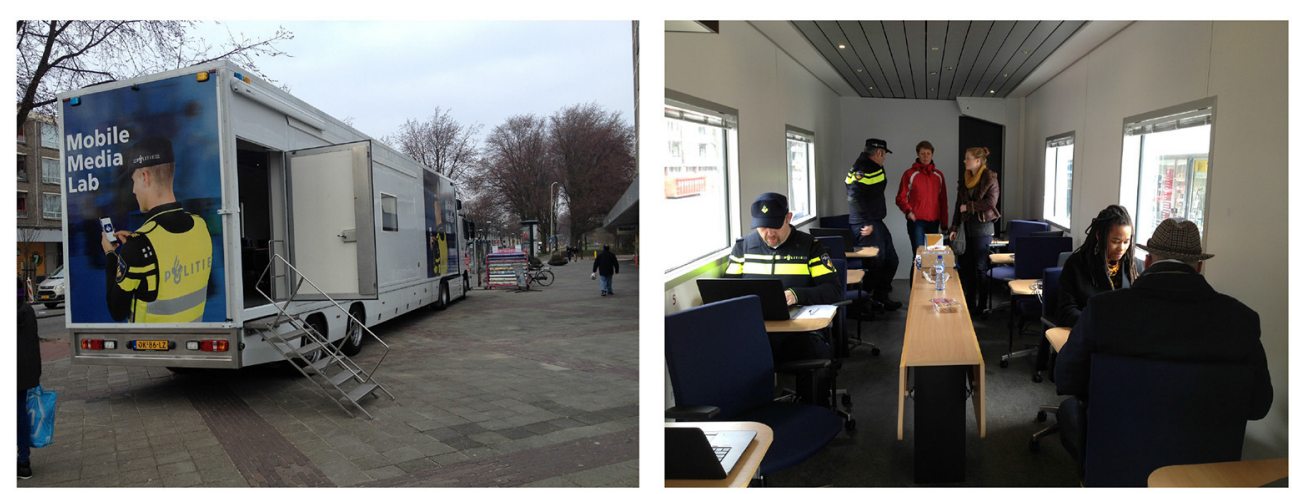

FIGURE 2 | The researchers invited citizens for an interview or to fill out the questionnaire in the mobile unit.

\begin{tabular}{|c|c|c|c|c|}
\hline & $\begin{array}{c}\text { CONNECT } \\
\text { WITH } \\
\text { NEIGHBOURHOOD }\end{array}$ & $\begin{array}{l}\text { IDENTIFY KEY } \\
\text { PARTNERS AND } \\
\text { STAKEHOLDERS }\end{array}$ & $\begin{array}{l}\text { GATHER DATA } \\
\text { AND DOING } \\
\text { ANALYSIS }\end{array}$ & $\begin{array}{c}\text { REFLECT ON } \\
\text { OUTCOMES WITH } \\
\text { STAKEHOLDERS }\end{array}$ \\
\hline Artistic research & \multicolumn{4}{|c|}{$x$} \\
\hline Desk research & \multicolumn{4}{|c|}{ 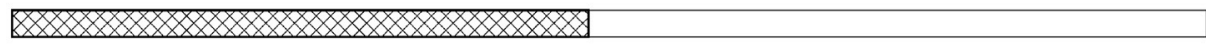 } \\
\hline Neighbourhood mapping & \multicolumn{4}{|c|}{ W } \\
\hline Interviews with community officers & \multicolumn{4}{|c|}{ (x) } \\
\hline Citizen questionnaire and interviews & \multicolumn{4}{|c|}{ 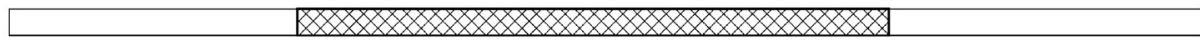 } \\
\hline Citizen focus groups & \multicolumn{4}{|c|}{$\alpha$} \\
\hline Installation & \multicolumn{4}{|c|}{ W } \\
\hline Design workshop & \multicolumn{4}{|c|}{ (2) } \\
\hline
\end{tabular}

involvement with the field through the artistic research, desk research, and neighborhood mapping was used in the case study as part of this activity. The artistic research was valuable for the researchers to develop a sense for Bouwlust, mostly in terms of the physical structure. For example, one observation was that many signs and fences restrict how public places are used in the neighborhood and that the community center building itself is visually closed off from the street (see Figure 4). As in the previous activities, the YUTPA framework (Nevejan, 2009) was used to structure the analysis of the observations and to interpret the photographs taken.

The desk research provided insight into demographics of Bouwlust, participation initiatives, and the liveability and safety problems citizens experience. The documents helped to understand the history of the neighborhood; how it has developed over the years into the very diverse and dynamic community it now is. An important insight in terms of social structure was, for example, that citizens, on average, live in Bouwlust for just 3 years. This high turnover of citizens complicates a general neighborhood sense of community. There is, however, a huge variation in the number of years citizens live in Bouwlust: from just 1 year to extremes up to 40 years. In terms of becoming acquainted with Bouwlust, the field visits were useful

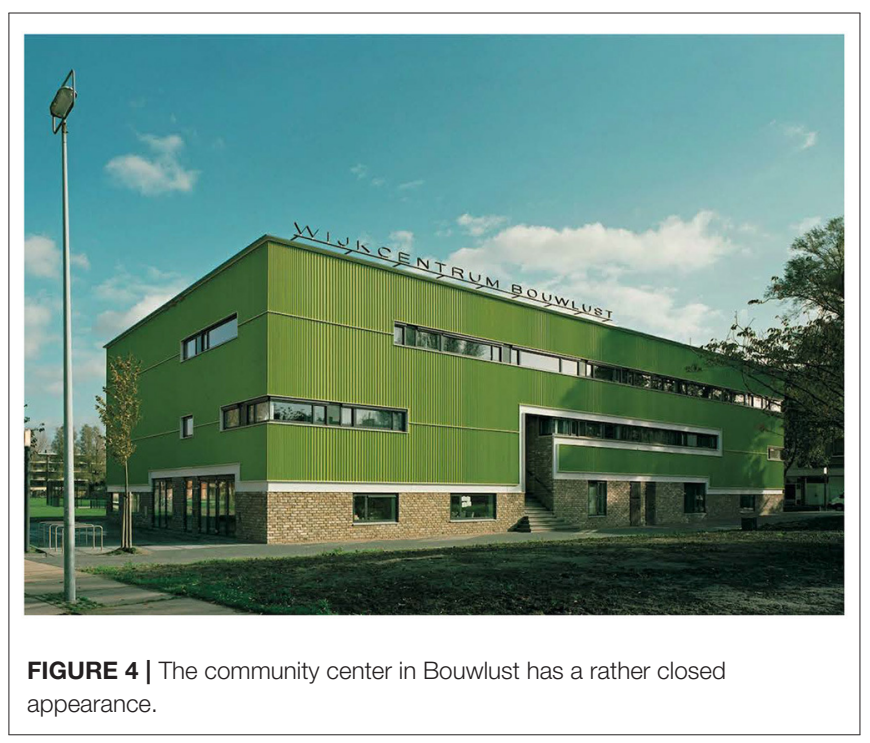

to get to know the important places in the neighborhood (such as the community center), while the desk research provided insights on what people in Bouwlust care about, which participation 
initiatives exist(ed), and the way the neighborhood is structured in terms of demographics. The methods helped to paint a rather conceptual picture of Bouwlust as there was limited engagement with the people whom live or work in Bouwlust. The interviews, focus groups, and installation used in the other activities provided much more insight into the social structure of, and networks in the neighborhood.

\subsubsection{Identify Key Partners and Stakeholders}

The aim of this activity is to acquire insight into the main actors in a neighborhood in terms of participation. The desk research contributed to this activity, complemented with the interviews, questionnaires, and focus groups with several of the obvious stakeholders. As in this research programme, the researchers were invited by the local police and government to explore citizen participation, these three stakeholders were an obvious starting point to identify other actors. The four methods used in this activity (see Figure 4) allowed to identify actors from different perspectives. Throughout these four methods, and the ones used beyond this activity, other key actors were identified. Insights in Bouwlust became more detailed and nuanced. This resulted in the notable insight that the notion of a key stakeholder is very dependent on context. For example, in some cases citizens are considered to be a single (type of) stakeholder in this context, while the desk research documents, citizen interviews and questionnaire showed that citizens organize themselves in communities according to cultural or ethnic background. For example, one citizen said: "Everybody is only connected to their own group, their own culture, and not with other people." Citizens can, in this context, not be considered to be a single stakeholder, but rather as multiple stakeholders who are organized based on culture. People are part of different cultures, around schools, religion, sports, housing blocks for example. Culture is used here in a broad sense and reflects a multiplicity of identities (de Jong, 2020).

The key stakeholders identified by the community police officers included the municipality, local care institutions, and housing corporations. Citizens did not make this distinction: they grouped these various governmental actors together as the community police officer stakeholder. This became clear during the focus groups and citizen interviews, in which citizens indicated that they reach out to their community police officers when they need help, independent of the issue. One of the community police officers stated: "We fill many gaps. We are in contact with schools, shops, care institutions and youth work." Another one said: "These professional partners come to me, [...] They call me to ask to go by one of their clients from which they haven't heard in a while. In these cases I decide if this is part of my job or if it's the partner's responsibility." The officer is the first contact point for most citizens when they need help and also for the professional organizations when they want to reach citizens. The three methods in this activity taught that there are different perceptions on key stakeholders and that for Bouwlust, the main interaction is between the community police officer and different groups of citizens. The focus groups stimulated an open and exploratory discussion between different citizens. The discussions were dynamic and interactive, contributing to a playful ambience. The research showed every specific and important social role these community police officers have, according to the interviewed residents.

\subsubsection{Gather Data and Doing Analysis}

This activity comprised many methods as shown in Figure 3. The interviews, questionnaires, and focus groups with citizens and community officers contributed to building relationships needed to gather data and analyze Bouwlust. Neighborhood mapping, the installation, and design workshop supported this activity as well. This variation of methods enables city stakeholders to engage at different moments, as it suits them. They were playful in the way data were collected, using traditional methods (interviews, questionnaires, and focus groups) and methods that fostered creativity, openness, and interaction (neighborhood mapping, installation, and design workshop). These methods created an iterative cycle to connect more and more with the neighborhood and deepen the relationships with stakeholders. City stakeholders simultaneously became familiar with the research project, decreasing the effort to convince stakeholders to participate. Strategic locations to attract a variety of citizen groups were selected: visiting schools, shopping areas, mosques, and playgrounds. The fact that these methods were mainly conducted out on the streets, using a visible mobile unit or installation, lowered the barrier for stakeholders to talk to the researchers and thus relaxed the effort to collect data.

On the other hand, this activity aims to invest in the relationships between the city stakeholders themselves. The design workshop brought citizens, police officers, and community workers together to discuss outcomes and collaboratively design solutions for three frequently mentioned problems in the neighborhood. Different stakeholders collaborated on a commonly felt problem, which contributed to their shared feeling and relationship. The design workshop was playful because it fostered an open and exploratory mindset of participants, as they were asked to consider perspectives of other stakeholders, social institutions, and physical/digital installations when coming up with solutions.

\subsubsection{Reflect on Outcomes With Stakeholders}

The aim of this activity is to find out where and how outcomes of the other activities can be fed back to the city stakeholders for reflection and discussion. In the design workshop, the results so far were summarized and presented to the participants. The main reason for this is to validate whether the participants recognize these results and are willing to adopt them further on in the process. To this end, the outcomes of the interviews and questionnaires were mapped on the YUTPA framework to understand the relationships between the different actors and how they perceive each other. This is illustrated in Figure 5, showing the YUTPA outcomes for citizens and community police officers. These graphs highlight which factors are supported, for which support is lacking, and how this differs between citizens and community police officers. This tool illuminates which factors have a basis and which relationships between the various city stakeholders can be developed. The right graph shows the YUTPA result when all graphs are combined, visualizing the 


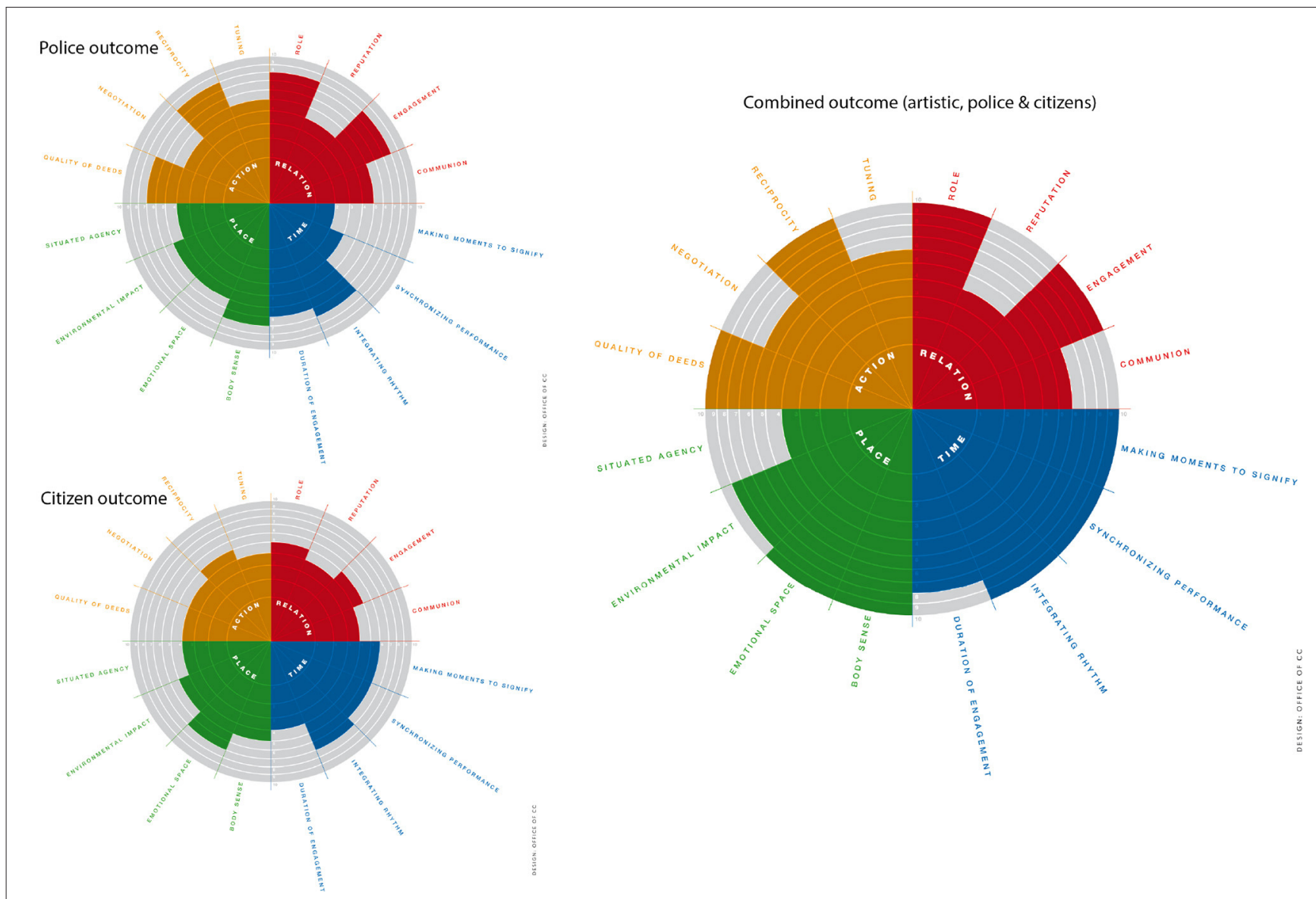

FIGURE 5 | Left part shows the difference between the YUTPA outcomes for citizens and police officers. Right graph is the result of combing all YUTPA analyses to identify possible design spaces. Scores higher than 5 show potential for design.

potential design spaces for participation in Bouwlust. The factors that score higher than 5 on this combined graph are considered to indicate a potential design space.

In Bouwlust, neighborhood mapping, an installation, and the design workshop were used to fulfill this aim. In addition, a website was made available for citizens and other stakeholders to be informed on the progress of the research and intermediate results ${ }^{3}$. Asking citizens to indicate which places in Bouwlust make them happy resulted in a list of locations that might be appropriate to disseminate outcomes. The installation provided insight into motivators for citizens to engage with their neighbors and neighborhood and other city stakeholders. The topic of safety in Bouwlust was identified as a topic that motivates citizens to contribute to neighborhood initiatives for a longer period of time.

As result of the research it became apparent that the time dimension of the YUTPA framework offers the best design solution space for enhancing social safety in Bouwlust. The first factor that can be enhanced in the time dimension is integrating rhythm. Many residents have reported that sharing activities like walking the dog, meeting at the school yard, and shopping at the

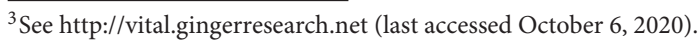

same time make it easier to engage with a basic trust among one another. Rhythms of daily life affect the sense of social safety in a neighborhood. The second factor that many residents agreed upon is the fact that the Bouwlust lost "moments to signify." In a neighborhood both the history of the place as well as a yearly festival for example, or a monthly newsletter give people a shared sense of where they are. The sharing of meaning, the actively being involved with contributing to this meaning of and in a neighborhood, enhances the sense of social cohesion and the sense of social safety as result. The longing for more meaning and active engagement with neighborhood histories is visible in local social media activities, but is not yet visible in the physical environment.

\section{DISCUSSION}

Analysis of the case study in Bouwlust provides insight into which methods are essential within the design framework proposed in this paper. To untangle participatory design processes and methods is a challenge (Sawhney and Tran, 2020): they are not easily separated because they influence each other constantly. To this end, researchers can move back and forth between the four 
activities of our framework using methods that can contribute to multiple activities at the same time as depicted in Figure 6. Such an iterative process is needed as the neighborhood is also continually changing. For example, the analysis showed that key partners and stakeholders are fluid, depending on who and when you ask. Going through multiple iterations using various methods also allows to step by step deepen the understanding and connection with the context, and to continuously inform next steps on what was learned. The resulting account to use different types of methods and to iterate within and between the four activities are the two main topics for discussing the analysis.

\subsection{Method Variety in Each of the Activities}

Eight different methods were used to explore participation with various stakeholders in Bouwlust. These methods purposefully offered neighborhood actors multiple ways to participate in the research. Citizens could engage in a way that suited their availability and commitment. The benefit of providing different modes or mediums to tailor participation was also highlighted in case studies on grassroots citizen communities (Slingerland et al., 2019b). The findings in Bouwlust show as well that multiple methods should be used in this kind of work to provide actors distinct ways to be involved and provide input to the research.

One activity in which many distinct methods were used was gather data and doing analysis. While the mobile unit for the citizen interviews received a lot of attention because it was placed at a strategic location where many people frequent, digital engagement on the website was considerably lower. Engagement, in this case, was measured in terms of how many citizens responded. These two channels nonetheless enabled different types of citizens to participate: ones whom do not find their way to a website or app and enjoy talking to a researcher, and ones whom prefer to give their feedback at home using their computer at a time that suits them. The YUTPA framework was helpful to integrate the insights from the various methods providing a generic coding scheme for the analysis of the variety of results, enabling comparison needed to identify design spaces for participation in the neighborhood.

\subsection{Timing and Sequence of Methods and Activities}

The four activities of the proposed framework were initially introduced without a pre-defined order. The case study in Bouwlust, however, suggests a preferred sequence of activities and methods. This sequence suggestion is added to Figure 6. Initial field involvement is an essential first step before any of the other methods can be applied. This initial step informs the researchers on which locations in the neighborhood people can be found and which people or parties should be considered in the furthering research. Interviews with citizens or city officials, for example, will not be less informative to researchers if they do not first engage with desk research and field visits to know which topics to address in the interviews. Interactive installations could also be used to become acquainted with the neighborhood, but researchers first need to know which are crowded locations to strategically place an installation. The prominent presence of such initial field work in seminal literature (e.g., Aoki et al., 2009;
Crivellaro et al., 2015; Parraagudelo et al., 2018; Custers et al., 2020) confirms that field involvement as part of connecting with the neighborhood is a critical first step in the proposed framework.

Following the case study analysis, connecting with the neighborhood seems to be the activity that needs to be executed first before the other three activities can be done. In contrast, the other three activities do not presume a specific sequence and continue to inform each other and the first activity as well. In the case of Bouwlust, results were mostly made visible to the community during the final stages of the research. Some methods (e.g., the installation) could have been applied already earlier to visualize intermediate outcomes. At the same time, the installation in Bouwlust was, for example, designed using insights from the interviews and questionnaire. The method sequence needs to be carefully considered, to find an appropriate chain of activities that build on each other's outcomes and disseminates these outcomes to the local community. A method, such as focus groups is also suitable to feed results back and discuss them with the community to inform further research activities (Pickering et al., 2012). Such a process, where directions and outcomes become apparent on the go, requires a lot of flexibility from researchers, participants, and funders, which is not always an option.

\subsection{Fulfilling the Four Pillars}

The design framework presented in this paper requires all activities to build on the four pillars: community, self-sustaining, inclusiveness, and playfulness. These pillars serve as a checklist when researchers are setting up their research design, selecting their methods for engaging with the various stakeholders. For the community pillar, this requires researchers to keep the local community in mind, even when they do not directly engage with them. When starting with desk research, for example, researchers should not only consider formal documents produced by professional actors, but also check for informal citizen networks and platforms where the local community might meet. In terms of self-sustaining, the methods selected should contribute to the local actors being able to independently continue exploration of participation in the neighborhood. To this end, researchers should not aim to solve problems of the community, but rather support the various stakeholders in collaboratively taking this up. The pillar of inclusiveness is fulfilled when researchers use different kinds of methods for people to participate on their terms and in a way that suits them. Method variety in terms of digital or physical participation as well as required time commitment are ways of achieving this. The playfulness pillar entails the need for researchers to offer creative and open-ended ways of engaging with the local community. This increases pleasure for participants, but also creates an environment for exploration and reflection with stakeholders.

\section{CONCLUSION}

This paper proposes a design framework to support city actors to make it work together, despite their sometimes conflicting values and interests. The framework is inspired by the playable city perspective. Based on insights from 


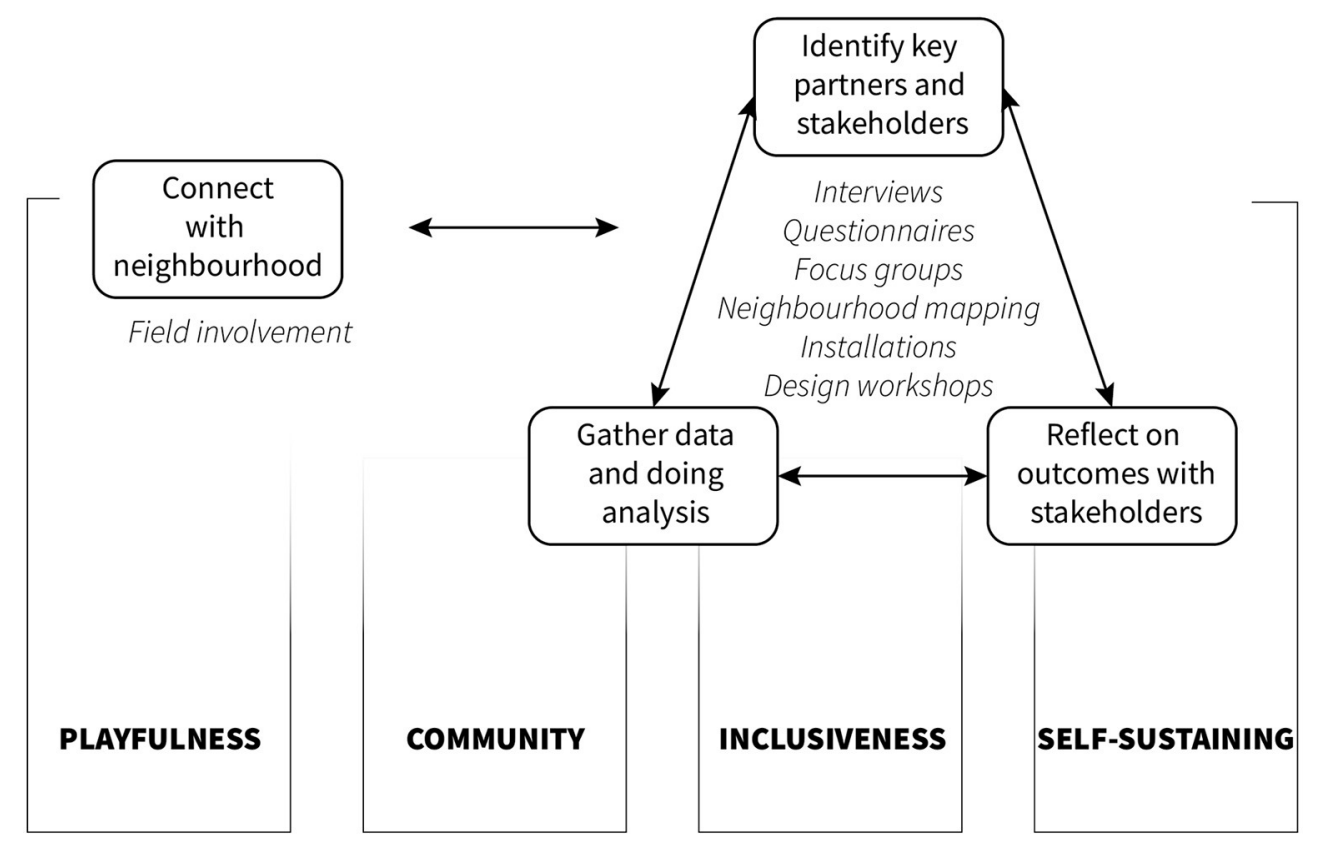

FIGURE 6 | The design framework suggests a sequence of activities and which methods to be used in them.

literature, the framework enables the construction of long-term and sustaining participatory city-making projects, in which all stakeholders are able to contribute and their input is equally valued. The foundation of the framework ensures an open and exploratory mindset of all actors through four pillars: community, self-sustaining, inclusiveness, and playfulness. Furthermore, the framework suggests to structure an exploration of the design space for participatory city-making around four activities. The value of the framework is demonstrated through a case study, in which further insights are gathered on the four activities and possible corresponding methods. The case study in Bouwlust (a neighborhood in The Hague, NL) was analyzed using the framework to understand which methods support city actors to together make it work.

The case study lasted in Bouwlust for 2 years in collaboration with the police and local government. Eight different methods were part of the study to involve community professionals and citizens in thinking about improving the liveability and safety in Bouwlust. Using the framework to analyze the citymaking process in Bouwlust resulted in valuable and relevant insights into how such processes can be best organized. The first insight was that method variety in each of the activities is needed to offer city stakeholders multiple ways to get involved, using digital channels or real-life engagements, with various levels of commitment. The second insight was the activity connect with the neighborhood needs to be done before the other three. The outcome from this activity informs the activities to identify key partners, gather data and doing analysis, and make outcomes visible and accessible. While untangling participatory design processes can be difficult (Sawhney and Tran, 2020), the framework presented in this paper demonstrated its value to do just that, to fill the gap of developing playable city design approaches that are inclusive and meaningful for the local community. Current research extends this research to focus on the development of a data approach to enhance rhythms in neighborhoods (2018-2023) in urban environments (Nevejan et al., 2018). Current research also explores a variety of interfaces in which online local activity becomes visible in the physical environment where the stories and data are gathered in a playful endeavor (Suurenbroek et al., 2019). Further analysis of other playable participatory case studies using this framework is one of the directions of our future work and aims to strengthen the contribution of this promising framework to the field of playable cities.

\section{DATA AVAILABILITY STATEMENT}

The raw data supporting the conclusions of this article will be made available by the authors, without undue reservation.

\section{ETHICS STATEMENT}

The studies involving human participants were reviewed and approved by HREC TU Delft. The patients/participants provided their written informed consent to participate in this study. Written informed consent was obtained from the individual(s) for the publication of any potentially identifiable images or data included in this article.

\section{AUTHOR CONTRIBUTIONS}

GS conducted the literature review and together with SL, $\mathrm{MH}$, and $\mathrm{FB}$ developed the proposed framework. $\mathrm{MH}$ and 
$\mathrm{CN}$ were involved in the field work in Bouwlust in each of the eight methods described. GS, SL, MH, CN, and FB conducted the analysis of the case study using the proposed framework, wrote, and revised the manuscript. All authors contributed to the article and approved the submitted version.

\section{FUNDING}

Funding for the BART project (www.bartportal.nl) was provided by a consortium of partners including the Municipality of the

\section{REFERENCES}

Aoki, P. M., Honicky, R. J., Mainwaring, A., Myers, C., Paulos, E., Subramanian, S., et al. (2009). "A vehicle for research: using street sweepers to explore the landscape of environmental community action," in Proceedings of Conference on Human Factors in Computing Systems (Boston, MA), 375-384. doi: 10.1145/1518701.1518762

Ashtari, D., and de Lange, M. (2019). Playful civic skills: a transdisciplinary approach to analyse participatory civic games. Cities 89, 70-79. doi: 10.1016/j.cities.2019.01.022

Bjögvinsson, E., Ehn, P., and Hillgren, A. (2012). Design things and design thinking: contemporary participatory design challenges. Des. Issues $28,101-$ 116. doi: 10.1162/DESI_a_00165

Bo Andersen, L., Danholt, P., Halskov, K., Brodersen Hansen, N., and Lauritsen, P. (2015). Participation as a matter of concern in participatory design. Codesign 11, 250-261. doi: 10.1080/15710882.2015.1081246

Bowles, S., and Gintis, H. (2002). Social capital and community governance. Econ. J. 112, F419-F436. doi: 10.1111/1468-0297.00077

Brandt, E. (2006). "Designing exploratory design games: a framework for participation in participatory design?" in Proceedings of the Ninth Participatory Design Conference 2006 (Trento), 57-66. doi: 10.1145/1147261.1147271

Brazier, F. M., and Nevejan, C. (2014). "Vision for participatory systems design," in 4th International Engineering Systems Symposium (CESUN 2014) (Hoboken, NJ).

Certomà, C., Dyer, M., Pocatilu, L., and Rizzi, F. (2017). Citizen Empowerment and Innovation in the Data-Rich City. Cham: Spinger Nature.

Chisholm, C. J., Falk, C. A., and Kozak, L. E. (2020). "Sticks, ropes, land: confronting colonial practices in public space design," in Proceedings of the 16th Participatory Design Conference 2020-Participation(s) Otherwise-Vol 2 (PDC '20: Vol. 2) (Manizales: ACM), 63-67.

Cila, N., Jansen, G., den Broeder, L., Groen, M., Meys, W., and Kröse, B. (2016). "Look! A healthy neighborhood: means to motivate participants in using an app for monitoring community health," in Proceedings of the 2016 CHI Conference Extended Abstracts on Human Factors in Computing Systems (San Jose, CA: ACM), 889-898. doi: 10.1145/2851581.2851591

Claes, S., Coenen, J., and Moere, A. V. (2017). "Empowering citizens with spatially distributed public visualization displays," in DIS'17 Companion: Proceedings of the 2017 ACM Conference Companion Publication on Designing Interactive Systems (Edinburgh), 213-217. doi: 10.1145/3064857.3079148

Claes, S., and Moere, A. V. (2017). "The impact of a narrative design strategy for information visualization on a public display," in DIS'17: Proceedings of the 2017 Conference on Designing Interactive Ssytems (Edinburgh), 833-838. doi: $10.1145 / 3064663.3064684$

Cooper, T., Bryer, T. A., and Meek, J. W. (2006). Citizen-centred collaborative public management. Public Admin. Rev. 66, 76-88. doi: 10.1111/j.1540-6210.2006.00668.x

Crivellaro, C., Comber, R., Dade-Robertson, M., Bowen, S. J., Wright, P., and Olivier, P. (2015). "Contesting the city: enacting the political through digitally supported urban walks," in Proceedings of Conference on Human Factors in Computing Systems (Seoul), 2853-2862. doi: 10.1145/2702123.2702176

Custers, L., Devisch, O., and Huybrechts, L. (2020). "Experiential evaluation as a way to talk about livability in a neighborhood in transformation," in
Hague, the National Police, Ministry of the Interior and Kingdom Relations, CGI, TNO, TUDelft, and TIGNL.

\section{ACKNOWLEDGMENTS}

The authors were very grateful to all citizens, professional stakeholders of Bouwlust, and the BART consortium for their participation. The authors also thank architect Afaina de Jong for her contribution to several of the participatory design research activities in Bouwlust, and the students for their work on mapping Bouwlust in collaboration with its citizens.

Proceedings of the 16th Participatory Design Conference 2020-Participation(s) Otherwise-Vol 2 (PDC '20: Vol. 2) (New York, NY: ACM), 114-118. doi: $10.1145 / 3384772.3385128$

de Jong, A. (2020). "Multiplicity of other," in Values for Survival eds C. Nevejan and H. A. Farè (Rotterdam: Het Nieuwe Institituut), 85-97.

De Koning, J., Puerari, E., Mulder, I., and Loorbach, D. (2017). Ten Types of Emerging City Makers. Oslo: SDA Systemic Design Association.

De Koning, J. I., Puerari, E., Mulder, I. J., and Loorbach, D. A. (2018). "Designenabled participatory city making," in 2018 IEEE International Conference on Engineering, Technology and Innovation, ICE/ITMC 2018-Proceedings (Stuttgart), 1-9. doi: 10.1109/ICE.2018.8436356

de Lange, M., and de Waal, M. (2013). Owning the city: new media and citizen engagement in urban design. First Monday 18, 1-13. doi: $10.5210 / \mathrm{fm} . v 18 \mathrm{i} 11.4954$

Disalvo, C., Louw, M., Coupland, J., and Steiner, M. (2009). "Local issues, local uses: tools for robotics and sensing in community contexts," in ACM Conference on Creativity and Cognition (Berkeley, CA), 245-254. doi: $10.1145 / 1640233.1640271$

Dörk, M., and Monteye, D. (2011). "Urban co-creation: envisioning new digital tools for activism and experimentation in the city," in Proceedings of the CHI Conference (Vancouver, BC).

Erete, S. L. (2015). "Engaging around neighborhood issues," in Proceedings of the 18th ACM Conference on Computer Supported Cooperative Work \& Social Computing (Vancouver, BC), 1590-1601. doi: 10.1145/2675133.2675182

Ferreira, V., Anacleto, J., and Bueno, A. (2017). "Designing ICT for thirdplaceness," in Playable Cities: Gaming Media and Social Effects, ed A. Nijholt (Singapore: Springer), 211-233. doi: 10.1007/978-981-10-1962-3_10

Fisher, P. T., and Hornecker, E. (2017). "Creating shared encounters through fixed and movable interfaces," in Playable Cities: The City as a Digital Playground, ed A. Nijholt (Singapore: Springer), 163-185. doi: 10.1007/978-981-10-1962-3_8

Fredericks, J., Tomitsch, M., Hespanhol, L., and McArthur, I. (2015). "Digital pop-up: investigating bespoke community engagement in public spaces," in OzCHI 2015: Proceedings of the Annual Meeting of the Australian Special Interest Group for Computer Human Interaction (Melbourne, VIC), 634-642. doi: $10.1145 / 2838739.2838759$

Gaventa, J. (2004). Representation, Community Leadership and Participation: Citizen Involvement in Neighbourhood Renewal and Local Governance. Technical Report July, Office of Deputy Prime Minister.

Golsteijn, C., Gallacher, S., Capra, L., and Rogers, Y. (2016). "Sens-Us: designing innovative civic technology for the public good," in Proceedings of the 2016 ACM Conference on Designing Interactive Systems (Brisbane, QLD: ACM), 39-49. doi: $10.1145 / 2901790.2901877$

Halskov, K., and Hansen, N. B. (2015). The diversity of participatory design research practice at PDC 2002-2012. Int. J. Hum. Comput. Stud. 74, 81-92. doi: 10.1016/j.ijhcs.2014.09.003

Hansen, N. B., Dindler, C., Halskov, K., and Schouten, B. (2019). "How participatory design works: mechanisms and effects," in OZCHI'19: Proceedingsof the 31st Australian Conference on Human-Computer-Interaction (Fremantle, WA), 30-41. doi: 10.1145/3369457.3369460

Harding, M., Knowles, B., Davies, N., and Rouncefield, M. (2015). "HCI, civic engagement \& trust," in Proceedings of Conference on Human Factors in Computing Systems (Seoul), 2833-2842. doi: 10.1145/2702123.2702255 
Hespanhol, L., Tomitsch, M., McArthur, I., Fredericks, J., Schroeter, R., and Foth, M. (2015). "Vote as you go: blending interfaces for community engagement into the urban space," in Proceedings of the 7th International Conference on Communities and Technologies-CeT '15 (Limerick), 29-38. doi: $10.1145 / 2768545.2768553$

Hosio, S., Kostakos, V., Kukka, H., Jurmu, M., Riekki, J., and Ojala, T. (2012). From school food to skate parks in a few clicks: using public displays to bootstrap civic engagement of the young. Pervasive 7319, 425-442. doi: $10.1007 / 978-3-642-31205-226$

Innocent, T. (2018). "Play about place: placemaking in location-based game design," in Proceedings of Media Architecture Biennale 2018 Conference (MAB'18) (Beijing), 7. doi: 10.1145/3284389.3284493

Juujärvi, S., and Pesso, K. (2013). Actor roles in an urban living lab: what can we learn from Suurpelto, Finland? Technol. Innov. Manag. Rev. 3, 22-27. doi: $10.22215 /$ timreview/742

Kleinhans, R., Van Ham, M., and Evans-Cowley, J. (2015). Using social media and mobile technologies to foster engagement and self-organization in participatory urban planning and neighbourhood governance. Plan. Pract. Res. 30, 237-247. doi: $10.1080 / 02697459.2015 .1051320$

Le Dantec, C. A., and Fox, S. (2015). "Strangers at the gate: gaining access, building rapport, and co-constructing community-based research," in Proceedings of the 18th ACM Conference on Computer Supported Cooperative Work \& Social Computing (Vancouver, BC: ACM), 1348-1358. doi: 10.1145/2675133.2675147

Leminen, S. (2013). Coordination and participation in living lab networks. Technol. Innov. Manag. Rev. 3, 5-14. doi: 10.22215/timreview/740

Leminen, S., Westerlund, M., and Nyström, A.-G. (2012). Living labs as open-innovation networks. Technol. Innov. Manag. Rev. 2, 6-11. doi: 10.22215/timreview/602

Mulder, I. (2012). Living labbing the Rotterdam way: co-creation as an enabler for urban innovation co-creation as an enabler for urban innovation. Technol. Innov. Manag. Rev. 2, 39-43. doi: 10.22215/timreview/607

Mulder, I. (2015). "Opening up: towards a sociable smart city," in Citizen's Right to the Digital City: Urban Interfaces, Activism, and Placemaking, eds M. Foth, M. Brynskov, and T. Ojala (Singapore: Springer), 161-173. doi: 10.1007/978-981-287-919-6_9

Nam, T., and Pardo, T. A. (2011). "Conceptualizing smart city with dimensions of technology, people, and institutions," in The Proceedings of the 12th Annual International Conference on Digital Government Research (College Park, MD), 282-291. doi: 10.1145/2037556.2037602

Nelson, S., and Baldwin, N. (2002). Comprehensive neighbourhood mapping: developing a powerful tool for child protection. Child Abuse Rev. 11, 214-229. doi: $10.1002 /$ car.741

Nevejan, C. (2007). Presence and the design of trust (Ph.D. thesis), University of Amsterdam, Amsterdam, Netherlands.

Nevejan, C. (2009). Witnessed Presence and the YUTPA framework. Psychnol. J. 7, 59-76. Available online at: http://sprouts.aisnet.org/9-21

Nevejan, C., and Brazier, F. (2011). "Witnessed presence in merging realities in healthcare environments," in Advanced Computational Intelligence Paradigms in Healthcare 5, Volume 326 of Studies in Computational Intelligence, eds S. Brahnam and L. Jain (Berlin; Heidelberg: Springer Berlin Heidelberg), 201-227. doi: 10.1007/978-3-642-16095-0_11

Nevejan, C., and Brazier, F. M. (2012). Granularity in reciprocity. AI Soc. 27, 129-147. doi: 10.1007/s00146-011-0332-8

Nevejan, C., and Brazier, F. M. (2015a). "Design for the value of presence," in Handbook of Ethics, Values, and Technological Design, eds J. van den Hoven, P. Vermaas, and I. van de Poel (Dordrecht: Springer), 403-430.

Nevejan, C., and Brazier, F. M. (2015b). "Presence and participation: values for designing complex systems," in Handbook of Ethics, Values, and Technological Design, eds J. van den Hoven, P. Vermaas, and I. van de Poel (Dordrecht: Springer), 403-430.

Nevejan, C., Sefkatly, P., and Cunningham, S. (2018). City Rhythm, Logbook of an Exploration. Delft: Delft University of Technology.

Nijholt, A. (2017). Playable Cities: The City as a Digital Playground. Singapore: Springer Science+Business Media.

Nijholt, A. (2020). Making Smart Cities More Playable. Singapore: Springer.

Nyström, A.-G., Leminen, S., Westerlund, M., and Kortelainen, M. (2014). Actor roles and role patterns influencing innovation in living labs. Ind. Market. Manag. 43, 483-495. doi: 10.1016/j.indmarman.2013.12.016
Palacin, V., Nelimarkka, M., Reynolds-Cuellar, P., and Becker, C. (2020). "The design of pseudo-participation," in Proceedings of the 16th Participatory Design Conference 2020-Participation(s) Otherwise-Vol 2 (PDC '20: Vol. 2) (Manizales: ACM), 40-44. doi: 10.1145/3384772.3385141

Parraagudelo, L., Choi, J. H., Foth, M., and Estrada, C. (2018). Creativity and design to articulate difference in the conflicted city: collective intelligence in Bogota's grassroots organisations. AI Soc. 33, 147-158. doi: 10.1007/s00146-0170716-5

Pickering, J., Kintrea, K., and Bannister, J. (2012). Invisible walls and visible youth: territoriality among young people in British cities. Urban Stud. 49, 945-960. doi: $10.1177 / 0042098011411939$

Puerari, E., de Koning, J. I., von Wirth, T., Karré, P. M., Mulder, I. J., and Loorbach, D. A. (2018). Co-creation dynamics in urban living labs. Sustainability 10, 1-18. doi: $10.3390 /$ su10061893

Sawhney, N., and Tran, A.-T. (2020). "Ecologies of contestation in participatory design," in Proceedings of the 16th Participatory Design Conference 2020Participation(s) Otherwise-Vol 1 (PDC '20: Vol. 1) (Manizales: ACM), 172-181. doi: $10.1145 / 3385010.3385028$

Schouten, B., Ferri, G., De Lange, M., and Millenaar, K. (2017). "Games as strong concepts for city-making," in Playable Cities: Gaming Media and Social Effects, ed A. Nijholt (Singapore: Springer), 23-45. doi: 10.1007/978-981-101962-3_2

Schroeter, R. (2012). "Engaging new digital locals with interactive urban screens to collaboratively improve the city," in Proceedings of the ACM 2012 Conference on Computer Supported Cooperative Work (CSCW '12) (Seattle, WA), 227-236. doi: 10.1145/2145204.2145239

Slingerland, G., Lukosch, S., and Brazier, F. (2020a). "Engaging children to co-create outdoor play activities for place-making," in Proceedings of the 16th Participatory Design Conference 2020-Participation(s) OtherwiseVol 1 (PDC '20: Vol. 1) (Manizales: ACM), 44-54. doi: 10.1145/3385010. 3385017

Slingerland, G., Lukosch, S., Comes, T., and Brazier, F. (2020b). Exploring design guidelines for fostering citizen engagement through information sharing: Local playgrounds in The Hague. EAI Endorsed Trans. Serious Games 18:e2. doi: 10.4108/eai.13-7-2018. 162636

Slingerland, G., Lukosch, S. G., Comes, T., and Brazier, F. M. (2019a). "Exploring requirements for joint information sharing in neighbourhoods: local playgrounds in The Hague," in Interactivity, Game Creation, Design, Learning and Innovation-7th EAI International Conference, ArtsIT 2018, and 3rd EAI International Conference, DLI 2018, ICTCC2018, Proceedings, eds A. Brooks, E. Brooks, and C. Sylla (Braga: Springer), 306-315. doi: 10.1007/978-3-030-061 34-0_35

Slingerland, G., Mulder, I., and Jaskiewicz, T. (2019b). "Join the park! Exploring opportunities to lower the participation divide in park communities," in Proceedings of the 9th International Conference on Communities TechnologiesTransforming Communities (Milan: ACM), 131-135. doi: 10.1145/3328320. 3328382

Stokes, B. (2020). Locally Played: Real-World Games for Stronger Places and Communities, 1st Edn. Cambridge, MA: MIT Press.

Suurenbroek, F., Nio, I., and De Waal, M. (2019). Responsive Public Spaces: Exploring the Use of Interactive Technology in the Design of Public Spaces. Amsterdam: Hogeschool van Amsterdam, Urban Technology.

Tan, E., and Portugali, J. (2012). "The responsive city design game," in Complexity Theories of Cities Have Come of Age, eds J. Portugali, H. Meyer, E. Stolk, and E. Tan (Berlin: Springer), 369-390. doi: 10.1007/978-3-642-245 44-2_20

Valkanova, N., Walter, R., Moere, A. V., and Müller, J. (2014). "MyPosition: sparking civic discourse by a public interactive poll visualization," in CSCW'14: Proceedings of the 17th ACM Conference on Computer Supported Cooperative Work \& Social Computing (Baltimore, MD), 1323-1332. doi: 10.1145/2531602.25 31639

Vlachokyriakos, V., Comber, R., Ladha, K., Taylor, N., Dunphy, P., McCorry, P., et al. (2014). "PosterVote: expanding the action repertoire for local political activism," in DIS'14: Proceedings of the 2014 Conference on Designing Interactive Systems (Vancouver, BC: ACM), 795-804. doi: 10.1145/2598510.25 98523 
Voida, A., Yao, Z., and Korn, M. (2015). "(Infra)structures of volunteering," in Proceedings of the 18th ACM Conference on Computer Supported Cooperative Work \& Social Computing (Vancouver, BC: ACM), 1704-1716. doi: 10.1145/2675133.26 75153

Wouters, N., Huyghe, J., and Vande Moere, A. (2014). "StreetTalk: participative design of situated public displays for urban neighborhood interaction," in Proceedings of the NordiCHI 2014: The 8th Nordic Conference on Human-Computer Interaction: Fun, Fast, Foundational (Helsinki), 747-756. doi: $10.1145 / 2639189.2641211$

Yin, R. K. (2003). Case Study Research: Design and Methods. Thousand Oaks, CA: SAGE Publications.
Conflict of Interest: The authors declare that the research was conducted in the absence of any commercial or financial relationships that could be construed as a potential conflict of interest.

Copyright (c) 2020 Slingerland, Lukosch, Hengst, Nevejan and Brazier. This is an open-access article distributed under the terms of the Creative Commons Attribution License (CC BY). The use, distribution or reproduction in other forums is permitted, provided the original author(s) and the copyright owner(s) are credited and that the original publication in this journal is cited, in accordance with accepted academic practice. No use, distribution or reproduction is permitted which does not comply with these terms. 


\section{Urban (Digital) Play and Right to the City: A Critical Perspective}

\section{Eunice Castro Seixas*}

Research Centre in Economic and Organizational Sociology (SOCIUS), Research in Social Sciences and Management (CSG), Lisbon School of Economics and Management, Universidade de Lisboa, Lisbon, Portugal

In this paper I discuss the concept of the right to the city in articulation with the concept of urban play and more specifically, the diverse body of research related with playable and playful cities. Following a brief review of these two concepts and related studies, I critically discuss the possibilities of articulating Lefebvre's radical concept of the right to the city to contemporary interventions on urban and digital play.

Keywords: urban play, right to the city, Lefebvre, playable cities, playful citizens

\section{OPEN ACCESS}

Edited by:

Mattia Thibault,

Tampere University, Finland

Reviewed by:

Lissa Holloway-Attaway,

University of Skövde, Sweden

Brenda Vertiz,

Aalto University, Finland

*Correspondence:

Eunice Castro Seixas

euniceseixas@gmail.com;

euniceseixas@socius.iseg.ulisboa.pt

Specialty section

This article was submitted to

Human-Media Interaction,

a section of the journal

Frontiers in Psychology

Received: 30 November 2020

Accepted: 15 February 2021

Published: 09 March 2021

Citation:

Castro Seixas E (2021) Urban (Digital)

Play and Right to the City: A Critical

Perspective.

Front. Psychol. 12:636111.

doi: $10.3389 /$ fpsyg.2021.636111

\section{INTRODUCTION}

Although urban play is not a new concept, it is becoming increasingly pervasive in the language and scholarly work on place-making, design and urban planning, particularly in regard to smart or digital cities. Nevertheless, the concept of urban play encompasses a variety of meanings, perspectives and urban interventions. In this paper I discuss Lefebvre's concept of the right to the city in articulation with the concept of urban play, and more specifically, the framework of playable and playful cities.

Lefebvre (1968) concept of the right to the city has inspired numerous studies from several academic disciplines, and remains today an important concept for critical scholars with an interest in the urban question. In his work as a whole, Lefebvre offers us a complex and holistic framework for understanding urbanization and urban life in relation to the growth of capitalism. His concept of the right to the city as a right "to urban life, to renewed centrality, to places of encounter and exchange, to life rhythms and time uses, enabling the full and complete usage of these moments and places" (Lefebvre, 1996, p. 179) reveals the author's attention to the multiple aspects of human experience (Purcell, 2014). The notion of "play" is also present in Lefebvre's concept of the right to the city, as the latter "stipulates the right to meetings and gatherings (...) the need for social life and a centre, the need and the function of play, the symbolic functions of space" (Lefebvre, 1996, p. 195).

Several scholars have drawn inspiration from Lefebvre's proposals related to creative space appropriation, art and urban social movements to argue for conceiving the urban environment as a play space. These perspectives share with Lefebvre a critique of a reductionist conceptualization of play as determined by the capital - the "abstract space," and restricted to specific designated areas in the cities. On the other hand, the radical nature of the right to the city concept as framed by Lefebvre is at odds with several of its current interpretations and applications, which tend to depoliticize his work (Busquet, 2013), and contribute to the narrative of technology as a solution to social problems (Caprotti, 2014). 


\section{THE RADICAL CONCEPTION OF THE RIGHT TO THE CITY}

The right to the city, as conceptualized by Lefebvre $(1968,1996)$ and Harvey $(2008,2012)$ is a collective right to change the city and shape the process of urbanization.

The right to the city is, therefore, far more than a right of individual access to the resources that the city embodies: it is a right to change ourselves by changing the city more after our heart's desire. It is, moreover, a collective rather than an individual right since changing the city inevitably depends upon the exercise of a collective power over the processes of urbanization (Harvey, 2008, p. 23).

Understood as a collective right, it necessarily starts from a critical awareness of urban structural inequalities, and involves social struggles for appropriating and reclaiming urban spaces. These include struggles for claiming specific rights, such as the right to housing, the right to mobility, the right to citizenship, the right to participation, the right to urban nature, or the right to rest and leisure, among other. According to Lefebvre (1996) the right to the city "manifests itself as a superior form of rights: the right to freedom, to individualization in socialization, to habitat and to inhabit" (p. 174). It is both "a cry and a demand" Lefebvre, 1968, or as Marcuse (2009) explains it, "a cry out of necessity and a demand for something more." It is a cry by city dwellers deprived of basic human rights, but it is also a demand by those seeking to develop their own potential for creativity in an urban context (Marcuse, 2009). Thus, the notion of right to the city gains relevance in the framework of contemporary urban conflicts and political struggles, namely regarding immigration and minorities' rights (Gilbert and Dikeç, 2008), but also within citizens' demands for participation in decision-making processes (Mitchell, 2014). The latter include participating in urban planning processes and reclaiming ownership of urban and digital technology. However, Lefebvre's proposals have been appropriated in many different ways and its radical conception is absent from most contemporary initiatives allegedly inspired by it (Purcell, 2014). It thus becomes crucial to clarify what the right to the city is not (Kothari and Chaudhry, 2009), while remaining vigilant toward its multiple uses and formulations.

The right to the city cannot be equated with smart city initiatives whose main goal is that of promoting a more efficient urban management, while maintaining the status quo, or even increasing the dominance of powerful actors, under the pretense of a participatory process (Kothari and Chaudhry, 2009; Kitchin, 2015; Willis, 2019). The right to the city is also not about producing creative cities or creative consumers, initiatives grounded on the entrepreneurial discourse of neoliberal urbanism (Harvey, 1989; Peck, 2005). And neither it is about constructing uneven eco-cities projects if these are conceived as technological fixes to sustainability concerns that reproduce socioeconomic inequalities (Caprotti, 2014).

Although this radicality can be considered as the most important aspect of the conception of the right to the city, there are other aspects worth mentioning. One is the emphasis on the "lived space" or the experiences of urban inhabitants, which stresses the importance of the use value of urban space over its exchange value, and provides for a more holistic understanding of social life. Such a perspective is shared by most of the perspectives on the right to the city across the academic, policy and activist spheres (Purcell, 2014). A third aspect is its conceptualization as an open-ended, pluralist process, in line with Lefebvre's proposal of city as "an oeuvre," a dynamic space reflecting "movement, complexity, conflicts, and contradictions" (Lefebvre, 1996, p. 53). Among these contradictions are the relationship between routine and creative play, and also between critique and creativity, which are understood by Lefebvre as productive juxtapositions, opening the possibility for new aesthetic and political senses of the urban (Gardiner, 2004; Lilliendahl Larsen and Brandt, 2018). These conceptualizations of creativity as linked, in a non-linear way, to the right to the city are often quoted but not always correctly understood from the part of contemporary authors working on (digital) urban play.

\section{URBAN (DIGITAL) PLAY, PLAYABLE CITIES AND THE PLAYFUL CITIZEN}

The pervasiveness of urban play is visible in the growing number of initiatives for making urban space and infrastructure more playable and citizens more playful. Play is now linked to multiple values, such as health, learning, efficiency, sociability, creativeness, experimentation, innovation and even subversion. Nonetheless, play, "urban play," playfulness and playability remain controversial concepts, "difficult to define and hard to distinguish" (Nijholt, 2017, p. 7). Urban play has been used, for example, to describe spontaneous and non-instrumental play, not only of children, but also of young people and adults. Some examples are young people's hanging out practices or parkour (Ameel and Tani, 2012; Pyyry and Tani, 2019). These can be considered as underground practices, and examples of city appropriation and reclaiming, in line with the concept of the right to the city. They highlight the disruptive and subversive potential of urban play, which has also been linked to the playfulness of various protests and social movements (Shepard, 2012; Bruttomesso, 2018), and to the practice of urban exploration (McRae, 2008). But urban play also includes forms of "digital play," such as the sensors and actuators embedded in urban environments, gaming technologies or pervasive games, in line with the growing importance of information and communication technologies (ICT) and the trend toward digitalization of contemporary societies. This diversity of expressions of urban play reinforces an idea of play as inherently ambiguous (Sutton-Smith, 2001), justifying an inductive approach to its conceptualization (Donoff and Bridgman, 2017).

The concepts of playable and playful cities/citizens presuppose the use of smart technology to create a "digital playground in the city," and appear in this context as critical, political and human-centered alternatives to smart cities, or at least to the technology-driven and efficiency based approaches to smart cities (Nijholt, 2017; De Lange, 2019; Innocent, 2020). In this framework, playfulness can be conceptualized "as a characteristic 
of human-computer interactions" that can be incorporated in the design of smartness and in making this smartness available for city dwellers (Nijholt, 2017, p. 3). The "playable city" is a broader concept that can be generally understood as "a vision of the city that makes room for play, playfulness and games as a fundamental goal of city-making" (Rivera et al., 2020, p. 91). This body of research presupposes a centrality of both play and digital technologies to contemporary urban life and it proposes, at the same time, to rethink how technology integrates with the social fabric.

The assumption that play has an intrinsic social value is highlighted by Innocent (2020), in his critique to smart cities' emphasis on datafication: "Sometimes, all that achieved is play-a problem may not be solved or identified-which is valuable in itself as play has its own intrinsic social value" (p. 28). Nonetheless, the author suggests that this issue can be overcome if the focus is on a participatory approach enabling "conversations about the city through play" (Innocent, 2020, p. 27). Bottom-up, participatory approaches have been emphasized by several authors within the frameworks of "hackable cities," "playful citizens," and "critical playable cities," who have argued that such methodologies allow for translating the right to the city into practice (Anastasiu, 2019), helping citizens to reclaim ownership of urban technology (Glas et al., 2019), and pacifying urban tensions/conflicts by channeling these into peaceful creative expressions (Hassan and Thibault, 2020). As in non-digital forms of urban play, the idea of play as subversive is also incorporated in several of these proposals, specifically in the concepts of the "hackable city" (De Lange and De Waal, 2019), and "critical playable cities" (Hassan and Thibault, 2020).

It is not my goal here to make a comprehensive review of these studies on urban digital play. Rather, I would like to suggest that, despite its diversity, this research appears to share: an assumption that play has an intrinsic social value; that playfulness should not be limited to places or activities traditionally linked to play (like playgrounds or thematic parks); a preference for participatory approaches that recognize the importance of the inhabitants' lived experiences as well as their power to introduce playful applications in the urban environment that also contribute to improve their daily lives. This is nicely summed up by Nijholt (2017): "Whether a smart city is playful depends very much on how residents experience the city and how the city stimulates "playful play." (p. 8).

The question of whether these initiatives can be understood as correctly translating Lefebvre's radical conception of the right to the city is less straightforward. Lefebvre (1991, p. 193) considers play as "a part of every human activity," linking it to work as well as pleasure. He sees spontaneous and creative play as citizens' action (and imagination) in space, with a potential to transform the city and disrupt capitalism norms. But not all types of play hold this potential for social change, as many of its current manifestations are officially sanctioned and controlled, designed to promote private and commercialized forms of leisure, or to increase urban entrepreneurialism.

\section{DISCUSSION}

The right to the city should be conceptualized from a transdisciplinary, multistakeholder and inclusive perspective, building from the dialogue between civil society members, decision-makers, scholars and practitioners from several fields. However, just following a multi-stakeholder model is not enough as participation processes have often been co-opted by powerful actors within neoliberal planning. The emphasis on a fair and inclusive participatory process is a concern shared by scholars working within the framework of playable cities with the goal of co-creating "an engaging and empowering participatory place to live" (Slingerland et al., 2020, p. 3), and of fostering "civic conversation" (Innocent, 2020, p. 27).

I argue that initiatives for promoting the right to the city should not neglect the key aspects of this radical concept, specifically: (i) its understanding as a collective right for changing the city, shaping the process of urbanization and fighting for social justice; (ii) the importance of a critical analysis of the inhabitants' everyday life experiences and informal practices of appropriation in the urban spaces, including contemporary practices related to digital interactions and play in urban contexts; and (iii) the creative, unpredictable and open-ended nature of these struggles. These aspects of the right to the city concept are not easily translatable into a framework of "city-making," nor was that the idea of Lefebvre. In fact, his conceptualization of the city as "an oeuvre" actually goes against any attempt to transform this conception into an action framework, and Lefebvre criticized models for being "abstract but serviceable representations of a projected, planned space in which some kinds of spatial practice are condoned and others dismissed as pathological" (Moravánszky et al., 2014, p. 160). Rather, the radical concept of the right to the city could be understood as an invitation to think critically about the complexity, contradictions and social struggles inherent to the process of urbanization, including the relationship between critique and creativity, and between digital and non-digital practices of space appropriations and urban play.

The growing importance of digital technologies in our societies is undeniable, and this is especially visible in the cities. That does not mean however that technology should be conceived as either a neutral solution for social problems, or as an alternative emancipatory narrative about city-making. More studies are needed in order to grasp the meaning and scope of citizens' participation in contemporary interventions related to digital cities (Cardullo and Kitchin, 2018). A focus on the fairness of the procedures should be complemented with a focus on the outcomes of participation in these smart, digital and playful cities' experiments. In this respect, there is some evidence suggesting that the goals of digital inclusion and participation, often asserted in smart city projects are sometimes pushed into the background, relatively to the goal of smart connectivity. For example, in their study of local smart city programmes across six UK cities, Cowley and colleagues have revealed a dominance of "entrepreneurial" and "service user" modes, grounded on the value of efficiency, as well as a difficulty in engaging the general public (Cowley et al., 2018). The authors show that 
in general, the activities oriented toward political and civic publicness tend to be less permanent than those invoking either entrepreneurial or more passive modalities, such as service-user publicness. Ultimately, we have to ask who drives the process, and especially, who benefits from these initiatives, or "whose right to the smart city" (Willis, 2019). Following Lefebvre, the question is: Do these experiments really contribute for allowing city dwellers to shape the process of urbanization and if so, in what way? And how do these interventions enable us to consider the right to the city within a larger framework, which means tackling problems related with citizenship, housing, mobility, work, education and poverty?

The thriving digital space has also revealed new social problems related with digital inequalities, surveillance, fake news, cyber-bullying, or the creation of narcissistic subjectivities, fed by social networks. Beyond the goals of developing playable cities, the right to the city should be updated in order to respond also to these newer problems. Play remains a multifaceted and disputed notion, as do conceptualizations of the "playful citizen" and "playable cities." These cannot be assumed a priori nor imposed top-down within initiatives allegedly designed to promote the right to urban play. Rather than taken as an end in itself, play, including digital play, should be approached critically in its relationship with social differences and inequalities, or, in Lefebvre's proposal, creativity should be linked to critique.

Finally, and despite the importance of creativity in Lefebvre's radical conceptualization of the right to the city, these two rights-the right to the city and the right to play-have different meanings, the former being much broader than the latter, possibly also encompassing the right not to play. The pervasiveness and over-inclusiveness of the concept of play in contemporary discourse should be subjected to a critical analysis, in the same manner as Lefebvre (1968) has engaged in a critical reflection about the right to nature, and how it has been co-opted

\section{REFERENCES}

Ameel, L., and Tani, S. (2012). Parkour: creating loose spaces? Geogr. Ann. B Hum. Geogr. 94, 17-30. doi: 10.1111/j.1468-0467.2012.00393.x

Anastasiu, I. (2019). "Unpacking the smart city through the lens of the right to the city: A taxonomy as a way forward in participatory city-making," in The Hackable City, eds M. De Lange and M. De Waal (Singapore: Springer), 239-260. doi: 10.1007/978-981-13-2694-3_13

Bruttomesso, E. (2018). Making sense of the square: facing the touristification of public space through playful protest in Barcelona. Tourist Stud. 18, 467-485. doi: $10.1177 / 1468797618775219$

Busquet, G. (2013). Political space in the work of Henri Lefebvre: ideology and Utopia. Spat. Justice 5, 1-12.

Caprotti, F. (2014). Eco-urbanism and the Eco-city, or, denying the right to the city? Antipode 46, 1285-1303. doi: 10.1111/anti.12087

Cardullo, P., and Kitchin, R. (2018). Being a 'citizen' in the smart city: up and down the scaffold of smart citizen participation in Dublin, Ireland. GeoJournal 84, 1-13. doi: 10.31235/osf.io/v24jn

Cowley, R., Joss, S., and Dayot, Y. (2018). The smart city and its publics: insights from across six UK cities. Urban Res. Pract. 11, 53-77. doi: 10.1080/17535069.2017.1293150

De Lange, M. (2019). "The playful city: Citizens making the smart city," in The Playful Citizen, eds R. Glas, S. Lammes, M. Lange, J. Raessens, by capital and transformed into leisure. Taking inspiration from Lefebvre's dialectical logic, it could be important to explore both the right to play and the right not to play in the city, as some of the city dwellers may actually highlight other dimensions of their experiences in urban spaces besides play, like relaxation and contemplation. Like the smart city discourse that co-produces a normative "smart city citizen," excluding those who do not fit into this framework (Vanolo, 2014), initiatives designed to promote playable/playful cities may also risk excluding citizens that do not identify with the "playful citizen" discourse.

\section{DATA AVAILABILITY STATEMENT}

The original contributions presented in the study are included in the article/supplementary material, further inquiries can be directed to the corresponding author/s.

\section{AUTHOR CONTRIBUTIONS}

EC, as the sole author, was responsible for reviewing and analyzing the literature and for the conceptualization and writing-up of this manuscript.

\section{FUNDING}

This work was supported by FCT, I.P., The Portuguese National Funding Agency for Science, Research and Technology, under the Project PTDC/SOC-SOC/30415/2017.

\section{ACKNOWLEDGMENTS}

I would like to thank the two reviewers for their valuable comments and suggestions. and I. Vries (Amsterdam: Amsterdam University Press), 349-369. doi: 10.1515/9789048535200-021

De Lange, M., and De Waal, M. (Eds.). (2019). The Hackable City: Digital Media and Collaborative City-Making in the Network Society. Singapore: Springer Nature. doi: 10.1007/978-981-13-2694-3

Donoff, G. and Bridgman, R. (2017). The playful city: constructing a typology for urban design interventions. Int. J. Play 6, 294-307. doi: 10.1080/21594937.2017.1382995

Gardiner, M. (2004). Everyday utopianism: Lefebvre and his critics. Cult. Stud. 18, 228-254. doi: 10.1080/0950238042000203048

Gilbert, L., and Dikeç, M. (2008). "Right to the city: politics of citizenship," in Space, Difference, Everyday Life. Reading Henri Lefebvre, eds K. Goonewardena, S. Kipfer, R. Milgrom, and C. Schmid (New York, NY; London: Routledge), 250-263.

Glas, R., Lammes, S., de Lange, M., Raessens, J., and de Vries, I. (Eds.). (2019). The Playful Citizen. Civic Engagement in a Mediatized Culture. Amsterdam: Amsterdam University Press. doi: 10.1515/9789048535200

Harvey, D. (1989). From managerialism to entrepreneurialism: the transformation in urban governance in late capitalism. Geogr. Ann. B Hum. Geogr. 71, 3-17. doi: $10.1080 / 04353684.1989 .11879583$

Harvey, D. (2008). The right to the city. New Left Rev. 53, 23-40.

Harvey, D. (2012). Rebel Cities: From the Right to the City to the Urban Revolution. London; New York, NY: Verso books. 
Hassan, L., and Thibault, M. (2020). "Critical playable cities," in Making Smart Cities More Playable: Exploring Playable Cities, ed A. Nijholt (Singapore: Springer), 71-85. doi: 10.1007/978-981-13-9765-3_4

Innocent, T. (2020). "Citizens of play: revisiting the relationship between playable and smart cities," in Making Smart Cities More Playable, ed A. Nijholt (Singapore: Springer), 25-49.

Kitchin, R. (2015). Making sense of smart cities: addressing present shortcomings. Camb. J. Regions Econ. Soc. 8, 131-136. doi: 10.1007/978-981-13-9765-3_2

Kothari, M, and Chaudhry, S. (2009). Taking the Right to the City Forward: Obstacles and Promises. Nairobi: UN-Habitat.

Lefebvre H. (1968). Le Droit à La Ville. Paris: Anthropos.

Lefebvre, H. (1991). Critique of Everyday Life, Vol. II. New York, NY: Verso.

Lefebvre, H. (1996). Writings on Cities. Oxford: Wiley-Blackwell.

Lilliendahl Larsen, J., and Brandt, J. (2018). Critique, creativity and the cooptation of the urban: a case of blind fields and vague spaces in Lefebvre, Copenhagen and current perceptions of the urban. Urban Plan. 3, 52-69. doi: 10.17645 /up.v3i3.1394

Marcuse, P. (2009). From critical urban theory to the right to the city. City 13, 185-197. doi: 10.1080/13604810902982177

McRae, J. D. (2008). Play city life: Henri Lefebvre, urban exploration and re-imagined possibilities for urban life (Master thesis), Queen's University, Kingston, ON, Canada.

Mitchell, D. (2014). The Right to the City: Social Justice and the Fight for Public Space. New York, NY: Guilford.

Moravánszky, Á., Schmid, C., and Stanek, L. (Eds.). (2014). Urban Revolution Now: Henri Lefebvre in Social Research and Architecture. Surrey: Ashgate Publishing, Ltd.

Nijholt, A. (2017). Playable Cities. Singapore: Springer. doi: 10.1007/978-981-10-1962-3

Peck, J. (2005). Struggling with the creative class. Int. J. Urban Regional Res. 29, 740-770. doi: 10.1111/j.1468-2427.2005.00620.x

Purcell, M. (2014). Possible worlds: Henri Lefebvre and the right to the city. J. Urban Affairs 36, 141-154. doi: 10.1111/juaf.12034
Pyyry, N., and Tani, S. (2019). More-than-human playful politics in young people's practices of dwelling with the city. Soc. Cult. Geogr. 20, 1218-1232. doi: 10.1080/14649365.2017.1358823

Rivera, M. B, Ringenson T., and Pargman D. (2020). "The sustainable playable city: making way for the playful citizen," in Making Smart Cities More Playable. Gaming Media and Social Effects, ed A. Nijholt (Singapore: Springer), 87-106. doi: 10.1007/978-981-13-9765-3_5

Shepard, B. (2012). Play, Creativity, and Social Movements: If I Can't Dance, It's Not My Revolution. New York, NY: Routledge. doi: 10.4324/97802038 31489

Slingerland, G., Lukosch, S., Brazier, F., Hengst, M. D., and Nevejan, C. (2020). Together we can make it work! Towards a design framework for inclusive and participatory city-making of playable cities. Front. Comput. Sci. 2:600654, 1-16. doi: 10.3389/fcomp.2020.600654

Sutton-Smith, B. (2001). The Ambiguity of Play. Cambridge, MA: Harvard University Press.

Vanolo, A. (2014). Smartmentality: the smart city as disciplinary strategy. Urban Stud. 51, 883-898. doi: 10.1177/0042098013494427

Willis, K. S. (2019). "Whose right to the smart city?" in The Right to the Smart City, eds P. Cardullo, C. Di Feliciantonio, and R. Kitchin (Bingley: Emerald Group Publishing), 27-42. doi: 10.1108/978-1-78769-139-1201 91002

Conflict of Interest: The author declares that the research was conducted in the absence of any commercial or financial relationships that could be construed as a potential conflict of interest.

Copyright $\odot 2021$ Castro Seixas. This is an open-access article distributed under the terms of the Creative Commons Attribution License (CC BY). The use, distribution or reproduction in other forums is permitted, provided the original author(s) and the copyright owner(s) are credited and that the original publication in this journal is cited, in accordance with accepted academic practice. No use, distribution or reproduction is permitted which does not comply with these terms. 


\title{
Urban Play as Catalyst for Social Wellbeing Post-Pandemic
}

\author{
Troy Innocent ${ }^{1 \star}$ and Quentin Stevens ${ }^{2}$ \\ ${ }^{1}$ School of Design, RMIT University, Melbourne, VIC, Australia, ${ }^{2}$ School of Architecture and Urban Design, RMIT University, \\ Melbourne, VIC, Australia
}

Keywords: playable cities, urban play, COVID-19, urban planning and design, public art

\section{OPEN ACCESS}

Edited by:

Anton Nijholt,

University of Twente, Netherlands

Reviewed by:

Viktor Bedö,

University of Applied Sciences and Arts Northwestern Switzerland,

Switzerland

Robby Van Delden,

University of Twente, Netherlands

*Correspondence:

Troy Innocent

troy.innocent@rmit.edu.au

Specialty section: This article was submitted to Human-Media Interaction, a section of the journal Frontiers in Computer Science

Received: 27 November 2020 Accepted: 18 February 2021 Published: 05 April 2021

Citation: Innocent T and Stevens Q (2021) Urban Play as Catalyst for Social Wellbeing Post-Pandemic.

Front. Comput. Sci. 3:634145. doi: 10.3389/fcomp.2021.634145
The modern science of urban planning emerged in the 19th century in response to public health crizes caused by cities due to the constraints of their medieval urban design. In cities like Barcelona, each deadly epidemic would kill a significant portion of the population due to overcrowding and chaotic infrastructure. This shift was characterized by urban planning that moved beyond the need for fortified, walled cities to focus on industrialization and free movement, communication and trade that led to urbanisation.

During the 2017 Smart Cities Expo in Barcelona, the 150th Anniversary of Cerdà's urban planning concept was celebrated with the claim that Barcelona's Eixample was the "original smart city"-pre-digital, big analog data that informed Cerdà's general theory of urbanization (Cerdà, 2018). This was part of a larger global movement that led to modern urban planning, with public health a key reason for the organization of cities. Cerdà's 1859 plan for the expansion of Barcelona responded to the need for natural lighting and ventilation in homes, greenery in public spaces and waste disposal infrastructure based on data collected on the movement of disease in the cramped conditions of Barcelona's old city. The current global pandemic has created another moment to reimagine urban life.

Within contemporary cities, public space plays a critical role in providing opportunities for people to come together. However, contemporary cities are also contested by competing future visions-the smart city, the capitalist city. Starting with efficiency and productivity driven by technological determinism, over the past decade these visions have been challenged by other value systems that focus on play, people, place and community.

Public spaces will play a key role in restarting our cities after the COVID-19 pandemic by providing environments for community connection and social wellbeing (Daly et al., 2020). Currently, during periods of lockdown, these spaces typically appear empty and strange, as people's interactions are governed by social distancing rules that literally reconfigure urban spaces via constraints imposed by rules such as keeping $1.5 \mathrm{~m}$ away from others, avoiding physical contact and limits to the number of people allowed to meet in one place. Critical urban play (Flanagan, 2009) can reimagine public spaces and reframe public art-connecting people and place in creative ways. This can start by responding to the ways people have been reconnecting to these spaces during the pandemic.

One of the few positive impacts of the pandemic has been a renewed connection with local neighbourhoods and community-largely through the simple act of walking (Franks, 2020). While there is much epidemiological research on the impact of walking and urban play on physical health and on mental health through the restorative power of nature and green spaces, there is less attention to their significant impacts on social wellbeing.

Walking presents a range of possibilities, from the political to the social. We are interested in the ways that an increased focus on public spaces during the pandemic has drawn attention to the lived experience of cities, particularly the interaction between urban design-cities' rules and structures-and urban life-how people respond to and play with these as constraints and opportunities. Urban play during the pandemic has an immediate impact on wellbeing through 
renewed connection to place and the emergence of playful forms of engagement, often shared on social media, happening spontaneously as part of urban life. It also has the potential for impact in the longer term in reshaping urban design as these playful, public actions become part of the "new normal" and are adopted by local government, or through increased awareness and popularity of longstanding tactical urbanism initiatives. The pandemic has put into motion connections between urban design and urban life, social wellbeing and critical play.

In cities that have been built around car culture and increased productivity, being a pedestrian is a radical act. Slowing down, being present in the street, and taking the scenic route all mean occupying public spaces for sheer enjoyment and in protest against cultures of accelerated consumption. Playful and reflective wandering in the modern city has a long history, from the NineteenthCentury flanerie of Charles Baudelaire (Benjamin, 2015) to the post-war dérive of the Situationist International and the millennial psychogeography of Iain Sinclair (Sinclair, 1999). While data on walking such as searches for directions on Apple's mapping services show a net decrease in walking to a specific destination, the anecdotal evidence tells the story of increased walking for recreation or within local neighbourhoods.

At the intersection of localism and urban play lies an increased social engagement that can engender a sense of connection with place and with community that supports social wellbeing and neighbourhood cohesion. In the short term this is often spontaneous and self-organized-chalk rainbows, bear maps, spoonvilles and GPS doodles (Lund, 2020)-and in the longer term can develop through joint initiatives between local government, creative communities and neighbourhoods.

Playful approaches to urbanism have an important role in supporting social wellbeing-by imagining new forms of engagement that can support the post-pandemic recovery of cities. These include public art that encourages exploration, stimulates action, and triangulates social encounters. Play introduces low-risk, low-stress, innovative ways of interacting with other people and building social connection. It can also involve creative and enjoyable ways of adapting social life to the constraints of social distancing such as giant circles painted in parks (Strauss, 2020) or finding other ways to share connection such as chalk messages and drawings on streets (Murray-Atfield, 2020).

A new public art project outside V\&A Dundee (Figure 1) has started exploring this concept. Inspired by pavement chalk drawings and simple games such as hopscotch, it creates a set of public conditions for play that comply with social distancing and create opportunities for social connection (One Play Thing, 2020). Apps that are situated around urban exploration can take on new significance as people explore and rediscover places close to home, through recreational play and random exploration. Analog games can encourage playful mappings of place such as the many ways that people have created a sense of connection on their daily walks during lockdown such as chalk drawings and messages, makeshift installations of toys and crafted objects. Now that people can go out to play again, playing with the thresholds and boundaries of social distancing protocols offers strategies for playful compliance.

Transforming public spaces is often a slow, bureaucratic process. However, with the increased pressure on local governments to reactivate these places comes curiosity and support for new approaches. This can be small changes such as reprogramming pedestrian crossings to slow down traffic, encouraging communities' own playful efforts at tactical urbanism, or large-scale re-allocation of urban spaces for new forms of socialization and play. Park (ing) Day began as a playful form of tactical urbanism to convert on-street parking spots into more green and sociable spaces, now it has become commonplace with semi-permanent parklets throughout Melbourne supporting al fresco dining over summer as part of local government initiatives (City of Melbourne, 2020).

These initiatives include converting parking bays into bike lanes and walking trails, opening up streets to outdoor dining, and supporting temporary public artworks that experimentally transform spaces. Such moves can open up opportunities for what play makes possible-structuring ideal social relations, overcoming transactional social interactions, and seeing cities as places for connection and experience rather than instrumental function or prevention.

Politicians in Australia and elsewhere have been emphasizing the essential importance of playing board games at home and exercising alone outdoors. We need to ask how we can bring together artists, urbanists, designers and policymakers to develop public play with a social purpose. Using Melbourne as a model, the real city outside the home offers a much richer context for playful interaction with others, combining social and physical engagement, and including playful engagement with strangers, which is so important for the sense of social wellbeing beyond our own social circle.

Public spaces are critical for community connection and social wellbeing. While Melbourne is currently the epicentre of Australia's second COVID-19 wave, it also has the potential to lead the return to a re-imagined social life in urban spaces post-pandemic-through its vibrant street life, arts and culture, local government expertize in place management, unique urban DNA and playful community spirit. Urban play has found a new sense of purpose in daily connection and as a methodology for speculative design (Dunne and Raby, 2013) in our rapidly changing cities through critical play that challenges accepted norms and conventions (Leorke and Wood, 2019).

The COVID-19 pandemic raises broader questions around the role and function of cities in relation to society. What are they for? Do we have enough open spaces and green areas? Do we need cities at all? Through a renewed focus on the capacity of urban public spaces to drive community connection and social wellbeing, our cities may be remade and reconfigured post-pandemic. Urban play 


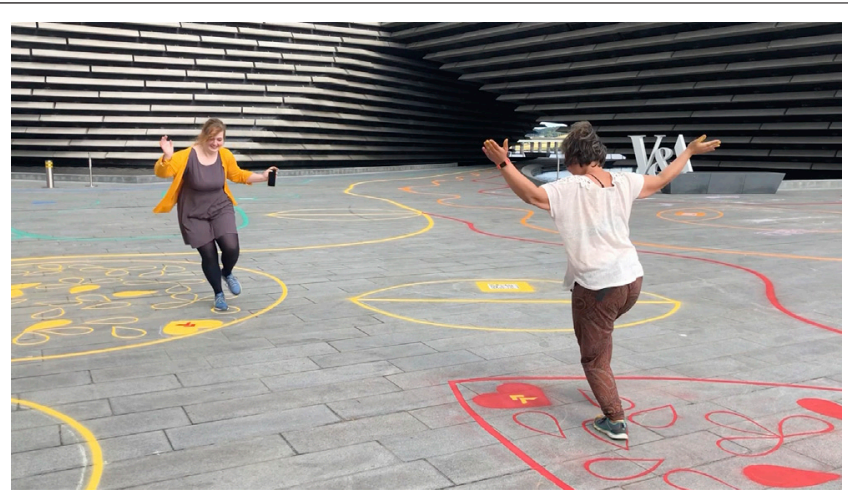

FIGURE 1 | Oneplaything @ V\&A Dundee: Slow dance.

can have a creative, productive, critical role in this reimagination of urban life.

\section{DATA AVAILABILITY STATEMENT}

The raw data supporting the conclusions of this article will be made available by the authors, without undue reservation.

\section{ETHICS STATEMENT}

Written informed consent was obtained from the individuals for the publication of any potentially identifiable images or data included in this article.

\section{REFERENCES}

Benjamin, W. (2015). Illuminations. London, United Kingdom: The Bodley Head. Cerdà, I. (2018). General theory of urbanization 1867. Editor V. Guallart (Barcelona, Spain: Actar D).

City of Melbourne (2020). Parklet policy. Available at: https://www.melbourne.vic.gov. au/SiteCollectionDocuments/extended-outdoor-dining-guidelines.pdf (Accessed November 25, 2020).

Daly, J., Dovey, K, and Stevens, Q. (2020). We can't let coronavirus kill our cities. Here's how we can save urban life. Available at: https://theconversation.com/we-cant-let-coronaviruskill-our-cities-heres-how-we-can-save-urban-life-137063 (Accessed January 25, 2021)

Dunne, A., and Raby, F. (2013). Speculative everything: design, fiction and social dreaming. Cambridge, United States: MIT Press.

Flanagan, M. (2009). Critical play: radical game design. Cambridge, United States: MIT Press. Franks, A. (2020). How 2020 became the year of the walker. Available at: https:// www.theguardian.com/travel/2020/dec/18/how-2020-became-the-year-of-thewalker (Accessed January 25, 2021).

Leorke, D., and Wood, C. (2019). 'Alternative ways of being': reimagining locative media materiality through speculative fiction and design. Media Theor. 3 (2), 63-102. Available at: http://journalcontent.mediatheoryjournal.org/index.php/mt/article/ view/93/83 (Accessed March 22, 2021).

Lund, S. (2020). GPS doodles. Available at: https://gpsdoodles.com/ (Accessed November 25, 2020).

\section{AUTHOR CONTRIBUTIONS}

During the COVID-19 pandemic a renewed interest and focus on responsive and adaptive urban planning policies has emerged. QS has articulated a particular focus on local community, pedestrian and bike-friendly planning initiatives and strategies that encourage reconnection with place. TI has researched and collated examples of urban play and playable cities in response to the pandemic. TI and QS developed the proposition that urban play acts as a catalyst for change in public spaces to enhance social wellbeing and community engagement. This article draws upon the knowledge of TI and QS in relation to playful and tactical responses to the impact of COVID-19 on public spaces to propose future directions for urban play in shaping cities postpandemic.

Murray-Atfield, Y. (2020). Chalk messages and drawings on streets are bringing hope during the coronavirus pandemic. Available at: https://www.abc.net.au/ news/2020-04-02/coronavirus-covid-19-chalk-messages-on-streets-aroundaustralia/12102778 (Accessed January 25, 2021).

One Play Thing (2020). Chalk playscape. Available at: https://www.vam. ac.uk/dundee/exhibitions/chalk-playscape (Accessed November 25, 2020).

Sinclair, I. (1999). Liquid city. London, United Kingdom: Reaktion Books

Strauss, A. (2020). How the creator of domino park's social distancing circles spends his sundays. Available at: https://www.nytimes.com/2020/07/10/ nyregion/domino-park-social-distancing-circles-nyc.html (Accessed January $25,2021)$.

Conflict of Interest: The authors declare that the research was conducted in the absence of any commercial or financial relationships that could be construed as a potential conflict of interest.

Copyright (c) 2021 Innocent and Stevens. This is an open-access article distributed under the terms of the Creative Commons Attribution License (CC BY). The use, distribution or reproduction in other forums is permitted, provided the original author(s) and the copyright owner(s) are credited and that the original publication in this journal is cited, in accordance with accepted academic practice. No use, distribution or reproduction is permitted which does not comply with these terms. 
OPEN ACCESS

Edited by: Anton Nijholt,

University of Twente, Netherlands

Reviewed by:

Robby Van Delden,

University of Twente, Netherlands António Fernando Coelho,

University of Porto, Portugal

${ }^{*}$ Correspondence:

Danica Mast

d.mast@hhs.n

d.mast@liacs.leidenuniv.nI

Specialty section:

This article was submitted to

Human-Media Interaction,

a section of the journal

Frontiers in Computer Science

Received: 28 February 2021

Accepted: 04 May 2021

Published: 04 June 2021

Citation:

Mast D, de Vries SI, Broekens J and Verbeek FJ (2021) The Participant Journey Map: Understanding the Design of Interactive Augmented

Play Spaces.

Front. Comput. Sci. 3:674132. doi: 10.3389/fcomp.2021.674132

\section{The Participant Journey Map: Understanding the Design of Interactive Augmented Play Spaces}

\author{
Danica Mast ${ }^{1,2,3 *}$, Sanne I. de Vries ${ }^{1}$, Joost Broekens ${ }^{3}$ and Fons J. Verbeek ${ }^{3}$ \\ ${ }^{1}$ Research Group Healthy Lifestyle in a Supporting Environment, Centre of Expertise Health Innovation, The Hague University of \\ Applied Sciences, The Hague, Netherlands, ${ }^{2}$ User Experience Design, Communication and Multimedia Design, Faculty for IT and \\ Design, The Hague University of Applied Sciences, The Hague, Netherlands, ${ }^{3}$ Leiden Institute of Advanced Computer Science, \\ Leiden University, Leiden, Netherlands
}

Augmented Play Spaces (APS) are (semi-) public environments where playful interaction is facilitated by enriching the existing environment with interactive technology. APS can potentially facilitate social interaction and physical activity in (semi-)public environments. In controlled settings APS show promising effects. However, people's willingness to engage with APS in situ, depends on many factors that do not occur in aforementioned controlled settings (where participation is obvious). To be able to achieve and demonstrate the positive effects of APS when implemented in (semi-)public environments, it is important to gain more insight in how to motivate people to engage with them and better understand when and how those decisions can be influenced by certain (design) factors. The Participant Journey Map (PJM) was developed following multiple iterations. First, based on related work, and insights gained from previously developed and implemented APS, a concept of the PJM was developed. Next, to validate and refine the PJM, interviews with 6 experts with extensive experience with developing and implementing APS were conducted. The first part of these interviews focused on influential (design) factors for engaging people into APS. In the second part, experts were asked to provide feedback on the first concept of the PJM. Based on the insights from the expert interviews, the PJM was adjusted and refined. The Participant Journey Map consists of four layers: Phases, States, Transitions and Influential Factors. There are two overarching phases: 'Onboarding' and 'Participation' and 6 states a (potential) participant goes through when engaging with an APS: 'Transit,' 'Awareness,' 'Interest,' 'Intention,' 'Participation,' 'Finishing.' Transitions indicate movements between states. Influential factors are the factors that influence these transitions. The PJM supports directions for further research and the design and implementation of APS. It contributes to previous work by providing a detailed overview of a participant journey and the factors that influence motivation to engage with APS. Notable additions are the detailed overview of influential factors, the introduction of the states 'Awareness,' 'Intention' and 'Finishing' and the non-linear approach. This will support taking into account these often overlooked, key moments in future APS research and design projects. Additionally, suggestions for future research into the design of APS are given. 
Keywords: augmented play spaces, playful interaction, urban interfaces, spatial augmented reality, user journey map, user experience design

\section{INTRODUCTION}

Augmented play spaces (APS) are (semi-) public environments where playful interaction is facilitated by enriching the existing environment with interactive technology. This can be facilitated by screens, projections (Gómez-Maureira, 2014; van Delden et al., 2017; Mast, 2019) and light, but also through sound (Schraffenberger and Van Der Heide, 2014), movement and other sensory perceptible manifestations. APS are also known as Co-located Augmented Play-spaces (CAPs) (van Delden et al., 2018), interactive play systems (van Delden et al., 2018), Interactive Playgrounds (Sturm et al., 2008), interactive open-ended play environments (Valk et al., 2012; de Valk et al., 2015) and Pervasive Games (Magerkurth et al., 2005).

APS can offer joyful, pleasant experiences, providing an entertaining pastime (van Delden et al., 2018). Furthermore, they can provide more serious benefits such as supporting a healthy lifestyle, facilitate social interaction (Bekker et al., 2010; Márquez Segura and Isbister, 2015), enhance cognitive development (Springlab Bewegend leren op de Springlab Beweegvloer voor kleuters en peuters, 2020; Hashagen et al., 2009; van Delden et al., 2018) and improve skills practice (van Delden et al., 2018).

Designers, developers and researchers are increasingly understanding how to design APS (Dalsgaard and Halskov, 2010; Dalsgaard et al., 2011; Valk et al., 2012; Márquez Segura et al., 2013; Márquez Segura and Isbister, 2015; Mueller et al., 2017), how people play (De Kort and Ijsselsteijn, 2008; Isbister, 2010; Santos, 2019), and how people interact with technology in general. But there are still many aspects to designing and implementing interactive augmented play spaces and playful interaction that we know much less about.

Much research into the design and use of APS focuses on what happens while people are playing with them. But there are preceding steps, before people are actually participating (Brignull and Rogers, 2003), that should be taken into account when these interfaces are to be implemented in situated environments. We know APS can be entertaining and stimulate positive behavior, but when no one participates-because the barrier to engage is too high, or no one understands them (Polaine, 2010)-then those benefits will never occur. Creating a seductive invitation to play is just as, or maybe even more, important than what happens after. Because, no matter how impressive the experience is that you're trying to lead people into, without a powerful invitation to play, they'll never reach that experience (Csikszentmihaly, 1990; Polaine, 2010) To be better able to achieve and demonstrate the aforementioned positive effects of APS, it is important to gain more insight in how to motivate people to engage with APS.

Based on related research, insights from previous design projects, and validation through expert interviews, we present the Participant Journey Map (PJM), providing insight into people's engagement with interactive augmented play spaces (APS) and the influential factors. Furthermore, we identify research gaps and provide suggestions for further research to better understand how to design effective and engaging Augmented Play Spaces.

\section{BACKGROUND}

An Augmented Play Space (APS) is where playful behavior and interaction emerges, facilitated by a technologically and sensory enriched, generally accessible environment. This section provides background on the aspects (semi-)Public Spaces, Augmented and Extended Reality, and Play, that come together in APS.

\section{(Semi-)Public Spaces}

APS can be part of a wide range of (semi-)public environments, both in- and outdoors and in various contexts. They can be found in many places, including indoor and outdoor playgrounds, implemented in museums and science centers, in urban settings in city squares, enriching architecture, and inside buildings, augmenting corridors and passageways a.o. These are all (semi-) public spaces with specific characteristics that distinguish them from private spaces.

Public spaces are places that are open and accessible to all people (UNESCO, 2021). They are the common physical spaces that members of a society share (Brok, 2010). Spaces that are considered to be part of public space are: roads, sidewalks, streets, public squares, parks, and beaches (UNESCO, 2021). Buildings that are generally freely accessible to the general public, are also considered to be part of public space, such as: libraries, government buildings and town halls.

Some private environments have many of the same characteristics as (truly) public environments. These semipublic spaces are places where everybody can come if they pay or have another reason of being there. Examples of semipublic spaces include indoor shopping centers and privatelyowned beaches (Vasagar, 2012), theaters, festival grounds, schools, museums, stores, train stations and amusement parks.

(Semi-)Public spaces can facilitate a variety and diversity of functions, and be places for self-expression, exchange, protest and social engagement (Harrouk, 2020). They regulate human behavior but also allow constitution and expression of individual identity (Capulong Reyes, 2016) and facilitate exposure to different types of people (Harrouk, 2020), enabling both creation and disruption of social encounters (Stavrides, 2016).

Because of their versatility, designing for (semi-)public spaces is challenging because there is a constant jumble of goals, functions, distractions and habits influencing and disrupting what people do, feel, think and notice. 


\section{Augmented and Extended Reality}

Augmented Reality (AR) in general is regarded as the phenomenon of virtual content being part of and appearing in the real world (Milgram and Kishino, 1994; Schraffenberger, 2018). Extended reality, the virtual supplementation of real environments is one of the forms of $\mathrm{AR}$ (Schraffenberger, 2018) and most relevant in the context of augmented play spaces. Spatial Augmented Reality (SAR, also known as projection mapping) is one of the manifestations of extended reality. In SAR, physical environments and/or objects are augmented without using intermediate devices (such as head mounted or handheld devices). Instead, (interactive) animations and/or images are projected, adding a virtual layer to a real environment, creating an immersive and integrated experience (Companje et al., 2006; Marner et al., 2011; Gómez-Maureira, 2014; Mast et al., 2015; van Delden et al., 2017; Mast, 2019).

Other technologies that support sensory perceptible manifestations to facilitate extended reality and spatial augmentation include screens, light (Dawson, 2019), spotlights, sound (Schraffenberger and Van Der Heide, 2014), movement (O'Toole et al., 2020), vibrations, and smell. To add interactivity, sensors can be used to register movement, touch, sound and presence, allowing the augmentations to respond to the presence and input of people (Mast et al., 2017b).

\section{Play}

Although everyone plays (Else, 2009; Sutton-Smith, 2009), knows what play is (Else, 2009) and what it feels like (Sutton-Smith, 2009)play is difficult to define (Garvey, 1990; Sutton-Smith, 2009). Play has many forms (Garvey, 1990) and although it is pleasant, it's not necessarily fun (Sicart, 2014). It can be defined as "a range of intrinsically motivated activities done for recreational pleasure and enjoyment" (Play (activity) - Wikipedia, 1990). Garvey inventories play as "pleasurable", "without extrinsic goals", "spontaneous and voluntary" and "involving some active engagement by the player" (Garvey, 1990).

Play is important and essential for our well-being, supports understanding of our surroundings and ourselves, facilitates social engagement (Sicart, 2014), and is beneficial to all people (Huizinga, 1940; Polaine, 2010). Although often associated with children, people of all ages play (Else, 2009). Play happens in all cultures (Bos, 2018) and is older than culture itself (Huizinga, 1940).

There are various conditions to enable play. Someone must have a playful (lusory) attitude (Suits, 2014) and the context and circumstances must be supportive. Although nowadays mainly used in the context of virtual gaming, the term magic circle was originally coined by Huizinga in the foundational work on play: 'Homo Ludens' (Huizinga, 1940). The magic circle can be considered as the area, moment, activity, mental state you enter when embarking on your playing journey, until you are back in the 'normal' world, picking up your daily (non-play) activities. The magic circle is where a game takes place. It might have a physical component, although many games have no physical boundaries (Salen and Zimmerman, 2003). The term magic circle is considered to be appropriate because something magical happens when play (of a game) begins (Salen and Zimmerman, 2003). In order to be able to design effective and engaging APS it is important that we understand how to get passers-by to navigate the chaotic network of influential factors and reach the 'Magic Circle.'

\section{RELATED RESEARCH}

Playful interactivity in (semi-)public spaces has been a research subject for some time, resulting in various frameworks and models providing insight into the design and use of these spaces and the behavior of participants in relation to these interactive environments. Furthermore, there is a great deal of diversity and versatility in research about interfaces in a public context and playful interfaces in general.

Some research primarily focuses on social interaction between players (De Kort and Ijsselsteijn, 2008; Gajadhar et al., 2008; Lindley et al., 2008; Isbister, 2010; Robbins and Isbister, 2014; Márquez Segura and Isbister, 2015), design principles (Parés et al., 2005; Snibbe and Raffle, 2009) or on interactivity (Salen and Zimmerman, 2003; Kultima and Stenros, 2010; Polaine, 2010; Hespanhol and Tomitsch, 2015). Other related research is more directly related and provides frameworks and models that focus on engaging people into public interfaces (Brignull and Rogers, 2003; Rogers and Rodden, 2003; Vogel and Balakrishnan, 2004; Peltonen et al., 2008; Finke et al., 2008; Müller et al., 2010; Polaine, 2010; Tieben et al., 2011; Michelis and Müller, 2011; Valk et al., 2012; Fischer and Hornecker, 2012; Memarovic et al., 2012, 2014; Bekker et al., 2014; Cheung, 2014; de Valk et al., 2015; Germany et al., 2019). In the "Insights from Related Research and Previous Design Projects" section we elaborate on related research and explain how aspects from previous research inspired the first concept of the Participant Journey Map.

Additionally, there is related work that provides background into phenomena that can influence behavior in these contexts: the 'honeypot effect' (Wouters et al., 2016); the 'peak-end rule' (Fredrickson, 2000; Kahneman, 2011; Mast et al., 2020); 'flow'(Csikszentmihaly, 1990); 'proxemics' (Marquardt, 2013; Mueller et al., 2014; McArthur, 2016); and 'interaction blindness' (Ojala et al., 2012).

Many of the models and frameworks that focus on participation are based on research of, and observations of a single or very similar interface(s). In doing so, they provide insights into that specific context, but their findings are not generally applicable. Combining insights from multiple studies, observations from multiple interfaces and analyzing previous research will lead to more substantiated insights, models and frameworks that are more widely applicable.Our work combines the diversity of insights from related research, previous design projects and knowledge of experts, attempting to lead toward a more broadly applicable model for situated augmented play spaces and providing directions for further research.

\section{RESEARCH APPROACH}

In order to gain insight into the phases and states a potential participant moves through toward engaging in augmented play 
TABLE 1 | Schematic representation of research approach.

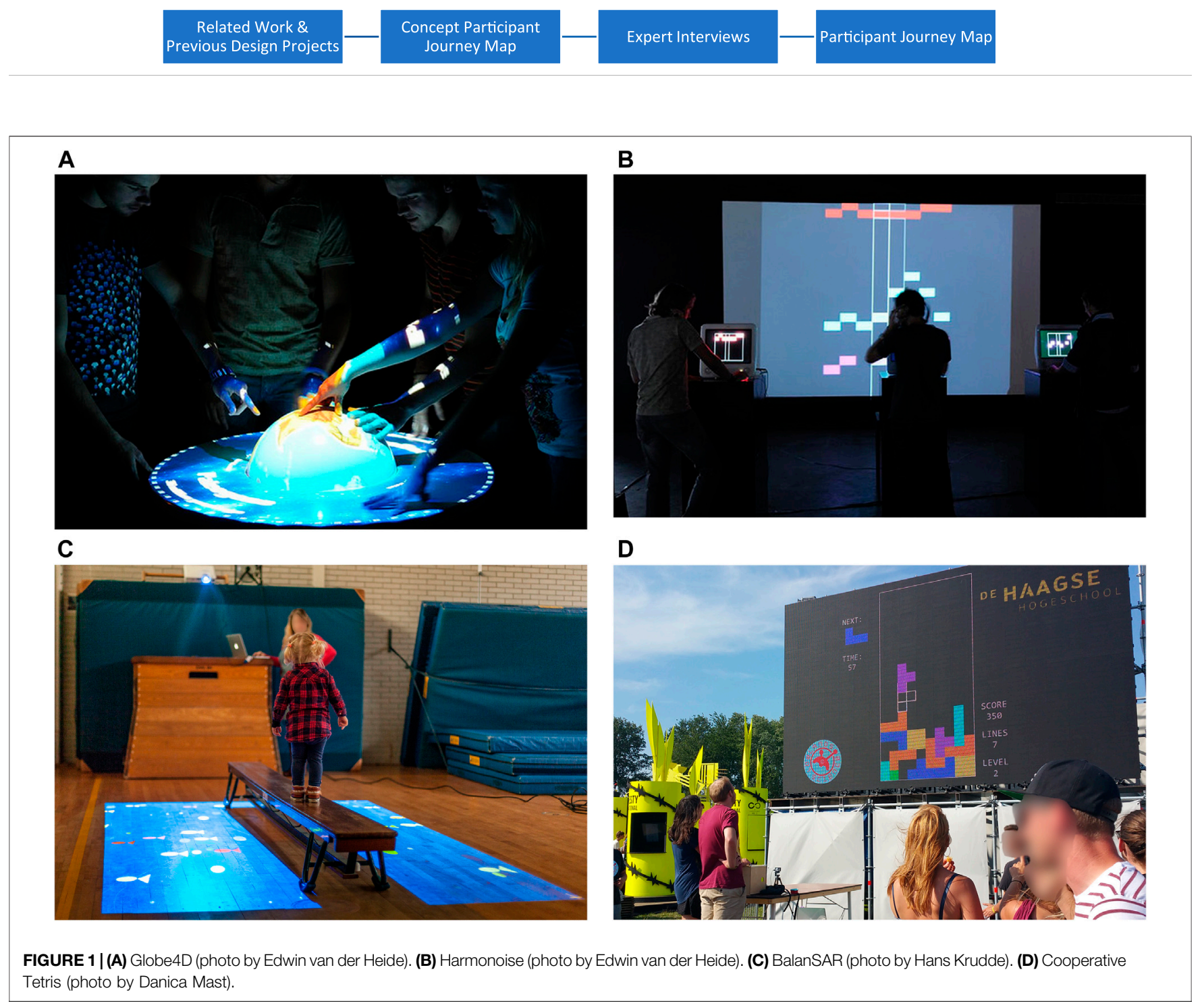

spaces and the factors that influence engagement, we first studied related work and previous APS design projects (section "Insights from Related Research and Previous Design Projects"). This resulted, through multiple iterations, in the creation of a concept version of the Participant Journey Map (PJM) (section "Concept Participant Journey Map"). Following, to validate and refine the concept version, a series of expert interviews were conducted (section "Expert Interviews"). This resulted in the design and development of the refined version of the Participant Journey Map (section "Participant Journey Map"). Table 1 illustrates this approach.

\section{INSIGHTS FROM RELATED RESEARCH AND PREVIOUS DESIGN PROJECTS}

Insights from related work and previous design projects formed the foundation for the concept Participant Journey Map. Our focus analyzing previous work and projects was on participation phases and states in relation to spatial technology-mediated interactivity in (semi-) public spaces. Six engagement states were classified and are discussed in the section "Engagement States". We first discuss the design projects that informed us briefly.

\section{Previous Design Projects}

Lessons learned from previous design projects involving APS were gathered, reviewed and summarized. These projects include the following.

Globe4D (Figure 1A) (Companje et al., 2006, 2007) is a fourdimensional globe for exploring the earth's history (e.g., continental drift), consisting of a circular table, a physically rotating outer ring and a sphere in the middle that can physically rotate in all directions. An interactive animation is projected on the sphere. Users can move the outer ring, to browse 
through earth's history and rotate the sphere to explore content from all angles. Globe4D is part of numerous temporary and continuous exhibits worldwide.

Harmonoise (Figure 1B) (V2 Lab for the Unstable Media, 2008) is an interactive art installation. Its key statement is "Disruption of personal or collective harmony in music. You influence the world around you and the world influences you... Collective harmony can only exist, if you are willing to give up certain personal desires," its focuses on the tension between altruism and egoism, and people's willingness to give up some of their personal desires for the greater good. Harmonoise consists of three music stations. Each station controls a different instrument, that can be heard on the headphones for that station. In the space where the three stations are located, all composed musical pieces are played simultaneously, sometimes creating a nuisance and a cacophony, at other times forming pleasant and interesting compositions.

BalanSAR (Figure 1C) (Mast et al., 2017a, 2017b) is developed as a research prototype and combines interactive video projections with traditional balancing exercises in Physical Education. It consists of a floor projection, augmenting balancing objects (e.g., bench, balancing stones) on the floor.

Cooperative Tetris (Figure 1D) (Mast and de Vries, 2017) has been developed as a research prototype to investigate the influence of physical activity on game experience and social interaction. A cooperative version of Tetris was developed in which the game is played by two players together. The exertion version is controlled by jumping, the passive version is controlled by pressing arcade buttons. Both variants of the input devices are novel to participants. Simultaneous actions cause rotation of the Tetris blocks, individual actions allow movement to the left or right.

These previous design projects provided valuable insights into the participation phases and states and the factors that influence engagement with APS.

\section{Engagement States}

Our analysis of literature and projects formed the foundation for the concept Participant Journey Map. Six engagement states were classified: Transit; Awareness; Interest; Intention to participate; Participation/Play and Intention to stop. Each state with their conditional influential factors is introduced and supported by insights from related work and previous design projects.

\section{Transit}

Transit is the state where a passer-by is moving from one location to another (Merriam-Webster, 2021). 'Passing by' is the action that belongs to this state of transit and is mentioned literally several times in related work (Müller et al., 2010; Michelis and Müller, 2011; Cheung, 2014; Parra et al., 2014). Other sources refer to a state of transit by using different wording: 'enter' (Finke et al., 2008), 'approach' (Germany et al., 2019), 'unoccupied' (Rubin, 2001) and 'not playing' (Moreno et al., 2012).

Experiences with previous design projects show that there are two distinct types of transit through a (semi-)public space. They relate to the reason and purpose of one's presence in that environment. In an environment such as a city square, train station or hallway in an educational building, passers-by are often in transit from one place to another with a purpose or task other than engaging with an APS. This can be considered a chance encounter. In a museum or festival environment it is often the intention of passers-by to become involved in experiences that cross their path. Often this is the main reason they are visiting that location. This can be considered a deliberate encounter.

\section{Awareness}

Once a passer-by encounters and notices an APS, they become aware of its existence and enter a state of 'awareness.' In order to become aware of the presence of an APS, they will have to notice it, therefore it has to be visible and to stand out in its surroundings. Related work mentions similar states, using various terminology, such as 'discovery' (Memarovic et al., 2012) and 'encounter' (Tieben et al., 2011).

An influential factor for entering a state of awareness is visibility, which is achieved by effective spatial and visual design. In previous design projects we learned that spatial design, together with visual design, plays an important role in gaining awareness. With Globe4D we learned that placement has an important role in the likelihood for people to become aware of its presence. Ideally the installation was placed in people's line of sight when approaching and in an environment with dimmed lighting, so that they would be more likely to notice it and the projected surfaces would stand out visually. In bright surroundings it was much more difficult to stand out. Cooperative Tetris was placed in the center of a large festival terrain, towering over the crowd, being very visible from afar. In Harmonoise, sound was used to draw attention, by playing the sound of three 'instrument stations' together in their surrounding space, resulting in something between a cacophonous or harmonious composition. Offering something novel, contrasting, or unexpected also helps to attract attention.

\section{Interest}

When someone has the opportunity, a positive lusory attitude (Suits, 2014), and is willing and curious to explore (what others are looking at, engaging with, or what the APS entails), they will enter a state of 'interest.'

Interest indicates a state where a passer-by is aware of the interface and shows interest by observing, approaching and/or standing still. The marketing model AIDA also mentions this by the term 'Interest.' Similar moments are mentioned in other work, some focusing on someone's role: 'spectator,' 'bystander,' 'observer' (Finke et al., 2008) or 'onlooker' (Parten, 1933) (Rubin, 2001), and others focusing on behavior: 'hovering' (Rubin, 2001), 'exploring' (Tieben et al., 2011), 'viewing' (Müller et al., 2010; Michelis and Müller, 2011) or 'passive engagement' (Memarovic et al., 2012).

The 'honeypot effect' is mentioned in the 'Audience funnel' framework (Michelis and Müller, 2011; Müller et al., 2010), as an influential factor of raising interest. Seeing other people interacting with an interface stimulates passers-by to approach, observe and engage too. This is behavior we also noticed in Globe4D, where people gathering around the interface and playing with it would attract others. This also occurred with Cooperative Tetris were seeing people play would attract others from afar.

A state of interest can be facilitated by design, allowing people to stand by without participating (yet). In previous design projects (Globe4D, Harmonoise, Cooperative Tetris) this was 
done by spatial placement of the installation, allowing people to observe from a distance. The circular design and central placement of Globe4D allows people to approach it from various directions. Harmonoise and Cooperative Tetris could be noticed from a distance, in Harmonoise because of its ambient/ ubiquitous sound, in Cooperative Tetris, because its large screen was visible from a distance at the festival terrain.

Other influencing factors include a passer-by's mindset and attitude toward APS or technology in general. This can be caused by previous experiences, for example with Globe4D it was noticed that people often would return and visit the installation multiple times because of positive previous experiences, wanting to explore more. With BalanSAR, on occasions with an audience interested in technology, visitors were easily interested. On other occasions where the audience was much less 'tech-savvy,' people seemed much more hesitant.

\section{Intention to Participate}

The state 'intention to participate' occurs when an interested passer-by develops a desire to participate and decides to actively engage with the interface. When someone decides to participate immediately this state can be very brief. In other cases, one has to find the right moment, look for an opportunity.

In related works this state has also been described as: 'choosing to play' (Kultima and Stenros, 2010), 'walks toward wall' (Cheung, 2014), 'desire' (AIDA), or 'potential interaction space' (Fischer and Hornecker, 2012).

An intention to participate is behavior that we have noticed in various installations. Bystanders, with the intention to participate, had to wait for a spot (Globe4D, Harmonoise, BalanSAR) or the right moment to join (Cooperative Tetris).

There are multiple factors that influence entering this state. Social dynamics play a role; in previous design projects the barrier to have the intention to participate would be much lower if friends were already participating, making it less scary and simultaneously making it attractive by showing the experience. Self-efficacy and self-confidence also play a role in this, relating to the expected usability and affordance of the APS. Interacting with an APS should give potential participants the impression it is achievable, doable, and they are capable of playing with it. This is something that was taken into account in the design of previous projects, by making technology invisible (Globe4D, BalanSAR), choosing a game that everyone knows how to play (Cooperative Tetris) or designing an easily understandable interface (Harmonoise).

\section{Participation/Play}

Participation is the state that is the ultimate and primary purpose of the participant journey. The passer-by becomes an active participant. All related work mentions this state, using various terminology, indicating specific behavior: 'active engagement' (Memarovic et al., 2012), 'explore and discover' (Cheung, 2014), 'exploration and immersion' (Valk et al., 2012; Bekker et al., 2014; de Valk et al., 2015), 'discover' (Tieben et al., 2011), 'perform gesture and observe video' (Parra et al., 2014), 'direct interaction' (Brignull and Rogers, 2003; Rogers and Rodden, 2003), 'social and cognitive play behavior' (Rubin, 2001), or 'exploration and playing' (Moreno et al., 2012).
Participation is a complex and layered activity, with its own dynamics and rules that should be captured in its own model in order to do full justice to this. In the PJM we focus on the aspects of participation that are influential for the participation journey.

In relation to participation, from previous design projects we learned many influential factors. In Globe4D, interface design and social dynamics were important factors influencing participation; a round table facilitates people to easily gather around, facing each other, motivating and stimulating conversations and facilitating social interaction. Furthermore, it was designed to evoke cooperation by allowing cooperative control, acting as a democratic interface. The table surface can rotate, influencing time in the form of continental drift. Because this is done physically, users have to make a joint decision in which direction it is moved. The same happens when interacting with the-also physically moving-sphere, people decide together which side of the globe to watch. The design ensures that users cooperate while using the interface. And because they have to reach a mutual agreement, they are in contact with each other in a playful, natural way.

In Harmonoise, interface affordance and play design were influential factors. The wall visualization of Harmonoise was designed to have an obvious relation with the composition and stations, making it clear that something can be influenced, facilitating low barrier participation. The layout of the stations was deliberately very easy to understand, lowering the barrier to engage. Each station has a screen, headphones and a mouse for selecting musical samples. The image on the screen is very basic, consisting of a moving line (indicating which sound is being played) and colored blocks. If visitors would put on headphones, they would hear one of the music channels and they could create their own composition. The navigation was designed to be intuitive, easy to understand, lowering the barrier to participate. By clicking a square, it would change color, changing or removing the instrument, rewarding exploration.

In Cooperative Tetris, opportunity and its interface and game design were influential factors. People were at a festival location, having a playful mindset and no pressing pre-occupations, enabling them to participate. It was designed to be very recognizable and comprehensible for bystanders and passers-by with understandable gameplay and rules that most people are already familiar with. Almost everyone has played Tetris at some point. It needs no explanation and requires no special skills to play, making it easily playable untrained (Mast and de Vries, 2017).

\section{Intention to Stop}

Eventually, there comes a moment at which the participant wishes or needs to stop, either voluntarily, because of external reasons or because the game ends. Most models primarily focus on facilitating and evoking engagement. With regards to ending an experience, models merely state that this occurs. In the models that do describe this state, the following wording is used: 'walks away from wall' (Cheung, 2014), 'continues on path' (Germany et al., 2019), or 'follow up actions' (Müller et al., 2010; Michelis and Müller, 2011).

None of the models specify the conditions under which this occurs, disregarding the important impact a pleasant ending could have on the overall perception of an experience 


\section{Participant Journey Map}

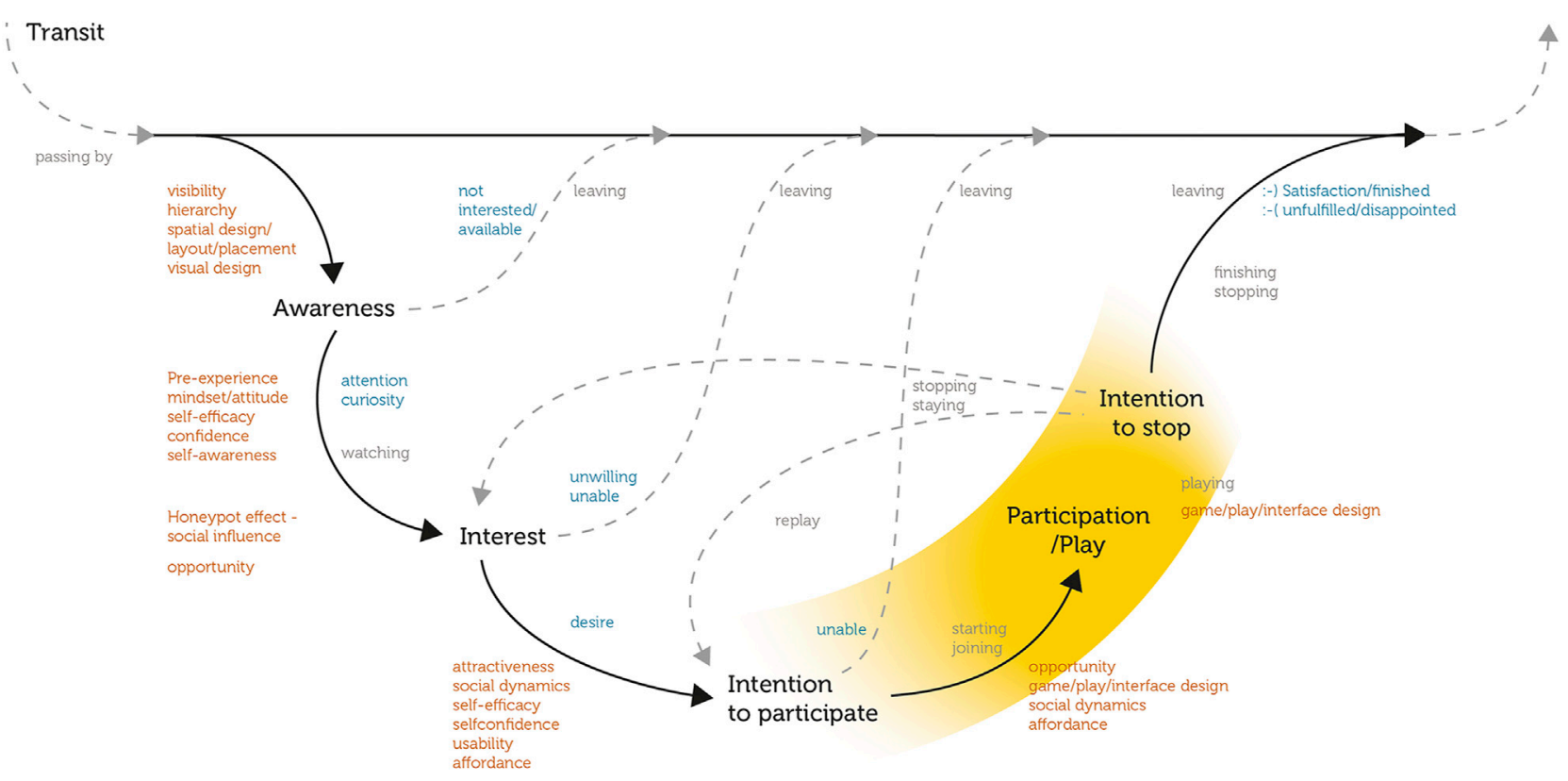

FIGURE 2 | Concept Participant Journey Map, consisting of 6 participation states: Transit; Awareness; Interest; Intention to participate; Participation/Play; Intention to stop, supported by influential factors.

(Fredrickson, 2000; Kahneman, 2011; Kane, 2018; Mast et al., 2020). We consider the end of an experience to be an important moment for a participant's attitude toward that interface or similar interfaces in the future.

Most of the previous design projects were designed to be openended-participants had the freedom to stop at any moment. People mainly seemed to stop when they had somewhere else to go or were done exploring. Cooperative Tetris was a structured game with an ending, that was decided by a timer (for research purposes). This left the participants often feeling disappointed with the sudden ending. BalanSAR has a more natural end, because participants walked from one side to the other, their participation would end when reaching the other end.

\section{Non-linearity}

So far, we have discussed the insights related to the different phases in a participation journey. An important insight, often underexposed in related research, is non-linearity. With non-linearity we mean that it is not necessary to go through all phases or states in a journey. It also refers to the ability to go back to previous states or phases.

Most participation models are linear and do not take into account that it is possible to move back and forth between phases or otherwise deviate from the default trajectory, allowing potential participants to 'skip steps.' However, some models do acknowledge forms of non-linearity. The 'Interactive Public Ambient Displays Framework' (Vogel and Balakrishnan, 2004) mentions fluid inter-phase transitions and the framework allows moving back and forth between states. The 'Stages of Playful Interaction' (Valk et al., 2012; Bekker et al., 2014; de Valk et al., 2015) also allows moving back and forth between stages. Furthermore, participants can enter the immersion stage without going through the other stages. The 'Urban HCI model' (Fischer and Hornecker, 2012) focuses on interaction spaces and mentions that people can move between roles over the course of an intervention.

Experiences with previous design projects emphasize the notion that a participation journey isn't necessarily linear and that potential participants do move back and forth between phases. This was added as a feature to the concept PJM (Figure 2).

In the PJM we regard 'states' as necessary steps toward participation. A participant always goes through them linearly, even though this can happen very quickly, in the blink of an eye. The nonlinearity in the PJM specifically refers to the fact that participants can deviate from this path when factors lead to a decision not to participate and when participants move back to previous 'states'.

\section{CONCEPT PARTICIPANT JOURNEY MAP}

Our analysis of phases and states resulted in the Participant Journey Map (Figure 2), which visualizes the participation journey. It illustrates the states, influential factors and transitions between states. The concept PJM consists of 6 participation states: 'Transit'; 'Awareness'; 'Interest'; 'Intention to participate'; 'Participation/Play'; 'Intention to stop.'

The approach of the Participant Journey Map is inspired by that of customer journey maps (Howard, 2014; Følstad and Kvale, 2018; Gibbons, 2018), a well-used tool in user experience design. 
TABLE 2 | Profiles of interviewed experts.

\begin{tabular}{|c|c|c|c|}
\hline Expert & $\begin{array}{l}\text { Years } \\
\text { active }\end{array}$ & Function & Context \\
\hline E1 & 12 & Art Director, Spatial Designer & $\begin{array}{l}\text { Festivals, Escape } \\
\text { rooms, Exhibits, } \\
\text { Theatre }\end{array}$ \\
\hline E2 & 15 & Creative Technologist & $\begin{array}{l}\text { Fairs, Festivals, Art } \\
\text { Installations }\end{array}$ \\
\hline E3 & 16 & Creative Technologist & $\begin{array}{l}\text { Festivals, Interactive } \\
\text { Outdoor Play Spaces }\end{array}$ \\
\hline E4 & 13 & Director of R\&D & $\begin{array}{l}\text { Interactive Outdoor } \\
\text { Playgrounds }\end{array}$ \\
\hline E5 & 20 & Head of Exhibits & Museum \\
\hline E6 & 16 & $\begin{array}{l}\text { Artist, Designer, Experimenter, } \\
\text { co-founder interactive design firm }\end{array}$ & $\begin{array}{l}\text { Large Augmented Play } \\
\text { Spaces, Museums }\end{array}$ \\
\hline
\end{tabular}

A 'customer journey map' is a visualization of the process that a person goes through in order to accomplish a goal (Gibbons, 2018). They offer an outline of a user's experience with a product over time (Howard, 2014).

\section{EXPERT INTERVIEWS}

Expert interviews were conducted to refine and validate the concept PJM. Expert interviews can reveal shortcomings and highlights of a concept design. They are a well-known and widely used method in design research and a way to quickly gain valuable perspective and insight into the context, background, recent findings, successes and failures in relation to a topic (IDEO, 2020). Examples of the use of expert interviews in $\mathrm{HCI}$ research include semi-structured expert interviews in exertion gaming research (Mueller and Isbister, 2014) and expert interviews with tangible user interface experts (Leong et al., 2017).

\section{Method \\ Participants}

The principal investigator of this study (DM) interviewed six experts [E1], [E2], [E3], [E4], [E5], [E6]. On average, the experts had over 15 years of experience, designing, developing and/or implementing playful installations in situated environments (festivals, fairs, exhibitions, museums, playgrounds, public parks, public spaces, etc.). One participant is from North America, the others from Europe. Three of the six experts have cross-continental experience. Four experts are currently active as developers and/or designers of APS, two experts are active as exhibition designers (in which playful interactivity has a prominent role) of which one is head of exhibits at a large museum. See Table 2 for expert profiles.

\section{Interviews}

One expert was interviewed in person, the others were interviewed in an online setting. The interviews took between 0:53 and 1:36 h (average: 1:09 h). Prior to the interview the experts were briefly informed in writing that the topic of the interview would be about the design and implementation of interactive play in semi-public environments. The interviews were semi-structured and consisted of two main parts: 1 -The expert's vision on phases and influential factors for engagement with APS, and 2-The expert's feedback on the concept PJM.

We started the interviews by showing the experts a sheet with a collage of pictures of augmented play spaces as a primer (Figure 3). Then, the experts were asked about the phases and factors they considered to be influential for engaging people into augmented play spaces. When needed, follow-up questions were asked to clarify answers or elicit more detailed answers, asking them about the why and how (Cooper-Wright, 2015). When the interviewer felt the general question was sufficiently answered (e.g., repeating concepts, no new issues addressed) the interview continued.

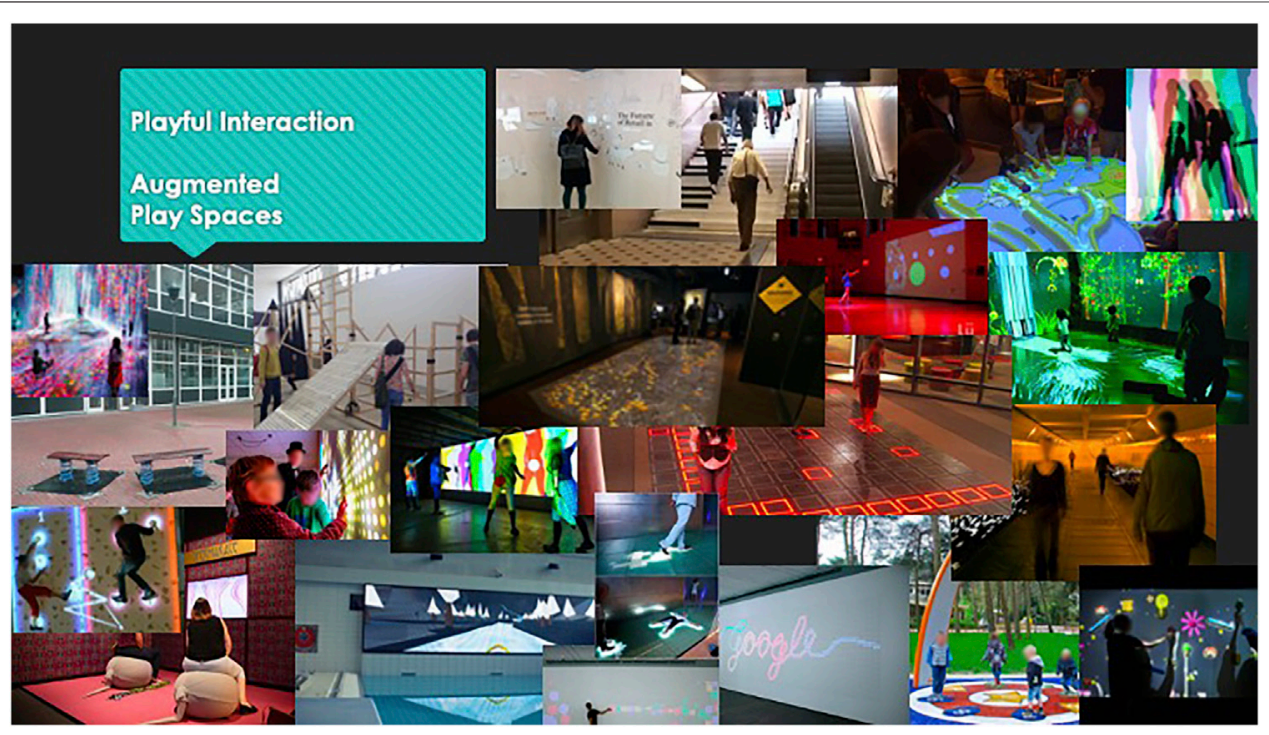

FIGURE 3 | Interview Primer: collage of APS examples. 
The second part of the interviews started by showing the experts the concept of our Participant Journey Map (Figure 2) and asking them to provide feedback.

\section{Analysis}

All interviews were coded following a combination of deductive (a priori) and inducive (emergent) coding. Coding was based on insights from the exploration of related research and previous design projects (section "Insights from Related Research and Previous Design Projects"), combined with codes for new concepts that emerged during analysis. First, all relevant quotations were marked, and initial coding was added, marking the phase, influential factors and other relevant data. Next, in multiple iterations the coding was refined, merging similar codes, subdividing them in categories and classifying them into phases, where applicable. Influential factors are classified in the phase for which they are a prerequisite.

\section{Results: Phases, States and Influential factors}

Through multiple iterations, the analysis of interview data has resulted in a detailed overview of influential factors and states of a participant journey. Table 3 shows a table with a summarized version of the expert interviews insights related to the participant journey. The results are explained per phase and state, followed by the revised PJM.

\section{Overall Feedback on Usability and Usefulness of the PJM}

The experts' reactions to the concept PJM were positive, expressing appreciation of its content and structure and recognizing what the model entails. Experts mention that they like it [E4], that "it makes sense" [E4], "it is complete" [E2][E4], recognizable [E2][E3], elegant and "(super) cool" [E6]. One expert [E2] repeatedly mentions how fascinating it is that the concept model matches their views during the first part of the interview very well, which they also find a nice confirmation for their own work.

The PJM could be useful as a (set of) guidelines for practice [E1][E2], giving insight into the considerations that should be made when designing or developing APS. The PJM could serve to indicate the broad outlines and the larger conceptual framework for implementing APS, providing guidance on the steps to follow for your own specific implementation [E2].

TABLE 3 | Summary of insights from the expert interviews, related to the participant journey.

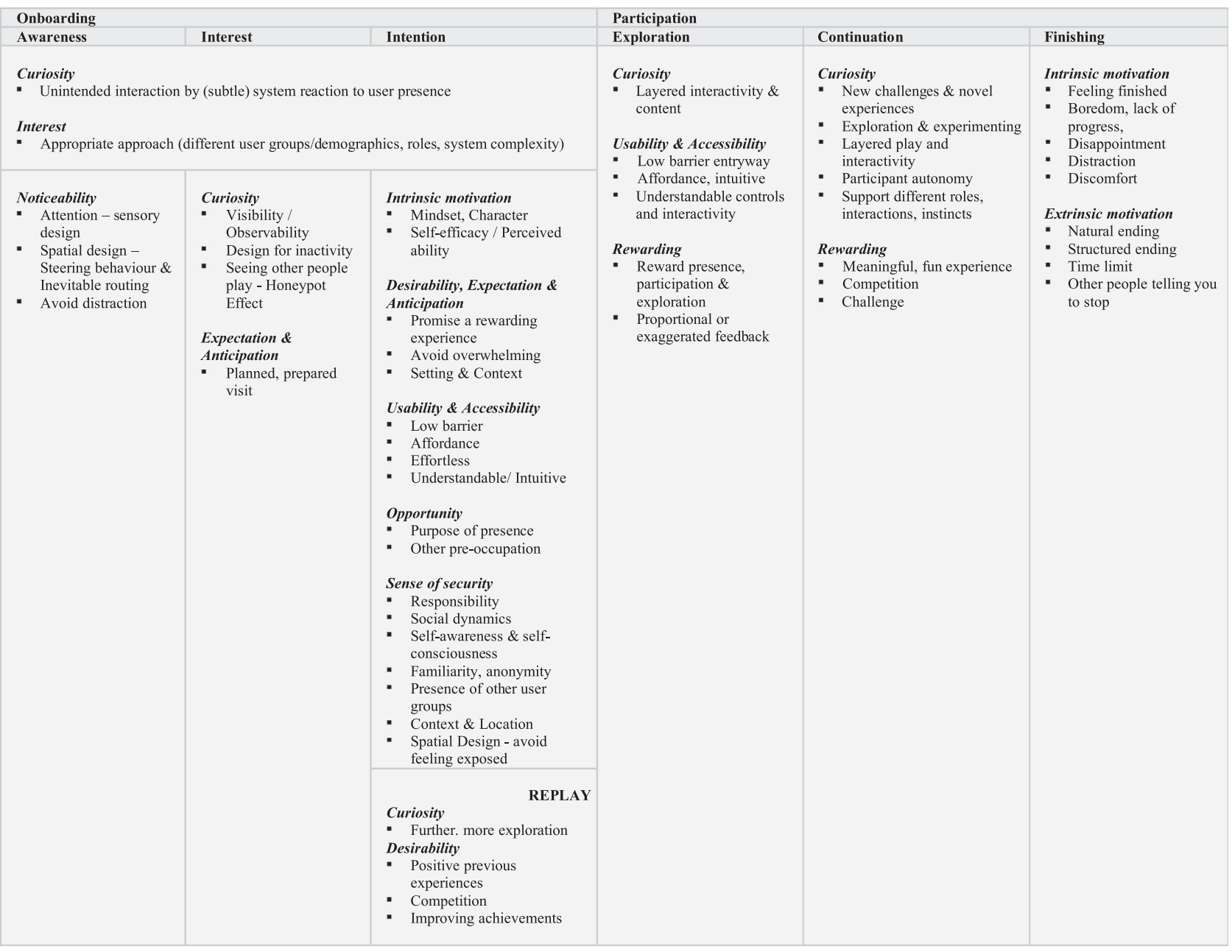


One expert [E5] remarks that in order for the PJM to be useful for them and other professionals, the usability of its design should be improved. Making it clearer what the goal and core message of the model is. Another expert [E4] likes that the participation phase is highlighted in orange, emphasizing what they mention as being 'the core.'

\section{Onboarding}

A number of experts made statements about influential factors that relate to (a combination of) steps or states ('Awareness,' 'Interest' and 'Intention') that lead to participation. This is mentioned as onboarding multiple times by one of the experts [E6]. We decided to regard onboarding as a distinct phase and include it as an overarching phase in the revised PJM.

Although 'onboarding' is previously defined in the context of gaming/playing by Petersen et al. as "The first few minutes of play" (Petersen et al., 2017), in the PJM 'onboarding' is regarded as the process of getting someone on board of the APS, including the preceding actions and steps. This is more in line with commonly used definitions of onboarding, such as "the act or process of familiarizing a new customer with one's products or services" (Merriam-Webster, 2020) and (more corporate) "the process in which new employees gain the knowledge and skills they need to become effective members of an organization" (Onboarding, 2020). It also relates to (transportation) "to go aboard (a vessel, train, aircraft, or other vehicle)" (Board definition and meaning, 2021) and (nautical) boarding: "to come alongside (a vessel) before attacking or going aboard" (Board - definition and meaning, 2021). These definitions all consider onboarding or going on board as the steps or actions preceding the entity that will be boarded, leading to boarding it. Therefore, in the PJM, we regard onboarding as the steps and activities leading to getting on board the APS.

Onboarding in the PJM involves the processes of encountering an APS, noticing it, becoming curious, getting closer, taking the decision to participate leading to exploration.

For some APS, 'Awareness,' 'Interest' and 'Intention' can seem to take place almost simultaneously in just a few seconds [E1]. Experts indicate curiosity and interest through an appropriate approach as influential factors relating to onboarding. Different user groups need slightly different onboarding approaches [E6] and there has to be something to experience for people in every role (waiting, observing, playing) [E3]. Additionally, a complex system should have a well thought out, tailored onboarding, whereas a simple system can have a simpler onboarding [E6].

Curiosity can be evoked by a subtle reaction of a system to user presence [E1][E2][E4]. For example, when they walk underneath an interface, and something happens [E4]. This can be an unintended action by the passer-by. This type of system reaction to user presence is also an effective way to inform a passer-by about the presence of an interactive system when no one is playing [E1]. One expert mentions that letting people participate unknowingly, could lead to making them feel they are lured in [E5] and should be considered very carefully. This subtle, unexpected and unintended interaction can be incorporated in an APS (to draw attention) under the condition that does not put the focus of attention on that individual specifically [E5].

\section{Awareness}

Awareness, the first state of onboarding, can be described as the knowledge that something exists (Awareness Meaning Cambridge English Dict, 2021) and is the state someone reaches once they have encountered and noticed the APS. Based on analysis of the expert interviews, combined with what we already found in related research and previous design projects we conclude that noticeability is a key influential factor for this state.

To gain awareness, an APS has to be noticed by passers-by. Therefore, it should be designed to stand-out [E4], attracting attention. This can be achieved by the use of sound and visual design (e.g., markers, lighting). Distraction (by irrelevant things) should be avoided [E1]. Spatial design (e.g., object placement, sight lines, lighting, routing) can steer user behavior to stimulate an encounter [E1]. Inevitable routing can make it almost impossible to walk past without noticing its interactivity [E1] [E6] and can avoid giving people room for a way out when passing by [E1].

\section{Interest}

Interest, the second state of the onboarding phase is mainly driven by curiosity. To become curious, people need to have the opportunity to observe the APS. Visibility and observability can be achieved by effective spatial, visual and interface design. An APS should be specifically designed for an idle/inactive situation without play, when the first user approaches [E1]. A playful installation can be made to look interesting when no one is playing by showcasing a demo or letting staff play [E3].

People already playing attract others [E4]. This corresponds with the previously mentioned honeypot effect (Brignull and Rogers, 2003; Wouters et al., 2016). Design of an APS should allow people to observe what others are doing [E1][E5][E6]. People like to observe first, design should facilitate a space to be near the installation without being in it [E6].

Preparation and expectation are other influential factors. When a passer-by expects to encounter an APS, they will be prepared and more likely to show interest. A planned visit evokes expectation [E5]. A visitor's expectations can be primed before visit (buying ticket, routing) or by hearing about it from others [E1].

\section{Intention}

The intention (to participate) is the state someone reaches when they are aware of the APS, interested and have decided (the intention) to participate. Entering this state is influenced by a mix of intrinsic, extrinsic, contextual and design factors.

According to the experts, someone's willingness to engage partly depends on their character and mindset [E1], intrinsic factors. Some people are self-conscious and naturally not or less likely to engage [E4][E5]. They might think playing is not for them (or their demographic) [E4]. Or they are worried about breaking things, unsecure and don't dare to participate [E4]. Other people are naturally curious and interested and have no fear or hesitation to participate [E3][E4][E5]. 
Anticipation and expectation also influence the intention to participate. It is important for a potential visitor to get an impression of what to expect. It should be clear what the reward of participation is [E1]. A promise of a positive experience or reward makes it desirable for potential participants. For example, seeing other(s) having fun lowers the barrier to want to try and engage [E1][E2][E5]. This can also be achieved by an APS that promises a magical experience [E6]. Also, a long queue raises the expectation that the APS must be worthwhile [E3].

Evoking an expectation of something less desirable might discourage participation. Therefore, an APS should not seem too wild and crazy [E6], have too much visible technology (screens, lights, sounds) or be too overwhelming, because that puts people off [E4]. There is a higher barrier to participate when no one is playing yet [E1], because it's not clear what to expect.

The purpose of presence and the opportunity that arises from it also influences someone's willingness to participate. When someone is pre-occupied with something else (e.g., work, grocery shopping, catching a train) the barrier to participate is high [E1]. At a later moment (e.g., during drinks after work) that willingness may be there [E3], because their purpose of presence has shifted (e.g. done working), giving them opportunity.

To engage people in a setting where they are likely to have an external preoccupation (e.g., shopping center), it must be taken into account in the design of an APS that they don't want to wait but want to be able to do something immediately. In a casual, leisurely setting (e.g., festival) participants don't mind waiting [E3].

Participation should seem to require little mental and physical effort. An APS should be accessible for any age and ability [E6], have a low barrier physical design [E4] and be designed for the lowest common denominator [E6]. It should not take too much effort before being rewarded [E6]. For example, asking people to hook up devices, such as VR-sets [E6] and embodied sensors, or to fill in too much information upfront [E6] should be avoided.

This also related to the importance of good affordance of an APS; people should understand the interaction [E3] and what they can and should do with the system [E1][E5]. The interface should appear intuitive, not complicated, not time-consuming upon first impression [E2].

Self-efficacy, someone's perceived ability also plays a role herein-how good does someone think they will be at playing? [E5]. Ideally, participation should not require special skills [E4], because practice is needed for gaining skills, raising the barrier to participate. APS (games) that rely on tactics have a low barrier, because practice is not required to perform well [E3].

According to the experts, the social dynamics is another influential factor for the intention to participate and relates to a sense of security. People should feel secure to start participating [E5].

Seeing others having fun lowers the barrier to want to try and engage [E1][E2], because of the aforementioned expectation it rises and because it makes people feel less vulnerable, compared to playing alone. On the other hand, other user groups participating (e.g., bigger kids, adults, other demographic) might give people the feeling it's not for them [E6]. Such is also the case for regular playground games [E4]. For example, kids feel vulnerable when many adults are already playing [E6] and might decide not to join while initially and/or actually wanting to join.

The location and setting of an APS are influential factors for the willingness of passers-by to engage with them. One expert explains that at a large music festival there is a certain anonymity, there's little fear of standing out, and visitors have a playful, open mindset [E3]. At a local village festival, or a business fair, there is a fear of standing out because everyone knows you [E3]. At these locations, the threshold for visitors to participate is much higher because of a fear of failure (in front of acquaintances). However, another expert mentions something seemingly opposite. An encounter in a space with only strangers being present raises the barrier [E1] whereas an encounter in a space with friends or family lowers the barrier to participate [E1]. Especially teenagers are naturally shy; they feel more secure when they can do something as a group [E6]. An any case, the degree of familiarity and anonymity seems to be an influential matter.

This also relates to people feeling insecure about participation because they are afraid of being laughed at by others [E3], they don't want to be made fun of [E5]. One expert explains that it should not stand out to others that you (as a player) are responsible for certain activity [E5]. Single player games have a higher barrier to participate because the player is individually responsible for the result [E3]. Multiplayer games have a lower participation barrier [E1] because participants share responsibility for the result [E3].

When you participate, you become a performer [E5], but not everyone feels comfortable being watched. Effective spatial design can make people feel less vulnerable. Creating a dark playing environment and avoiding bright environments with people watching [E6] helps to achieve this. Other solutions are to let people play alone with no bystanders (although this has many other undesirable effects) or facilitate crowded anonymity [E1] (creating a crowded environment where participants feel anonymous). VR can also make people feel vulnerable: you don't know who's watching and what they might be doing to you without you noticing [E2].

Inviting people to participate is complicated. Create a safe comfortable setting and avoid pushing or explicitly inviting them to participate [E1][E3]. Avoid petrifying potential participants by directly addressing them. Instead, nudge them playfully [E3] and let people make a conscious decision to engage [E5].

\section{Intention: Replay}

So far, the intention to participate focused on the situation of a first encounter. However, when someone considers playing again (after temporarily stopping or re-encountering an APS), specific factors influence the intention to replay-participate again.

Curiosity facilitates the desire to play again (next time) and can be evoked by finding out there is more to explore [E2]. This can be achieved by providing room to observe after play to enable discovery of new unexplored content [E2] and making each time someone participates different. 
Competition is another factor that can affect willingness to replay. The urge to improve your previous or someone else's score [E3][E4] can be a motivating factor to come back. Although a personal experience with a simple, meaningful interface is worth more than winning with a complex interface [E2].

People are always influenced by what they know or experienced before [E1]. A memory of a positive previous experience with an APS (or similar interface) [E1] influences the intention to participate. Therefore, a previous encounter should have evoked a meaningful personal experience [E5].

\section{Participation}

The participation phase is the ultimate goal of the participation journey. Based on the results of the expert interviews this phase includes the states exploration, continuation and finishing.

\section{Exploration}

Participation starts with exploration. This state is facilitated by the influential factors: curiosity, usability and reward.

To enable participation, the APS should be designed to have an inviting, low barrier [E1], obvious and easy entryway [E6]. Affordance is important, the installation should be intuitive [E1] and not time-consuming to consider or understand [E2]. An APS design should be intuitive to use, clearly indicating the choices that can be made [E5] and what to do with the system [E1]. Furthermore, form and/or experiences should indicate functionality instead of explicitly explaining functionality [E4][E6].

Interactivity and content should be layered [E6], supporting curiosity. When a user steps in, an APS should take you onboard a story [E5] and reward participation and exploration [E4]. It should be immediately clear that it's interactive and that their presence has impact [E6]. The APS should react immediately/promptly to user presence [E6] and input [E4]. Start with minimal required input, the more comfortable participants get, the less selfconscious and shy they will feel and the more they can commit to the experience [E6]. Once participants understand it is interactive, allow them to explore and tease out other interactive things [E6]. Desirable actions should be rewarded instead of enforced [E6]. Any movement should elicit a system response, giving proportional or exaggerated feedback [E6]. Following, there can be less intuitive interaction, still fairly easy to discover and often related to the first interactions [E6]. Ending with the possibility for in-depth, complex experiments [E2], with interactive elements that take longer to discover but create a layer of magic [E6], leading to continued participation.

\section{Continuation}

After a participant has explored interacting with the APS, they will enter a state of continuation. The main factors influencing this state of continuation are curiosity, which is facilitated by novelty, exploration, autonomy, variety and versatility, and offering rewarding objectives.

According to the experts, an APS should support many different roles and interactions, speaking to different instincts [E6]. Ensure that an experience continues to be fun by matching a participant's realm of experience [E4] and allow them to give meaning to their experience [E5]. To keep it interesting, an APS should give a participant autonomy [E6]. This can be done by allowing them to go through structured content at a chosen speed [E2], allowing them set new targets [E5], giving them control over level choice, letting them explore new things [E4] and allowing experimentation [E2]. Furthermore, an APS should adjust difficulty and challenge to user skills and progress [E4], giving the user a feeling of improvement [E5].

Participation can be extended by facilitating amorphic and emergent play [E6]. This can be done by offering the participant variety [E5]: new challenges [E2][E4][E5], novel experiences [E2] [E4] and layered complexity [E6]. Continuously bringing a participant in a new play state and dosing their frustration [E5] is another effective way of elongating participation. Although competition (facilitated by a scoring system) can also be an effective trigger goal [E3].

One expert mentions that the quality of an experience should be the goal, not the duration [E2]. This indicates that not in all circumstances elongated continuation should be a core objective of an APS.

\section{Finishing}

Finishing or the intention to stop is the final state of participation. Experts recognize it when they see it suggested in the PJM concept, remarking that it makes sense and is very elegant [E6]. One expert also mentions that what happens after someone is done playing is often overlooked [E1].

The intention to stop can be fueled by intrinsic motivators: feeling finished [E1], the impression to have gotten as much out of it as possible [E6], boredom [E4][E5], lack of progress [E5], disappointment because of mismatched expectations [E3], distraction [E6][E4] and physical discomfort [E6]. Other motivators are external: time is up [E5][E6], parents telling kids to go [E4][E6] or players having the feeling they're not playing for themselves anymore, but for the audience or maker(s) [E5].

Play can have a structured, closed ending or an unstructured open ending. Closed ended play provides more structure [E4] than open ended play, but offers less room for exploration, experimentation and player autonomy. Open endedness is very nice, and allows for exploration, but it can also cause player interest to fade when implemented wrong [E4]. Open endedness should not be an excuse for not having to design structure, as this might result in players not finding it interesting at all [E4]. Successful open-ended games often still offer a lot of structure, providing many rules, but also shouldn't determine too much [E4]. Another expert explains that successful unstructured play needs to be layered and leveled [E6].

An APS can prompt participants to end their participation by having a natural ending (time is up, story is finished, game over) to a structured game [E1], a designed obvious ending (dark screen, movie stops, end of space) [E1], because the story ends [E5], or by creating a natural ending to an unstructured game (e.g., day-night cycle to indicate end of day) [E6]. 
An experience should end in a positive way. Whatever happens, celebrate the end and avoid a sad ending [E3]. Afterward, people will remember things that did not work well or responded differently than expected. Negative experiences linger longer [E1]. When an experience is overwhelmingly awesome or great, the end becomes less important and flaws during the experience will matter less [E1]. One expert mentions finding it challenging to design a peaking ending, because there are so many moments when someone can stop [E4]. Another expert mentions that in general museums (consider to be play experiences in their entirety) lack in giving visitors a sense of completion at the end of a visit [E5]. One expert mentions that an experience can be purposely designed to evoke a feeling of frustration or disappointment, when those feelings are a predetermined (and essential) part of the experience [E2]. This applies, for example, to more artistic works with the aim to convey a message, to make people think through a specific experience or an emotion.

A scoring system as an objective, although effective [E3] is also considered to be very blunt and in the end there will always be a winner and a loser [E5]. Therefore, evoking a meaningful, magical experience [E1] might be a better objective goal to ensure a positive ending [which is important for the intention to play with similar systems (section "Intention Replay") and replay with the same system (section "Intention Replay")].

\section{Other Results}

In the previous section, we discussed the results of the interviews related to participation stages, states, and influencing factors of the PJM. The interviews also revealed additional results relating to the context of the participant journey. These results are described in this section.

\section{Chronology and Time Frame}

Although most influential factors happen during a visit, some can take place prior to a visit [E1]. This may be because someone has prepared for a visit, creating anticipation and expectation. Someone usually plans a visit to a museum or festival, and the visitor knows more or less what to expect. Here the preparation plays an important role in creating expectation and anticipation, influential factors for entering states of Interest and Intention.

While most encounters happen during one visit, a participant journey can also take place over the course of several encounters. Where 'awareness' takes place during an earlier visit than 'intention to participate.' It is suggested to be useful to mention this in relation to the PJM [E1].

An example of such a situation is when someone encounters 'the piano stairs' - an interactive staircase in a station (Review Piano Stairs - Beyond Social, 2020) that plays piano sounds when you walk over it. They may come across this APS while trying to catch the train, not having the opportunity to pay much attention to it. On a subsequent visit, that time might be there, and they remember noticing the piano stairs previously, but not having the opportunity then and decide to pay attention now. In this case, the participant journey is spread over a time frame of several visits.

Another expert mentions that the faster someone can go through the phases; the smaller chances are that they will disengage [E2]. When people have the chance to think too long, they might choose not to try. When there are more conscious steps to take, it becomes easier to decide not to follow through.

\section{Non-linearity}

Multiple positive remarks were made [E6] about the PJM having loops back to previous phases. Emphasizing that people need space to stop interacting, process what they've experienced and make the decision whether they're really done playing or want to play more. They mention that there are definitely cycles occurring in a participation journey and remark that building for those cycles is a very good way to approach interaction design [E6]. Another expert mentions they appreciate the feedback loop from 'intention' to 'interest' and recognize that this often happens [E4]. They give the example of kids stopping, watching how others are playing and decide to continue playing or play again. One expert mentions that (although undesirable) it's very recognizable that there are four possible moments when someone can decide to leave before participation [E1].

\section{PARTICIPANT JOURNEY MAP}

The revised version of the Participant Journey Map (PJM) (Figure 4) combines the insights from related research and previous design projects (section "Insights from Related Research and Previous Design Projects") (that formed the foundation for the concept PJM (Figure 2, section "Concept Participant Journey Map") with the input and feedback of experts (section "Expert Interviews").

The Participant Journey Map consists of four layers: Phases, States, Transitions and Influential Factors. There are two overarching phases: 'Onboarding' and 'Participation' and 6 states a (potential) participant goes through when engaging with an APS: 'Transit,' 'Awareness,' 'Interest,' 'Intention,' 'Participation,' 'Finishing.' When passers-by go through the process to engage with an APS, they transition between different states. This includes transitions resulting from decisions not to partake in an APS (leaving or remaining an observing bystander) or to revisit a previously experienced state (finished playing and becoming a spectator again or waiting until there is opportunity to participate again). Transitions are affected by influential factors.

\section{Adaptations and Preservations Compared to the Concept PJM}

Based on insights from the expert interviews, the Participant Journey Map was refined and updated. The original structure was largely maintained.

The state of transit was maintained, although this was not explicitly mentioned by or discussed with the experts. However, no comments were made in the interviews about the presence of this state in the PJM, it appeared to be taken for granted and considered to be obvious.

An overarching phase 'Onboarding' was added, under which the already existing states 'Awareness,' 'Interest' and 'Intention to 


\section{Participant Journey Map}

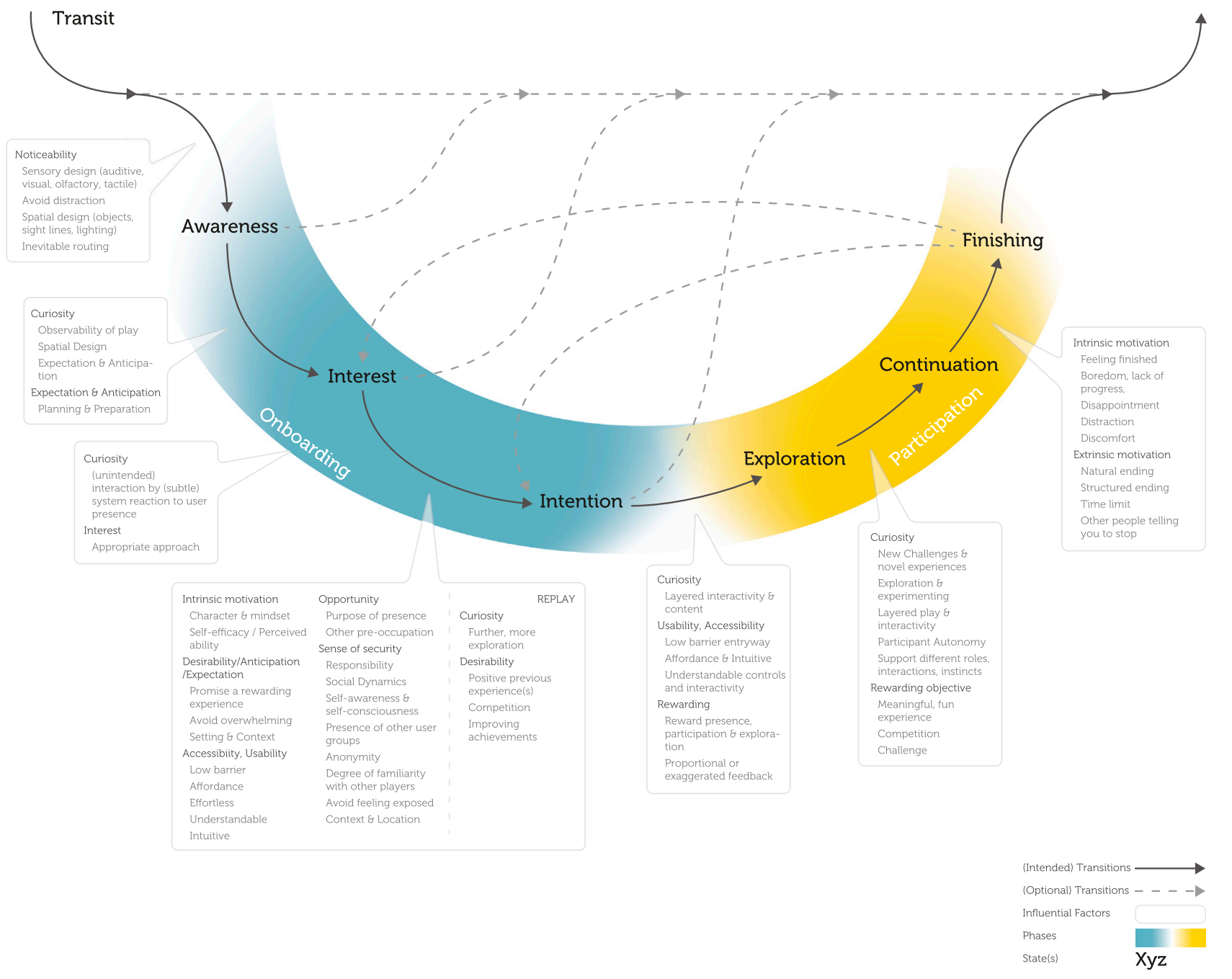

FIGURE 4 | Participant Journey Map.

participate' are placed. It flows into the state of 'Exploration' of the 'Participation' phase. This is in accordance with one of the experts explicitly mentioning onboarding as a phase and other experts indicating that these states often happen in a flow.

The 'Participation' phase was (visually) emphasized, within which the states 'Exploration,' 'Continuation' and 'Finishing' are placed. This structure emphasizes that what happens within these phases can occur in a flow of events, where it can be difficult to distinguish sub-states. Also, some influential factors mentioned by experts relate to the series of events that occur in a phase like onboarding as a whole and don't relate to just one of the substates.

'Exploration' is a newly added state. The interviews indicated that this is a separate state during participation with its own characteristic features. The state of 'Finishing' was renamed (previously Intention to stop). This better describes that a participant is in a state of completion of participation at that moment.

A distinction is no longer made between different types of influencing factors. They turned out to be so diverse in terms of cause and underlying reasons that they proved too complex to classify into categories.

The journey directions were maintained, still allowing nonlinear movement through the model. Influential factors were updated, according to expert input as explained in the section "Expert Interviews".

The PJM was visually improved. Colored bands were emphasized for the overarching phases, making it clearer that the underlying states flow into each other. The contrast of the 
'transit' line was decreased, since this is an undesired (optional) route and should therefore not be emphasized visually.

\section{DISCUSSION AND DIRECTIONS FOR FUTURE RESEARCH}

In this section we provide an overview of notable findings and directions for further research. This includes ambiguities, research gaps, emerged questions and interesting findings that are promising to further look into.

\section{Design for Inactivity}

Experts indicate that an APS should be designed specifically for a situation of inactivity. When no one is playing yet it should still be able to attract attention, create the right expectation of its experience and how to interact with it. A way to do this is by showcasing play (Tieben, 2015) or directly trying to elicit interaction (Parker and Tomitsch, 2017; Parker, 2018).

Related research and design primarily focus on how to design for participation but tend to overlook that the majority of the time an APS will be in a state of inactivity. While, when an APS is implemented in a semi-public environment, this is a key moment leading toward eventual participation. More research is needed to better understand how to design for inactivity and be better able to effectively implement APS in situated environments.

\section{Clear Expectations vs. a Magical Experience}

An APS should have a low barrier entryway, the affordance of an APS should be apparent quickly and it should be very clear to an observer what experience to expect. But participation with an APS should also be surprising and evoke a magical feeling (Reeves et al., 2005; Reeves, 2011). How can a truthful expectation be achieved without giving away all the magic?

\section{Annoying vs. Enticing Unintended Interaction}

Opinions of experts toward incidental interaction when passing by were twofold. Some suggest making a system react to a passer-by not yet aware of the system and hereby provoking awareness and a reaction. However, it was also mentioned that this might cause an adverse reaction, evoking a feeling of selfawareness in passers-by and giving them the feeling of being lured in. Further research could tell where the line is between unintentional interactivity being annoying or enticing.

\section{Visibility of Play: Attraction vs. Barrier}

Experts mention that an APS and current participants, should be clearly visible for potential players (Dalton et al., 2010; Akpan et al., 2013). Visibility of people playing attracts others, the honeypot effect (Brignull and Rogers, 2003; Wouters et al., 2016), and offers an expectation of the experience that awaits someone once they decide to participate. Also, the promise of playing with other people lowers the sense of vulnerability during play because of joint responsibility. On the other hand, strangers and people with a different demographic raise the barrier to participate. This can be caused by social barriers and feelings of exclusion ("it's not for me"). Furthermore, experts indicate that participants shouldn't feel being observed or watched, because this makes them feel vulnerable and self-conscious. This presents an interesting paradox regarding the visibility of play. It provides a challenge to better understand how to design an APS and its context in such a way that it is visible while avoiding giving current players a vulnerable, unsecure feeling by being watched. Further research is needed to understand the variables that play a role in the attractiveness vs. the barrier of visibility of play and how APS visibility can facilitate the most fluent participant journey.

\section{Familiarity with Potential Co-Players and the Audience}

Experts suggest that the degree of familiarity with people already playing or that they will potentially play with, influences one's willingness to engage into a situation where people are already playing. It is suggested that presence of good friends or family lowers the barrier. Experts experienced that when the audience consists of people that know you, but that you don't feel completely at ease with (co-workers, neighbors) raises the barrier to participate. Whereas they experience that complete anonymity lowers the barrier.

Further research on the influence of familiarity on the barrier to engage, will support understanding of how to design APS that are effective for different social circumstances. Familiarity with potential co-players and people watching should also be taken into account when designing experimental setups, as this can influence people's engagement.

\section{Influence of Previous Experiences on Willingness and Recurrent Play}

An experience is often regarded as just that occurrence. An experience however already starts before a visit, (long) before the actual activity starts. The journey leading toward an experience influences how someone approaches an APS, their mindset and attitude. This relates to someone's previous positive experiences with the same (aka. recurrent play Tieben et al., 2013; Tieben, 2015) or similar systems. But also to expectations that are based on their attitude toward interactive technology in general, which is influenced by all previous experiences with similar technology. Little is known about the influence of these pre-encounter influences and how to support recurrent play. Future research should take this into account.

\section{Design for Any Ability and Level of Competence}

A design approach for interfaces is usually user-centered, focusing on a specific audience. One of the experts mentions that an APS should be designed for any ability and level of competence [E6]. This seems contradictory, however, considering that APS are implemented in public environments where all kinds of people pass by and there often isn't a specific 
user group, designing for a broad audience makes sense. To allow APS to be effective in these contexts it must appeal to a broad audience with a various range of skills and interests. It remains to be seen it is feasible to design for any ability and level of competence while keeping the APS interesting, challenging and doable for all users.

\section{Play-Mindedness}

One aspect that is occasionally briefly mentioned but that we have not emphasized yet is differences in behavior and experience with respect to play. This is highlighted for example between children and adults. Based on the interviews, related work and design projects there are indications that these different groups behave in different ways. Children have a much more open mindset, wanting to try and experiencing little barriers. Adults often think that playing is not for them, while playfulness is also beneficial to them. This is something to take into account in future research. An interesting approach would be to design APS that works for multiple user groups with different levels of play-mindedness.

\section{Democratic Interfaces}

Group dynamics play an important role in how people use and experience an APS. The way people jointly use an interface is then determined by social cohesion, dynamics and hierarchy. How can we design democratic, social (Isbister, 2010; Moreno et al., 2012; van Delden, 2012), cooperative (Parés et al., 2005; Robbins and Isbister, 2014) interfaces-that facilitate joint decision making?

\section{Structure}

Open ended (de Valk et al., 2015), unstructured-and-closed ended, structured play have different characteristics. Open ended, unstructured play facilitates fulfilling curiosity by allowing exploration and giving a participant autonomy. Closed ended, structured play allows setting clear goals. How can an unstructured APS be designed to give participants autonomy, but also ensure that they perform certain actions, perform desired behavior and acquire intended knowledge? And how can autonomy and exploration be facilitated in structured APS? It is interesting for future research to investigate the characteristics of successful structured and unstructured APS, to better understand how to implement these aspects. This is highly related to the paradox of open world games in the digital gaming field.

\section{Leveled and Layered Interactivity and Content}

Experts emphasize that layered and leveled interactivity and content is important for prolonged and recurrent participation. Including these aspects into an APS design can support feelings of curiosity and challenge, both motivators for the willingness to play longer, or again (Tieben, 2015). Many current APS however have quite shallow game designs. How to incorporate this and to what extent is a topic for further research.

\section{Positive Ending (and Memory) of Play}

Ending play and how to facilitate a positive ending to play is a still under-researched topic. Most research and design projects focus on how to achieve participation and what happens during participation and how to design for this. But generally, HCI design and research, tends to overlook that there's also something that happens when someone is done participating. Something that could possibly even be a key aspect influencing a remembered experience (Fredrickson, 2000; Kahneman, 2011; Kane, 2018; Mast et al., 2020), and therefore evoking a positive attitude toward participation and replay in future encounters with the same or similar systems. This is something that is valuable for HCI researchers and practitioners to focus on in future research.

\section{Applicability to Other Fields}

We suspect that the Participant Journey Model is also applicable to other types of human computer interaction such as game development, human-robot interaction, and e-health/m-health. We see many opportunities to explore in future research what the similarities and differences are between participant journeys for various interfaces. Because it takes into account the pre-experience and ending of an experience, the PJM can provide interesting perspectives for exploring participant journeys in other contexts.

\section{CONCLUSION}

In this article we presented the Participant Journey Map (PJM). The PJM illustrates the journey a potential participant takes when encountering an augmented play space, and the factors that influence their decisions during this journey.

The PJM was developed following multiple iterations. Based on related work, and insights gained from previously developed and implemented APS, a first concept of the PJM was developed. Following, interviews with 6 experts with extensive experience with developing and implementing APS were conducted. The first part of these interviews focused on influential (design) factors for engaging people into APS. In the second part, experts were asked to provide feedback on the first concept of the PJM. Based on the insights from the expert interviews, the Participant Journey Map was adjusted and refined.

The Participant Journey Map provides insight into people's engagement with interactive augmented play spaces and the influential factors facilitating their journey. It consists of four layers: Phases, States, Transitions and Influential Factors. There are two overarching phases: Onboarding and Participation and 6 states a (potential) participant goes through when engaging with an APS: Transit, Awareness, Interest, Intention, Participation, Finishing. When passers-by go through the process to engage with an APS, they transition between states. Transitions are affected by influential factors.

The PJM contributes to previous work by providing a detailed overview of a participant journey and the factors that influence motivation to engage with APS.

Notable additions to previous research are (1) a detailed insight into factors that influence decision making of people encountering an APS and (2) providing a structured overview of the phases and states a potential participant goes through on their participation journey. In particular the introduction 
of the states 'Awareness,' 'Intention' and 'Finishing' and the non-linear approach are novel compared to other models. Especially 'Awareness' and 'Finishing' will support taking into account these often overlooked, key moments in APS research and design projects.

Our work provides a basis for future research, contributing to a better understanding of designing Augmented Play Spaces and the implementation of playful interaction in (semi-)public spaces. At the same time the Journey map gives directions for design and implementations of APS.

\section{DATA AVAILABILITY STATEMENT}

The datasets presented in this article are not readily available because, they contains information that can be traced back to individuals. Requests to access the datasets should be directed to “d.mast@hhs.nl”.

\section{ETHICS STATEMENT}

Ethical review and approval was not required for the study on human participants in accordance with the local legislation and institutional requirements. Written informed consent was not

\section{REFERENCES}

Akpan, I., Marshall, P., Bird, J., and Harrison, D. (2013). "Exploring the effects of space and place on engagement with an interactive installation," in Conference on Human Factors in Computing Systems-Proceedings, New York, NY: ACM Press, 2213-2222. doi:10.1145/2470654.2481306

Awareness Meaning Cambridge English Dict. (2021). Available at: https://dictionary. cambridge.org/dictionary/english/awareness (Accessed February 24, 2021).

Bekker, T., De Valk, L., and Eggen, B. (2014). A toolkit for designing playful interactions: The four lenses of play. J. Ambient Intell. Smart Environ. 6, 263-276. doi:10.3233/AIS-140259

Bekker, T., Sturm, J., and Eggen, B. (2010). Designing playful interactions for social interaction and physical play. Pers Ubiquit Comput 14, 385-396. doi:10.1007/ s00779-009-0264-1

Board - definition and meaning Collins English Dict. (2021). Available at: https:// www.collinsdictionary.com/dictionary/english/board (Accessed March 26, 2021).

Bos, M (2018). Spelen is bloedserieus, als je naar de gezichten in "De Spelende Mens" kijkt| Trouw. Available at: https://www.trouw.nl/nieuws/spelen-is-bloedserieus-als-je-naarde-gezichten-in-de-spelende-mens-kijkt b5a398cd/ (Accessed December 14, 2020).

Brignull, H., and Rogers, Y. (2003). Enticing People to Interact with Large Public Displays in Public Spaces. Interact 14, 17-24. doi:10.1145/2757710.2776803

Brok, J. (2010). De onzichtbare openbare ruimte: exploratief onderzoek naar de ontwikkeling van het beleidsdomein openbare ruimte. London: Markdal.

Capulong Reyes, R. (2016). Public Space as Contested Space: The Battle over the Use, Meaning and Function of Public Space. Ijssh 6, 201-207. doi:10.7763/ IJSSH.2016.V6.643

Cheung, V. (2014). "Improving interaction discoverability in large public interactive displays," in ITS 2014-Proceedings of the 2014 ACM International Conference on Interactive Tabletops and Surfaces, New York, NY: Association for Computing Machinery, Inc, 467-472. doi:10.1145/2669485.2669489

Companje, R., Van Dijk, N., Hogenbirk, H., and Mast, D. (2006). Globe4D, Proceedings of the 14th annual ACM international conference on Multimedia-MULTIMEDIA’06, New York, NY: ACM, 959-960. doi:10. $1145 / 1180639.1180850$ provided because participants provided recorded verbal consent to participate in this study and to their data being used.

\section{AUTHOR CONTRIBUTIONS}

DM was the principal investigator for this study and responsible for the study design, conducting the review of related work and previous design projects, conducting and analyzing the expert interviews and designing the Participant Journey Model. JB, SV and FV supervised and supported all research activities and contributed to the manuscript revisions. All authors reviewed and approved the final manuscript.

\section{FUNDING}

This Ph.D. research is funded by the Dutch Research Council (NWO) doctoral Grant for teachers (023.013.062).

\section{ACKNOWLEDGMENTS}

We would like to thank the experts for volunteering their time to participate in the interviews.

Companje, R., Van Dijk, N., Hogenbirk, H., and Mast, D. (2007). "Globe4D, timetraveling with an interactive four-dimensional globees," in SIGGRAPH '07: ACM SIGGRAPH 2007 emerging technologies, New York, NY: ACM, 26.

Cooper-Wright, M. (2015). The Importance of How and Why in a Design Research Interview. Medium. Available at: https://medium.com/design-research-methods/ the-importance-of-how-and-why-4560bf7ae488 (Accessed June 3, 2020).

Csikszentmihaly, M. (1990). Flow: The Psychology of Optimal Experience. London: Harper \& Row.

Dalsgaard, P., Dindler, C., and Halskov, K. (2011). Understanding the dynamics of engaging interaction in public spaces. Lect. Notes Comput. Sci. 6947, 212-229. doi:10.1007/978-3-642-23771-3_17

Dalsgaard, P., and Halskov, K. (2010). Designing urban media façades. Conf. Hum. Factors Comput. Syst. Proc. 4, 2277-2286. doi:10.1145/1753326.1753670

Dalton, S. N., Marshall, P., and Dalton, R. C. (2010). "Measuring environments for public displays," in Conference on Human Factors in Computing Systems-Proceedings, New York, NY: ACM, 3841-3846. doi:10.1145/ 1753846.1754066

Dawson, C. S. (2019). 'Olafur Eliasson: In Real Life' Review: A Shallow Experience. Medium. Available at: https://medium.com/c.shepdaw/olafur-eliasson-in-reallife-review-a-shallow-experience-ba0435bac4la (Accessed April 12, 2021).

De Kort, Y. A. W., and Ijsselsteijn, W. A. (2008). People, places, and play. Comput. Entertain. 6, 1-11. doi:10.1145/1371216.1371221

de Valk, L., Bekker, T., and Eggen, B. (2015). Designing for social interaction in open-ended play environments. Int. J. Des. 9, 107-120. doi:10.4108/icst. intetain.2015.259742

Else, P. (2009). The value of play. Dallas, TX: Continuum.

Finke, M., Tang, A., Leung, R., and Blackstock, M. (2008). "Lessons learned," in DIMEA, Proceedings-3rd International Conference on Digital Interactive Media in Entertainment and Arts, New York, NY. ACM Press, 26-33. doi:10.1145/1413634.1413644

Fischer, P. T., and Hornecker, E. (2012). "Urban HCI," in Conf. Hum. Factors Comput. Syst.-Proc., New York, NY: ACM Press, 307-316. doi:10.1145/ 2207676.2207719

Følstad, A., and Kvale, K. (2018). Customer journeys: a systematic literature review. Jstp 28, 196-227. doi:10.1108/JSTP-11-2014-0261 
Fredrickson, B. L. (2000). Extracting meaning from past affective experiences: The importance of peaks, ends, and specific emotions. Cognit. Emotion 14, 577-606. doi:10.1080/026999300402808

Gajadhar, B., de Kort, Y., and IJsselsteijn, W. (2008). "Influence of social setting on player experience of digital games," in Proceeding of the twenty-sixth annual CHI conference extended abstracts on Human factors in computing systems-CHI'08, New York, New York. ACM Press, 3099. doi:10.1145/ 1358628.1358814

Garvey, C. (1990). in Play. Editor B. Lloyd (Cambridge: Harvard University Press). doi:10.2514/6.1990-3679

Germany, J. O., Speranza, P., and Anthony, D. (2019). Eliciting Public Display Awareness and Engagement: An Experimental Study and Semantic Strategy. Int. J. Human-Computer Interact. 35, 1975-1985. doi:10.1080/10447318.2019.1597572

Gibbons, S (2018). "Journey Mapping 101. Nielsen Norman Gr," Available at: https:// www.nngroup.com/articles/journey-mapping-101/ (Accessed December 3, 2020).

Gómez-Maureira, M. A. (2014). Illuminating Shadows: Introducing Shadow Interaction in Spatial Augmented Reality. ChiSparks 11, 33. doi:10.1109/ ismar-adjunct.2016.0062

Harrouk, C. (2020). Public Spaces: Places of Protest, Expression and Social Engagement | ArchDaily. ArchDaily. Available at: https://www.archdaily.com/941408/public-spacesplaces-of-protest-expression-and-social-engagement (Accessed December 14, 2020).

Hashagen, A., Büching, C., and Schelhowe, H. (2009). "Learning Abstract Concepts through Bodily Engagement: A Comparative, Qualitative Study," in Proceedings of the 8th International Conference on Interaction Design and Children-IDC '09, New York, NY. ACM Press. doi:10.1145/1551788.1551839

Hespanhol, L., and Tomitsch, M. (2015). Strategies for intuitive interaction in public urban spaces. Interact. Comput. 27, 311-326. doi:10.1093/iwc/iwu051

Howard, T. (2014). Journey Mapping: A Brief Overview. Available at: http://www. adaptivepath.com/ideas/theanatomyofan (Accessed December 3, 2020).

Huizinga, J. (2008). Homo ludens: Proeve eener bepaling van het spel-element der cultuur. tweede her. Amsterdam: H. D. Tjeenk Willink \& Zoon N.V. - Haarlem. doi:10.5117/9789089640031

IDEO (2020). Design Kit. Available at: https://www.designkit.org/methods/43 (Accessed December 16, 2020).

Isbister, K. (2010). Enabling Social Play: A Framework for Design and Evaluation. Evaluating User Experience in Games. London: Springer, 11-22. doi:10.1007/ 978-1-84882-963-3_2

Kahneman, D. (2011). Thinking, fast and slow. New York, NY: Farrar, Straus and Giroux.

Kane, L. (2018). The Peak-End Rule: How Impressions Become Memories. Nielsen Norman Gr. Available at: https://www.nngroup.com/articles/peak-end-rule/ (Accessed December 18, 2019).

Kultima, A., and Stenros, J. (2010). "Designing games for everyone," Future Play 2010: Research, Play. Share-International Academic Conference on the Future of Game Design and Technology, 66-73. doi:10.1145/1920778. 1920788

Leong, J., Perteneder, F., Jetter, H.-C., and Haller, M. (2017). What a Life!. TEI 2017-Proceedings of the 11th International Conference on Tangible, Embedded, and Embodied Interaction, Yokohama. Association for Computing Machinery, Inc., 57-66. doi:10.1145/3024969.3024985

Lindley, S. E., Le Couteur, J., and Berthouze, N. L. (2008). Stirring up experience through movement in game play. Conf. Hum. Factors Comput. Syst. Proc. 7, 511-514. doi:10.1145/1357054.1357136

Magerkurth, C., Cheok, A. D., Mandryk, R. L., and Nilsen, T. (2005). Pervasive games. Comput. Entertain. 3, 4. doi:10.1145/1077246.1077257

Marner, M. R., Smith, R. T., Porter, S. R., Broecker, M. M., Close, B., and Thomas, B. H. (2011). Large Scale Spatial Augmented Reality for Design and Prototyping. in Handbook of Augmented Reality. New York: Springer, 231-254. doi:10.1007/978-1-4614-0064-6_10

Marquardt, N. (2013). Proxemic interactions with and around digital surfaces. ITS 2013-Proceedings of the 2013 ACM International Conference on Interactive.New York, NY: Tabletops and Surfaces, 493-494. doi:10.1145/2512349.2512354

Segura, E. M., and Isbister, K. (2015). Enabling Co-Located Physical Social Play: A Framework for Design and Evaluationin Game User Experience Evaluation. Berlin: Springer, 209-238. doi:10.1007/978-3-319-15985-0_10

Márquez Segura, E., Waern, A., Moen, J., and Johansson, C. (2013). The design space of body games. Conf. Hum. Factors Comput. Syst. Proc. 15, 3365-3374. doi:10.1145/2470654.2466461
Mast, D. (2019). "Social interaction in spatial augmented exertion interfaces," in CHI PLAY 2019-Extended Abstracts of the Annual Symposium on Computer-Human Interaction in Play. London: Association for Computing Machinery, Inc., 29-34. doi:10.1145/3341215.3356331

Mast, D., Bosman, M., Schipper, S., and De Vries, S. (2017a). "BalanSAR," in TEI 2017-Proceedings of the 11th International Conference on Tangible, Embedded, and Embodied Interaction. London: Association for Computing Machinery, Inc., 625-631. doi:10.1145/3024969.3025085

Mast, D., Bosman, M., Schipper, S., Diederiks, S., and de Vries, S. (2017b). “Adding Interactivity to BalanSARACM," in Extended Abstracts Publication of the Annual Symposium on Computer-Human Interaction in Play. New York, NY, USA: ACM, 383-389. doi:10.1145/3130859.3131327

Mast, D., de Krom, J., and de Vries, S. (2015). Exploring the Application of Interactive Video Projection in Physical Education. Proceedings of the Ninth International Conference on Tangible, Embedded, and Embodied Interaction. New York, NY, USA: ACM, 551-555. doi:10.1145/2677199.2687901

Mast, D., and de Vries, S. (2017). "Cooperative tetris: The influence of social exertion gaming on game experience and social presence," in Lecture Notes of the Institute for Computer Sciences, Social-Informatics and Telecommunications Engineering, LNICST. Berlin: Springer Verlag, 115-123. doi:10.1007/978-3-319-49616-0_11

Mast, D., Vries, D., Broekens, J., Verbeek, F., Vries, S. D, Broekens, J., et al. (2020). The importance of the peak-end rule for repeated visits to Augmented Play Spaces Persuasive 2020 Adjunct Proceedings (Aalborg, Denmark). Available at: http://ceurws.org/Vol-2629/8_poster_mast.pdf (Accessed December 14, 2020).

McArthur, J. A (2016). Digital proxemics : how technology shapes the ways we move. Available at: https://dl.acm.org/doi/abs/10.5555/3027590 (Accessed April 8, 2021). doi:10.3726/978-1-4539-1724-4

Memarovic, N., Gehring, S., Fischer, P. T., Fischer, T., and Fischer, P. T. (2015). ELSI Model: Bridging User Engagement around Interactive Public Displays and Media Facades in Urban Spaces. J. Urban Technol. 22, 113-131. doi:10.1080/ 10630732.2014.942169

Memarovic, N., Langheinrich, M., Alt, F., Elhart, I., Hosio, S., and Rubegni, E. (2012). "Using public displays to stimulate passive engagement, active engagement, and discovery in public spaces," in Proceedings of the 4th Media Architecture Biennale Conference on Participation-MAB'12. New York, NY: ACM Press, 55-64. doi:10.1145/2421076.2421086

Merriam-Webster Onboarding (2021). Definition. Available at: https://www. merriam-webster.com/dictionary/onboarding (Accessed March 26, 2021a).

Merriam-Webster Transit (2020). Definition. Merriam-Webster. Available at: https:// www.merriam-webster.com/dictionary/transit (Accessed August 4, 2020b).

Michelis, D., and Müller, J. (2011). The Audience Funnel: Observations of Gesture Based Interaction With Multiple Large Displays in a City Center. Int. J. Human-Computer Interact. 27, 562-579. doi:10.1080/10447318. 2011.555299

Milgram, P., and Kishino, F. (1994). A Taxonomy of Mixed Reality Visual Displays Using Stereoscopic Video for Defence Teleoperation, IEICE Trans. Inf. Syst. 77. Available at: http://vered.rose.utoronto.ca/people/paul_dir/IEICE94/ieice.html (Accessed April 11, 2021), 1321-1329.

Moreno, A., van Delden, R., Reidsma, D., Poppe, R., and Heylen, D. (2012). An annotation scheme for social interaction in digital playgrounds. in Lecture Notes in Computer Science (including subseries Lecture Notes in Artificial Intelligence and Lecture Notes in Bioinformatics) (Springer), 85-99. doi:10. 1007/978-3-642-33542-6_8

Mueller, F., and Isbister, K. (2014). "Movement-based game guidelines," in Conference on Human Factors in Computing Systems-Proceedings. New York, NY, USA: Association for Computing Machinery), 2191-2200. doi:10. 1145/2556288.2557163

Mueller, F., Stellmach, S., Greenberg, S., Dippon, A., Boll, S., Garner, J., et al. (2014). "Proxemics play," in Proceedings of the Conference on Designing Interactive Systems: Processes, Practices, Methods, and Techniques. London: DIS (Association for Computing Machinery), 533-542. doi:10.1145/2598510.2598532

Mueller, F. F., Gibbs, M. R., Vetere, F., and Edge, D. (2017). Designing for bodily interplay in social exertion games. ACM Trans. Comput.-Hum. Interact. 24, 1-41. doi:10.1145/3064938

Müller, J., Alt, F., Michelis, D., and Schmidt, A. (2010). "Requirements and Design Space for Interactive Public Displays," in MM'10-Proceedings of the ACM Multimedia 2010 International Conference. New York, NY: ACM, 1285-1294. doi:10.1145/1873951.1874203 
O’Toole, M., Ratcliff, A., Charnas, I., and Witte, A. (2020). About the Waterfall Swing-Waterfall Swing. Available at: https://www.waterfallswing.com/about (Accessed April 12, 2021).

Ojala, T., et al. (2012). Multipurpose Interactive Public Displays in the Wild: Three Years Later. Computer 45 (5), 42-49.

Onboarding (2020). Definition Cambridge English Dict. Available at: https://ictionary. cambridge.org/dictionary/english/onboarding (Accessed March 26, 2021).

Parés, N., Durany, J., Carreras, A., and Carreras, A. (2005). "Massive flux design for an interactive water installation," in ACE '05: Proceedings of the 2005 ACM SIGCHI International Conference on Advances in computer entertainment technology, New York: NY: ACM, 266-269. doi:10.1145/1178477.1178523

Parker, C. (2018). Augmenting Space: Design approaches for making public interactive displays relevant in hyperconnected societies. Available at: https://ses.library.usyd.edu. au/handle/2123/18993. doi:10.1145/3205873.3205889

Parker, C., and Tomitsch, M. (2017). Bridging the interaction gulf. ACM Int. Conf. Proceeding Ser. 14, 482-486. doi:10.1145/3152771.3156162

Parra, G., De Croon, R., Klerkx, J., and Duval, E. (2014). "Quantifying the interaction stages of a public display campaign in the wildFun, Fast, Foundational," in Proceedings of the NordiCHI 2014: The 8th Nordic Conference on Human-Computer Interaction, New York: NY: ACM, 757-760. doi:10.1145/2639189.2639216

Parten, M. B. (1933). Social play among preschool children. J. Abnormal Soc. Psychol. 28, 136-147. doi:10.1037/h0073939

Peltonen, P., Kurvinen, E., Salovaara, A., Jacucci, G., Ilmonen, T., and Evans, J. (2008). "It's Mine, Don't Touch!," in Conference on Human Factors in Computing Systems-Proceedings, New York: NY: ACM, 1285-1294. doi:10.1145/1357054.1357255

Petersen, F. W., Thomsen, L. E., Mirza-Babaei, P., and Drachen, A. (2017). "Evaluating the Onboarding Phase of Free-toPlay Mobile Games," in CHI PLAY 2017-Proceedings of the Annual Symposium on Computer-Human Interaction in Play, New York: NY: ACM, 377-388. doi:10.1145/3116595.3125499

Play activity - Wikipedia Wikipedia (1990). Available at: https://en.wikipedia.org/ wiki/Play (Accessed April 20, 2021).

Polaine, A. (2010). Developing a Language of Interactivity Through the Theory of Play. Thesis (PhD). Available at: http://hdl.handle.net/10453/20225 (Accessed July 10, 2020).

Reeves, S. (2011). A Framework for Designing Interfaces in Public Settings. Des. Interfaces Public Settings 33, 141-175. doi:10.1007/978-0-85729-265-0_8

Reeves, S., Benford, S., O’Malley, C., and Fraser, M. (2005). "Designing the spectator experience CHI 2005: Technology, Safety, Community," in Conference Proceedings-Conference on Human Factors in Computing Systems. New York, NY: Association for Computing Machinery, 741-750. doi:10.1145/1054972.1055074

Review Piano Stairs - Beyond Social. (2020). Available at: https://beyond-social. org/wiki/index.php/Review_Piano_Stairs (Accessed December 20, 2020).

Robbins, H., and Isbister, K. (2014). "Pixel Motion: A Surveillance CameraEnabled Public Digital Game," in Proceedings of Foundations of Digital Games. New York, NY: Association for Computing Machinery.

Rogers, Y., and Rodden, T. (2003). "Configuring Spaces and Surfaces to Support Collaborative Interactions." in Public and Situated Displays. Dordrecht: Springer, 45-79. doi:10.1007/978-94-017-2813-3_3

Rubin, K. H. (2001). The Play Observation Scale (POS). Dordrecht: Springer.

Salen, K., and Zimmerman, E. (2003). Rules of Play: Game Design Fundamentals. Cambridge: MIT Press.

Santos, C. P. (2019). Understanding People through Games. Available at: https:// pure.tue.nl/ws/portalfiles/portal/127357625/20190624_Pereira_Santos.pdf.

Schraffenberger, H. K. (2018). Arguably augmented reality: relationships between the virtual and the real. Available at: https://hdl.handle.net/1887/67292

Schraffenberger, H., and Van Der Heide, E. (2014). "The real in augmented reality," in Proceedings of the Second Conference on Computation, Communication. London: Aesthetics and $\mathrm{X}, \mathrm{xCoAx}$.

Sicart, M. (2014). Play Matters. MIT Press. doi:10.7551/mitpress/10042.001.0001

Snibbe, S. S., and Raffle, H. S. (2009). "Social immersive media," in Conference on Human Factors in Computing Systems-Proceedings. New York, NY: ACM Press, 1447-1456. doi:10.1145/1518701.1518920

Springlab Bewegend leren op de Springlab Beweegvloer voor kleuters en peuters (2020). Available at: https://springlab.nl/ (Accessed December 20, 2020).

Stavrides, S. (2016). Common Space: The City as Commons. London: Zed Books. doi:10.5040/9781350219267
Sturm, J., Bekker, T., Groenendaal, B., Wesselink, R., and Eggen, B. (2008). "Key issues for the successful design of an intelligent, interactive playground," in Proceedings of the 7th international conference on Interaction design and children-IDC '08. New York, NY: ACM Press, 258. doi:10.1145/1463689. 1463764

Suits, B (2014). The Grasshopper-: Games, Life and Utopia. Cambridge: Broadview Press. Sutton-Smith, B. (2009). The ambiguity of play. Cambridge: Harvard University Press.

Tieben, R. (2015). Activating Play-A design research study on how to elicit playful interaction from teenagers. Available at: https://research.tue.nl/files/3857195/ 798382.pdf

Tieben, R., Bekker, T., and Schouten, B. (2011). "Curiosity and interaction: Making people curious through interactive systems," in Proceedings of HCI 2011-25th BCS Conference on Human Computer Interaction, New York, NY: ACM Press, 361-370. doi:10.14236/ewic/hci2011.66

Tieben, R., Sturm, J. A., Bekker, M. M., and Schouten, B. A. M. (2013). Eliciting Recurring Curiosity Through Playful Interactions. Berlin: Springer.

UNESCO Inclusion Through Access to Public Space (2021). United Nations Educ. Sci. Cult. Organ. Available at: http://www.unesco.org/new/en/social-andhuman-sciences/themes/urban-development/migrants-inclusion-in-cities/ good-practices/inclusion-through-access-to-public-space/ (Accessed February 9, 2021).

V2 Lab for the Unstable Media. (2008). Media Technology MSc exhibition-six years of creative research. Available at: https://v2.nl/events/media-technologymsc-exhibition (Accessed March 26, 2021).

Valk, L. D., Rijnbout, P., Bekker, T., Eggen, B., Graaf, M. D., and Schouten, B. (2012). "Designing for playful experiences in open-ended intelligent play environments," in Proceedings of the IADIS International Conference Game and Entertainment Technologies. New York, NY: ACM Press, 3-10.

van Delden, R. (2012). "Towards a socially adaptive digital playground," in ACM International Conference Proceeding Series. New York, NY: ACM Press, 355-358. doi:10.1145/2307096.2307166

van Delden, R., Gerritsen, S., Heylen, D., and Reidsma, D. (2018). Colocated augmented play-spaces: past, present, and perspectives. J. Multimodal User Interfaces 12, 225-255. doi:10.1007/s12193-0180269-z

van Delden, R., Moreno, A., Poppe, R., Reidsma, D., and Heylen, D. (2017). “A Thing of Beauty," in Conference on Human Factors in Computing Systems-Proceedings. London: Association for Computing Machinery, 2462-2472. doi:10.1145/3025453.3025816

Vasagar, J. (2012). Privately owned public space: where are they and who owns them? |News|The Guardian. Guard. Available at: https://www.theguardian. com/news/datablog/2012/jun/11/privately-owned-public-space-map (Accessed November 20, 2020).

Vogel, D., and Balakrishnan, R. (2004). "Interactive public ambient displays," in Proceedings of the 17th annual ACM symposium on User interface software and technology-UIST '04, New York, NY: ACM Press. doi:10.1145/1029632. 1029656

Wouters, N., Downs, J., Harrop, M., Cox, T., Oliveira, E., and Webber, S. (2016). "Uncovering the Honeypot Effect," in DIS 2016-Proc. 2016 ACM Conf. Des. Interact. Syst. Fuse, New York, NY: ACM Press. 5-16. doi:10.1145/2901790. 2901796

Conflict of Interest: The authors declare that the research was conducted in the absence of any commercial or financial relationships that could be construed as a potential conflict of interest.

Copyright $\odot 2021$ Mast, de Vries, Broekens and Verbeek. This is an open-access article distributed under the terms of the Creative Commons Attribution License (CC $B Y)$. The use, distribution or reproduction in other forums is permitted, provided the original author(s) and the copyright owner(s) are credited and that the original publication in this journal is cited, in accordance with accepted academic practice. No use, distribution or reproduction is permitted which does not comply with these terms. 


\title{
Catch the Bus: Probing Other-Than-Human Perspectives in Design Research
}

\author{
Viktor Bedö* \\ Critical Media Lab, Institute for Experimental Design and Media Cultures, Academy for Arts and Design, University of Applied \\ Sciences North-West Switzerland, Basel, Switzerland
}

Prompted by Catch the Bus, an experimental street game design project with and for autonomous buses, this study explores strategies to substantiate the speculation about other-than-human perspectives. It builds on philosophical arguments about the role of species similarity in grasping nonhuman experience and applies these arguments to thing perspectives. Gameplay and props from Catch the Bus instantiate a kind of similarity between human players and autonomous buses that emerges through the adoption of certain choreographies and sensing capabilities. The study contributes theoretical arguments to the debate of other-than-human perspectives in more-than-human design.

Keywords: street game design, thing perspective, species similarity, autonomous buses, embodiment, more-thanhuman design

\section{OPEN ACCESS}

Edited by:

Mattia Thibault,

Tampere University, Finland

Reviewed by:

Charlotte Magnusson,

Lund University, Sweden

Anton Nijholt,

University of Twente, Netherlands

${ }^{*}$ Correspondence:

Viktor Bedö

viktor.bedoe@fhnw.ch

Specialty section: This article was submitted to Human-Media Interaction, a section of the journal

Frontiers in Computer Science

Received: 30 November 2020 Accepted: 14 June 2021 Published: 12 July 2021

Citation:

Bedö V (2021) Catch the Bus: Probing Other-Than-Human Perspectives in

Design Research.

Front. Comput. Sci. 3:636107. doi: $10.3389 /$ fcomp.2021.636107

\section{INTRODUCTION}

What design research can gain from grasping other-than-human or alien perspectives is the ability to expand the range of beings and things that humans can engage with responsibly. Adopting alien or unfamiliar perspectives often demands a kind of probing. Space probes are sent out into unchartered territories to collect data samples from places no humans can reach. "Cultural probes" in social or design research provide designers with insight into other peoples' hopes and fears (Boehner et al., 2012). Probing takes up the challenge of adopting a vantage point other than one's own and thus engages with situations and places where the bodily or cultural presence of the researcher or designer is challenging or impossible. The challenge of exploring perspectives that emerge from experiences, interactions, and entanglements that are different from the designer's experiences is not new. When probing other-than-human perspectives, however, this endeavor is extended to beings or things that have ascribed the agency to engage with the world based on their material specificity and specific locale, but not primarily based on discursive, cultural, or cognitive terms. Imagining what the world is like for nonhumans-for example, autonomous buses-thus involves a fair amount of fiction or speculation.

Depending on the desired epistemic outcome of design exploration, the design researcher may attempt to substantiate speculation with something that is grounded in experience. Gameplay or playful enactment can seamlessly overlay everyday life with fiction and thus is a fertile ground for balancing everyday experiences with speculation. Street games in particular are embedded in specific urban contexts so that the mechanisms of the city and the rules, props, and fiction of the games merge to form a coherent experience in gameplay, rendering them in situ laboratories for alternative or future imagination of the city (Bedö 2019). The street game designer balances the amount of fiction or imagination that is injected into the experience of a site during gameplay with real-life variables, such as pedestrian flows, technology use, or traffic. Thus, gameplay can be used as a strategy to have 
players adopt alien perspectives by placing them at alien sites, equipping them with alien capacities, and framing alien entanglements with other beings and things.

Expanding on Catch the Bus, an experimental street game design project, this study investigates the potential strategies and limitations of adopting the perspective of an autonomous bus. ${ }^{1}$ The creative process of the Catch the Bus project resulted in a design artifact and playful interactions which triggered this study's reflections on nonhuman perspectives. The ambition to engage with an other-than-human perspective through playfully enacting an autonomous bus was implicitly present throughout the design process. Grasping the perspective of another being or a thing foregrounds more fundamental epistemological dimensions of design research. This study attempts to make modes of engagement with nonhuman perspectives explicit by relating arguments from ontology, philosophy of the mind, and nonhuman turn debates to the street game design project. The argument develops based on an interpretation of perspective that emphasizes a being's or thing's material/bodily and sensory constitution and unique position from which entanglements with other things emerge. The study explores the role of similarities in bodily and material constitution, size, shape, and sensing capability as central aspects in substantiating the adoption of alien perspectives. With this, the study contributes to the theoretical backdrop for explorative methodologies of designing for humans and autonomous things.

\section{CATCH THE BUS PROJECT}

The following section briefly introduces the Catch the Bus project's context, the design process, and some of the games that emerged from it. The project took place in the private road network of the Charité Hospital campus in Berlin Mitte where the Berlin public transport company (Berliner Verkehrsbetriebe, BVG) operates one of its prototype autonomous bus services. The buses are stage $3+$ autonomous vehicles which means that they autonomously follow a preprogrammed route and carry passengers, but they still require monitoring and occasional interventions by a human operator who is present on the bus at all times. The tasks of the operators-who in this case were former BVG bus drivers-include releasing the emergency brake when necessary and manually maneuvering via a portable control panel around parked cars that obstruct the path of the bus. Our contacts from the BVG supported our explorations and design process by granting us access to the buses both within and outside of regular operational times and introduced us some aspects of the technology which are not accessible to the wider public.

\footnotetext{
${ }^{1}$ Catch the Bus is a 2019 project with and for autonomous buses by Simon Johnson (Cofounder of Free Ice Cream: http://freeicecream.co.uk) and myself (Tacit Dimension: http://tacitdimension.com and Critical Media Lab Basel: https:// criticalmedialab.ch), commissioned by the Fiction Forum in Berlin. Fiction Forum is a 2019 initiative of the German Federal Ministry for Economic Affairs and Energy with the mission to make visible creative industries' economic, societal, and innovative impact.
}

Project duration was 10 days, including an exploration phase, game design, a public playtesting session, a public game release session, and a panel discussion about mobility. In the first two days of the project, we undertook exploratory design research which included familiarizing ourselves with the BVG pilot project and the operation of the autonomous buses during a guided tour, by interacting with the bus itself. We investigated the behavior of the bus by triggering emergency brakes in different ways (we later promised the BVG not to include jumping in front of the bus as a game mechanic) and overtook the bus on foot and on bikes to explore what makes it slow down or stop. We observed how pedestrians who were too close to the curb slowed down the bus or brought it to a halt, which happened regularly at narrow sidewalks. We spoke to the bus operators about their tasks and responsibilities, learning that, as an act of courtesy, they sometimes switch to manual mode when approaching an intersection to signal to an approaching car that they will give way. Finally, we talked to passengers to learn about their level of trust in the autonomous buses.

After the exploration, we created game prototypes which we tested in a public playtest. The playtest session took place on the fifth day of the project with testers from Fiction Forum and the Berlin street game design community. For the playtest, we arranged four game prototypes in a game tour around the Charité campus. We moderated the session by setting up games, guiding the players through the tour, and introducing the rules of each game. After the playtest session, we iterated the games based on player feedback and our own observations and finalized some of them for the public release event. This took place on the last day of the project with a game tour featuring three games, two of which are outlined below. In addition to the communities who took part in the playtest, the Fiction Forum's stakeholders from the Ministry of German Federal Ministry for Economic Affairs and Energy and BVG joined in for the game release event.

We approached the design process with initial questions about care, sensing capabilities, and world-making of the buses, but we did not hold these directions strongly and allowed the research and design process to be guided by unexpected cues in the field. The aim to mimic the operational principles of an autonomous bus in the game was present very early in the project. To better understand how an autonomous bus engages with the city and traffic, one of the first design commitments in the project planning phase was to build our own autonomous bus comprising low-tech sensing, wet intelligence (players), and muscle-propelled movement. This "toy bus" was realized in the form of a metal frame (in BVG yellow) with the footprint of the real autonomous bus and equipped with proximity sensors (Figure 1).

A prominent feature that the toy bus emulated from the BVG bus was its ability to sense the environment. The BVG bus's key sensing instruments are light detection and ranging (LIDAR) sensors, with 3D sensors to the front and back and 2D sensors on all four corners. The bus essentially follows virtual tracks manually hard-wired into the map software of the bus, so the LIDARs provide sufficient sensing for the bus to slow down or stop if objects such as falling leaves or dense rain obstruct its path 


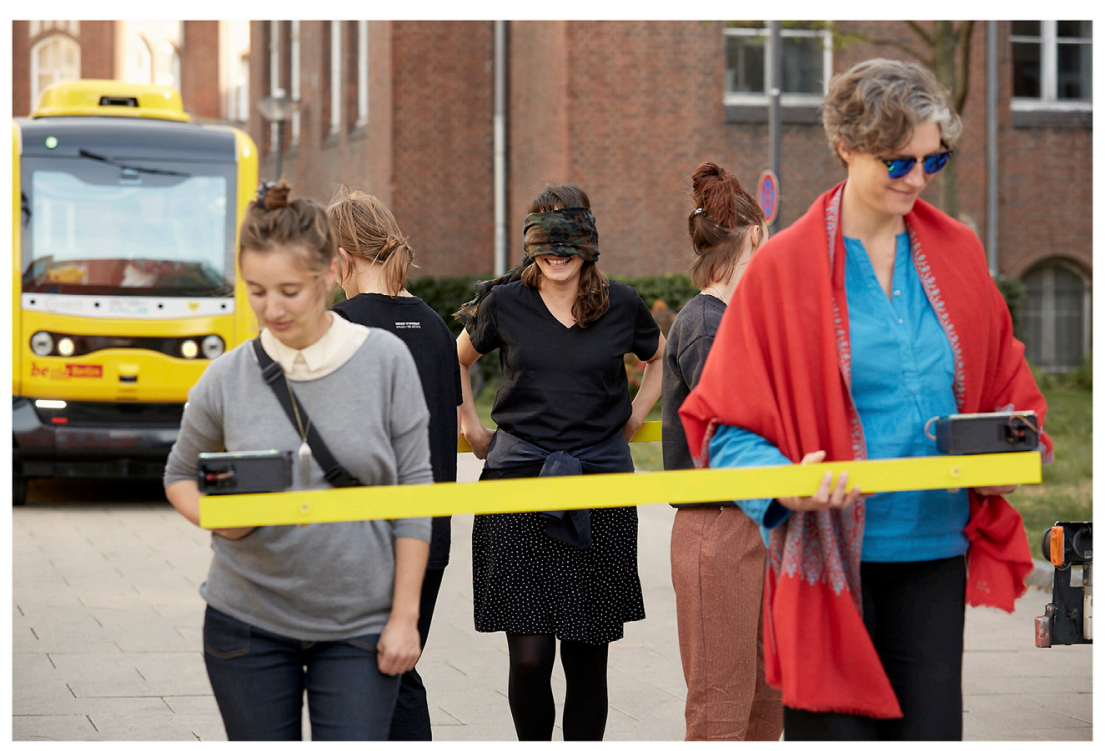

FIGURE 1 | Toy bus with players.

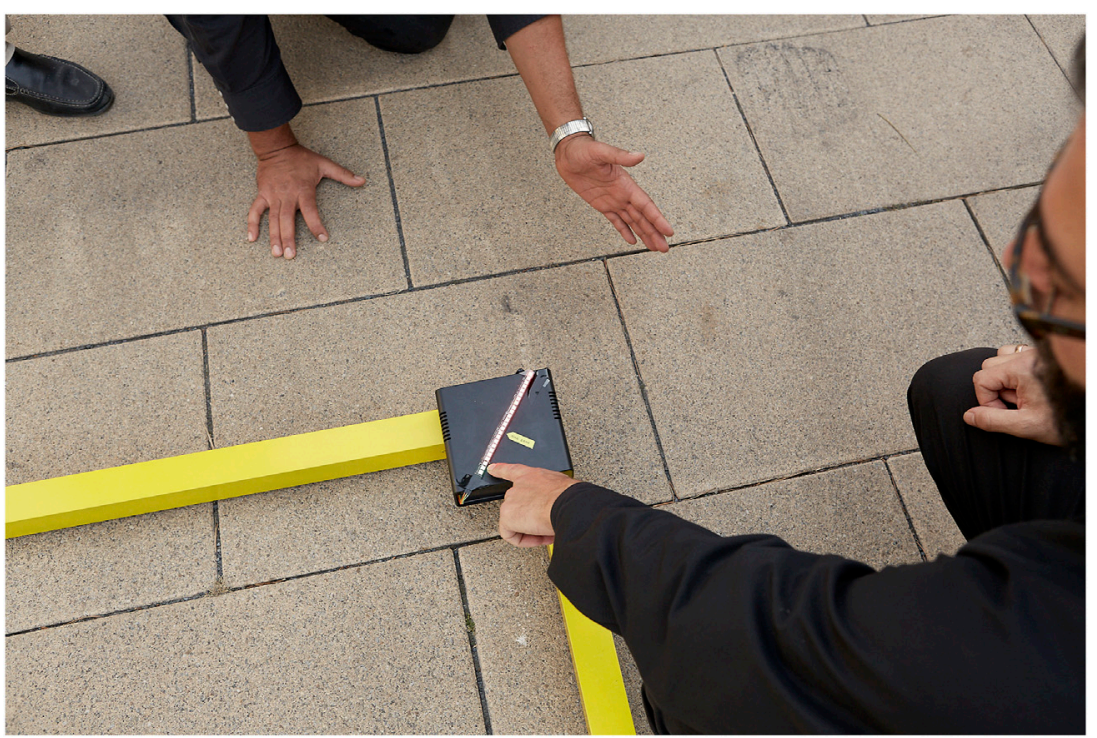

FIGURE 2 | Proximity sensor with display.

or come too close. Although the BVG buses are equipped with cameras, they were not in use and were even covered with duct tape by the time the project took place.

Based on that, we equipped the rectangular metal frame of the toy bus with proximity sensors and set up minimalist LED-based displays in all four corners (Figure 2). The distance sensors were directed outwards at an angle of $135^{\circ}$ from the four corners of the frame and measured the proximity of objects in a range of $0-4 \mathrm{~m}$ (Figure 3). On the housing of the sensors, we mounted LED light strips as simple displays showing the distance to objects around the frame. The lights gradually turned from green to red when something came close to the frame. As well as on this gradual scale, there were two marks, one for "close" when objects were within a $2 \mathrm{~m}$ " range and another for "too close" when objects were within $0.5 \mathrm{~m}$. These settings imitated the behavior of the BVG bus, which slows down if something gets within a range of $1.5 \mathrm{~m}$ and comes to a halt at a range of $0.5 \mathrm{~m}$. The buses turned out to be defensive with an extremely low-risk affinity, an observation that was later clearly confirmed by the BVG as one of the current core design principles.

During gameplay, players stepped inside the frame of the toy bus and carried it by holding it. Four "sensor players" were positioned in each corner of the toy bus at the sensor boxes with the display. A blindfolded "steering algorithm" player held on to 


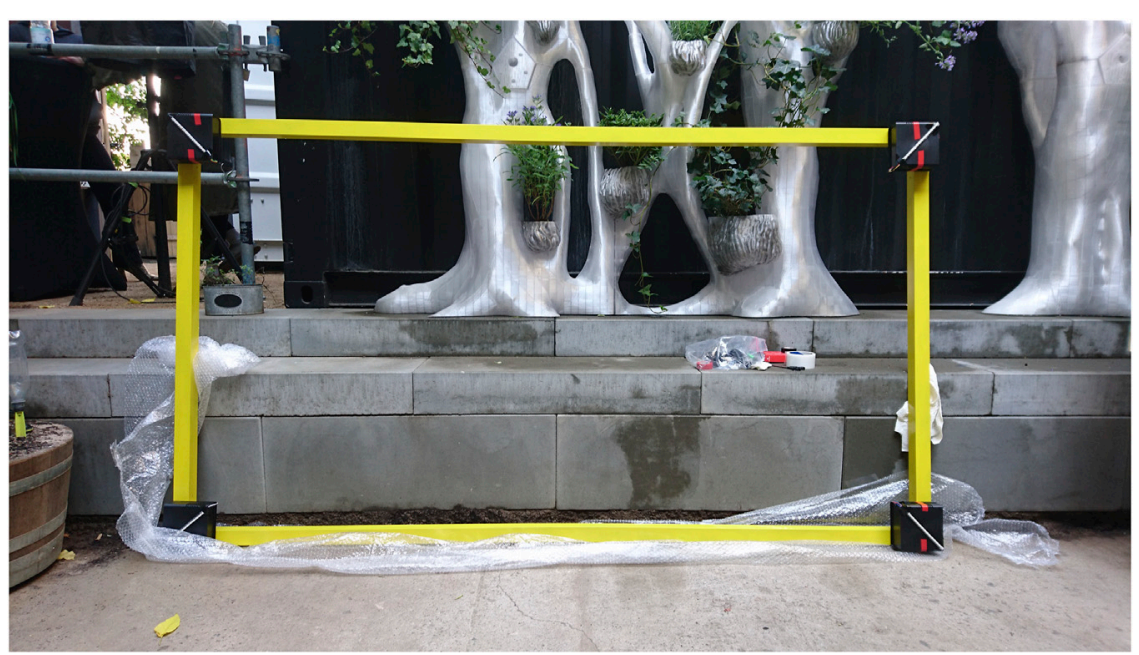

FIGURE 3 | Toy bus.

the back of the toy bus and steered it left or right. The sensor players were responsible for communicating the sensor readings on the display to the steering algorithm player who was navigating. Forwarding the sensor readings to the blindfolded steering algorithm turned out to need a fairly high level of coordination. Only after a learning curve of one or $2 \mathrm{~min}$ did a protocol emerge of calling out sensor readings in a way that the steering algorithm could correctly interpret. Even after establishing this protocol, the toy bus continued to operate with some lag. This lag and the process of establishing and iterating the protocols for coordinating between sensor players, the steering algorithm, and objects in the environment turned out to be the strongest mechanic in the gameplay.

\section{THE GAMES}

In this section, I will introduce two of the games that were played in the final release of Catch the Bus so that the specificities of the game mechanics and the playful interaction between players, game props, and the environment can stand as a heuristic device for the arguments about adopting nonhuman perspectives that follow in Probing Alien Perspectives and Like a Bus.

\section{Invisible Map}

We named this game after a map that remained invisible to some players during gameplay. In the Invisible Map, besides the players operating the toy bus ("sensors" and steering algorithm), we introduced the "environment" player-type. The main mechanic of the game is that the toy bus navigates a path and tries to avoid collisions with the environment, namely, players who embody objects in the environment alongside the path of the bus. The Invisible Map is a cooperative game where the toy bus players and the environment players work together to get the bus from Bus Stop 1 to Bus Stop 2.
A standard path between Bus Stop 1 and Bus Stop 2 was approximately $50 \mathrm{~m}$ long and several paths were marked out on the ground by tape dots (Figure 4). Environment players would stand on the dots to create the boundaries of the path and guide the toy bus. For replayability, we overlayed several paths on the ground using different colors. Only environment players knew the color of any current round so that the bus players were not able to effectively navigate based on the colored dots and had to rely on the environment. For complexity, we also added forks in the path, opening up alternative routes. The width of the path was approximately $2-2.5 \mathrm{~m}$, approximately 1.5 times the width of the bus body so that it was challenging but possible for the bus to move on the path flanked by the environment. The distance between the dots measured approximately one step, dense enough that the toy bus could not slip between two environment players on one side of the path but rare enough that the environment did not too obviously delineate the path ahead for the sensor players.

According to the game fiction, the environment players are "downloaded in real time on the map": they stand on the marks on both sides of the path, and when the back of the toy bus passes an environment player, the player moves quickly to take up their place at the front of the line (Figure 5). The environment players form a dynamic urban landscape that flanks the path (for which a minimum of four environment players are needed) and which the toy bus can sense (Figure 6).

The goal of the game is for the toy bus and the environment to cooperate in allowing the toy bus to travel from one bus stop to the other. If the bus hits an object in the environment (player or nonplayer) - that is, if the reading on any of the sensor boxes shows "too close"-everybody loses a point. Players succeed in the game if the toy bus arrives at the goal bus stop without losing more than three points. If the bus hits an object more than three times, the autonomous bus does not pass the road safety standards test and everybody loses. 


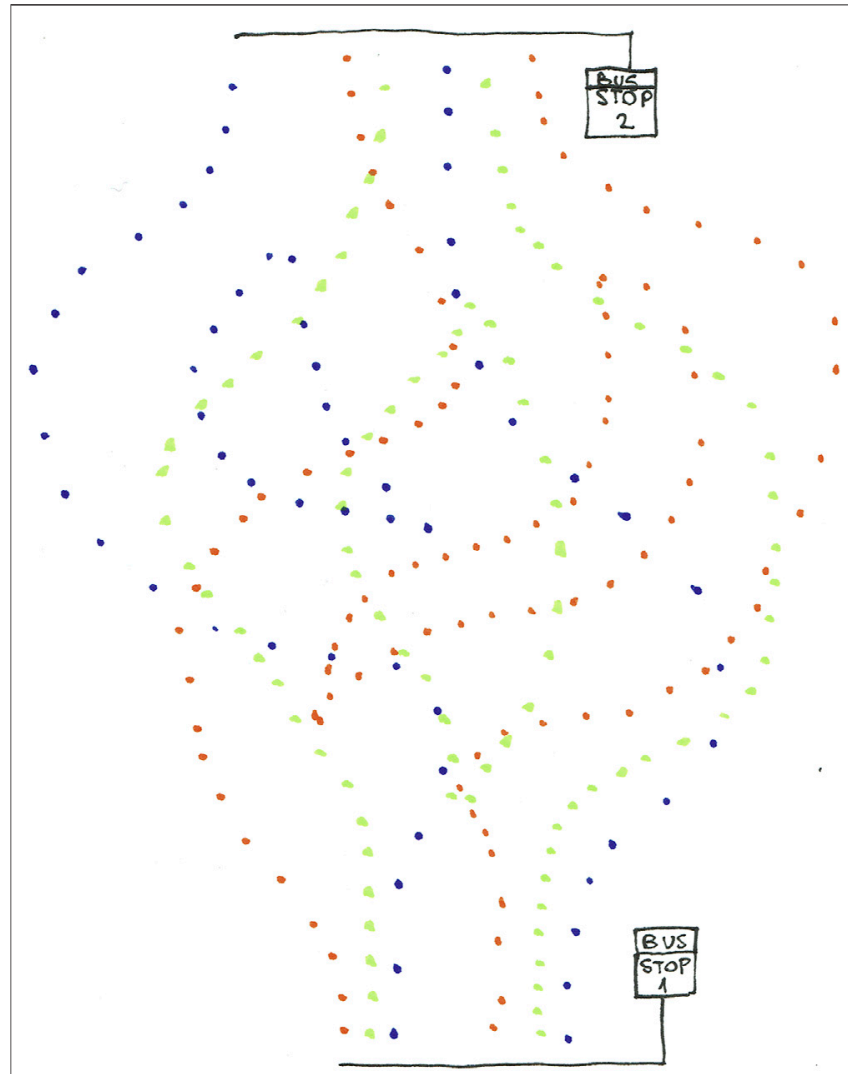

FIGURE 4 | Invisible Map.

The player experience turned out to center on the dynamic attunement between sensors, steering algorithm, and environment. Each became attuned to the other in the cooperative game setting, as they pulled each other toward Bus Stop 2. We even could have introduced environment in the game fiction as something internal to the bus's navigational mechanisms, such as "map data," without changing the interplay between the players, which hints at the blurring of the perceptive and proprioceptive aspects of navigation. This interplay between bus players and the environment players was a sound instantiation of the situated entanglements of an autonomous bus with its environment and thus created a unique bus perspective relative to its position and bodily and sensory constitution.

\section{The Overtake}

It is worth to briefly mention another game from the release, where the sensing and steering mechanisms of the toy bus were the same as in the Invisible Map, but the toy bus interacted with the real BVG bus instead of an environment constituted by players. The goal in The Overtake was to overtake the BVG bus with the toy bus without bringing the BVG bus to a halt. The "bus" players' setup in the toy bus was identical to the Invisible Map setup, with four sensor players and one blindfolded steering algorithm. The challenge was to get close enough to the BVG bus during the maneuver so that it slowed down but not so close that it would come to a halt (Figure 7). In this maneuvering game, the sensing and steering mechanisms of the two busses entered into negotiations to keep moving safely. The challenge for the toy bus was to coordinate the movement of both buses while adjusting to the road conditions and environment. To succeed, the toy bus needed to become attuned to both the street and the real autonomous bus (Figure 8).

\section{PROBING ALIEN PERSPECTIVES}

Perspective in the context of this study refers to the distinctive entanglements which emerge from the unique position, history, and momentary bodily engagement of beings and things with others in their more or less immediate proximity. Grasping the perspectives of other people is less about reading their mind than about understanding with whom and what they interact in a given moment and how these interactions are rooted in their unique life experiences, attitudes, and abilities. Likewise, grasping a bus's perspective is not necessarily about un-black-boxing or reverseengineering the algorithms of an autonomous vehicle, but rather about the unique relations it enters into with other things in its proximity during a specific moment and place: interactions with pedestrians, traffic, its operator, entanglement with regulations, or operational mechanisms that emerge through its material specificities (such as its algorithms, materials, dimensions, and sensing capabilities). For design research, in the sense of generating knowledge that informs better designs, the interest around grasping a nonhuman perspective is primarily epistemological. Ontological questions such as whether intelligence, mind, or sentience are qualities that the bus possesses have implications for the politics of design but are outside the scope of this study.

Although the Catch the Bus games do not share many similarities with cultural probes in their use and mechanisms, they share one key affordance, namely, enabling the adoption of unfamiliar and otherwise inaccessible perspectives. Cultural probes are research tools that design researchers or social scientists use to learn about other people's lives, kits that are sent out to people to use in their everyday life before sending them back. Kits might contain tools for recording and marking, for example, a camera, a notebook, a calendar, or a map, as well as a set of instructions on how, where, and when to use these tools. The users of the kit would take photos in specific situations or about a specific object, markdown feelings, encounters, or any kind of notes guided by the instructions which come with the kit. The instructions are worded in such a way that they constrain the topics the probe addresses and encourage the answers to be formatted in a certain way, while at the same time allowing for some degree of openness and improvisation (Boehner et al., 2012). Graver and Dunne, who coined the term cultural probe, conceived it as an explorative and playful tool to understand people and settings, "[making] a virtue of uncertainty and risk, acknowledging and celebrating the idiosyncratic interpretations of designers and participants." (Boehner et al., 2012, p185). When researchers cannot follow the same trajectories and engage with the same things or beings as the people whom they would like to 


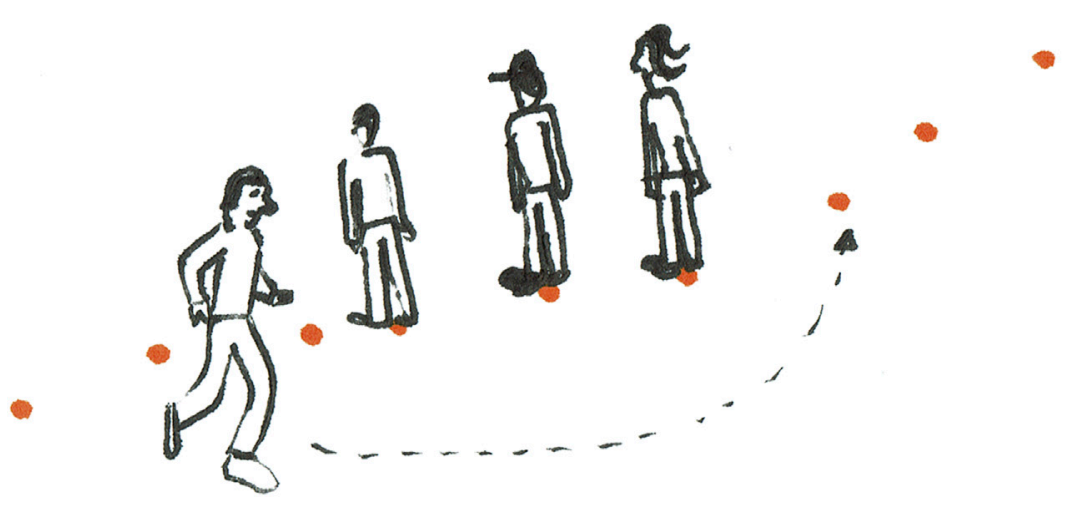

FIGURE 5 | Dynamic urban landscape.

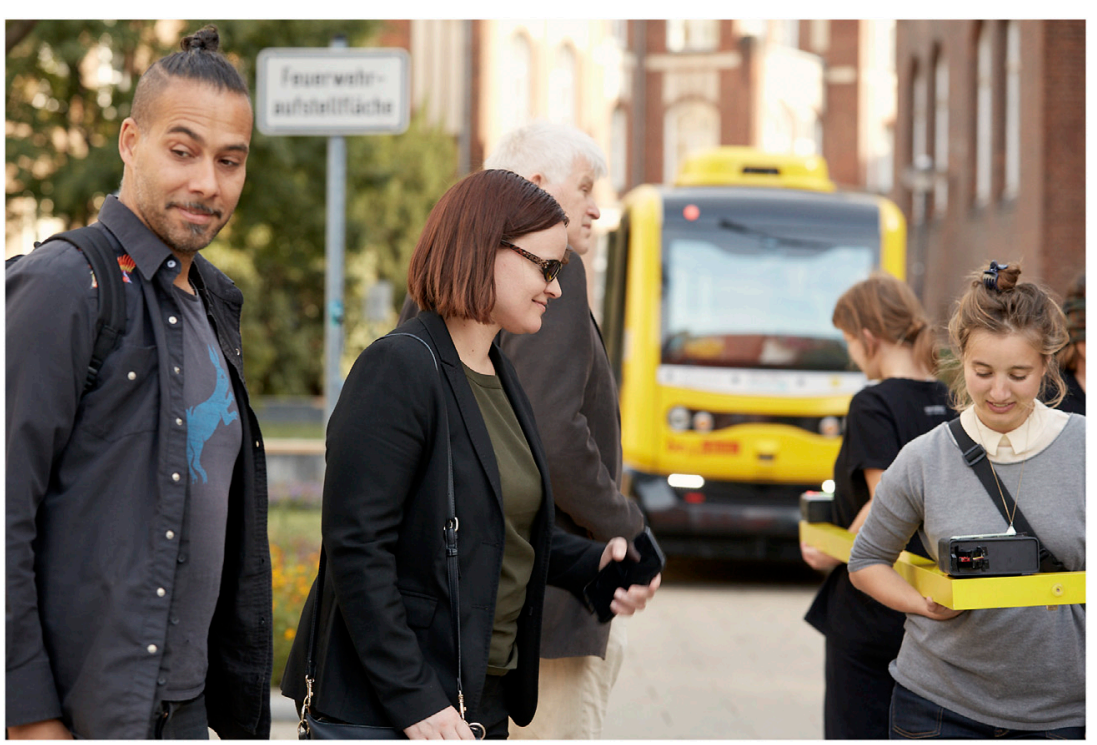

FIGURE 6 | The toy bus in the environment.

learn more about, they rely on probing how their research subjects are affected by certain events and encounters that materialize on those trajectories. The further apart the life experiences of a researcher are from the other person's experiences, the more they have to rely on instruments of probing to develop a grasp of what it is like for the other person. Also, with increasing distance, the interpretation of the data returned by probes increasingly turns speculative, in the sense of not being grounded in one's own experiences.

In adopting alien perspectives, such as a "thing perspective," speculation of some kind seems to be the only option. Speculating about an alien or other-than-human perspective means building to some extent on plausible human knowledge about the kind of entanglements a nonhuman being or thing is embedded in, but applying fiction wherever this knowledge thins out. The podcast
"Everything is Alive"2 features interviews with things such as sand, a bar of soap, and a subway seat. In the podcast, we learn about their life, their joys, fears and desires, and connections both with other things and with humans. The things are impersonated by actors, who use the improv theatre method for the unscripted interviews. The human impersonating sand builds on their obviously limited access to how the world is for sand, and their knowledge about how sand is handled, used, transported, and its value in production processes combined with a huge amount of imagination, allows plausible, although fictive and speculative, immersions into the sand's perspective.

${ }^{2}$ https://www.everythingisalive.com. 


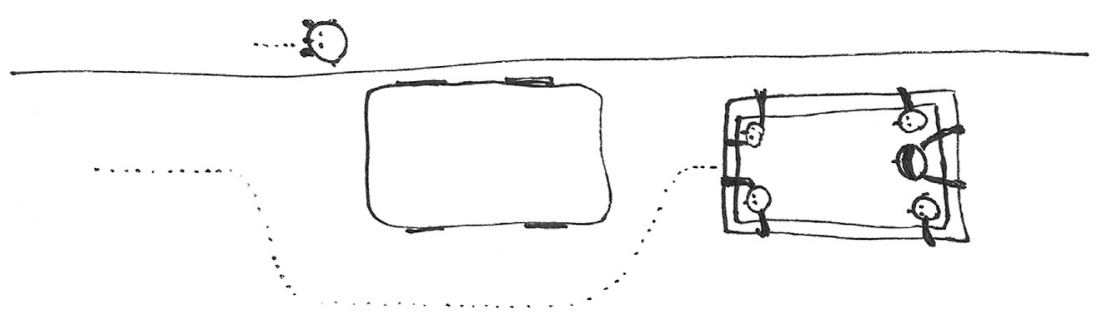

FIGURE 7 | The overtake maneuver.

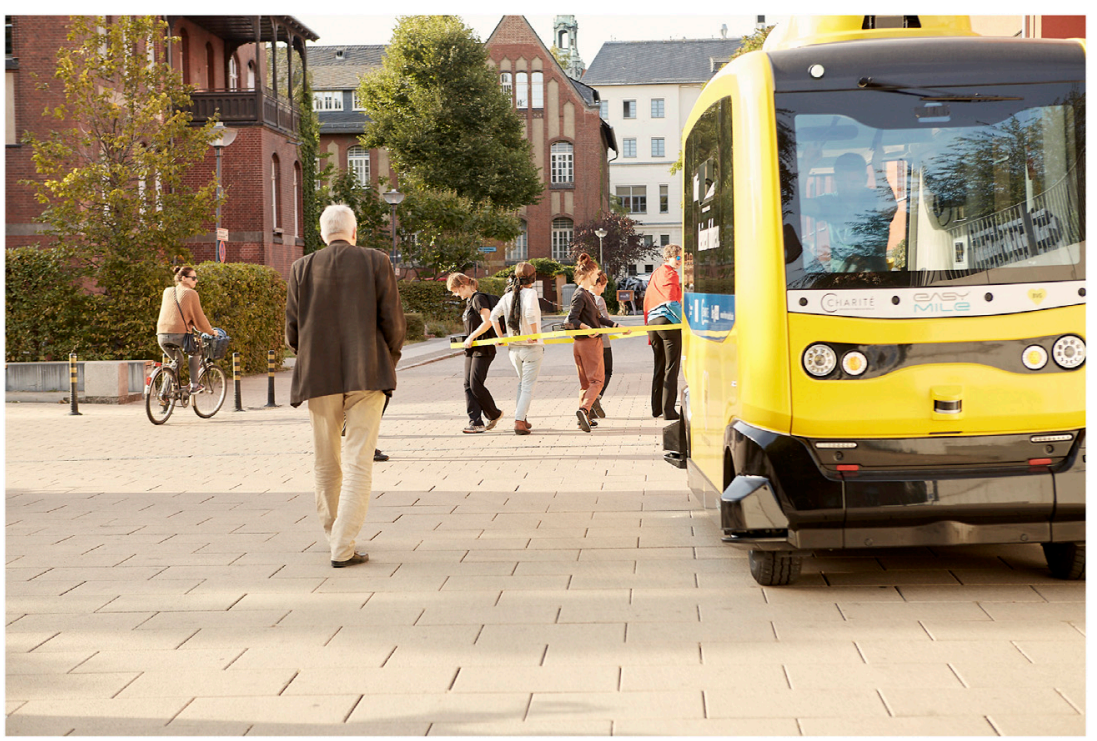

FIGURE 8 | The overtake.

Another point of reference for adopting other-than-human perspectives is the design method "Interview with Things" (Chang et al., 2017; Reddy et al., 2021). Similar to the "Everything is Alive" interviews, it builds on impersonating things in interviews to explore everyday sociomaterial networks in which the things are operating. However, as a design research method, its ambition is to substantiate the speculation with experiential data as much as possible. To this end, the Interview with Things method seeks to reduce the amount of speculation in the interview by finding ways of extracting information and knowledge from the situated and material contexts of the interviewed thing and applying them during the interview. In an instance of employing the Interview with Things method for exploring urban scooters in Taipei, design researchers mounted cameras and sensors on the scooters to capture photo and video footage and sensor readings. The researchers then preprocessed this data to make it available to the actors, who studied and internalized the materials in preparation for the interviews.

Certainly, many more projects could instantiate speculative strategies when engaging with unfamiliar and alien perspectives. The aim here was merely to illustrate the principles of blending empirical knowledge, data gathering, and fiction in speculating about thing perspectives in design research. Adopting other people's perspectives can be challenging enough; adopting the perspectives of nonhuman beings is, some might say, impossible or fictional altogether. The epistemological question to explore for design research remains: What are the fruitful pursuits for strengthening experiential and/or embodied knowledge in the speculation about nonhuman perspectives?

\section{LIKE A BUS}

To highlight the key role of similarity with nonhumans in the ability to adopt nonhuman perspectives, this section looks at experiments and theoretical arguments about the possibility of grasping nonhuman experience by enacting the situatedness of nonhumans and placing oneself within nonhuman niches. I will suggest that the Catch the Bus project probes the capacity of such similarity by placing players in traffic, choreographing them into adopting the physical footprint of an autonomous bus, and modulating their sensory and navigational data processing capacities so that they mimic the sensing and processing capacities of the bus.

Adopting a nonhuman perspective by temporarily sharing the environmental niche of another species was attempted by ex-vet and barrister Charles Foster (2016) who committed to living like a 
badger, an otter, an urban fox, a deer, and a swift, each for a short amount of time. During the attempt to live like an urban fox, for example, he foraged in bins and slept in gardens. In a similar vein, designer Thomas Thwaites (2016)joined goats in the Alps. He took the experiment even further by modifying body posture and locomotion using a prosthetic exoskeleton, to approximate a goat-like physicality. Both Foster's and Thwaites's ambitions were to better connect to the animal world by experiencing what the world is like for animals. When reflecting on Fosters's and Thwaites's experiments from a performance studies perspective, Orozco and Parker-Starbuck not only point out how the playfulness of pretending allows a different relationship to the animals (Orozco and ParkerStarbuck 2017, p64), but emphasize the primacy of a physical approach over a discursive one. Referring to Foster and Thwaites, they argue that situating embodiment is a more authentic way of apprehending the nonhuman than rational scientific discourses and welcome the "favouring of embodiment [as] recognition of the opening that performance, pretense and mimicking bring about as a potential reaching out towards the animal" (Orozco and ParkerStarbuck 2017, p64). An interpretation of perspective that emphasizes a being's or thing's unique position and material/bodily and sensory constitution is more invested in prediscursive, prelingual, or precognitive aspects of engaging with nonhumans. This prelingual, preconceptual, prediscursive, and pre-emotional mode of interacting or intra-acting with other things constitutes what Massumi describes as the space of effect (Massumi, 2015), and Shaviro describes as sentience (2015). In this sphere, the entanglements of things with other things emerge from their material specificities, unique positions, and their proximity to each other. Adopting a perspective in this sense means engaging with the things that the other is engaging with and engaging in similar ways, which in turn shifts resemblance and similarity into focus.

Prediscursive strategies are central for the adoption of nonhuman perspectives not only because we cannot ask an urban fox about their experience of the urban or ask a bus about its experience of traffic. Through the ability to speak, we can share to a much greater extent "what it is like" for other humans. But the private and public aspects of a human or nonhuman entity always go together, and ultimately, we always lack full cognitive access to other humans' inner experience: "What David Chalmers calls the 'hard problem' of consciousness indeed plays out the same way in relation to a bat or a cat-or for that matter, in Chalmers's notorious example, to a thermostat-that it does in relation to another human being" (Shaviro 2015, p29), and although we have a better grasp of other humans than we do of nonhumans such as animals, for example, a more extensive grasp of another being's experience based on species similarity is only a difference in degree and not in kind (Shaviro 2015, p29).

Species similarity was raised most prominently as a key discussion point in grasping nonhuman points of view or experience by philosopher Thomas Nagel in "What Is It Like to Be a Bat?" (1974). His core argument was that because of a different sensory and bodily setup, humans are not able to grasp what the world is like for bats (i.e., bat experience), and thus, it is impossible to know as humans whether bats have consciousness at all. For the philosophy of mind, Nagel's ontological question of whether bats have minds is of key interest. However, the relevance for design research is in the epistemological implications of how Nagel builds his arguments. Nagel's choice of bats as a case in point for his argument zeroes on a sphere where the similarity between humans and other species becomes elusive enough to support the problematization of adopting a nonhuman perspective: "I have chosen bats instead of wasps or flounders because if one travels too far down the phylogenetic tree, people gradually shed their faith that there is experience there at all" (Nagel 1974, p438). Nagel elaborates on how bats precisely discriminate between distance, size, shape, motion, and texture of things by echolocation, which is based on how objects reflect the bats' high-frequency shrieks. He argues that this form of perception is so different in its operation to human senses that humans can neither experience nor imagine what it is like to be a bat. Nagel poses the question of what method could possibly permit us to extrapolate the inner life of the bat from our own experience:

"Our own experience provides the basic material for our imagination, whose range is therefore limited. It will not help to try to imagine that one has webbing on one's arms, which enables one to fly around at dusk and dawn catching insects in one's mouth; that one has very poor vision, and perceives the surrounding world by a system of reflected high-frequency sound signals; and that one spends the day hanging upside down by one's feet in an attic. In so far as I can imagine this (which is not very far), it tells me only what it would be like for me to behave as a bat behaves. But that is not the question. I want to know what it is like for a bat to be a bat. Yet if I try to imagine this, I am restricted to the resources of my own mind, and those resources are inadequate to the task. I cannot perform it either by imagining additions to my present experience, or by imagining segments gradually subtracted from it, or by imagining some combination of additions, subtractions, and modifications. To the extent that I could look and behave like a wasp or a bat without changing my fundamental structure, my experiences would not be anything like the experiences of those animals. [...] Even if I could by gradual degrees be transformed into a bat, nothing in my present constitution enables me to imagine what the experiences of such a future stage of myself thus metamorphosed would be like" (Nagel 1974, p439).

Nagel delivers the argument that on grounds of the constitution of human bodies and sensing capabilities, it is impossible to extrapolate from human experience the experience of a bat; in other words, certainty about the existence of bat consciousness is beyond the epistemological horizon of any human being. At the same time, with his argument, he also outlines the path to the grasping of bat experience, which although we never pursue entirely, we can partially explore for a better grasp of nonhuman perspectives.

We see how with decreasing similarity in sensory and bodily constitution, humans' ability to take the perspective of other lifeforms decreases too. Being confronted with decreasing similarity with the nonhuman, as Shaviro points out in reference to Nagel's argument, "[ $t]$ he best we can do is to create metaphors and similes-or as I would rather say, esthetic semblances-that allude in some way to chiropteran or canine existence" (Shaviro 2015, p26). While the challenge of grasping other humans' unique perspectives emerges through differences in culture and personal histories (a challenge that is addressed by cultural probes), grasping perspectives of very different beings, such as ants, or even things, such as thermostats, is always in 
a sense speculative. When similarity in bodily and sensory makeup ceases to support the epistemology of grasping other-than-human perspectives, it is metaphors, speculation, and fiction that start to take over. However, strategies to increase similarity offer a means by which to achieve a less arbitrary and anthropomorphistic grasp of other-than-human perspectives.

During gameplay in the Catch the Bus project, players move among other vehicles in a metal frame which has the footprint of a small autonomous bus. They rely on distance sensors for sensing and navigating the environment, resembling the sensing and navigating principles of the autonomous bus's LIDAR system. The similarity of the toy bus with the original autonomous bus is evidently imperfect, partial at best. However, players who were partaking in the Catch the Bus games most likely displayed the highest level of similarity to an autonomous bus as ever before.

\section{CONCLUSION}

In design research, exploratory prototypes turn into speculative design artifacts when the design proposals they embody address future or alternative realities, with diminishing similarities to the contemporary context. Design exploration and testability gradually give way to fiction. It is in the hands of the design researcher to create a balance between prototyping and speculation based on the epistemological ambitions of a project. Speculative design is a powerful approach to creating imaginaries about desirable futures or scrutinizing dystopian extrapolations of our present. At the same time, an increasing degree of speculation detaches the design artifacts from their anchorage in everyday experiences. This shift from prototyping to speculation is somewhat analogous to the increasing level of speculation in adopting alien perspectives: with decreasing similarity of the beings or things whose perspective the human designer aims to grasp, the degree of fiction increases in the speculation about their perspective. If the general ambition of a design researcher's exploration is to generate substantiated design knowledge about the way a thing engages with other things, reducing the degree of fiction becomes the prime challenge. Game design manages this by merging fiction and prop enactment with real urban mechanisms.

The Catch the Bus project's scope of playfully exploring how people, traffic, and autonomous busses engage with each other did not allow for in-depth research about insights and knowledge that the experience generated for participants. But it generated a setup for shifting perspectives that is arguably a source of new knowledge. It is evident that enacting an autonomous bus as a collective of players can only provide a highly fictitious grasp of what it is like to navigate traffic as a bus. However, any increase of similarity to the build and situatedness of an autonomous bus carries the promise of increasing the authentic grasp of an autonomous bus's perspective. Performing and mimicking nonhumans does not mean that humans turn into nonhumans, but allows for successful strategies of turning to nonhuman beings (Orozco and Parker-Starbuck 2017, p67).

Tapping into philosophical debates about the nonhuman turn and design research, this study argues that adopting some degree of similarity in bodily and sensory makeup becomes key in substantiating the speculation about nonhuman perspectives. In Donna Haraway's "Camille" stories, the reader witnesses how more-than-human symbionts emerge over five generations as a deliberate strategy to better "live in intimate and worldly care-taking symbiosis with another animal as a practice of repairing damaged places and making flourishing multispecies futures" (Haraway 2016, p146). As a symbiont who links a human body to a monarch butterfly, Camille has vibrant orange and black skin and altered sensing capabilities provided by butterfly antennae. Mimesis is not the ultimate point of the alterations in Haraway's speculative fabulation; instead, species similarity becomes a central strategy in extending what she calls "respons-ability" to the more-than-human realm: "[The symbionts] roles in the symbioses were to teach and to flourish in every way possible in dangerous and damaged times" (Haraway, 2016, p147). The Catch the Bus project gives an instance of an exploratory design research approach for decentering from the human perspective. It opens up the possibility of generating design knowledge from a nonhuman vantage point while incrementally shifting the weight from fictions and metaphors to embodied experience. Any movement in this direction reduces the weight of fiction and, with this, the pitfalls of anthropomorphizing the bus perspective. The combination of playfulness-merging the real and fictive-and probing-shifting away from one's own perspective to otherwise inaccessible perspectives-is the basis of its epistemological export for design exploration.

\section{DATA AVAILABILITY STATEMENT}

The original contributions presented in the study are included in the article/supplementary material; further inquiries can be directed to the corresponding author.

\section{AUTHOR CONTRIBUTIONS}

The author confirms being the sole contributor of this work and has approved it for publication.

\section{FUNDING}

The writing of this study was supported by the Swiss National Science Foundation (grant number 175913).

\section{ACKNOWLEDGMENTS}

I thank Simon Johnson with whom I created the Catch the Bus games and who came up with the idea of the toy bus in the first place. Also, I thank Jennifer Aksu and the whole Fiction Forum team for inviting Simon Johnson and me to create this project and for their support in producing it. I am grateful to Iohanna Nicenboim for her comments about the main arguments of this study. 


\section{REFERENCES}

Bedö, V. (2019). "Rapid Street Game Design: Prototyping Laboratory for Urban Change," in The Hackable City (Singapore: Springer), 51-65. doi:10.1007/978-981-13-2694-3_3

Boehner, K., Gaver, W., and Boucher, A. (2012). "Probes," in Inventive Methods: The Happening of the Social. Editors C. Lury and N. Wakeford (Abingdon: Routledge), 185-201.

Chang, W. W., Giaccardi, E., Chen, L. L., and Liang, R. H. (2017). “"Interview with Things" A First-Thing Perspective to Understand the Scooter's Everyday SocioMaterial Network in Taiwan," in Proceedings of the 2017 Conference on Designing Interactive Systems, 1001-1012.

Foster, C. (2016). Being a Beast: Adventures across the Species divide. MacmillanNew York, NY.

Haraway, D. (2016). Staying with the Trouble: Making Kin in the Chthulucene. Duke University Press Durham.

Massumi, B. (2015). "The Supernormal Animal," in Nonhuman Turn. Editor R. Grusin(Minneapolis: University of Minnesota Press Minneapolis), 1-18.

Nagel, T. (1974). What Is it like to Be a Bat?. Phil. Rev. 83, 4435-4450. doi:10.2307/ 2183914

Orozco, L., and Parker-Starbuck, J. (2017). Goats, Badgers and Other Beasts. Perform. Res. 22 (2), 63-68. doi:10.1080/13528165.2017.1315972
Reddy, A., Kocaballi, B., Nicenboim, I., Søndergaard, M. L. J., Lupetti, M. L., Key, C., et al. (2021). "Making Everyday Things Talk: Speculative Conversations into the Future of Voice Interfaces at Home," in Extended Abstracts of the $2021 \mathrm{CHI}$ Conference on Human Factors in Computing Systems (Yokohama, Japan. ACM, New York, NY, USA: CHI '21 Extended Abstracts).

Shaviro, S. (2015). "Consequences of Panpsychism," in Nonhuman Turn. Editor R. Grusin(Minneapolis: University of Minnesota Press Minneapolis), 19-44.

Thwaites, T. (2016). GoatMan: How I Took a Holiday from Being Human. Chronicle Books London.

Conflict of Interest: The author declares that the research was conducted in the absence of any commercial or financial relationships that could be construed as a potential conflict of interest.

Copyright $(2021$ Bedö. This is an open-access article distributed under the terms of the Creative Commons Attribution License (CC BY). The use, distribution or reproduction in other forums is permitted, provided the original author(s) and the copyright owner(s) are credited and that the original publication in this journal is cited, in accordance with accepted academic practice. No use, distribution or reproduction is permitted which does not comply with these terms. 


\section{OPEN ACCESS}

Edited by:

Mattia Thibault,

Tampere University, Finland

Reviewed by:

Joseph Macey,

University of Turku, Finland

Frances Brazier,

Delft University of Technology,

Netherlands

Geertje Slingerland,

Delft University of Technology, Netherlands, in collaboration with

reviewer FB

*Correspondence:

Michael Oduor

michael.oduor@oulu.fi

Specialty section:

This article was submitted to

Human-Media Interaction,

a section of the journal

Frontiers in Computer Science

Received: 06 May 2021

Accepted: 30 June 2021

Published: 11 August 2021

Citation:

Oduor M and Perälä T (2021) Interactive Urban Play to Encourage Active Mobility: Usability Study of a

Web-Based Augmented

Reality Application.

Front. Comput. Sci. 3:706162.

doi: $10.3389 /$ fcomp.2021.706162

\section{Interactive Urban Play to Encourage Active Mobility: Usability Study of a Web-Based Augmented Reality Application}

\author{
Michael Oduor ${ }^{1 *}$ and Timo Perälä \\ ${ }^{1}$ OASIS Research Unit, Faculty of Information Technology and Electronic Engineering, University of Oulu, Oulu, Finland, ${ }^{2}$ Navico \\ Oy, Oulu, Finland
}

Owing to increasing cases of sedentary lifestyles and their negative impact on health, practical solutions are needed to address the physical and mental wellbeing of citizens and to enhance their standard of living. Among the problems are premature mortality rates caused by physical inactivity, which leads to chronic diseases. Innovative solutions are needed to address many of the problems that we face as a society. Location-based games have been identified as effective solutions for increasing physical activity, enhancing social interaction, and exploration in urban environments. In this pilot study, we explore how to encourage active mobility (walking and cycling) through urban play by integrating technology into the built environment. We examined the usability of a web-based augmented reality application in providing interactive experience to users as they explored the urban environment looking for tasks. Overall, participants' perceptions of the usability of the application were positive; they enjoyed how the application revealed the tasks at each location and all the checkpoints at the different locations had at least a couple of visitors. We present limitations and future research directions.

Keywords: urban play, physical activity, location-based games, built environment, usability

\section{INTRODUCTION}

Most of the world population living in urban areas continues to grow (United Nations, 2018). As the global population shifts to urban areas, there is an increased need for practical solutions to address the physical and mental wellbeing of citizens and to enhance the standard of living in urban environments. One of the major global challenges is premature mortality rates caused by physical inactivity and sedentary lifestyles, which lead to chronic diseases (Heath et al., 2006). According to World Health Organization (WHO), (n.d.), physical inactivity and sedentary behavior could partly be attributed to the effects of urbanization, which has led to detrimental factors such as increase in traffic, low air quality, and lack of recreational facilities. Reversing mortality rates resulting from physical inactivity and other lifestyle-related behaviors could enhance the overall health and mental wellbeing of the population and save healthcare costs (Heath et al., 2006; Lee and Maheswaran, 2011).

We need innovative solutions to address many of the problems that we face as a society (Morford et al., 2014). There has been a steady growth in systems aimed at motivating people to attain their goals by guiding them toward healthier behaviors (Chatterjee and Price, 2009). Digital interventions have transformed the sustainability, healthcare, and wellness sectors by enhancing users' 
independence in improving their own wellbeing and overall health. Using technology in these different domains applying game mechanics to start and/or maintain self-beneficial behavior is nowadays commonplace (Morford et al., 2014; Hamari and Koivisto, 2015). Game mechanics are interactions through which players interact with a game or gamified system (Haahr, 2017). For example, Arjoranta, Kari, and Salo (2020) investigate how game features, such as catching new Pokémon and exploring Pokéstops, in a location-based game can be linked to specific behavior types by investigating users' actual experiences while using the game.

This pilot study is part of an ongoing project on urban design and wellbeing. A major aim of the project is to investigate how to integrate technology into existing urban environments to encourage physical activity, city exploration, community awareness and to improve access to and the delivery of services. In this study, we examine the role of playful games in encouraging active mobility (walking and cycling) by using a web-based augmented reality (webAR) application to provide an enjoyable and interactive experience while exploring an urban environment. The study was set up as part of a family sports day where we analyzed the use of the application to engage users at the point of interaction (checkpoints) by revealing different tasks. We placed AR tags in 30 different locations across Oulu, a Finnish city in northern Finland, and scanning the tags revealed the tasks that participants were to do at each location. The specific focus was on 1) encouraging active mobility and exploration through interactive play, 2) exploiting characteristics of the urban environment, and 3) investigating users' perception of the usability of the webAR application.

Research shows how the characteristics of urban environments can contribute positively to health by influencing people's physical activity levels (Lopez 2012; Coombes, Sluijs, and Jones 2013; Sallis et al., 2016; Kärmeniemi et al., 2018). Environmental approaches promoting wellbeing may complement frequently used individual and lifestyle modification strategies because they can benefit all people exposed to the environment rather than focusing on influencing one person at a time (Heath et al., 2006). Such community-wide interventions are effective in increasing levels of mental wellbeing among the physically inactive and in promoting increased levels of physical activity (Coombes and Jones, 2016; Harris, 2018a, 2018b). Using locative media to move through familiar surroundings can also increase the quality of fun, social interaction, and exploration (Haahr, 2017; Korhonen et al., 2017; Papangelis et al., 2020; Tzima et al., 2021). However, the impact of locative media on physical activity tends to reduce over time (Broom and Flint, 2018) and research suggests that there are limited options or increased barriers for minority populations to play (Hjorth and Richardson, 2017).

This article reports on a study testing the usability of a webAR and how to enhance urban exploration and encourage active mobility thus augmenting other research on locative media (see, e.g., Kaczmarek et al., 2017; Broom and Flint 2018; Pang et al., 2019; Fonseca et al., 2021). The study also presents an example of how to integrate AR applications into existing urban environments to encourage play and physical activity at the point of interaction using the features present at a particular location.

\section{RELATED WORK}

According to Chien et al. (2021), the most common research topics in location-based game research are the Urban Space (herein referred to as the built environment), Physical Activity, and Pokémon GO (AR). These are discussed in the following sections and are some of the key topics in the project and are important in this pilot study, which focuses on using fun and games to encourage active mobility in urban spaces.

\section{Exploiting Features of the Built Environment to Promote Physical Activity}

The topic Urban Space in relation to location-based game research focuses on where these games are played, and it is often (although not always) in the built environment (Chien et al., 2021). The built environment refers to the man-made elements that are part of everyday lives and Lopez (2012), for example, addresses the relationship between the built environment and health. The health effects of the built environment occur on multiple areas, such as houses, streets, neighborhoods, parks, and green spaces (Lopez, 2012). Growing evidence shows that some environments afford healthier living practices than others, and there are programs, policies, and projects that can change or be integrated into the environment to promote health (Lopez, 2012; Coombes et al., 2013; Sallis et al., 2016; Kärmeniemi et al., 2018). For example, objective Geographic Information System (GIS)-based measures of the built environment such as new infrastructure for walking, cycling or public transport, accessibility to sporting facilities, or in terms of distance to parks, recreational park improvements, and street network connectivity (Lee and Maheswaran, 2011; Kärmeniemi et al., 2018). Objective measures refer to improvements in neighborhood or townlevel infrastructure (Kärmeniemi et al., 2018).

Urban areas can be designed to support various activities in outdoor and indoor environments including people's mobility behaviors (Stibe and Larson, 2016). Examples of applying technology to outdoor environments include installations that transform public spaces into playgrounds that encourage social interactions. In Montreal, swings set up between two streets enable people to participate in a collective musical production in which a single moving swing sets off a note, and several create a melody (Figure 1A). ${ }^{1}$ To encourage cycling, street signs show an approximate number of calories burned between two points or the number of people who have passed through a specific location at a certain point in time (Figure 1B). ${ }^{2}$ In indoor environments, situated displays integrated with sensors could encourage people to use the stairs instead of the elevator (Stibe and Larson, 2016).

${ }^{1}$ https://awards.ixda.org/entry/2013/21-balancoires/

${ }^{2}$ https://yle.fi/uutiset/3-11584433 


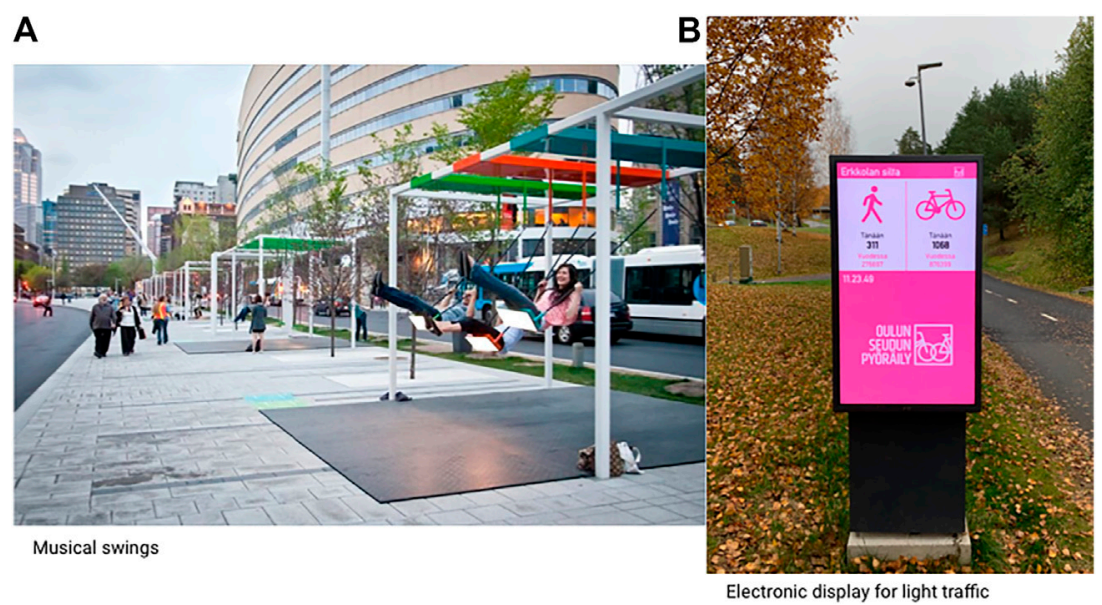

FIGURE 1 | 21 Balançoires (21 Swings) and Display for light traffic.

Below are a few examples of research that link characteristics of the environment with experimental studies that take advantage of objective built environment features to promote physical activity. Helbich et al. (2016) examined how the natural and built environments influence transport behavior by tracking children's trips with a global positioning system. The results showed that the distance between locations was insignificant in children's active travel to school if positive urban design features such as well-connected streets and cycling lanes were considered in the analyses. Coombes, Sluijs, and Jones (2013) showed that an activity's intensity-whether light, moderate, or vigorous-and length depend on the characteristics of the built environment. In their study, they used accelerometers and global positioning systems in a sample of school children to investigate whether different intensities of activities occur in different environments (Coombes et al., 2013). The findings showed different environments-buildings, pavements, and green spaces (gardens, parks)-support varying intensities and lengths of activity (Coombes et al., 2013). In a later study, Coombes and Jones (2016) investigated how to get children more active by encouraging long-term sustainable mobility in their neighborhood and while traveling to schools. Using tracking technology and a reward scheme, they recruited the participating school children via an intervention and control school. They quantitatively tested the impact of the study that turns a city into a game where players register their walking or cycling journeys, on levels of active travel using objective measures of change in physical activity recorded by the tracking device. There was no large effect, but they observed that self-reported active travel increased at the intervention school compared to the control. Overall engagement with the system was low, but there was evidence that children who engaged more increased their physical activity times when commuting to school (Coombes and Jones, 2016). Investigating the same system and focusing on how physical activity is linked to mental wellbeing, Harris (2018a, 2018b) found comparable results to Coombes and Jones, (2016) on a more diverse sample-from school children under ten to adults over 70 . The findings provided preliminary evidence that the system may be a promising approach to raising levels of mental wellbeing at a community-wide level for those who are physically inactive (Harris, 2018a; 2018b). However, future studies should measure a wider set of outcomes and use objective measures of physical activity (e.g., log data from activity trackers), in addition to exploring the mechanisms that underpin the relationship between physical activity and mental wellbeing (Harris, 2018a; 2018b).

\section{Location-Based Games}

Digital technologies' importance in society is undeniable and technology increasingly "co-constitutes" our experience of the urban environment (Papangelis et al., 2020). As we increasingly interweave our lives with playful virtual environments, "mobile urban games can be seen as illustrative of the playful way in which we collectively and creatively perform place and our social selves" (Hjorth and Richardson, 2017).

Location-based games incorporate physical locations and resource gathering (involving physical movement) into the gaming experience (Haahr, 2017; Chien et al., 2021). In these games, location is tied to and accessed via specific geographic information. They encourage playful behavior by motivating people to discover places in their surroundings that they have not visited (Pang et al., 2019; Fonseca et al., 2021). Location-based games take place in the environment, promote citizen engagement, require exploration, and encourage physical activity (Kaczmarek et al., 2017; Broom and Flint, 2018; Pang et al., 2019; Fonseca et al., 2021; Tzima et al., 2021). However, in the same way that location-based games such as Pokémon GO lower social barriers and can be deployed to facilitate social interaction, they can also be used as a shield to avoid engagement with others in public spaces (Hjorth and Richardson, 2017).

Pang et al. (2019) investigate how location-based games can increase community awareness during transit. In the article, they investigate how users capture, share, and view location-based 
community information. Findings indicate that use of City Explorer, the application investigated in the study, did not adversely change users' transit behaviors and most relied on their old ways during transit. In some cases, the recommendations from the application helped users explore nearby places, but most users did not feel the need to socially connect with other commuters during transit as it was considered their personal time. What they valued most from using City Explorer was the increased awareness of their travel routines (Pang et al., 2019).

Fonseca et al. (2021) propose design recommendations for serious games to promote social interaction and citizen engagement. According to Fonseca et al. (2021), even though it is known why digital serious games to increase social interaction are successful, there is hardly any information on how and why design choices are made and how they affect players' behavior. Consequently, there are no concrete design guidelines for meaningful social interactions. The study focuses on teenagers' meaningful interaction with the environment and strengthening the engagement with their own neighborhood. The teenagers take part in the design, development, and evaluation of a location-based game framework, which results in design guidelines for games for social interaction (Fonseca et al., 2021).

While location-based AR games have existed for more than a decade, it is only with the launch of Ingress and Pokémon GO that the genre entered the public mainstream (Haahr, 2017). No location-based mobile game has attracted as much attention as Pokémon GO, and it has been prominent in academic research from the time of its release in 2016 (Chien et al., 2021). Pokémon GO has primarily been investigated in the context of encouraging physical activity, social interaction, and exploration (Chien et al., 2021).

Broom and Flint (2018) investigated differences in physical activity, sitting time, and perceptions of physical activity and health between users and nonusers of Pokémon GO in a preand-post-test study-launch of the application in the United Kingdom and 3-month follow-up. Using Pokémon GO increased and maintained the frequency of physically active days at both time points but increased their sitting time on weekdays. This highlighted the need for an intervention to prevent prolonged sitting (Broom and Flint, 2018). Kaczmarek et al. (2017) examined whether specific gaming motives, for example, potential health benefits, influenced Pokémon GO gaming time and gaming health outcomes. Findings show that those who spend more time playing were more physically active, suggesting that health motivation is aligned with the previously identified reasons for gaming (Kaczmarek et al., 2017).

Location-based games are not beyond critique, however, as Lindqvist et al. (2018) and Hjorth and Richardson (2017) have outlined. Lindqvist et al. (2018) qualitatively studied the effects of Pokémon GO on families by recording their experiences. While generally positive, like the above studies, that indicated a positive correlation of increased physical activity with game play, Lindqvist et al. (2018) outlined potential safety concerns and dishonesty in game play by some players. In the study, participants reported accidents that occurred while playing the game (e.g., falling into a ditch). Parents also expressed concern about the lack of awareness of the surroundings when playing. Hjorth and Richardson (2017) outlined the possibility of location-based games accentuating feelings of loneliness for those less physically mobile and increasing dangers for those who are stigmatized or marginalized.

The above studies highlight the importance of social and health motivations in increasing gaming time. The studies also show that game mechanics and incentives can enhance people's participation and experience with their community (Pang et al., 2019). However, in the case of Pokémon GO, the potential to be an effective intervention to increase physical activity in the long term is short-lived (Broom and Flint, 2018). When considering long-term engagement of locative media and full compatibility with the outdoor environment, there should be a balance between the physical world and the virtual world-offering a sense of immersion into the gameplay without losing the sense of presence in the physical space. Many location-based augmented reality games excel at the former but fail at the latter (Haahr, 2017). An example study that uses AR to retain the sense of presence in the real environment is by Tzima et al. (2021). In the study, players detected hidden physical objects and digital information using an AR application to solve riddles about the local cultural heritage. The game was designed to be implemented at the physical environment and could be played only in the selected place (Tzima et al., 2021). This creates a mediated experience that is close to the natural way of perceiving the environment (Haahr, 2017).

\section{MATERIALS AND METHODS}

We set up the study as a test case to examine the usability of a webAR when integrated into the built environment to provide an interactive experience to participants as they actively explored the urban environment. The study was in partnership with an urban planning and design agency. We conducted the study during a family sports day held on September 12, 2020. It was organized as part of an initiative called Lähirähinä, which loosely translates to Good for Hood in English. This is a voluntary initiative started 5 years ago in Oulu to encourage people to be physically active within their own neighborhoods by using the available sporting facilities or playgrounds to organize different sporting events. The sports day was organized as a day for fun and to bring together residents from the different neighborhoods. This was the second time the sports event was organized.

\section{Participant Recruitment}

We asked participants to download and print instructions for completing the tasks from the events website ${ }^{3}$ if they wanted to participate. The event was publicized through social media and word of mouth. This included short video previews of some checkpoints' location. Participation in the event and its activities

${ }^{3}$ https://lahirahina.fi/lrp2020/ 
TABLE 1 | Respondent characteristics.

Frequency

$\begin{array}{ll}\text { Gender } & \text { Male } \\ \text { Age } & \text { Female } \\ & 30 \text { or under } \\ & 31-40 \\ & 41-50 \\ \text { Education } & 50 \text { and older } \\ & \text { Elementary and vocationa } \\ \text { AR use before } & \text { Bachelors degree } \\ \text { Self-reported duration of weekly physical activity (hrs) } & \text { Masters degree } \\ & \text { Yes } \\ & \text { No } \\ & 0-4 \\ & 5-9 \\ & 10 \text { and above }\end{array}$

was at participants' own risk. They were also informed that they were responsible for their own medical cover in case of any accidents during the event. As the event was during the Covid-19 pandemic, we followed the health regulations and recommendations from the authorities. During the event, participants were requested to share photos and videos of themselves doing the tasks with the event's hashtag and their location on social media. The event was open to all and no participant information was collected prior to the event. After the event, we sent a follow-up survey to those who participated in the raffle (see Launching the web augmented reality application at the checkpoints and Measures). Tables 1 shows the descriptive statistics of the participants who responded to the follow-up survey. The survey was anonymous and participants' information could not be linked to their responses or the checkpoints they visited.

\section{Implementation}

The AR application was developed using Zappar's platform to ensure there is webAR compatibility across a wide range of mobile devices. The application runs on the cloud on Zappar's servers and a mobile device/client pulls data from there. This makes it easier compared to developing native $A R$ applications. With Zappar's platform one can create an AR experience using Zappar's ZapWorks studio. For the application tested in this study, neither a database nor a backend system was used. Rather, just ZapWorks studio ${ }^{4}$ and C\# on top of it were used. ${ }^{5}$

System log data whenever the application was accessed were also collected and reviewed after the event. The data recorded the location and the number of times the application was activated. As it was web-based, the application could run on any platform and all that was needed was a mobile device and internet connection.

\section{Launching the Web-Augmented Reality Application at the Checkpoints}

After downloading the task sheet, participants were free to start exploration from a checkpoint of their choice. We encouraged participants to either walk, cycle, or use public transportation to get to any of the 30 different checkpoints around the city of Oulu and its surroundings. Participants navigated across the city using an analog map, which guided them to the checkpoints (Figure 2).

At each of the checkpoints, they had to find where the poster with the AR tag was placed (Figure 3). The map hinted at the approximate location and clues where to find the AR tags (Figure 3A), instead of revealing the exact location. When they found the poster, they were to open a $\mathrm{url}^{6}$ on their mobile phone, press the "LAUNCH" button, and allow access to the devices' camera. Then, align the camera with the AR tag and a video with the task was displayed (Figure 3B). Each location had a unique letter code displayed after the video played and participants were to enter this code in the task sheet (Figure 3C). The tasks required the use of facilities or the features available at each location, for example, using outdoor stairs for light workout, walking/jogging to the top of a hill and taking a photo of the view, exercising with outdoor gym equipment, long jumps, playing a short game of beach volleyball or basketball, and so on.

Completing a minimum of six tasks entitled participants free access to two football matches-starting at 2 and $5 \mathrm{pm}-$ on the same afternoon of the sports day. Participants were free to complete as many tasks as they wanted and there were special prizes for the best performers. To enter a draw for the chance to win different prizes, participants needed to complete six or more tasks. The task sheet with their contact details was to be returned by $5 \mathrm{pm}$ at an information point at the stadium where the matches were played. A raffle was held at the halftime break of the match starting at $5 \mathrm{pm}$ and the winners were announced.

${ }^{4}$ https://zap.works/studio/

${ }^{5}$ This information was provided by a representative of the organization who developed the application we tested.

${ }^{6}$ web.zappar.com 


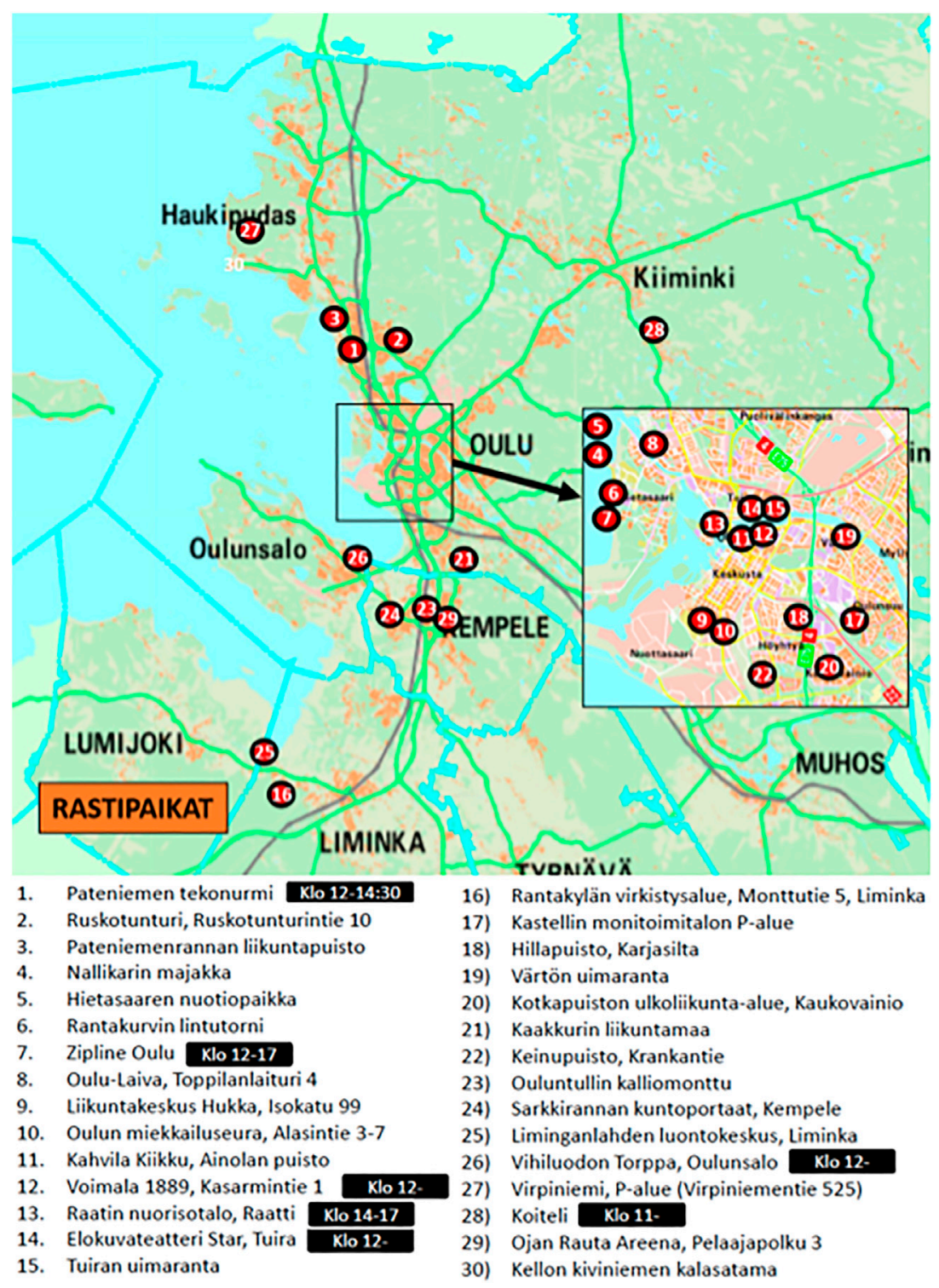

FIGURE 2 | Checkpoints.

\section{Measures}

After the event, we posted a follow-up questionnaire asking the participants to record their sociodemographic information, how the webAR compared to AR applications they have used earlier, and the duration of weekly exercise. The questionnaire also included the system usability scale (SUS) (Brooke, 1996, 2013) added with an adjective rating scale (Bangor et al., 2009) to assess usability features of the application. The questionnaire was posted on the event's pages on social media and also sent to the participants who participated in the raffle during the sports day.

SUS provides a measure of people's subjective perceptions of the usability of a system and stands out with its simplicity and ease of use (Bangor et al., 2009; Brooke, 1996, 2013). SUS is composed of ten statements, each having a five-point scale that ranges from Strongly Disagree to Strongly Agree. There are five positive statements and five negative statements, which alternate to avoid response bias (Bangor et al., 2009; Brooke, 1996, 2013). The items were selected so that the common response to five of them was strong agreement and to the other five, strong disagreement (Brooke, 2013). As suggested in Bangor, Kortum, and Miller (2009), we added a short set of instructions to remind respondents to mark a response to every statement and not to dwell too long on any one statement. The 10 items in SUS and their Finnish translations are presented in Table 2. For the translation, the first author first translated the items, then the second author, a native speaker, reviewed the translated text. This was to ascertain the quality of the translation and its semantic equivalence. We slightly adjusted the wording of some items to fit the webAR context by replacing the word system in the SUS items with AR application. 


\section{A}

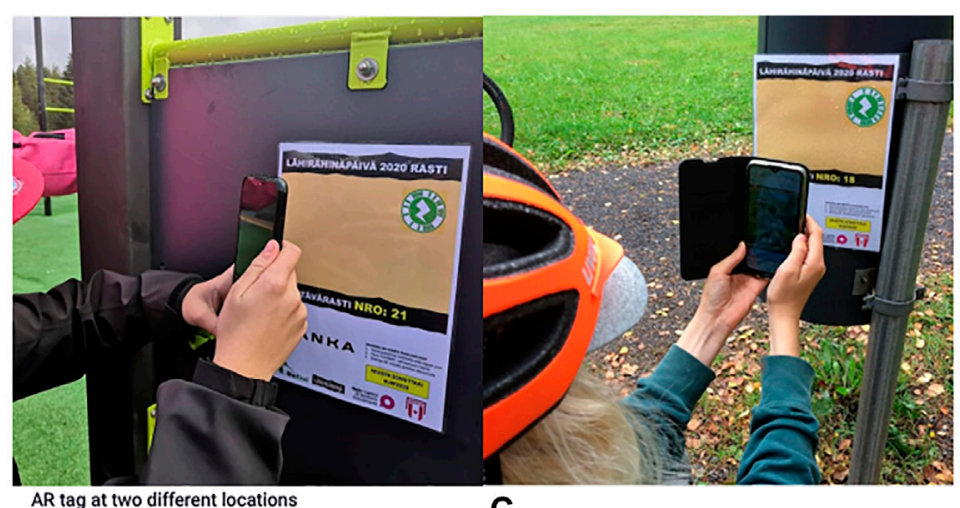

B

AR tag at two different locations

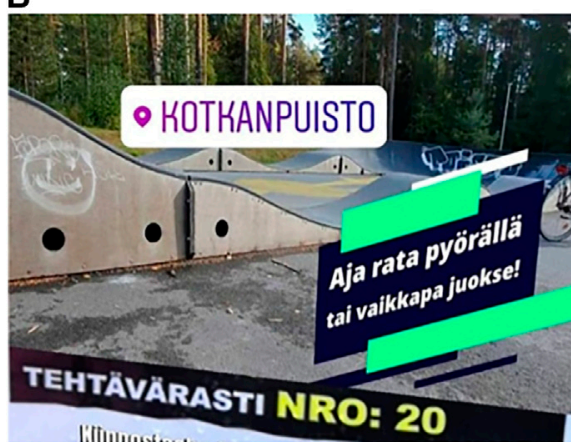

Video displayed after scanning the tag
C

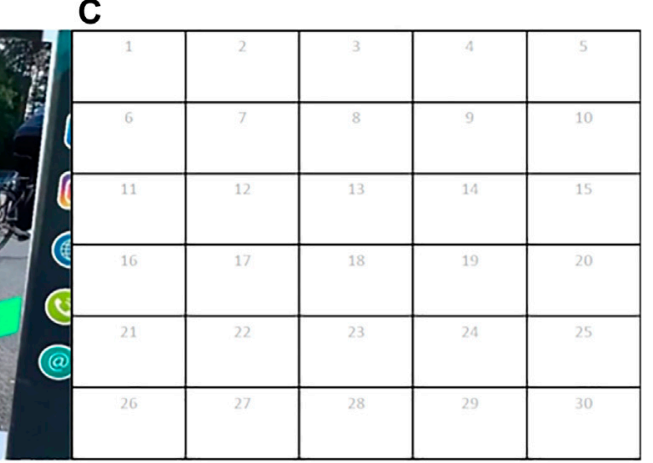

Form for filling in the letter codes after completing a task and the code is displayed in the video.

FIGURE 3 | AR tags, content displayed after scanning the tag, and task form.

To give an absolute judgement of the usability of a product, a 7point adjective-anchored Likert scale is added as the 11th question. The question is: "Overall, I would rate the user-friendliness of this product as:" and the answer to this question ranges from " 1 : Worst imaginable" to "7: Best imaginable." The aim was to explain what a single SUS score means on its own (for example, is a 68.5 good or bad?) (Bangor et al., 2009).

The authors considered SUS a viable instrument for this study because, in addition to encouraging active mobility and urban exploration through interactive play, we also wanted to investigate users' perceptions of the application.

\section{Data Analysis}

The survey responses were downloaded in a structured format and analyzed in Python using the Jupyter Notebook. ${ }^{7}$ The analysis for the survey data is available online in a github repository ${ }^{8}$.

According to Tullis and Stetson (2004), sample sizes of at least 12-14 participants are enough to get reasonably reliable results from SUS analysis. In their study, Tullis and Stetson (2004) compared five questionnaires for assessing the usability of a website and analyzed the data to determine the changes in results at different subsample sizes from 6 to 14 . Out of the 5, SUS and the computer usability questionnaire (CSUQ) converged most quickly to the correct conclusion regarding the differences

${ }^{7}$ https://jupyter.org

${ }^{8}$ https://github.com/Modago/sus

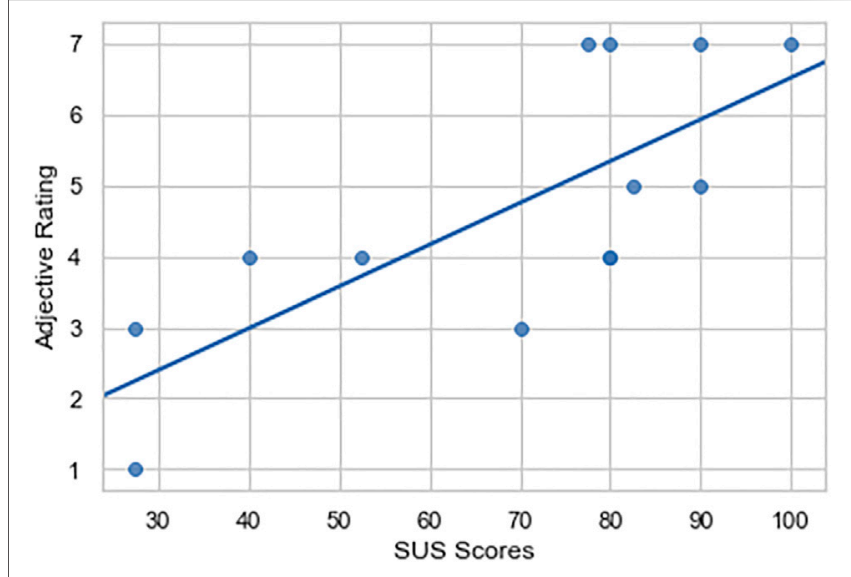

FIGURE 4 | Correlation between SUS score and adjective rating scores.

in the website's usability. They yielded the most reliable results across sample sizes. SUS was approximately $75 \%$ accurate at a sample size of 8 and this improved to between 90 and 100 in the 12-14 range (Tullis and Stetson, 2004). To calculate the SUS score, first sum the score contributions from each item. Each item's score contribution will range from 0 to 4 . For the oddnumbered items, the score contribution is the scale position minus 1. For the even-numbered items, the contribution is five minus the scale position. After determining the sum of 
TABLE 2 | SUS items in English and Finnish.

\section{Original item}

I think that I would like to use the AR application frequently

I found the AR application unnecessarily complex

I thought the AR application was easy to use

I think that I would need the support of a technical person to be able to use the AR application

I found the various functions in this AR application were well integrated

I thought there was too much inconsistency in this AR application

I would imagine that most people would learn to use this AR application very quickly

I found the AR application very cumbersome to use

I felt very confident using the AR application

I needed to learn a lot of things before I could get going with this AR application

\section{Corresponding item in Finnish}

Luulen, että haluaisin käyttää AR-sovellusta usein

AR-sovelluksen käyttö oli tarpeettoman monimutkaista

AR-sovellus oli helppo käyttää

Olisin tarvinnut teknisen henkilön tukea voidakseni käyttää AR-sovellusta

AR-sovelluksen eri toiminnot olivat hyvin integroituneita AR-sovelluksessa oli liian paljon epäjohdonmukaisuutta

Luulen, että useimmat inmiset oppisivat käyttämään tätä AR-sovellusta hyvin nopeasti

Minusta AR-sovellus oli erittäin hankala käyttää

Tuntui luontevalta käyttää AR-sovellusta

AR-sovelluksen käyttäminen vaati minulta monien uusien asioiden oppimista the scores, they are multiplied by 2.5 to get the overall value of SUS, usually in the 0 to 100 range (Brooke, 1996).

\section{RESULTS}

\section{Respondent Characteristics}

Initially, we posted a public link of the survey to the social media pages of the event asking all those who took part to respond. This led to three responses, so we contacted those who had submitted their contact details on the day of the event. 65 participated in the raffle and 10 of them responded to the survey. We summarize their details in Table 1. Follow-up statistics from Webropol, the survey tool used, shows that 110 respondents opened the survey.

\section{System Usability Scale}

Analysis of SUS includes aggregating the overall usability scores. SUS yields a single number representing a composite measure of the overall usability of the system being studied. The adjective rating scale was calculated as outlined in Bangor, Kortum, and Miller (2009). This involves doing a correlational analysis to reveal how well the SUS scores match with the adjective rating scale (Figure 4). The results are in line with earlier findings showing a positive correlation between the SUS scores and the scale $(r=0.75)$. Previous studies have found correlations of 0.822 Bangor, Kortum, and Miller (2009), 0.94 Ghosh et al. (2018), and 0.848 Grier et al. (2013). However, in these earlier studies they were comparing the usability of 2 or more systems.

The average perceived usability of the AR application was 69.04 , as it is close to the average score of 68.00; this indicates an acceptable system. This means that it is close to the 50th percentile (Bangor et al., 2009). We present the mean and standard deviations of the SUS scores and adjective rating scale of the AR application in Table 3. Overall, participants' perceptions of the usability of the application were mostly positive. From the open text responses, one respondent stated that compared to other AR applications, this was easier to use. For some participants scanning the codes during the event took longer than expected or the application did not work at all. For example, three participants left a note on their task sheets stating that the application did not work in one of the six
TABLE 3 | Average SUS scores and adjective rating scale of the AR application.

\begin{tabular}{ccccc} 
& \multicolumn{2}{c}{ SUS score } & \multicolumn{2}{c}{ Adjective rating scale } \\
\hline AR application & Mean & Standard deviation & Mean & Standard deviation \\
& 69.04 & 24.20 & 4.70 & 1.90
\end{tabular}

checkpoints they visited, so they could not get the code. The video was also interrupted whenever the phone camera shook or was moved.

\section{Participants' Online Posts and Completed Tasks}

We scanned social media for posts using the event's hashtags and other identifiable location hashtags related to the event. There were fewer than one hundred posts related to the event on Instagram and some of these were for a different event that used a similar hashtag. From the posts, participants enjoyed the overall experience of the event and appreciated how the application was used to reveal the challenges. An example comment translated from Finnish, "It is great that such events are organized. Technology was used with the help of AR codes, where a video was found that told the task and the identification code." Many other posts just stated the locations participants visited.

Majority of the participants did six tasks. The highest number of completed tasks was 15 (Figure 5), meaning that there were participants who did the challenges in 15 out of the 30 different locations. Five participants completed 15 tasks, from the provided contact details in the returned tasks sheets, four were members of the same family.

\section{Checkpoint Visits and Number of Application Downloads}

Each time the application was opened at a checkpoint, it was counted as a download. System log data showed that three checkpoints had more than 100 unique downloads, 132 being the most at one location. The least visited location had only three downloads (Figure 6). Although it is uncertain whether all those 


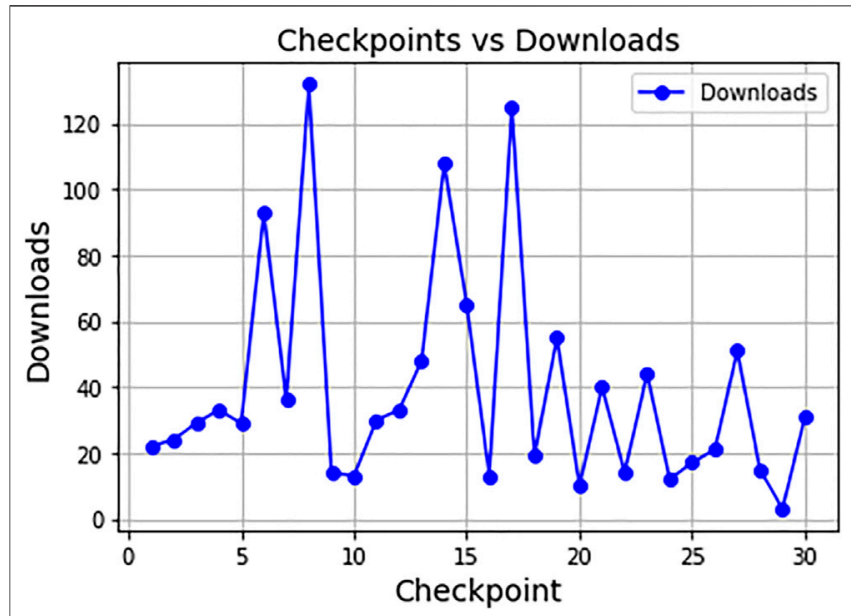

FIGURE 5 | Number of downloads at each checkpoint.

who visited a checkpoint completed the tasks or were just curious to find out how the application worked.

Further analysis of the task sheets returned by the 65 participants revealed that one of the three checkpoints with the most downloads was among the most visited locations. This checkpoint was outside a movie theater and the task was to do a drop jump. The checkpoint had a total of 108 downloads and was visited by 53 of the 65 participants who returned the task sheets. The other two most visited checkpoints, with 46 and 33 downloads respectively, were both at the beach. The second most visited location was a few meters away from the most visited one. The task at this location was to test the temperature of the water by hand and/ or to swim. At two checkpoints, the total number of downloads (33 and 14) matched the number of completed tasks in the returned task sheets. The tasks were to visit an e-sports center located in a gym, to count the number of steps leading up to the top of a castle by the beach, check how many strides were needed to get to the top, and once at the top, take a photo of the view. One location had 21 downloads, but none of these downloads were by the 65 participants who returned the task sheets. Figure 7A presents a summary of the numbers of tasks completed by each of the 65 participants and Figure 7B compares these to the total number of downloads at each checkpoint.

\section{DISCUSSION}

In the present study, we examined how to encourage active mobility and exploration through interactive play by exploiting the characteristics of the urban environment. We also examined the usability of a webAR application in creating an interactive experience in the built environment by revealing tasks at different checkpoints. Of those who took part in the event, 13 responded to a questionnaire about the usability of the AR application. The low response rate could be because families took part in the event and only one person from a family with children, for example, responded. Although a small sample, it met the minimum requirement to test the usability of the application (Tullis and Stetson, 2004), but it was not enough for further analyses such as comparing differences between groups and/or learnable and usable scales as presented in Lewis and Sauro (2009) to extract additional information from SUS data. The advantage of SUS is that it is technology-agnostic and is suitable for usability testing as technology evolves (Brooke, 2013). SUS just gives an overview of the usability of the system but does not identify specific usability concerns. We received some of these concerns from the open text responses and in three task sheets where participants mentioned the problems they had launching the application at one of the checkpoints.

Despite the few respondents to the follow-up survey, from the system logs, returned task sheets and some of the posts in

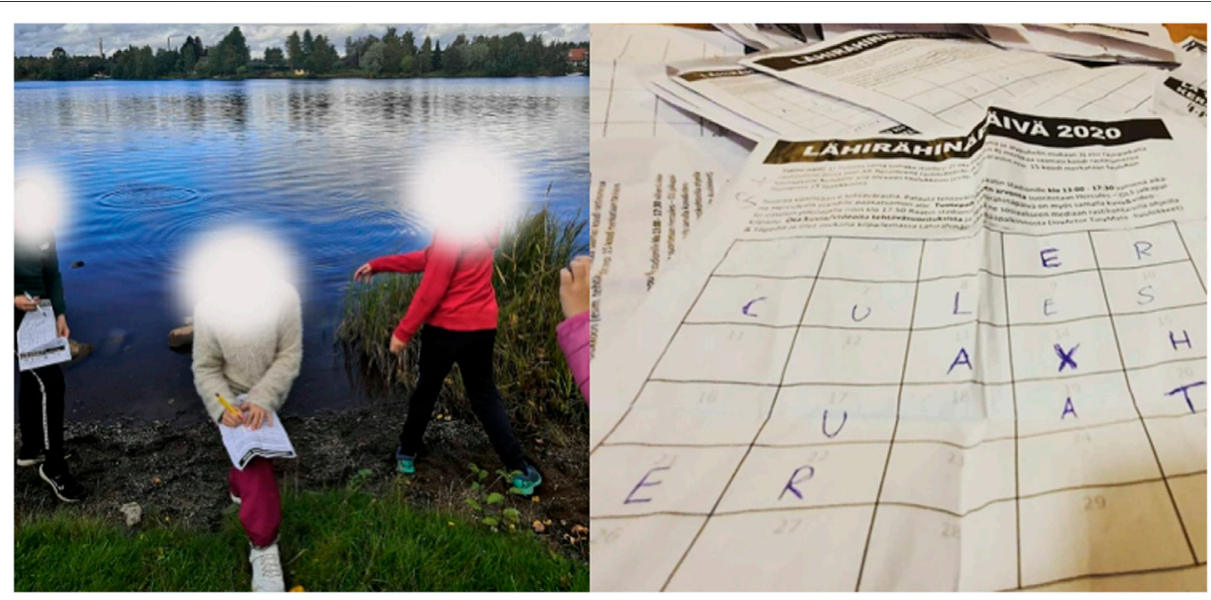

FIGURE 6 | Participants filling in the task sheet (left) and returned task sheet (right). Checkpoint visits and number of application downloads. 


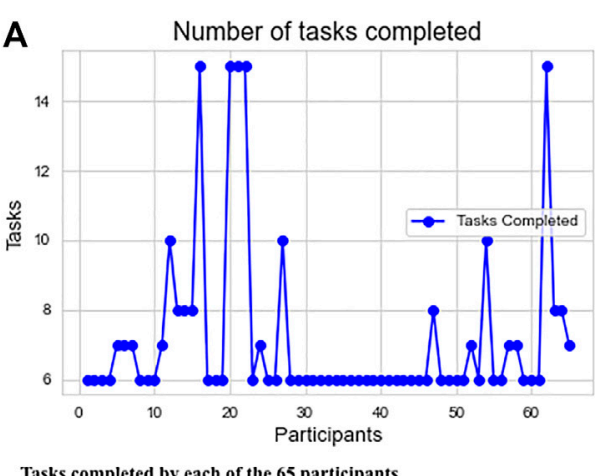

Tasks completed by each of the 65 participants

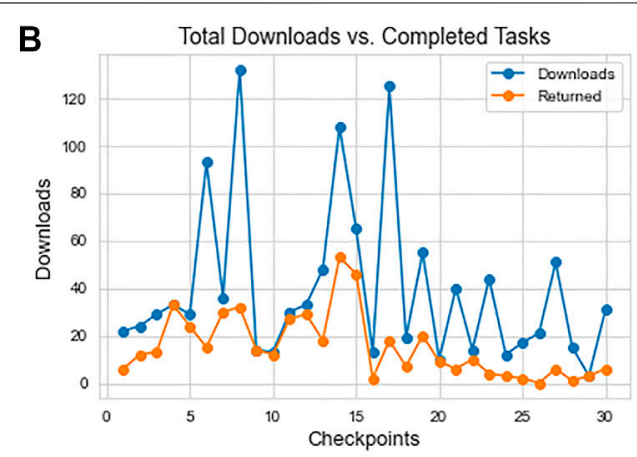

Tasks completed compared to total downloads

FIGURE 7 | Number of tasks completed by participants compared to total downloads.

social media, we could see that many participants interacted with the application and visited the checkpoints. Based on the system logs, there were hundreds of interactions with the application during the event. As doing the tasks required some form of interaction and collaboration, the results show that the study created opportunities to socially interact and explore different outdoor environments. Although it was not digital, participants could navigate with the map we provided and find the location of the AR tags. Some checkpoints were easy to find, and others were in close proximity to each other. Scanning the tags revealed the tasks required of participants. Because the event was for a single day, these tasks were relatively simple and required minimal effort. Some tasks required participants to only visit a specific location, take a photo, and share it on social media. There were fewer than 100 posts related to the event and some of these were by the same participants. This study contributes to the research on play in urban spaces by examining how games contribute to social interaction, urban exploration, and community awareness (Lindqvist et al., 2018; Pang et al., 2019; Fonseca et al., 2021; Tzima et al., 2021). The online posts and number of tasks completed by the 65 participants who participated in the prize draw demonstrate that people value fun, competitive games, and rewards afforded through locative play in public spaces (Papangelis et al., 2020).

The research focused on active mobility and urban exploration because prior research has shown the health benefits of being physically active, the impact of the built environment on physical activity and the role of locative media in engaging users and promoting health (Heath et al., 2006; Lee and Maheswaran, 2011; Coombes et al., 2013; Helbich et al., 2016; Kaczmarek et al., 2017; Broom and Flint, 2018). Integrating interactive technology into the environment may also be an effective way to analyze tendencies of human behavior over time, compare, for example, how participants from different locations or age groups respond to certain design features, and the effect of changes in the built environment on exercise behaviors and overall wellbeing (Coombes and Jones, 2016; Harris, 2018a; Kärmeniemi et al., 2018). Although it is possible to analyze data from activity-tracking applications in given locations, augmenting technology into the built environment offers the possibility of gathering more precise information regarding people's interactions with the features in the built environment (Kärmeniemi et al., 2018).

We did not have any data on the home location of the participants, so the study could not track how far participants ventured outside their own neighborhoods. However, analysis of the participants who visited the most locations shows they covered a distance of approximately $15 \mathrm{~km}$ (measured from the first location they visited to the last one-according to the numbered locations in the task sheet) (see Figure 5). The possibility of tracking their location as in Pang et al. (2019) would have provided information about their means of travel and how much time they spent at each checkpoint. This study was only for a day and the application was only used at the checkpoints, to have a better idea of how such an app can enhance interactivity and encourage active mobility; a longer duration and an application with more game elements are needed. Related studies are Pang et al. (2019) month-long field study on increasing community awareness during transit and Fonseca et al.'s (2021) study encouraging school-aged children to explore the environment searching for solutions to challenges and engage with other players and/or even strangers. The advantage of our study setup, although not conducive for evaluating the long-term impact, was that anyone could participate in playful exploration without feeling pressured or obligated to reveal any information. A future consideration for locative media is when considering residents with mobility challenges and those marginalized or stigmatized (Hjorth and Richardson, 2017; Lindqvist et al., 2018).

It was a rainy day when we conducted the study, which could have affected the level of participation. Maybe, such mobile urban games are more effective during dry weather as they rely on participants to travel actively outdoors (Coombes and Jones, 2016). When interpreting the results, it is also important to remember the limitations of the mostly educated survey demographic, a majority of whom were $41-50$ years. The lack of prior recruitment, which would have given the researchers more control over participants' actions, also limited the study. A mitigating factor in future studies would be to have a pre-andpost-test experimental design on a larger sample, where we collect 
participants' physical activity measures at baseline and at the end of the study. With multimethod approaches combining both subjective (surveys and interviews) and behavioral data (system logs), it is possible to gain a more accurate understanding of the impact of locative media.

There were hundreds of interactions with the application, but we do not know whether all these were by participants or curious passers-by. Comparing the number of downloaded task sheets with application downloads would have revealed the actual number of participants. Another limitation was the activation of the AR tags. In some locations, the tags failed to display the video, and in others, the video was interrupted with any slight movement. This hindered the overall experience for some participants and future iterations should make this process more streamlined. For example, by displaying the videos once it scans the AR tag without needing to align the phone's camera throughout the duration of the video, or receiving an alert when near a tag and the media displaying automatically or after being activated when within a specified distance. WebAR is perhaps more readily accessible, but it offers a limited selection of features compared to using a mobile application. In a mobile application, there are options for more interactivity.

Future improvements include adding gamified elements such as points, challenges, leaderboard, and virtual rewards (Pang et al., 2019; Fonseca et al., 2021) and considering player's preferences as there are contexts where users prefer certain features over others, as in Lindqvist et al. (2018) where cooperation, especially among families, was valued over competition. Future work should also focus on addressing the balance between the virtual and the physical world (Haahr, 2017; Korhonen et al., 2017) and linking in-game virtual rewards to actual activity in the physical environment as highlighted in Korhonen, Oduor and Isomursu's (2017) study about Zombies Run!

This pilot study outlined how to encourage urban exploration and active mobility through interactive games and is an initial step for a more comprehensive evaluation of community-wide locationbased games. The study suggests that this may be effective if the challenge of getting participants to engage can be overcome (Coombes and Jones, 2016; Harris, 2018a). As with earlier research, the key challenge is always developing solutions with long-term impact on lifestyle behavior change. Designing locative games for wellbeing requires considerate design choices of how to augment game mechanics into the built environment and of players' preferences and needs to take advantage of the strong connection between space and play (Dourish, 2006) to create playful designs. This would enable conducting research regarding the generality and maintenance of behavior change produced by these games (Morford et al., 2014). And how to integrate technology into the built environment to provide opportunities to influence behaviours at scale (Stibe and Larson, 2016).

\section{REFERENCES}

Arjoranta, J., Kari, T., and Salo, M. (2020). Exploring Features of the Pervasive Game Pokémon GO that Enable Behavior Change: Qualitative Study. JMIR Serious Games 8 (2), e15967. doi:10.2196/15967

\section{CONCLUSION}

The current study focused on encouraging active mobility and urban exploration through play. In setting up the study, we were interested in evaluating how the webAR application enhanced interactivity by having a decisive role in the activities but not dominating the user experience and interfering with the natural environment. We analyzed the usability of the application and users' perception was mostly positive. Results show that there were hundreds of interactions with the application and all 30 checkpoints had at least one visitor. Those who participated in the draw, visited 29 of these checkpoints. Among the limitations include the short duration of the study without active recruitment of participants, the sample size, limited features, and web-based nature of the application which limited the user experience for some participants. Overall, the study offered a test case for how to combine the built environment with interactive technology to encourage urban exploration, social interaction, exploration, and active mobility.

\section{DATA AVAILABILITY STATEMENT}

The dataset presented in this study can be found in online repository. The names of the repository can be found below: https://github.com/Modago/sus

\section{ETHICS STATEMENT}

Ethical review and approval was not required for the study on human participants in accordance with the local legislation and institutional requirements. Written informed consent from the participants' legal guardian/next of kin was not required to participate in this study in accordance with the national legislation and the institutional requirements.

\section{AUTHOR CONTRIBUTIONS}

MO was responsible for the literature review, analysis and documentation of the research. TP was responsible for the implementation of the study.

\section{ACKNOWLEDGMENTS}

We acknowledge grant support from the Finnish Cultural Foundation. The funder played no role in designing, conducting, interpreting or publishing the study.

Bangor, A., Kortum, P., and Miller, J. (2009). Determining what Individual SUS Scores Mean: Adding an Adjective Rating Scale. J. Usability Stud. 4, 114-123.

Brooke, J. (1996). "SUS: a 'quick and dirty' usability scale," in Usability Evaluation in Industry. Editors P. W. Jordan, B. Thomas, B. A. Weerdmeester, and I. L. McClelland, 189-194. 
Brooke, J. (2013). SUS: a retrospective. J. Usability Stud. 8 (2), 29-40.

Broom, D. R., and Flint, S. W. (2018). Gotta Catch 'Em All: Impact of Pokémon Go on Physical Activity, Sitting Time, and Perceptions of Physical Activity and Health at Baseline and Three-Month Follow-Up. Games Health J. 7 (6), 401-408. doi:10.1089/g4h.2018.0002

Chatterjee, S., and Price, A. (2009). Healthy Living with Persuasive Technologies: Framework, Issues, and Challenges. J. Am. Med. Inform. Assoc. 16 (2), 171-178. doi:10.1197/jamia.M2859

Chien, L., Koskinen, Elina., Leorke, Dale., Nummenmaa, Timo., and Peltonen, J. (2021). The World Is Your Playground: A Bibliometric and Text Mining Analysis of Location-Based Game Research. in Interactivity and Game Creation: 9th EAI International Conference, ArtsIT 2020, Aalborg, Denmark, December 10-11, 2020 (Springer Nature), 160.

Coombes, E., and Jones, A. (2016). Gamification of active travel to school: A pilot evaluation of the Beat the Street physical activity intervention. Health \& Place 39, 62-69. doi:10.1016/j.healthplace.2016.03.001

Coombes, E., van Sluijs, E., and Jones, A. (2013). Is environmental setting associated with the intensity and duration of children's physical activity? Findings from the SPEEDY GPS study. Health \& Place 20, 62-65. Health \& Place. doi:10.1016/j.healthplace.2012.11.008

Dourish, P. (2006).Re-space-ing place. Proceedings of the 2006 20th Anniversary Conference on Computer Supported Cooperative Work. New York, United States: ACM Digital Library, 299-308. doi:10.1145/1180875.1180921

Fonseca, X., Slingerland, G., Lukosch, S., and Brazier, F. (2021). Designing for meaningful social interaction in digital serious games. Entertainment Comput. 36, 100385. doi:10.1016/j.entcom.2020.100385

Ghosh, D., Foong, P. S., Zhang, S., and Zhao, S. (2018). Assessing the Utility of the System Usability Scale for Evaluating Voice-based User Interfaces. Proc. Sixth Int. Symp. Chin. CHI - ChineseCHI '18, 11-15. doi:10.1145/3202667.3204844

Grier, R. A., Bangor, A., Kortum, P., and Peres, S. C. (2013). The System Usability Scale. Proc. Hum. Factors Ergon. Soc. Annu. Meet. 57 (1), 187-191. doi:10.1177/ 1541931213571042

Haahr, M. (2017), Creating Location-Based Augmented-Reality Games for Cultural Heritage. Serious Games. JCSG 2017. Lecture Notes in Computer Science. Editors M. Alcañiz, S. Göbel, M. Ma, et al. 10622 (p. 313, 318). doi:10.1007/978-3-319-70111-0_29

Hamari, J., and Koivisto, J. (2015). Why do people use gamification services? Int. J. Inf. Management 35 (4), 419-431. doi:10.1016/j.ijinfomgt.2015.04.006

Harris, M. A. (2018b). Beat the Street: A Pilot Evaluation of a Community-wide Gamification-Based Physical Activity Intervention. Games Health J. 7 (3), 208-212. doi:10.1089/g4h.2017.0179

Harris, M. A. (2018a). The relationship between physical inactivity and mental wellbeing: Findings from a gamification-based community-wide physical activity intervention. Health Psychol. Open 5 (1), 205510291775385. doi:10.1177/2055102917753853

Heath, G. W., Brownson, R. C., Kruger, J., Miles, R., Powell, K. E., Ramsey, L. T., et al. (2006). The Effectiveness of Urban Design and Land Use and Transport Policies and Practices to Increase Physical Activity: A Systematic Review. J. Phys. Activity Health 3, S55-S76. doi:10.1123/jpah.3.s1.s55

Helbich, M., Emmichoven, M. J. Z. v., Dijst, M. J., Kwan, M.-P., Pierik, F. H., and Vries, S. I. d. (2016). Natural and built environmental exposures on children's active school travel: A Dutch global positioning system-based cross-sectional study. Health \& Place 39, 101-109. doi:10.1016/ j.healthplace.2016.03.003

Hjorth, L., and Richardson, I. (2017). Pokémon GO: Mobile media play, placemaking, and the digital wayfarer. Mobile Media Commun. 5 (1), 3-14. Mobile Media \& Communication. doi:10.1177/2050157916680015

Kaczmarek, L. D., Misiak, M., Behnke, M., Dziekan, M., and Guzik, P. (2017). The Pikachu effect: Social and health gaming motivations lead to greater benefits of Pokémon GO use. Comput. Hum. Behav. 75, 356-363. doi:10.1016/ j.chb.2017.05.031

Kärmeniemi, M., Lankila, T., Ikäheimo, T., Koivumaa-Honkanen, H., and Korpelainen, R. (2018). The Built Environment as a Determinant of
Physical Activity: A Systematic Review of Longitudinal Studies and Natural Experiments. Ann. Behav. Med. 52, 239-251. doi:10.1093/abm/kax043

Korhonen, O., Oduor, M., and Isomursu, M. (2017). Personalizing Narratives to Support Motivation for Physical Activity. Proceedings of the 30th Bled EConference: Digital Transformation: From Connecting Things to Transforming Our Lives. doi:10.18690/978-961-286-043-1.24

Lee, A. C. K., and Maheswaran, R. (2011). The health benefits of urban green spaces: A review of the evidence. J. Public Health 33 (2), 212-222. doi:10.1093/ pubmed/fdq068

Lewis, J. R., and Sauro, J. (2009). "The Factor Structure of the System Usability Scale," in Human Centered Design. Editor M. Kurosu (Germany: Springer Berlin Heidelberg), Vol. 5619, 94-103. doi:10.1007/978-3-642-02806-9_12

Lindqvist, A.-K., Castelli, D., Hallberg, J., and Rutberg, S. (2018). The Praise and Price of Pokémon GO: A Qualitative Study of Children's and Parents' Experiences. JMIR Serious Games 6 (1), e1. doi:10.2196/games.8979

Lopez, R. P. (2012). The Built environment and public health, Vol. 16. New Jersey, United States: John Wiley \& Sons.

Morford, Z. H., Witts, B. N., Killingsworth, K. J., and Alavosius, M. P. (2014). Gamification: The Intersection between Behavior Analysis and Game Design Technologies. Behav. Analyst 37 (1), 25-40. doi:10.1007/s40614-014-0006-1

Pang, C., Pan, R., Neustaedter, C., and Hennessy, K. (2019). City Explorer. Proc. 2019 CHI Conf. Hum. Factors Comput. Syst., 1-15. doi:10.1145/3290605.3300571

Papangelis, K., Saker, M., and Jones, C. (2020). Smart Cities at Play: Technology and Emerging forms of playfulness. Behav. Inf. Technology 39 (6), 607-609. doi:10.1080/0144929X.2020.1749338

Sallis, J. F., Cerin, E., Conway, T. L., Adams, M. A., Frank, L. D., Pratt, M., et al. (2016). Physical activity in relation to urban environments in 14 cities worldwide: A cross-sectional study. The Lancet 387 (10034), 2207-2217. doi:10.1016/S0140-6736(15)01284-2

Stibe, A., and Larson, K. (2016). Persuasive cities for sustainable wellbeing: Quantified communities. Int. Conf. Mobile Web Inf. Syst., 271-282. doi:10.1007/978-3-319-44215-0_22

Tullis, T., and Stetson, J. (2004). A Comparison of Questionnaires for Assessing Website Usability, in Usability Professional Association Conference. (Minneapolis, MN, United States) 1, 1-12.

Tzima, S., Styliaras, G., and Bassounas, A. (2021). Revealing Hidden Local Cultural Heritage through a Serious Escape Game in Outdoor Settings. Information 12 (1), 10. doi:10.3390/info12010010

United Nations (2018). $68 \%$ of the world population projected to live in urban areas by 2050. United Nations - Department of Economic and Social Affairs. https://www.un.org/development/desa/en/news/population/2018-revision-ofworld-urbanization-prospects.html.

World Health Organization (WHO) (n.d.). Physical Inactivity: A Global Public Health Problem. Retrieved from: https://www.who.int/teams/healthpromotion/physical-activity. (November 20, 2021).

Conflict of Interest: The authors declare that the research was conducted in the absence of any commercial or financial relationships that could be construed as a potential conflict of interest.

Publisher's Note: All claims expressed in this article are solely those of the authors and do not necessarily represent those of their affiliated organizations, or those of the publisher, the editors and the reviewers. Any product that may be evaluated in this article, or claim that may be made by its manufacturer, is not guaranteed or endorsed by the publisher.

Copyright (c) 2021 Oduor and Perälä. This is an open-access article distributed under the terms of the Creative Commons Attribution License (CC BY). The use, distribution or reproduction in other forums is permitted, provided the original author(s) and the copyright owner(s) are credited and that the original publication in this journal is cited, in accordance with accepted academic practice. No use, distribution or reproduction is permitted which does not comply with these terms. 


\section{OPEN ACCESS}

Edited by:

Anton Nijholt,

University of Twente, Netherlands

Reviewed by:

Viktor Bedö,

University of Applied Sciences and Arts Northwestern Switzerland,

Switzerland

Ricardo José Vieira Baptista University of Porto, Portugal

Troy Innocent,

RMIT University, Australia

*Correspondence: Ash Eliza Smith

ash.e.s@unl.edu

${ }^{t}$ These authors have contributed equally to this work and share first authorship

Specialty section:

This article was submitted to Human-Media Interaction,

a section of the journal Frontiers in Computer Science

Received: 08 May 2021

Accepted: 11 August 2021

Published: 28 October 2021

Citation:

Sherman S, Smith AE, Forster D and Emmenegger C (2021) Adventure

Mode: A Speculative

Rideshare Design.

Front. Comput. Sci. 3:707081. doi: 10.3389/fcomp.2021.707081

\section{Adventure Mode: A Speculative Rideshare Design}

\author{
Stephanie Sherman ${ }^{1 \dagger}$, Ash Eliza Smith ${ }^{2 \dagger \star}$, Deborah Forster ${ }^{3}$ and Colleen Emmenegger ${ }^{4}$ \\ ${ }^{1}$ University of the Arts, London, United Kingdom, ${ }^{2}$ University of Nebraska-Lincoln, Lincoln, NE, United States, ${ }^{3}$ Independent \\ Researcher, San Diego, CA, United States, ${ }^{4}$ UC San Diego Design Lab, University of California, San Diego, San Diego, CA, \\ United States
}

Most smart city projections presume efficiency, predictability, and control as core design principles for smart transportation. Adventure Mode is a speculative design proposal developed as part of a research project with a major automotive company that proposes uses and interactions for Autonomous Vehicles (AVs) and rideshare advancements that defy these normative presumptions. Adventure Mode reframes the focus of moving vehicles from destination-based experiences to journey-based ones. Adventure Mode pushes the probabilities for unexpected encounters and anonymous play in increasingly predictable and predicted urban environments. It embraces the submission to algorithmic decision and chance as a ludic modality in human-computer interactions and urban artificial intelligence.

Keywords: Human-Centered Design (HCD), Design Fiction, Smart Cities, Speculative Design, Autonomous Vehicles (AVs), Play, Locative Media, Human-Computer Interaction (HCl)

\section{ADVENTURE MODE: A SPECULATION}

You step outside on Tuesday at 5:30 pm. It is a summer afternoon in downtown San Diego. It is balmy, and you smell salt. You were going to join your office workers for a happy hour, but you long for something different and less predictable in the transition between work and home. You open your rideshare app, and when prompted to enter your destination, you click the button that says, "Adventure Mode: Take me somewhere new." You answer a few questions about your preferences for the experience: duration, mood, sensations, sociality, strenuousness, anonymity, and risk. You select a three out of ten on the sociality scale when prompted: you want to hang out with 1 or 2 people, but probably not for very long. You have no idea what the encounter will be like. It could be pleasant or jarring, flat or fantastic. This is what excites you. Last time you found yourself on an all-night hike with a crew to the top of Mount Helix (having selected a ten for many preferences that evening). This afternoon calls for something lighter. The car picks you up, and there are two people inside. Are they also in Adventure Mode? It does not matter. You are already feeling exhilarated by ditching the obligatory happy hour, ready for the unexpected. One of the riders introduces themself via the app as $\mathrm{Ha} \mathrm{Ha.} \mathrm{"Hey} \mathrm{Ha} \mathrm{Ha,"} \mathrm{you}$ say directly to them: "are you also in Adventure Mode"? Ha Ha grins. The driverless van dips into traffic, and for a moment, you get concerned that this Adventure is going to be sitting in rush hour traffic, but then you get a sync-indicator from another van a few lanes away. The two vehicles exit under the overpass and stop at a tiny inlet park beside a parking lot. You find yourself under a tree full of parrots beside a moss-covered fountain, eyes shut, doing a few songs of whisper karaoke with a group of four strangers. You are not much of a singer, but it does not matter since slight discomfort with the unexpected is exactly what you craved. The hour before dinner with your inlaws offers an unforgettable moment of respite from everything predictable about a normal day in algorithmic life.

Dialogues about trust and efficiency often dominate speculations about automation and driverless cars in smart cities. Through the premise of playable cities, researchers, practitioners, and theorists 
have challenged rationalistic smart city narratives, conceptualizing their transformation through intermediation, interfaces, and pervasive play, challenging the presumed realities of technologically transformed and algorithmically driven urban environments, and focusing on smart city applications that allow for social, entertaining, and affective interactions (Nijholt, 2017). Less considered are the ways that emerging transportation design might transform play and how play might transform transportation design (Figure 1).

Autonomous Vehicles (AVs) can be viewed as "multidisciplinary technology," one that not only provides enhanced digital connectivity but also has the potential to adjust the logics of navigation and transport in the city and the connection between its human users. This offers a special opportunity to leverage AVs as playspaces. The promises of AV technology typically include reduced travel time, environmental impact, and traffic congestion, all which rely on efficient and intelligent pathfinding through connected-vehicles communications (Bagloee et al., 2016; Abduljabbar et al., 2019). But as the history of any technological development shows, all outcomes of such capacity will not be practical or rational. Leveraging route optimization algorithms and the ability to communicate easily between vehicles also open opportunities for play, an extension of AV technologies that is often overlooked by manufacturers. As a design method for investigating possible futures, speculative design can deploy play as a means to challenge normative presumptions about transportation use in design processes and to explore secondary effects and unintended outcomes of AV development (Dunne and Raby, 2013). Focusing on the potential for play in AV design not only enables focus beyond traditional metrics, but also is one way to accelerate reductions in emissions and vehicle miles traveled by encouraging shared vehicle use and reducing our current motivations for individual vehicle ownership.

\section{RE-WORKING THE DREAM OF SEAMLESS TRANSIT}

In 2019, a leading automotive original equipment manufacturer (OEM) commissioned a team of researchers at the UC San Diego Design Lab Automation team to research in-transit amenities for future rideshare experiences. The OEM's design briefly proposed a rideshare scenario where a middle-aged woman signs up for a rideshare taxi. Their prompt text reads "Sally taps on the offers page and is immediately drawn to an advertisement about discounts on Dyson products for new riders. She taps on the advertisement and is brought to an Amazon page, which states that there is a 20 percent exclusive discount on all Dyson items for new autonomous-driving taxi riders. Sally happily purchases a Dyson vacuum cleaner from Amazon, filling out the necessary details." Between the user-interface presumption that the rider would use an in-car screen and the gendered presumption of a purchase of a vacuum cleaner by a woman rider, the Automation Team knew we had a lot to do to revise this commercialized and oversimplified vision of the future. During weekly workshops, undergraduate students developed DIAL maps (Day-in-a-Life) and Journey Maps based on observational data and their own travel experiences. These maps also asked participants to depict an improved transit future based on their imagined ideas, which typically focused on reduced transitions, seamless routes, and trafficless encounters (Figure 2).

The OEM's vision was consistent with the majority of perspectives of workshop participants, students, transport designers, smart city planners, and consultants. In these contexts, even the most enlightened participants almost always imagine the future of transportation as one of efficiency and hyper commercialization. Transit is regularly idealized as part of an optimized future, where direct routes and trafficless journeys avoid all interruptions, transitions, and altercations with the help of autonomous algorithms. This dream of seamless transit has long been embedded in transit imaginaries. GM's 1939 exhibit for the World's Fair, designed by Bel Geddes, depicted smooth trafficless highways. Most urban planners and engineers still aspire to recreate this fantasy, using smart cities to solve problems by eliminating conflict and disadvantageous clustering through prediction and anticipation of human mobility patterns. Although transportation experts are now including activitybased travel demand models in their analyses (Hagerstrand, 1970; McNally and Rindt, 2008; Pinjari and Bhat, 2011), these models are still based on synthetic populations that presume that the intention of all travel redesign is to exclusively improve efficiency. But efficiency itself often turns out to be inefficient in the long run. Pursuits of efficiency ultimately encounter the challenges of Braess's Paradox which describes the fact that expanding capacity induces demand (Frank, 1981). Efficiency, in fact, always loses to desire. Anthony Downs describes this as the principle of triple convergence (Downs, 2005), in which any initial reductions in congestion using supply-side tactics will rapidly be offset by drivers who formerly used alternative routes coming back to the roadway. Efficiency not only cannot account for the entire transit development paradigm of the future, but also is a limited framework for understanding behavior in the present. To counteract these normative tendencies and logics, a team of four speculative designers worked alongside the human-centered researchers, developing possibility grids based on near, long-term, and far future outlooks through discussion and brainstorming sessions. Their mandate was to develop provocations and systems to challenge the presumed design assumptions about mobility futures. Over five weekly sessions, the speculative design team developed "What If... ?" proposals and counterfactuals that challenged the presumptions of efficiency and seamless transit. The aim was to complexify the idea of in-transit amenities for the OEM through opportunities for experiential play, but also to understand play as a design principle to unlock presumptions about linear projections of the future.

\section{LEISURE}

While most smart city rhetorics promise to eliminate wasted energy, time, and space to provide safety and health, there are also a number of inquiries around the new forms of play emerging amidst the efficiency fantasies. Smart cities, as Townsend 
describes, are "places where information technology is combined with infrastructure, architecture, everyday objects, and even our bodies to address social, economic, and environmental problems" (Townsend, 2013). Smart cities also offer new excesses and ludic dimensions, since the integration of information technology produces new opportunities and constraints. Car and mobility cultures have always produced surpluses that respond to phenomena beyond need: hacking, augmenting, freeriding, and repurposing, from aestheticization of cars as cultural expressions to their expanded uses in pleasure, sex, and sport.

Transport histories also demonstrate the ways in which the ludic and leisurely has long combined with utility and efficiency in accelerating transportation development. Henry Ford's Model T was marketed not as a means of getting to work (that was the job for the streetcar), but as a device for weekend exploration and wilderness adventures. Ford shifted the workweek from six days to five, organizing the weekend to enhance the assembly line worker's desire to purchase their own Ford (Doray and Macey, 1988). At the same time, amusement parks became popular destinations, producing new physical experiences of motion and exhilaration, accelerating bodies through physical spaces as worker bodily movement was reduced and constrained in repetition. The "ride" encapsulates this dual meaning, suggesting both the simple act of traveling from one point to another on or in a vehicle, but also the act of transport as enjoyment rather than perfunctory action, the out-of-controlness and submission to movement. In this way, transport serves this dual function of a path to an end and the pleasure of passage itself. The recent popularity of scooters and micro mobility reinforces this lineage, recentering the journey rather than destination. The purpose of the speculative design team was to build upon this legacy and contemporary shifts. Most speculative work on autonomous futures tends to focus on the interior of the car as a source of entertainment (video gaming, movie watching), rather than approaching the journey as entertainment itself. Rather than reduce future imaginaries to the digital realm, the speculative design team imagined how algorithmic rideshare might transform urban play. Smart cities presume that urban subjects are locatable and located, promising that everything can be computationally discovered, controlled, shared, and predicted.

Smart city infrastructures and the global positioning system (GPS) enables both transit vehicles and users to be tracked geospatially, producing aggregate data about mobility and traffic patterns that can inform infrastructural decisions. These networks have enabled the creation of locative media, which uses technologies such as GPS, WiFi, Radio-frequency identification (RFID), and location-aware mobile devices to create geospatial experiences that digitally play in real world locations. Real-time or mixed reality is overlaid with augmented or virtual reality, allowing users to visit real life locations in order to experience digital interfaces. These designs rely on the interconnection between situated physical spaces and a digital twin or digital overlay. Increasing public concerns over surveillance, data privacy, and security push toward a potential need for the ludic, where the unpredictable, undisclosed route becomes a form of pleasure, and both public transport and private transport offer opportunities for reinscribing urban landscapes with unknown journeys.
Amusement might then be understood as transportation without a destination, mobility without locatability.

\section{ADVENTURE MODE}

Adventure Mode is a speculative proposal for a rideshare experience that augments and counteracts the focus on efficient mobility experiences in the smart city. The premise is a simple provocation - an option inside a rideshare app called Adventure Mode that allows riders to let the algorithm ultimately choose the destination and route, allowing the rider to select certain parameters to curate or modify their experiencelenleadertwodots. Selection parameters might be elements like the popularity of prior visits based on place or time-specific constraints, sociability, routes that are specifically under construction or reconstruction, temperature or weather conditions, and draw upon other adventures programmed or suggested by participants. The Adventure Mode algorithm might also incorporate pre-existing needs of the car like car-washing or checkups into rider experiences, merging automaintenance with human experience. The Adventure Mode algorithm could draw upon previous rider selections and experience reviews, host adventures designed by other riders, or encourage direct real-time synching with a broader network of user profiles and identities.

Harnessing the opportunities of mobility-as-service, Adventure Mode re-imagines mobility as play. It addresses three critical aspects of play as a means for harnessing the unknown in an ever more interpretable, navigable, and computational mobile world. It posits 1) chance: the intentional construction of happenstance via technology, 2) de-control: ambiguity and the freedom not to choose, and 3) role-play: the option of anonymity and ambiguity in embodied interactions in an ever identifiable and attributable world (Caillois and Barash, 2001). Adventure Mode uses geolocation to dislocate its users. The premise is to enhance uncertainty and presence at once, to bring together strangers, to add the experience of unknown locability and destination (or lack thereof) travel, and to create a condition wherein one can intentionally submit to the algorithm, severing the knowability or intentionality of participants to various information streams. In a world where we can always map and be mapped and located, the premise of an unknown destination or direction, the act of giving up control, becomes a means of recovering the lost art of exploration. Instead Adventure Mode offers the sensibility of happenstance, a submission to the adventure and re-engaging of presence, one of the core aspects of play.

\subsection{Self-Driving Dérives}

Adventure Mode is inspired by The Situationist concept of the de' rive (drift), a practice of exploring the city through unplanned adventures with unknown outcomes, with the intent of encountering the city's unexpected confluences and conditions. As Situationist leader Guy Debord said of de'rive participants, they "let themselves be drawn by the attractions of the terrain and the encounters they find there" (Debord, 1994). De'rives were mostly notoriously done on foot, but they were also done via taxi cab, coercing a driver to participate or even lead a quasi- 
enchanted series of twists and turns taken in response to emerging circumstances rather than in pursuit of a final locale. This concept was extended in Thomas Pynchon's V. (Pynchon, 1963), in which characters "yo-yo," riding the subway beneath the city along its entire loop as a means to inscribe the movement of urban infrastructure flows within their body, consciously tracing the typically unconscious paths of systems within themselves.

\subsection{Ambiguity as Adventure}

Adventure Mode embraces play as a celebration of ambiguity. In Performance Studies: An Introduction, Richard Schechner argues that "playing is double-edged, ambiguous, moving in several directions simultaneously" (Schechner, 2017). It is never resolute; following an indeterminate path is both the experience and the phenomenon itself. Brian Sutton-Smith (Sutton-Smith, 1997) follows Williams Empson's classic Seven Types of Ambiguity (Empson, 1953), showing how they apply to play, including ambiguity of intent ("are all the passengers in "Adventure Mode" or are they just on their way home from work?"), transition ("now are we in "Adventure Mode"...?"), contradiction (a rider in "Adventure Mode" introducing themselves under a pseudonym), and meaning ("is this “Adventure Mode" or "play ridenmeet"?"). Just as amusement park rides pushed an industrial immobilized working body in new directions, our contemporary world invites play experiences that build upon the pleasure of cognitive submission, activating the freedoms not to choose as a key form of enjoyment in contexts where everything is customizable and personal and on-demand. Play is pretend, but in the smart city, it is also about losing control over every single instance, of separating mastery of one's own knowledge from what the city might know about you.

\subsection{Spontaneous Communities}

In an era where identities are hyper-contested and commodified, where every social profile is an exposure of preferences and interpersonal networks, Adventure Mode offers an option of more varied forms of interpersonal connectivity. It lets you be a stranger interacting with other strangers in unexpected ways; it invites avatars, anonymity, pretending, or hyper-identities. It generates a point of mediation that offers safety and protection through appified experience but also generates a degree of risk and uncertainty, an aspect of the city or megacity no longer present in a seamless and an efficient smart city world. In this way, Adventure Mode might produce what Victor Turner called "spontaneous communitas" (Turner, 1974), a phenomenon in which status is abolished and recomposed through an unexpected or unpredictable shared circumstance. Turner described the phenomenon as producing the ability for people to encounter each other directly, "nakedly" and intimately in a face-to-face encounter through a shared or common space and time. In Adventure Mode, this encounter may be intentionally disguised or directly honest, as raw and cloaked identities in Adventure Mode play are intentionally indistinguishable. Nonetheless, a sense of conviviality produces a temporary cultural commons, which generates a spirit or sensibility of shared movement in that particular moment. Turner describes this as a form of "long-form improvisation" where the pilgrimage or journey requires the realization of a number of spontaneous actions in response to ever-changing circumstances. Adventure Mode creates a shared social encounter that navigates the rules of play, forwarding the ludic dimensions of identity and community.

Adventure Mode accelerates the ways that mobile phones and "smart" connectivity has overcome the logic of stranger danger that characterized liberal messaging about others and otherness throughout the late 20th century. Rideshare, especially pool systems that partner you on routes to share with other riders, has already disrupted long-held maxims about never getting into cars with strangers. Rideshare is already poised to embrace chance and coincidence, albeit constrained by the logics of destination. Adventure Mode enhances the algorithmic intersection between places, strangers, and route, repositioning the future of transportation towards a new publicness and phenomena of the commons that enables unpredicted formations of connected strangers.

\subsection{Risk}

Adventure Mode might allow users to select the level of uncertainty and risk that they desire. Should a user select a higher level, deep and/or dark play might occur. Deep play is all-absorbing, pushing experience to ecstatic heights; i.e., biking in a dense urban city that requires weaving in and out of the cars with precise concentration produces enhanced dimensions of embodiment. It is akin to Callois's ideas of vertigo or ilinx (Greek for whirlpool), where the consequences are altered perception or loss-of-control, generating an out-of-body experience that reinforces physical sensation and vulnerability (Caillois and Barash, 2001). Dark play occurs when some of the players do not know that they are playing; it is also known as pervasive play, where the rules of play or the "magic circle" spill out into everyday life, mixing the spaces of pretend and reality. People pretending to be crazy in a park, where the passing commuters do not know that they are pretending, is dark play, creating a "lusory attitude" or awareness of the playspace that is not shared by the non-player or observers (Fischer and Hornecker, 2017). Adventure Mode can activate these forms of deep and dark play against the safety and surveillance orientations of the smart city, using disruption and inversion to subvert identity transparency and efficiency, allowing users to lose themselves in a world where one is always locatable, intelligible, and found. Adventure Mode might be understood as an "infinite game" in transportation; the goal is not to realize any particular objective or rules, but rather to harness the mobility network as a source of collective exaltation (Carse, 2011).

Adventure Mode is not an idealization; it is a speculation with obvious downsides. Adventure Mode does not intend to establish an autonomous form of play; rather it is contingent upon the algorithms of rideshare platforms and AV systems, subject to the same compromises of data, privacy, and capital that rideshare apps today require in exchange for use. Using driverless vehicles for play and entertainment has the potential to increase the number of vehicles in already congested and carbonconsumptive urban areas. The shift away from personal vehicle ownership towards mobility-as-service ecosystems will engage social, geographic, ecological, and psychic 


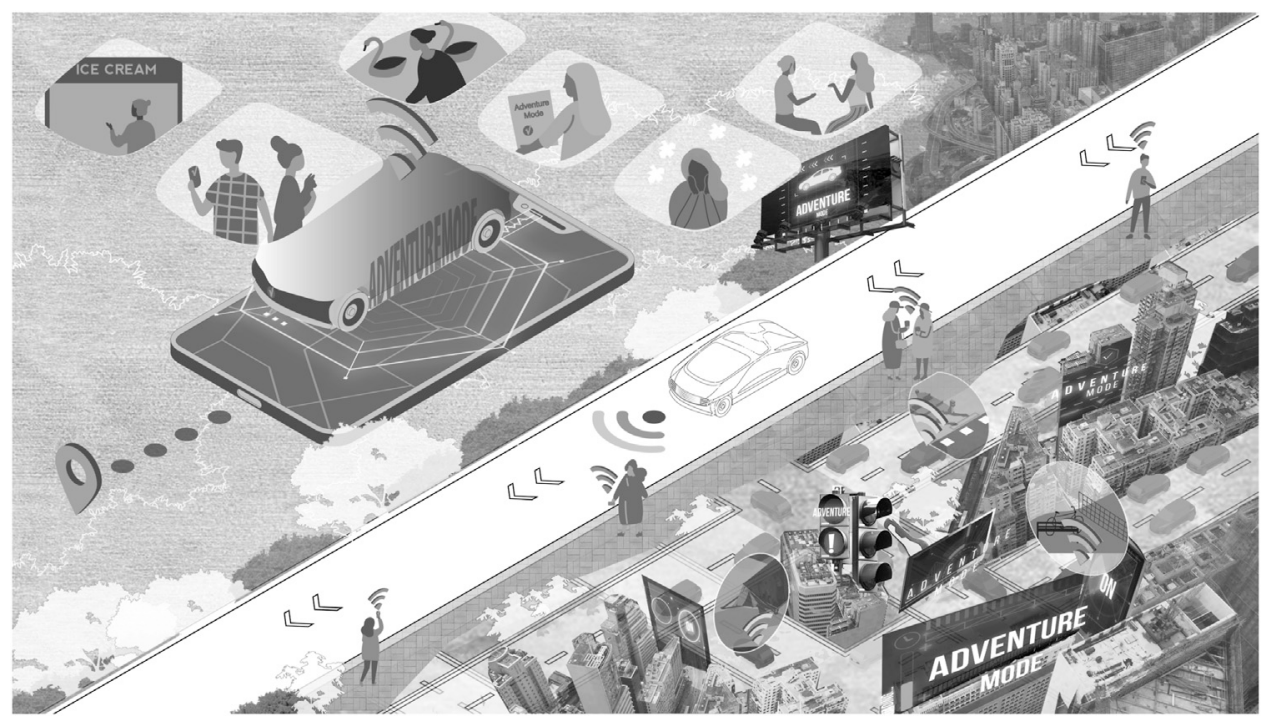

FIGURE 1 | Adventure Mode (image by Hanwen Chen).

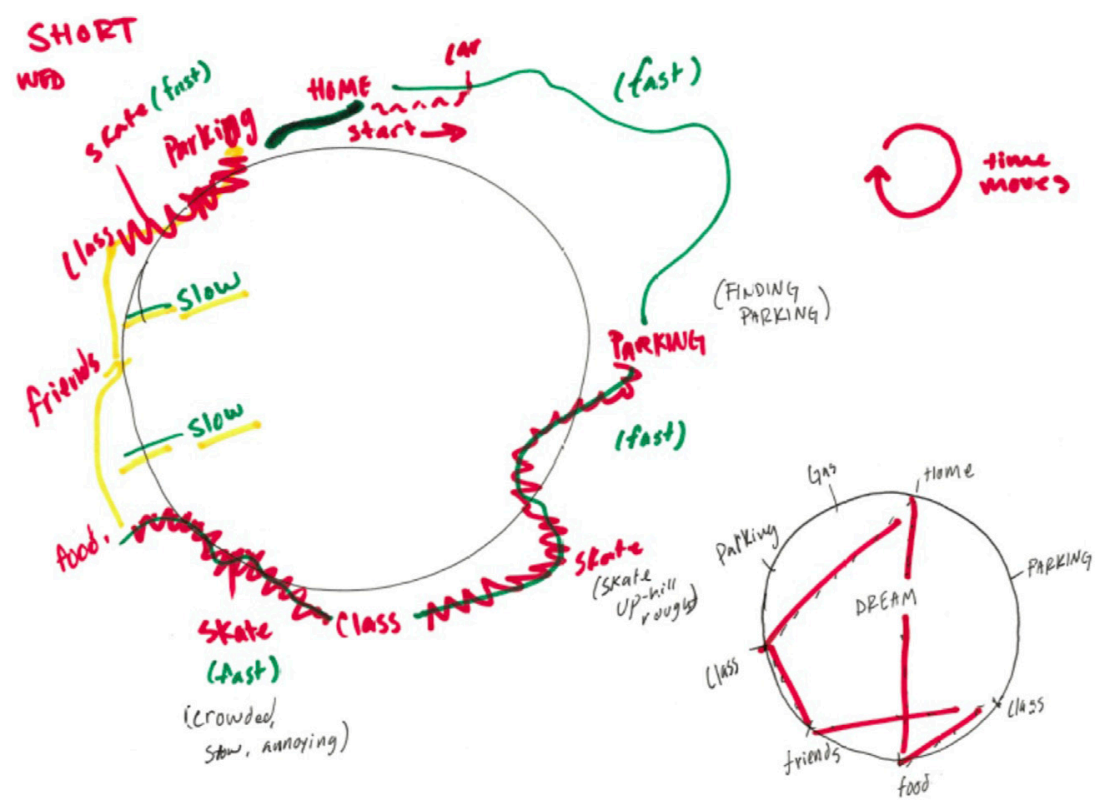

FIGURE 2| This Journey Map depicts a day in the life of a mobility user. Participants map an experienced day (larger upper left image) and an ideal future day (small lower right image). Notice the future ideal with short, straight, extremely efficient lines within the circle, in contrast to the more chaotic lines of the experienced day.

transformations for vehicle ownership and its logics of isolation and control. It relies on participants who have leisure time and funding to cover entertainment costs and who are free from dependents. While Adventure Mode could certainly accommodate various levels of ability, safety, and trust, it would need to encourage this for the more vulnerable, less recognized, and ensure its algorithm and technologies supported trust and security during play. Adventure Mode is likely largely an urban game, making encounters over close proximity and short time frames.

\section{TRANSIT PLAY IN THE SMART CITY}

As a speculative design proposal, Adventure Mode operates more as a provocation than a proposition. It agitates the typical dialogues about trust that often dominate automation and driverless car debates, and the emphasis on efficiency across smart cities. It extends the existing narratives around the potential for play and smart cities into the transportation space, linking the rides of autonomous cars and their algorithms with amusement experiences. Since Adventure 
Mode puts more trust in the vehicle system rather than less, it imagines a world in which the autonomous network generates a retreat from the banalities of the efficiencies it provides. Adventure Mode opens up a playspace of transportation and technological movement experiences.

Proposals for algorithmic decisions almost never account for experiential value: the default for Google maps is to route journeys based on efficiency in timing (or distance), which often puts cars on highways for short periods of time, even if the difference between highway and streets is but a matter of minutes. Adventure Mode accounts for other priorities, like psychological experiences of time in terms of view, perspective, and complexity of surroundings; the need for interaction and chance encounters with strangers and unexpected places; and the desire for embodied movement in various forms. In sum, it offers a new way to consider play in smart cities as a means of moving through and with complexity. Adventure Mode might contribute to the pragmatic and functional considerations that shape User Interaction and Experience as a thought experiment, but its true goal is to embed play in smart city contexts. The premise is to not only simply reproduce what has been historically achieved in transport design, but to entangle the ludic and algorithmic and mechanic aspects of the journey in unexpected configurations that challenge normative human interaction and social behavior, embracing play beyond the perfunctory in transport design.

\section{REFERENCES}

Abduljabbar, R., Dia, H., Liyanage, S., and Bagloee, S. A. (2019). Applications of Artificial Intelligence in Transport: An Overview. Sustainability 11, 189. doi:10.3390/sul1010189

Bagloee, S. A., Tavana, M., Asadi, M., and Oliver, T. (2016). Autonomous Vehicles: Challenges, Opportunities, and Future Implications for Transportation Policies. J. Mod. Transport. 24, 284-303. doi:10.1007/s40534-016-0117-3

Caillois, R., and Barash, M., (2001). Man, Play, and Games (Trans.) (Chicago: University of Illinois press).

Carse, J. (2011). Finite and Infinite Games (New York: Simon \& Schuster).

Debord, G. (1994). The Society of the Spectacle (New York: Zone Books).

Doray, B., and Macey, D. (1988). From Taylorism to Fordism: A Rational Madness (London: Free Association Books).

Downs, A. (2005). Still Stuck in Traffic: Coping with Peak-Hour Traffic Congestion (Washington, DC: Brookings Institution Press).

Dunne, A., and Raby, F. (2013). Speculative Everything: Design, Fiction, and Social Dreaming (Cambridge, MA: MIT press).

Empson, W. (1953). Seven Types of Ambiguity. London: William Empson. (Chatto and Windus).

Fischer, P. T., and Hornecker, E. (2017). Creating Shared Encounters through Fixed and Movable Interfaces. In Playable Cities (New York: Springer). 163-185. doi:10.1007/978-981-10-1962-3_8

Frank, M. (1981). The Braess Paradox. Math. Programming 20, 283-302. doi: $10.1007 / \mathrm{bf} 01589354$

Hagerstrand, T. (1970). What about People in Regional Science. New York: Springer.

McNally, M. G., and Rindt, C. (2008). The Activity-Based Approach.. Berlin: Researchgate.

Nijholt, A. (2017). Towards Playful and Playable Cities. In Playable Cities (New York: Springer). 1-20. doi:10.1007/978-981-10-1962-3_1

\section{DATA AVAILABILITY STATEMENT}

The original contributions presented in the study are included in the article, and further inquiries can be directed to the corresponding author.

\section{AUTHOR CONTRIBUTIONS}

All authors listed have made a substantial, direct, and intellectual contribution to the work and approved it for publication.

\section{FUNDING}

Funding for the research was provided through a gift from Hyundai Motor Company. The authors declare that this study received funding from Hyundai Motor Company. The funder was not involved in the study design, collection, analysis, interpretation of data, the writing of this article or the decision to submit it for publication.

\section{ACKNOWLEDGMENTS}

Thanks are due to Sascha Pohflepp, a co-creator of Adventure Mode, and the dedicated group of undergraduate students that assisted in the research as part of the UC San Diego Automation Playground Team.

Pinjari, A. R., and Bhat, C. R. (2011). Activity-based Travel Demand Analysis. In A Handbook of Transport Economics (Massachusetts: Edward Elgar Publishing).

Pynchon, T. (1963). V.: A Novel. Philadelphia: Lippincott Philadelphia.

Schechner, R. (2017). Performance Studies: An introduction (Oxfordshire, England: Routledge).

Sutton-Smith, B. (1997). The Ambiguity of Play (Cambridge: Harvard University Press).

Townsend, A. M. (2013). Smart Cities: Big data,Civic Hackers, and the Quest for a New Utopia (WW Norton \& Company).

Turner, V. (1974). Dramas, fields and Metaphors, Ithaca and London (Cornell University Press).

Conflict of Interest: The authors declare that this study received funding from Hyundai Motor Company. The funder was not involved in the study design, collection, analysis, interpretation of data, the writing of this article or the decision to submit it for publication.

Publisher's Note: All claims expressed in this article are solely those of the authors and do not necessarily represent those of their affiliated organizations, or those of the publisher, the editors and the reviewers. Any product that may be evaluated in this article, or claim that may be made by its manufacturer, is not guaranteed or endorsed by the publisher.

Copyright (C) 2021 Sherman, Smith, Forster and Emmenegger. This is an open-access article distributed under the terms of the Creative Commons Attribution License (CC $B Y)$. The use, distribution or reproduction in other forums is permitted, provided the original author(s) and the copyright owner(s) are credited and that the original publication in this journal is cited, in accordance with accepted academic practice. No use, distribution or reproduction is permitted which does not comply with these terms. 


\section{OPEN ACCESS}

Edited by:

Yoram Chisik,

Independent researcher, Haifa, Israel

Reviewed by:

António Fernando Coelho,

University of Porto, Portugal

Jussi Holopainen,

University of Lincoln, United Kingdom

Tonguc Ibrahim Sezen,

Teesside University, United Kingdom

*Correspondence: Louis Chew

louis.chew@sydney.edu.au

Specialty section:

This article was submitted to

Human-Media Interaction,

a section of the journal

Frontiers in Computer Science

Received: 30 November 2020 Accepted: 28 September 2021 Published: 15 November 2021

Citation:

Chew L, Hespanhol L and Loke L (2021) To Play and To Be Played:

Exploring the Design of Urban Machines for Playful Placemaking.

Front. Comput. Sci. 3:635949.

doi: 10.3389/fcomp.2021.635949

\section{To Play and To Be Played: Exploring the Design of Urban Machines for Playful Placemaking}

\author{
Louis Chew*, Luke Hespanhol and Lian Loke \\ Design Lab, School of Architecture, Design and Planning, The University of Sydney, Sydney, NSW, Australia
}

Within the paradigm of the smart and playable city, the urban landscape and street furniture have provided a fertile platform for pragmatic and hedonic goals of urban liveability through technology augmentation. Smart street furniture has grown from being a novelty to become a common sight in metropolitan cities, co-opted for improving the efficiency of services. However, as we consider technologies that are increasingly smarter, with human-like intelligence, we navigate towards uncharted waters when discussing the consequences of their integration with the urban landscape. The implications of a new genre of street furniture embedded with artificial intelligence, where the machine has autonomy and is an active player itself, are yet to be fully understood. In this article, we analyse the evolving design of public benches along the axes of smartness and disruption to understand their qualities as playful, urban machines in public spaces. We present a concept-driven speculative design case study, as an exploration of a smart, sensing, and disruptive urban machine for playful placemaking. With the emergence of artificial intelligence, we expand on the potential of urban machines to partake an increasingly active role as co-creators of play and playful placemaking in the cities of tomorrow.

Keywords: play, playable city, urban machines, placemaking, interaction design, public bench, urban prototype, smart city

\section{INTRODUCTION}

Against the smart city backdrop (Nam and Pardo, 2011), the advent of playable cities has brought a creative imperative to urban liveability. The fabric of the city is reconfigured for playful human experiences, with streets, buildings, and street furniture transformed into potential ludic opportunities through digital augmentation. The interweaving of technology with the urban fabric advances the implementation of creative solutions addressing not only efficiency but also the quality of city services, processes, and interactions (Calder, 2016; Ligthart and Ramjee, 2017; Mosco, 2019). Moreover, the functionalities of urban technology are adaptable to serve both pragmatic and hedonic purposes across different use situations, where the benefits of citizen participation, engagement, and co-creation are typically sought after by city-makers (Fredericks et al., 2016; Lim et al., 2018; Glas et al., 2019; Rodriguez Bolivar and Alcaide Munoz, 2019; Cardullo, 2021). With the increasing ubiquity of digital urban infrastructure, smart street furniture has grown from being a novelty to become a common sight in metropolitan cities. In the smart city paradigm, street furniture has primarily been co-opted into streamlining of city services through digital data collection and monitoring (Nassar et al., 2019). On the other hand, the playable city movement seeks creative opportunities for transforming street furniture as part of playful, digital placemaking. 
However, the implications to urban environments having a new genre of street furniture embedded with increasing levels of artificial intelligence and autonomy are yet to be fully understood.

In this article, we explore the overlap between smart and play in the design of street furniture through an exemplar study of the ubiquitous public bench. Whilst traditionally public benches serve the purpose of providing seats for people, they continue to be appropriated for playful, creative, and entertainment purposes, most recently through the addition of digital technology. Drawing on the notion of urban machines for public spaces in contemporary digital culture (Del Signore, 2018), we re-conceptualise the public bench as a form of playful urban machine. The article presents an analytical tool in the form of a graphical axis, which illustrates key characteristics of playful urban machines represented by design precedents of public benches across the two dimensions of smartness and disruption. Through our analysis, we identified an under-researched category of public bench as smart, sensing, and disruptive, especially in regards to emerging technologies of artificial intelligence (AI) and robotic features. The application of $\mathrm{AI}$, machine learning, and robotics opens up a design space of expressive, social machines for cities. Thus, we offer our version of the smart, sensing, and disruptive public bench to expand the concept of an anthropomorphic urban machine for playful interactions, through an urban prototype (Korsgaard and Brynskov, 2014) -I Have Feelings Too-deployed in a public festival setting.

With a design research process that connects real-world implementation and theoretical speculation, the urban prototype is regarded as both a technology probe (Hutchinson et al., 2003; Boehner et al., 2007) and a speculative artefact (Auger, 2013; Muller, 2013; Wakkary et al., 2015). We then reflect and speculate on what it means to play with and be played by urban machines and examine the possibilities of public benches in a future where urban machines become personified entities. Key to our thinking is a shift from primarily designing for playful humans to designing playful, not just playable, machines. The study concludes with the significance of such machines to the identity of places in which their role shifts from a plaything for humans to active co-creators of playful placemaking.

\section{BACKGROUND}

Empowering citizens to rewrite the services and stories of city life, the movement of playable cities (Nijholt, 2017) has been discussed as a contrast to the ideology of smart cities embedded with digital technology ${ }^{1}$. Despite so, it is a misconception to perceive the utilitarian use of digital technology as separate from the intentions of playfulness. Deliberating on the concept of playable cities, Nijholt (2020) highlights the synergistic relationship between smart and play and positions smart technology as pivotal for enhancing playful experiences. With our focus on the evolution of smart and playful

\footnotetext{
${ }^{1}$ https://www.playablecity.com/.
}

street furniture, the notion of playful placemaking provides a productive frame for understanding the potential of technology augmented street furniture to foster a sense of belonging by citizens in public spaces. The concept of urban machines is unpacked to provide a definition that takes account of the morphing of street furniture from an object to a machine, with increased autonomy and function, resulting in new and different affordances for design and use.

\subsection{Technology and Playful Placemaking}

As part of digital urbanism, most examples of playful street furniture seek to engage communities, stimulate public behaviour change, and advocate for the advantages of playable cities (Leorke and Owens, 2020). More importantly, these urban interventions form a stronger connection between people and place, with greater emphasis placed on lived experience through active participation rather than the mere provision of utility. That said, when designing street furniture to be playful, the subjectivity of human perceptions and situated conditions of the urban space heavily influence the process of interaction and resulting user experience. The act of playing also has an inherent association with children, games, and leisure. Hence, it is often deemed as a luxury to adults; secondary, unproductive, and non-essential. Coupled with the multi-layered complexities of public situations, it can be argued that the challenge of designing a compelling invitation to play is as important as ensuring a suitable fit of culture and environment for playing (Innocent, 2019). Considering the outcomes of placemaking, we acknowledge that the present and future developments of play in cities indicate a continued necessity to appreciate the effects of technology on the identity and experiences of places. Thus, we focus on playful placemaking (Innocent, 2016; Stokes et al., 2017; Luostarinen, 2019; Chew, 2020)—a variant of placemaking adapted from traditional and contemporary methods outlined by Jacobs (Jacobs, 2016), Whyte (Whyte, 1980), and other influential urbanism organisations such as $\mathrm{Gehl}^{2}$ and the Project for Public Spaces ${ }^{3}$. Supporting urban liveability, it is a placemaking process involving the public as co-creators of city life by means of playful interactions designed for the built environment. In this context, the relationship between smart and playful street furniture can also be described as contrasting but interconnected-the former focusing on efficient productivity, the latter on vibrancy, and enjoyment. Playful street furniture designed with smart (digital) technology offers added capabilities for interaction and immersion. Conversely, smart street furniture made playful humanises technology to become more personal, engaging, and situated for users. This conversion of street furniture into urban machines follows the common understanding of the efficiency and intelligence portrayed by smart cities but also includes the ingenuity and novelty of creative technological applications.

Although a quick review of related literature reveals that the key themes of play (Huizinga, 1949; Caillois, 2001; Eberle, 2014),

${ }^{2}$ https://gehlpeople.com/.

${ }^{3}$ https://www.pps.org/. 
urban technology (Shin, 2009; Nagenborg, 2018; Nagenborg et al., 2021), and placemaking (Whyte, 1980; Jacobs, 2016; Hespanhol, 2017) are not entirely new concepts, opportunities arise from alternative ways of understanding those concepts when exploring the capabilities of technologies for the next generation of urban play. Designing existing technology for playfulness highlights the feasibility and limitations of contemporary urban play, while the emergence of new technology drives upcoming trends that provide indicators of future possibilities for playful placemaking. As robotics grows beyond the industrial and manufacturing context, urban robots are also granted autonomy to assist with package delivery ${ }^{4}$, public space cleaning $^{5}$, and patrol surveillance ${ }^{6}$ (Prassler et al., 2012). During events and festivals, other variations of robots and drones are programmed to perform and entertain; creating chalk drawings in a laneway (Hoggenmueller et al., 2020), performing aerial light shows (Fingas, 2016), and amusing people while serving drinks (Giuliani et al., 2013). Infused with artificial intelligence (AI), robotic machines designed to be playful and sociable remain useful but expanded in their feasibility as entertainment, artistic, or cultural representations. Hence, we see the likes of robotic pets or toys functioning as expressive and intelligent companions (Melson et al., 2009; Pelikan et al., 2020), an ultra-realistic robot artist who makes original $\operatorname{artworks}^{7}$ (Newstex, 2020), and a social robot that became popularised as a non-human icon ${ }^{8}$ (Turner, 2017). Once pervasive AI becomes fully integrated into the citywide network infrastructure, the potential of smarter, responsive machines deployed in public spaces to maintain and improve city life would then be actualised as a connected, digital ecosystem (Kirwan and Zhiyong, 2020; Ullah et al., 2020). We could then perceive urban machines as agents personifying the identity of different places and initiating interactions with humans. Being intelligent and expressive, urban machines would also become playful entities in public spaces-learning, facilitating, and coplaying with humans to generate meaningful urban experiences.

\subsection{Understanding Machines for the Urban Context}

Taking reference from Nagenborg in his discussion on responsible urban innovation, we can understand urban machines through the definition of urban technologies, which "refers to technologies that are shaping or are being shaped by city life" (Nagenborg, 2018, p.2). As such, urban technologies cover a broad range of technology types, focusing on the interdependence between technology and the city. A design depicting an urban technology highlights distinct urban features and technological properties that are unique for the purpose of citymaking. From this standpoint, urban machines can be understood as

${ }^{4}$ https://www.starship.xyz/.

${ }^{5}$ https://fetchrobotics.com/fetch-robotics-blog/build-with-robots-fetch-roboticsand-the-city-of-albuquerque-launch-the-breezy-one-autonomous-disinfectingrobot-at-albuquerque-international-sunport/.

${ }^{6}$ https://www.knightscope.com/.

${ }^{7}$ https://www.bbc.com/news/uk-england-oxfordshire-48498853.

${ }^{8}$ https://www.hansonrobotics.com/sophia/. being part of but also different from urban technologies. They are less all-encompassing and shift our focal point towards the self-contained, mechanical, and materialised forms of technology in cities. Breaking down the terminology, urban maintains a straightforward definition of "relating to, or characteristic of a town or city" (Urban, Adj, 2021), whereas machine has several connotations that are both rudimentary and philosophical. Through Deleuze and Guattari's theory of assemblage (or agencement) (Deleuze, 1987), a machine can be described as a collection or arrangement of various components composed and organised to establish logic and meaning. It is " $a$ composition of heterogeneous elements-subjective, social technical, spatial physical and process-related - that delimits a series of conditions for the production of the real' (Del Signore, 2018, p.6). An urban machine may portray a combination of hardware and software put together to serve one or more purposes in urban situations. It is also part of a larger assemblage that forms public spaces where the urban machine mediates the connection between people and place. Conversely, as a singular feature or component, an urban technology (such as geolocation tracking, machine learning, or programmable LED lights) is not necessarily an urban machine when it is perceived as separate from an assembled system.

As a whole, urban machines are "a family of projects designed and developed to mutually enrich relationships between people, the space they inhabit, and the urban environment" (Del Signore, 2018 , p.6). We are not fixated on a particular category of machines, but we do recognise the diversity of urban machines that consist of both non-digital machinery operating on conventional mechanisms and modern devices integrated with digital computing systems. We also include the spectrum of multi-sensory, autonomous robots varying across levels of functional sophistication and replication that reflects or mimics the human body (Der and Martius, 2012; Kanniah, 2014). Although not all complex machines are robots, it is valid to consider all robots and drones deployed, functioning, and automated in public spaces as urban machines. It is also noted that urban machines exemplifying new technologies become common and pervasive when they are assimilated into the artificial structure of cities while appearing entirely natural in everyday life (Hård and Misa, 2010). Given our understanding and interpretation of urban machines, we can explain the augmentation or redesign of the public bench to be smarter and/or playful as an evolution process of the street furniture changing into a machine. With smart public benches, recent trends have illustrated a preference to support or add utility features that are directly or indirectly associated with publicsitting behaviour. Smart public benches like Soofa ${ }^{9}$ and Synergy ${ }^{10}$ are powered by solar energy and provide mobile device charging stations. Other technological features that are proven to be applicable options for the street furniture include free public Wi-Fi, integrated digital display for advertising, and LED ambient lights ${ }^{11}$. As the designs are refined with sensors, computation, and

\footnotetext{
${ }^{9}$ https://www.bizjournals.com/bizwomen/news/profiles-strategies/2018/03/smartbenches-help-cities-work-better.html? page=all.

${ }^{10} \mathrm{https} / / /$ www.synergy.net.au/Global/solar-bench.

${ }^{11}$ https://www.specsolutions.com.au/connect/sedi.
} 


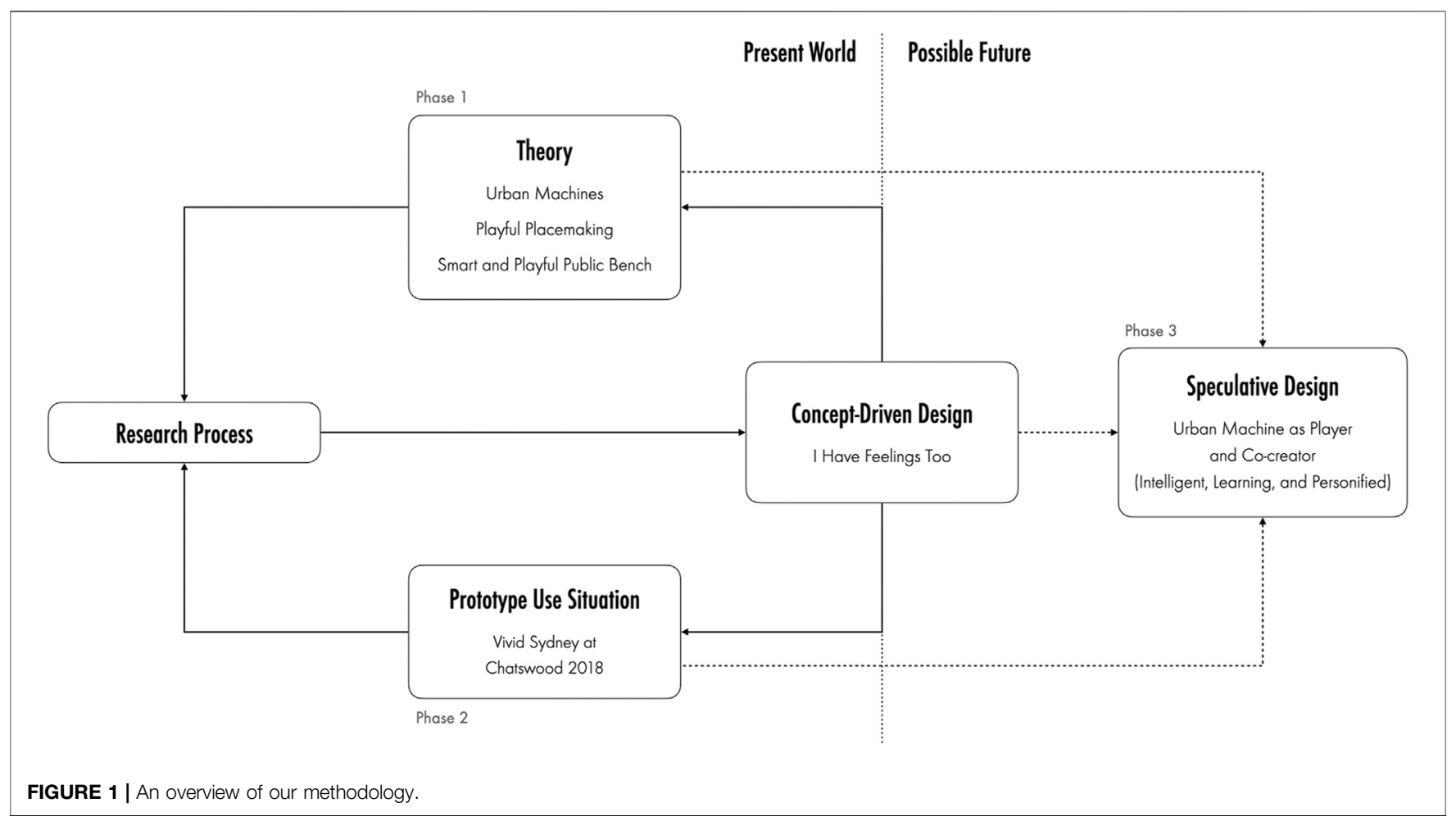

AI, they shift towards being more machine-like with capabilities to sense environmental conditions ${ }^{12}$ (air quality, temperature, humidity), collect usage data (number of people, duration of use, energy consumption), and even optimise the display of ads relevant to passers-by ${ }^{13}$. In addition to having technological features, Smart Palm adopted the aesthetic shape of a palm tree to cater for the cultural context of Dubai in the United Arab Emirates $^{14}$. Targeting specific groups of urban dwellers who commute on electric bikes and scooters, Steora Cyclo was also equipped with attached bike racks, high-powered charging, a repair station, and an air compressor ${ }^{15}$. Although there seem to be stark differences in the characteristics of smart and playful, they are not mutually exclusive when designing urban machines. Depending on the level of integrated smart technology, public benches can become urban machines that are both smart and playful with an overlap of purposes to maintain or disrupt urban activities. We expand upon this in our subsequent analysis.

\section{METHODOLOGY}

Our study combines scholarly analysis of design precedents, with a concept-driven speculative approach to design (see

\footnotetext{
${ }^{12} \mathrm{https} / / /$ strawberrye.com/smartCityBench.html.

${ }^{13}$ https://include.eu/b2g/steora-smart-benches/city/

${ }^{14} \mathrm{http} / /$ bigd.es/en/portfolio/smartpalmen/.

${ }^{.15} \mathrm{https} / / /$ include.eu/b2g/steora-smart-benches/cyclo/.
}

Figure 1). In the first phase, we reviewed related literature on present developments of urban technologies and established an understanding of urban machines for the purpose of play in the future of placemaking. Focusing on existing designs of the playful public bench identified as an urban machine, we broke down various aspects of each design within the context of play and examined the impact on public-sitting activities. After selecting ten case studies that spanned a spectrum of variations on the common construct of the traditional public bench, we then conducted an analysis against two dimensions: the degree of smartness and the degree of disruption. The two dimensions are further elaborated and justified in the analysis section below.

In the second phase, we commenced the design, development, and evaluation of a concept-driven prototype. We adopted the Concept-Driven Interaction Design Research approach (Stolterman and Wiberg, 2010) and combined principles from the approach with speculative design (Dunne, 2013; Forlano and Mathew, 2014; Coombs et al., 2018; Wong and Khovanskaya, 2018). In doing so, we sought a theoretical analysis that is blended with the use situation of design to discuss the possibilities of urban machines for present and future developments (see Figure 1). With our methodology, we also deliberated on our public bench prototype to depict an idea of how humans can play with and be played by urban machines, rather than address a specific human problem or urban issues associated with the street furniture. We designed and developed I Have Feelings Too as a concept-driven prototype of a playful urban machine that explored anthropomorphising the public bench with digital technology for the purpose of playful 


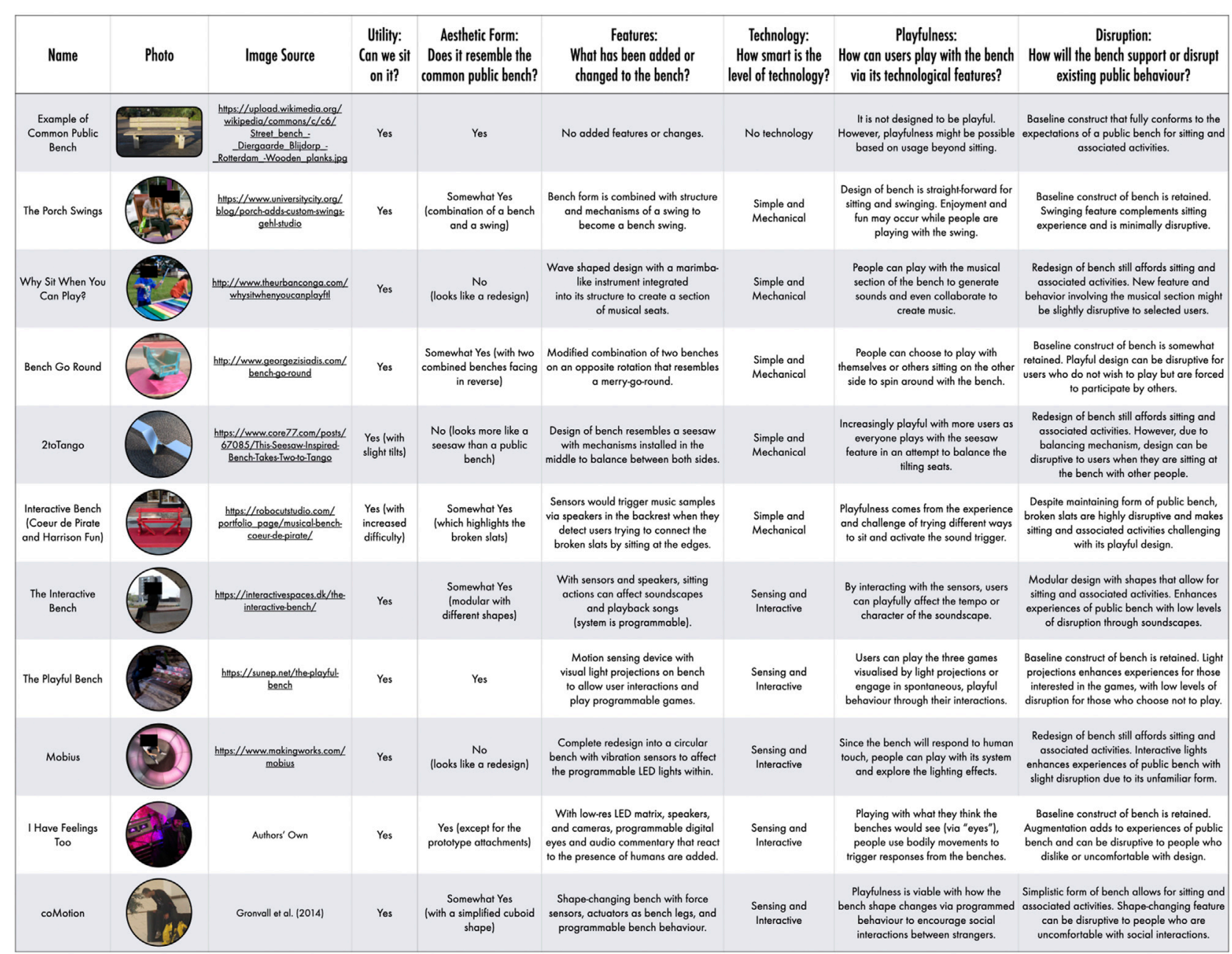

FIGURE 2 | Analysis of design examples as an urban machine through the lens of play.

placemaking. The prototype was deployed in an outdoor mall area in Chatswood, Sydney, Australia, as part of a public festival, Vivid Sydney 2018. We conducted a field study to observe human behaviour towards the prototype and sought to understand its effect on the surrounding atmosphere and identity of its location. Like a technology probe (Hutchinson et al., 2003; Boehner et al., 2007) in an actual use situation, the prototype uncovered the advantages and disadvantages of creating disruption with public sitting and utilising anthropomorphism as an approach to design urban machines. Data collection methods of in-the-wild observation and survey were approved by The University of Sydney ethics committee.

For the final phase of analysis and speculation, we positioned I Have Feelings Too as a speculative artefact (Auger, 2013; Muller, 2013; Wakkary et al., 2015) of the situated, everyday public bench. We then pursued the possibility of people being played by urban machines and deliberate on this notion as a proposal of future playful, playable living in digitised, intelligent cities.

\section{ANALYSING DESIGN EXAMPLES OF PLAYFUL PUBLIC BENCHES}

In our analysis of playful public benches, ten design concepts (excluding the basic form of public bench for a reference point) were examined to serve as case studies (see Figure 2). From this sample of designs, we selected public benches that were predominantly playful in ways that deviated from publicsitting norms to spark spontaneous human behaviour. We considered augmentations and/or redesigns across varying degrees of smartness to have an adequate spread of representations with urban technology. Given the small sample size, we focused on the quality and accuracy of our analysis, and only accepted examples that provided substantial documentation on concept, implementation, and interaction design. Information for each example was available online via a combination of sources with photos, videos, and/or written articles, except for I Have Feelings Too, which will be detailed in the following sections. Inclusive of both temporary and permanent installations, the case studies also illustrate different contexts 
of urban situations and geographical locations but are similar in portraying an interpretation of what we could and should do with the public bench.

As playful urban machines, each design precedent was reviewed based on two dimensions (continua), corresponding to their level of 1) disruption and 2) smartness, to create four differing quadrants. Disruption is associated with the subversive nature of play that is found in playful experiences and approaches to design (Huizinga, 1949; Alfrink, 2015; Fuchs, 2018). It is emergent from our initial understanding of smart and playful benches and highlights the extent of how much an urban machine conforms or disrupts public-sitting norms, usage, and regulations. Smartness is derived from the broad topic of urban technology for smart and playable cities (Nam and Pardo, 2011; Calder, 2016; Ligthart and Ramjee, 2017; Nijholt, 2017; Nijholt, 2020; Mosco, 2019; Nagenborg et al., 2021). It depicts the spectrum of interactivity and autonomy that begins with minimal or simple use of technology and increases in sophistication as a design incorporates digital sensory systems, machine behaviour, and autonomous features. Based on this explanation, we would place ordinary public benches at an extreme end of the disruption continuum-compliant and conforming to situated conditions. Referencing the ordinarily recognised, everyday design, full conformance maintains existing human behaviour emerging around the street furniture that we call a public bench. It fulfils minimal ergonomic form to accommodate people sitting in public space without requiring unnecessary effort to perform the action. Its aesthetic qualities clearly communicate essential affordances and do not suggest any other purpose beyond the typical and expected. Moreover, its design conforms to the norms of its primary function for the context of its location-be it at a bus stop, in a park, or around an open plaza. While the usual experiences of a regular public bench are not particularly playful or fun, they are mostly safe, familiar, and appropriate. On the other hand, full disruption describes a public bench that challenges the accepted and known use of the street furniture, questioning its purpose and changing human opinions towards it. Hence, it is a design that goes beyond the basic function and assumed narrative of the object-a sense of defiance against the norms. Its aesthetic qualities introduce peculiar affordances to suggest atypical and unexpected purposes, which change how people perceive public sitting. While the new experiences may be playful and fun, such designs can also feel discomforting, unfamiliar, and risky.

In terms of smartness, the common public bench is also regarded as basic with "No Technology" integrated for the purpose of playful interactions. It has no digital augmentation of any kind or playful enhancements of existing activities associated with its surroundings. It is not intelligent and does not respond or react to the presence and behaviour of humans in any way. That said, it represents the baseline in terms of potential for playful redesign with urban technology. Installing "Simple and Mechanical" functions into a public bench, we then enhance existing activities of the street furniture or introduce new features that inspire playful human behaviour. At this technological level, specific parts of the public bench structure are made movable, adjustable, or reactive with materials, gears, and actuators. The components can be electronic and programmable, but the circuitry and mechanisms remain simplistic and operate on minor use of digital technology. Finally, smart, playful public benches can be described as "Sensory and Interactive". Embracing creativity and complexity in system design, these benches may be built with a combination of mechanical and digital features but are distinguishable by their adaptive capabilities for programming machine behaviour and content changes via digital means. They are also highly responsive to the presence and actions of humans through integrated sensors and devices. As we progress towards AI and machine learning, the public bench can also be redesigned as an intelligent and expressive urban machine with multi-functional roles and unique personalities.

Having established an understanding of smartness and disruption, we can categorise the case studies across four quadrants (see Figure 3):

\subsection{Simple, Mechanical, and Conforming}

Representative examples of the playful public bench are The Porch Swings ${ }^{16}$ and Why Sit When You Can Play $?^{17}$. In this category, the street furniture preserves key aspects of the common public bench while having new features that either complements the primary function of sitting or incorporates optional playing activities. The use of technology is also generally minimal or predictable. Despite being a combination of bench and swing, The Porch Swings adds pleasure and ease to the sitting experience by seeking to replicate the enjoyment of swinging on a front porch. Although Why Sit When You Can Play? has a different aesthetic shape and form, users can simply choose to sit and not play with the musical xylophone seats. Thus, playfulness is rather limited to the physicality of the public bench, with its design implying a natural association to safer, reasonable experiences that cater for the surroundings.

\subsection{Simple, Mechanical, and Disruptive}

Representative examples of the playful public bench are Bench Go Round $^{18}, 2$ to Tango ${ }^{19}$, and Interactive Bench ${ }^{20}$. In this category, the street furniture defamiliarises key aspects of the common public bench to encourage playful behaviour in a situation where sitting becomes secondary to playing-some users might even visit the public bench for the sole purpose of playing rather than sitting. The use of technology (with mechanical and electronic components) is essential but not complex. The physical construct of Bench Go Round and 2toTango bear greater resemblance to their inspired form of a merry-go-round and seesaw respectively, which prompts usage and activities of play related to associated affordances. Likewise, Interactive Bench depicts a broken public bench and reinvents the act of sitting into an invitation to connect the bench slats and trigger music. Building on a creative

\footnotetext{
${ }^{16} \mathrm{https}$ //www.universitycity.org/blog/porch-adds-custom-swings-gehl-studio.

${ }^{17} \mathrm{http}: / /$ www.theurbanconga.com/whysitwhenyoucanplayftl.

${ }^{18} \mathrm{http}: / /$ www.georgezisiadis.com/bench-go-round.

${ }^{19} \mathrm{https}$ ://www.core77.com/posts/67085/This-Seesaw-Inspired-Bench-Takes-Twoto-Tango.

${ }^{20} \mathrm{https}$ ///robocutstudio.com/portfoliopage/musical-bench-coeur-de-pirate/.
} 


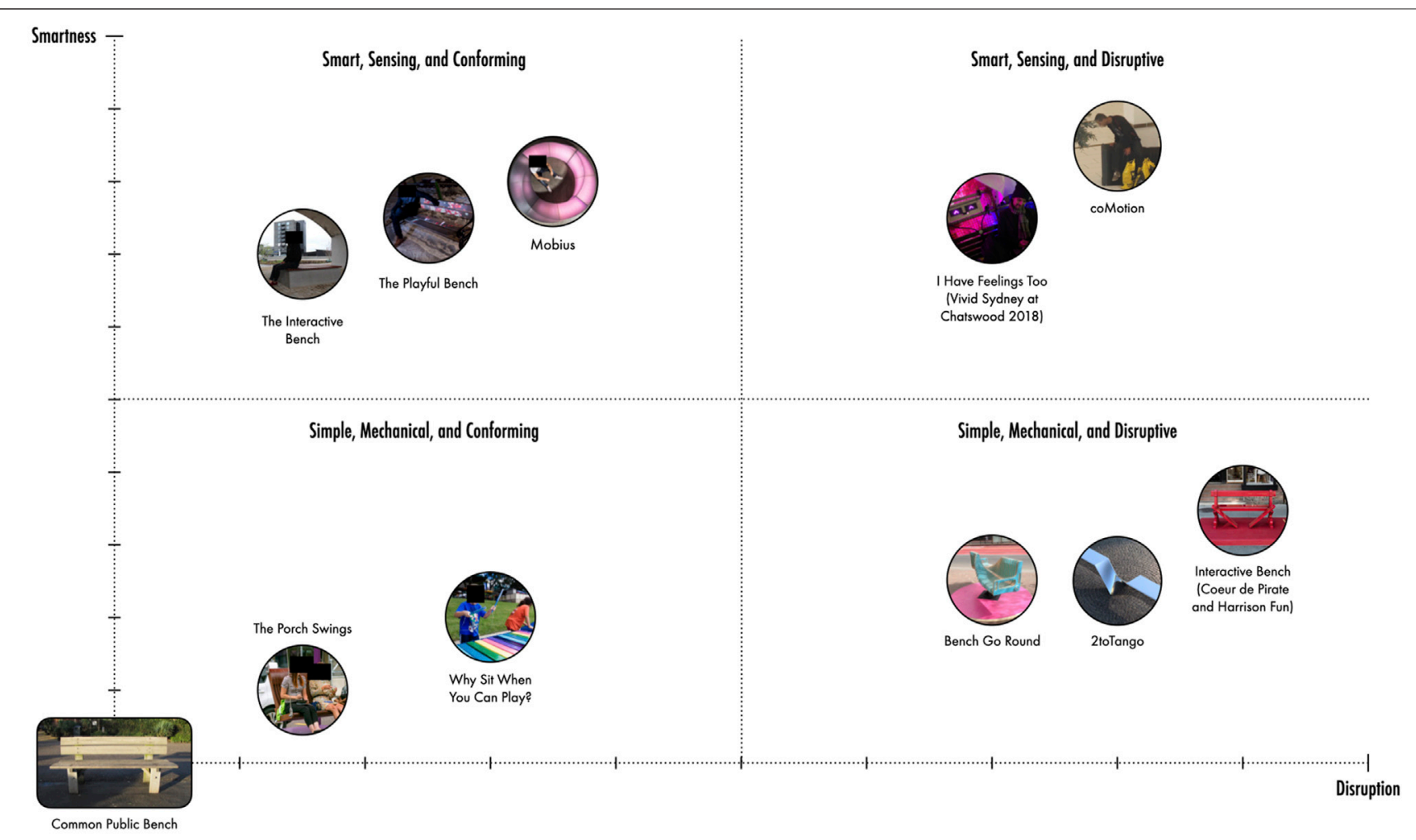

FIGURE 3 | Overview of analysis on an axis diagram with dimensions of disruption and smartness.

interpretation of public sitting, the playful experience can occasionally be awkward and embarrassing, yet remains sufficiently light-hearted and enjoyable for the context of its location.

\subsection{Smart, Sensing, and Conforming}

Representative examples of the playful public bench are The Interactive Bench ${ }^{21}$, The Playful Bench ${ }^{22}$, and Mobius ${ }^{23}$. In this category, the public bench design balances between being a street furniture and an urban machine. It generally fulfils the usual expectations of public benches but also advances existing designs with new changes bespoke for the context of different locations. Digital technology and sensory systems are also integral in facilitating playful interactions that do not strongly interfere or interrupt public sitting. Without drastic changes to the overall form of a common public bench, The Interactive Bench utilises the existing human motion of sitting to trigger and control localised soundscapes and music. Similarly, The Playful Bench allows people to use their movements to play games that are projected as light visuals on the public bench. Redesigned with new shape and form, Mobius displays enhanced visual aesthetics with integrated light patterns that respond to vibrations. While it pushes the boundaries on what is acceptable, the smart and

\footnotetext{
${ }^{21} \mathrm{https} / /$ interactivespaces.dk/the-interactive-bench/.

${ }^{22}$ https://sunep.net/the-playful-bench.

${ }^{23} \mathrm{https}$ //www.makingworks.com/mobius.
}

conforming public bench remains focused on providing a sufficiently comfortable sitting experience and injects a sense of cohesiveness and inclusion into the identity of places.

\subsection{Smart, Sensing, and Disruptive}

Representative examples of the playful public bench are I Have Feelings Too and coMotion (Grönvall et al., 2014a). In this category, the design skews toward creating an urban machine and is less concerned with preserving the nature of the street furniture type. It might fulfil the basic expectations of public benches as an urban object for sitting but quickly demands the attention of users to play with the urban machine. Although they are not fully subversive of the usual shape and form identified with the conventional street furniture, I Have Feelings Too and coMotion prioritise playful social interactions (over sitting) with and among people, which might be meaningful but not necessarily desired by users. Pushing towards smarter designs with digital systems, both examples redefine public benches as becoming artificially alive and active; the former using anthropomorphic emotional expressions and the latter shape-changing via programmed machine behaviour. Instead of being homogeneous and stereotypical, those examples also convey divergent concepts with sophisticated, intelligent, and learning designs. With the potential to develop unique character and personality, the smart and disruptive public bench is provocative and may evolve alongside its surrounding environment to shape the identity of places. 


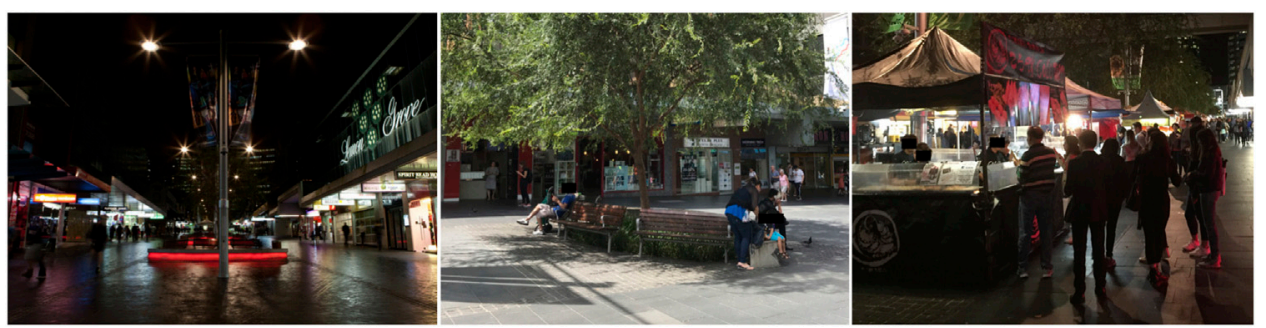

FIGURE 4 | Victoria Avenue Mall, Chatswood, during regular days. Left: The mall in the evening. Centre: Pre-existing public benches around the mall. Right: Pop-up food stalls during weekly night markets.

Although we are analysing the examples based on the context of their design and deployment, it should be noted that conformance and disruption are more evident in specific circumstances and remain subjective to individuals. The playful but disruptive public bench meant for a temporary, public festival might seem out-of-place and confusing for users in a permanent, everyday situation. On the other hand, a conforming, subtle form of playful street furniture in a mundane environment would be more preferable to emphasise key features that enhance daily activities. In a public setting, playful experiences can also be influenced by our preferences when playing, and how we think others are judging our actions in a social context. Hence, in the next section, we examine the playful public bench in a real-world situation to explore human behaviour when people interact with a smart, sensing, and disruptive urban machine.

\section{CASE STUDY: I HAVE FEELINGS TOO}

During Vivid Sydney at Chatswood 2018, we deployed I Have Feelings Too as a concept-driven prototype at Chatswood Mall (also known as Victoria Avenue Mall) in the suburb of Chatswood, Sydney, Australia (see Figure 4). Connecting various shopping malls and landmarks within the vicinity, the location consists of a wide pedestrianised street with storefronts along both sides and restricted vehicular traffic. With people moving to and from a nearby transport hub interchange, the overall street mainly functions like a thoroughfare, with some sections viable as plazas or gathering spots for human activities. Across the entire stretch of urban space, there are regular pockets of a sitting area with concrete and wooden benches for the general public to rest and relax. When seated in those areas, most people lingering at the pedestrian mall are observed to be eating, reading, using their mobile devices, or people watching while waiting for a meet-up. For the Vivid Sydney festival 2018 program, the local council included numerous installations and a junkyard-themed night market at the pedestrian mall. With a concept that builds on existing public benches and situated human activities, I Have Feelings Too was implemented within the junkyard market amongst curated scaffolding and makeshift store tents. Since the event lasted around 3 weeks, the installation focused on a temporary design that was seemingly an extension of the public bench with detachable components, as opposed to modifying the physical bench permanently.

\subsection{Concept-Driven Prototype and Technology Probe}

As a concept-driven design, I Have Feelings Too explored the possibilities of humanised urban machines in the playable city through the redesign of public benches for playful interactions. It was inspired by the developing discourse of AI for smart cities (Allam and Dhunny, 2019; Kirwan and Zhiyong, 2020; Ullah et al., 2020; Cugurullo, 2021) and expanded on the growing potential of street furniture for digital placemaking (Tomitsch et al., 2015; Stokes et al., 2021). The concept is built on 1) the anthropomorphic approach extensively applied in human-robot interaction (HRI), 2) the personification of voice assistant with speech interfaces, and 3) an understanding of playful learning as part of machine behaviour development. It seeks the advantages of anthropomorphized technology to establish an emotional connection when humans socially interact with robots and machines (Cid et al., 2014; Lee et al., 2018; Salles et al., 2020). It also acknowledged the simple use of personified voice as an effective way for machines to communicate with children, parents, and the elderly across different circumstances (Yarosh et al., 2018; Kim and Choudhury, 2021; Poushneh, 2021). The concept was designed as an ideal of a playful, anthropomorphized public bench: emotional, talkative, and integrating AI with sensors and a voice system, which constantly learns to develop its personality-in sum, a smart, sensing, and disruptive urban machine that engages in conversation with users and becomes an expressive, social entity of a place.

In comparison to the ideal, we constructed I Have Feelings Too as a high-fidelity urban prototype mixing interactive and wizardof-oz (Dow et al., 2005) features for the large-scale light festival. To serve the purpose of a technology probe (Hutchinson et al., 2003; Boehner et al., 2007), the goals of the prototype were to gather information about users and use of an anthropomorphized bench in the wild, field-test an abstraction of a learning machine that processes questions from users to evolve its personality and further elaborate our speculation of playful urban machines. In contrast to its ideal concept-driven design, we also made concessions to improvise our lack of access to specific technology and cater for the requirements of the festival (see Figure 5). Augmenting three existing public benches situated at 


\begin{tabular}{|c|c|c|}
\hline Design Type & Ideal Concept-driven Design & $\begin{array}{l}\text { Urban Prototype as Technology Probe } \\
\text { (Deployed in the Wild) }\end{array}$ \\
\hline $\begin{array}{c}\text { Design } \\
\text { Implementation }\end{array}$ & Redesign of a public bench with in-built anthropomorphic features, sensors, and speakers. & Augmentation of three existing public benches with modular attachments and plug-in speakers. \\
\hline Sensory Input & $\begin{array}{l}\text { Combination of sensors (motion, sound, and image) working together to function as the sight } \\
\text { and hearing of the urban machine. }\end{array}$ & $\begin{array}{l}\text { Cameras to detect human movements and presence at the public bench via blob tracking } \\
\text { with computer vision. }\end{array}$ \\
\hline Visual Output & High-res digital display with wide range of generative eye expressions and visual icons. & Low-res LED matrix with pre-programmed eye expressions mimicking text-based emoticons. \\
\hline Voice Output & $\begin{array}{l}\text { Spoken answers and verbal expressions (real-fime and responsive) are provided through speakers. } \\
\text { Urban machine voice changes accordingly to match its current emotion, expression, and personality. }\end{array}$ & $\begin{array}{l}\text { Spoken answers and verbal expressions (pre-recorded and pre-programmed) are } \\
\text { provided through speakers. } \\
\text { Voice-changing soffware was used to generate a robotic voice output with varying level of pitch to } \\
\text { represent three extreme emotion types - ioy, annoyance, and sadness. }\end{array}$ \\
\hline Interactivity & $\begin{array}{l}\text { Combination of sensor inputs would allow machine to constantly receive a variety of data } \\
\text { from human activities occurring in its surroundings. } \\
\text { With visual and speech interface, the machine would then converse with users by } \\
\text { telling stories, answering questions, cracking jokes, and making comments } \\
\text { based on its current emotion, personality, and the surroundings. }\end{array}$ & $\begin{array}{l}\text { Camera input tracks movement and distance to determine which pairing of pre-programmed visual } \\
\text { and voice expressions are visualised and played back for users. } \\
\text { Each public bench has three preprogrammed states; } \\
\text { Standby (moves eyes randomly with periodic comments about surroundings when there is no one), } \\
\text { Greet (looks at the general direction of user and greets the person when someone is detected), and } \\
\text { Converse (displays emotional eyes and cycles through voice responses when user lingers at bench). }\end{array}$ \\
\hline $\begin{array}{l}\text { Learning machine } \\
\text { with developing } \\
\text { personality }\end{array}$ & $\begin{array}{l}\text { The urban machine would begin with an initial set of training data to mimic } \\
\text { a preferred range of human emotional expressions and personality traits for deployment onsite. } \\
\text { Affer it has been deployed, the machine will learn from its interactions with users and exposure to } \\
\text { surrounding activities, resulting in an evolving personality with increased variety of responses } \\
\text { and conversations. }\end{array}$ & $\begin{array}{l}\text { Each public bench begins with a fixed extreme emotion that dictates their initial personality type and } \\
\text { interactive voice responses (of likes, dislikes, and conversations). } \\
\text { As part of simulating a learning machine, the personality of each public bench evolves with new voice } \\
\text { responses added twice a week by designers, which were based on observations of human behavior } \\
\text { during festival, feedback collected from survey conducted, and real-time weather conditions. }\end{array}$ \\
\hline
\end{tabular}

FIGURE 5 | Comparing key differences between our ideal concept-driven design and the urban prototype deployed.
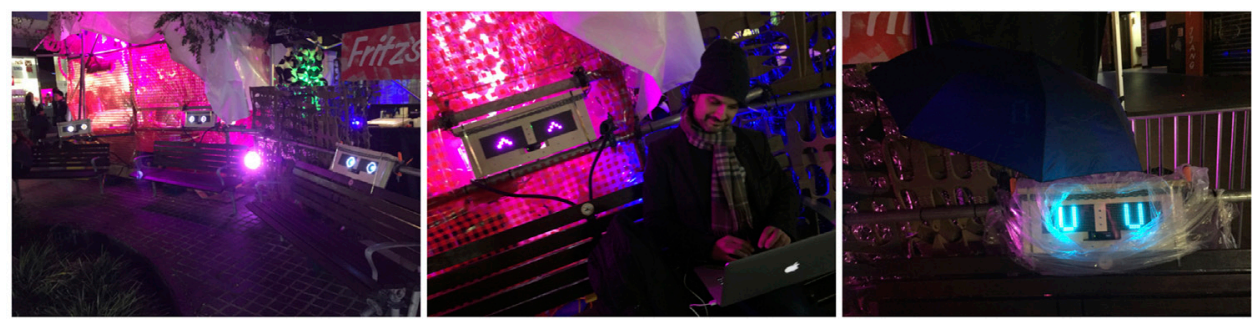

FIGURE 6 | / Have Feelings Too deployed at Chatswood Mall during Vivid Sydney 2018. Left: The three anthropomorphized public benches. Centre: A user working at the joyous bench. Right: The gloomy bench further decorated during a stormy winter evening.

Chatswood Mall, the installation featured extreme personas of joy, annoyance, and sadness for each bench (see Figure 6). The prototypes detected the movements of people by using cameras (as sensor input) and created sound through hidden speakers (as voice output). Digital eyes were also implemented with low-res LED matrices (as visual output), pre-programmed to match voice output, so that the benches would react to human presence with a combination of audiovisual responses. In doing so, our goal as designers was to create a social situation enabling the previously inanimate street furniture to voice their thoughts and emotions through spoken words and audio manipulation of the pitch.

Although our prototypes did not incorporate an actual AI, we simulated the process of learning for the machine by manually collecting, processing, and generating voice responses for each public bench. An initial set of verbal expressions was created based on the context of the location and festival, and later expanded with additional responses throughout the event. Through usage documentation, feedback gathered from users, and environmental conditions, the personalities of the public benches developed specific likes and dislikes based on their emotional characteristics to communicate responses about people, place, and activities:

- Joy-The joyous bench was always happy and enjoyed the company of humans. With eyes representing the text-based emoticon of joy ${ }^{\wedge} \_$- when users were up-close or seated, this bench greeted visitors warmly with an excited "Hello there?", asked them "How is your day?", and remarked: "Cow \& the Moon has the best ice-cream!". Overall, the joyous bench uttered 15 different voice responses, expressing how much it liked being a bench, befriending people, and taking selfies, among other things.

- Annoyance-The annoyed bench constantly declared its irritation and dislike for many things. With eyes representing the text-based emoticon of annoyance -_when users were up-close or seated, this bench greeted visitors coldly with a displeased "Hello.", asked them "Do I have to talk to you?", and complained: "People annoy me!". 


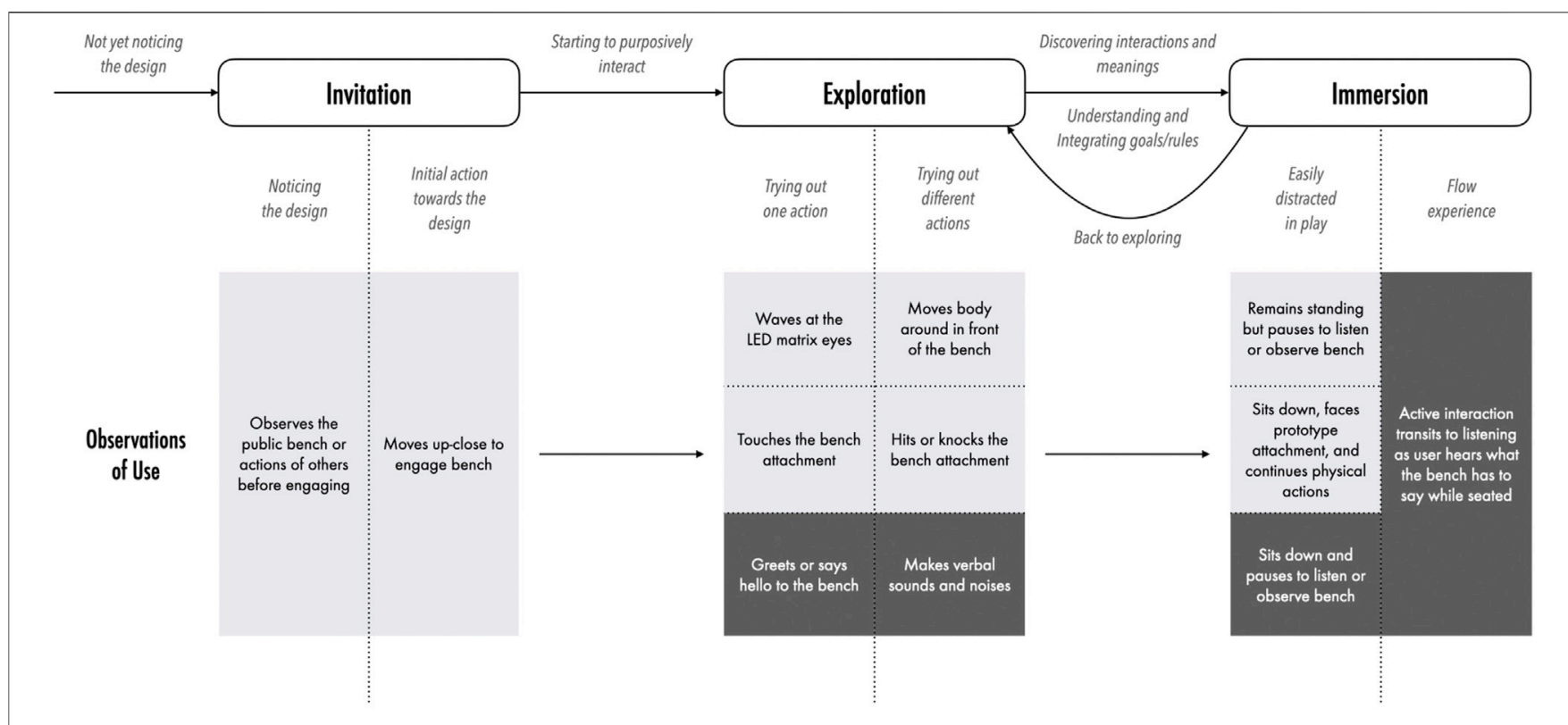

FIGURE 7 | Understanding user behaviour through the stages of playful interactions.

Overall, the annoyed bench uttered 14 different voice responses, expressing how much it disliked crowds, noise, rain, and being a bench, among other things.

- Sadness-The gloomy bench perceived the world as hurtful and depressing. With eyes representing the text-based emoticon of sadness $u_{-} u$ whenever users were up-close or seated, this bench greeted visitors with a melancholy tone "Hey there.", told them "I feel so sad.", and lamented: "No one loves me." Overall, the gloomy bench uttered 15 different voice responses, expressing how people kept hitting and yelling at it, how lonely it felt, how it would like to befriend people on Facebook, among other things.

\subsection{In-The-Wild Data Collection}

Across the duration of the festival, I Have Feelings Too was active and running for 22 out of 23 evenings, with a power outage at the night market during an evening that prevented the operation. From Mondays to Thursdays, the installation was activated between 5.30 and $10 \mathrm{pm}$, while it ran till $10.30 \mathrm{pm}$ on Fridays and weekends. This added up to 104.5 available hours for data collection. For the purpose of our observations, we had at least one researcher onsite for 14 evenings (observing for about $3 \mathrm{~h}$ per evening), comprising of various weekdays and weekends, which totalled to approximately $42 \mathrm{~h}$. The entire process was primarily conducted with observation note-taking and focused on human activities across the three activity spaces of Peripheral awareness, Focal awareness, and Direct interaction (Brignull and Rogers, 2003), relative to the augmented public benches. Using photos as secondary visual data to complement the written observations, we recorded how people approached the installation, their exploratory behaviour, recurring attempts of interactions, and verbalised speech towards the benches (if any). We observed positioning and bodily movements during interactions and noted how the affordances of the anthropomorphized benches supported or limited playing.
We also conducted 17 onsite surveys with individuals (either alone or part of a group) to collect feedback on user experience and gather content input to generate new voice responses for the public benches. To cater for possible reluctance to participate from festival-goers, we restricted the length of our surveys to a mixture of only four multiple-choice and two open-ended questions. Each survey was done immediately after a user had interacted with the installation and was leaving the location. Fridays and weekends were preferred for conducting surveys as those days had larger crowds. The survey included questions about the 22 Playful Experience (PLEX) categories (Lucero et al., 2014), thoughts regarding interactions with the installation, and what users would ask the anthropomorphized public benches in a conversation.

\subsubsection{Observations of Use}

The most basic form of the public bench as a street furniture provides seats to people as they relax, communicate, or partake in other associated activities. However, I Have Feelings Too is a prototype of the smart, sensing, and disruptive urban machine, which deems sitting as merely one of the actions triggering machine responses. In our analysis of observation data, we sought to identify common themes of playful user behaviour that were different from or disrupted the behavioural norms of public sitting. When seated and/or interacting with the urban machine, users were given an unspoken permission to freely participate in a lived experience that is distinct from the ordinary, mundane usage of street furniture. Inside the invisible boundaries that form the magic circle of play (Huizinga, 1949; Tekinbas and Zimmerman, 2003), they can explore with their movements or actions and attempt to converse with the public bench, yet, all the while, keep an open mind about embarrassing themselves during the process of playing. With the play lens outlining the stages of playful interactions (Bekker et al., 2014), we grouped similar acts 


\begin{tabular}{|c|c|c|c|c|c|}
\hline & $\begin{array}{l}\text { Captivation } \\
\text { Forgetting one's surroundings }\end{array}$ & $88.2 \%$ & $\begin{array}{l}\text { Exploration Intended Experience } \\
\text { Investigating an object or situation }\end{array}$ & $11.8 \%$ & $\begin{array}{l}\text { Simulation } \\
\text { An imitation of everyday life }\end{array}$ \\
\hline & $\begin{array}{l}\text { Challenge } \\
\text { Testing abilities in a demanding task }\end{array}$ & $5.9 \%$ & $\begin{array}{l}\text { Expression } \\
\text { Manifesting oneself creatively }\end{array}$ & & $\begin{array}{l}\text { Submission } \\
\text { Being part of a larger structure }\end{array}$ \\
\hline & $\begin{array}{l}\text { Competition } \\
\text { Contest with oneself or an opponent }\end{array}$ & $5.9 \%$ & $\begin{array}{l}\text { Fantasy } \\
\text { An imagined experience }\end{array}$ & $35.2 \%$ & \begin{tabular}{l|l} 
Subversion & Intended Experience \\
Breaking social rules and norms
\end{tabular} \\
\hline & $\begin{array}{l}\text { Completion } \\
\text { Finishing a major task, closure }\end{array}$ & & $\begin{array}{l}\text { Fellowship } \\
\text { Friendship, communality or intimacy }\end{array}$ & & $\begin{array}{l}\text { Suffering } \\
\text { Experience of loss, frustration, anger }\end{array}$ \\
\hline & $\begin{array}{l}\text { Control } \\
\text { Dominating, commanding, regulating }\end{array}$ & $64.7 \%$ & \begin{tabular}{l|l} 
Humour & Intended Experience \\
Fun, joy, amusement, jokes, gags
\end{tabular} & $23.5 \%$ & \begin{tabular}{l|l} 
Sympathy & Intended Experience \\
Sharing emotional feelings
\end{tabular} \\
\hline & $\begin{array}{l}\text { Cruelty } \\
\text { Causing mental or physical pain }\end{array}$ & & $\begin{array}{l}\text { Nurture } \\
\text { Taking care of oneself or others }\end{array}$ & & $\begin{array}{l}\text { Thrill } \\
\text { Excitement derived from risk, danger }\end{array}$ \\
\hline $58.8 \%$ & $\begin{array}{l}\text { Discovery Intended Experience } \\
\text { Finding something new or unknown }\end{array}$ & & $\begin{array}{l}\text { Relaxation } \\
\text { Relief from bodily or mental work }\end{array}$ & & \\
\hline & $\begin{array}{l}\text { Eroticism } \\
\text { A sexually arousing experience }\end{array}$ & & $\begin{array}{l}\text { Sensation } \\
\text { Excitement by stimulating senses }\end{array}$ & & \\
\hline
\end{tabular}

of use and mapped our observations against each stage of Invitation, Exploration, and Immersion to breakdown but also structure our findings (see Figure 7). From this perspective, it is clear that the first stage of Invitation begins with how people make sense of the anthropomorphized benches and their augmented features-either by observing them or other users around. This quickly translates into direct interactions as a person approaches one of the benches and enters the next stage of Exploration, triggering responses with numerous types of behaviour. After experimenting with a series of actions, the user eventually arrives at the stage of Immersion, where direct physical interactions decrease and the actions transit into listening. Although our analysis of findings through the play lens provided a coherent overview and logic of human behaviour, we note that exploratory actions are not always organised and sequential in the chaos that comes with playful interactions. From the listing of six actions identified (in Exploration), users have been observed to engage the benches with any combination of behaviour and develop a preference for one or more actions in their interactions. The same chaos persists as users remain immersed inside the magic circle surrounding the installation, with different actions performed alongside listening as a way of multi-tasking in the flow between exploring and immersing.

Acknowledging that the anthropomorphized benches merged the affordances of both street furniture and urban machine, we observed that the social norms of public benches remained when people were playing: users generally avoided interacting with any bench that had occupied seats, unless sufficient sitting was vacant for more users. However, if everyone was standing and facing the bench while playing, interactions from multiple strangers with a bench at the same time were considered acceptable and appropriate. Furthermore, in our analysis, we found a pattern of human behaviour (highlighted with darker grey boxes in Figure 7) that emerged as a possible variant of playful sitting for urban machines. Unlike the other case studies considered above, this variant of playful sitting requires users to participate verbally and listen to the urban machine while seated. Although our findings reflected the preliminary state of our prototype and only presented a snippet of actions indicating the beginnings of a conversing behaviour, they were aligned with the intentions of our concept-driven design with speech interfaces and real-time conversations for the public bench. Directing the focus of interactions away from the moving physical body or the sensations of active sitting, playful sitting could be achieved through the core activities of talking and listening by both humans and machines. In these circumstances, playfulness is found in the novelty and laughter of socially interacting via storytelling, jokes, pranks, and light-hearted banter. Similar to urban projects of chat benches ${ }^{24}$ where people could seek a good conversation with one another, this approach to playful sitting through urban machines would reinforce the notion of public benches being a social resource and a place for people to belong.

\subsubsection{Experiences of Users}

In general, I Have Feelings Too also aimed to be a playful design aligned with the concept of ludic engagement (Morrison et al., 2007; Gaver, 2015), which seeks curiosity and ambiguity as desirable qualities of user experience. From our observation findings, the installation clearly gave users a sense of freedom that does not overly enforce an approach of fixed interactions and offers sufficient room for personal interpretations and uses. It

\footnotetext{
${ }^{24}$ https://www.collaborativenewcastle.org/news/happy-to-chat-benches/.
} 
appropriated the affordances of the public benches to "support social engagement in ludic activities" and "allow the ludic to be interleaved with everyday utilitarian activities" (Gaver et al., 2004, p.14). Utilising the PLEX categories, the ideal concept-driven design of I Have Feelings Too would provide Discovery, Exploration, Humour, Subversion, and Sympathy. Nevertheless, we expected users to report their playful experiences with some disparity in accordance with the technological limitations of our prototypes. Comparing intended against reported experiences (see Figure 8), the most selected PLEX category was Exploration at $88.2 \%$ (15 out of 17 users). This was followed by Humour at 64.7\% (11 out of 17 users) and Discovery at 58.8\% (10 out of 17 users). On the flip side, the remaining PLEX categories of Subversion and Sympathy were lower with 35.2 and $23.5 \%$, respectively. Based on user feedback, we can derive that the installation was sufficient as an exploratory prototype of playful urban machines in public space. Users found the anthropomorphized benches humorous to an extent; however, almost half of them did not perceive the prototype to be a design of discovery. As for the less favourable statistics of Subversion and Sympathy, we can also infer a correlation between some of the simulated technology (such as $\mathrm{AI}$, speech recognition) and the lack of specific playful experiences. However, more research is required to validate this hypothesis, namely that an increase in technological complexity of disruptive, real-time machine responses with emotional personalities would produce more profound experiences.

\section{DISCUSSION}

The insights above reveal the extensive scope of urban machines in smart cities, with recent trends on public bench augmentation and/or redesign suggesting greater potential for this street furniture type to support playful placemaking through AI and robotic functions. As a technology probe, I Have Feelings Too explored the design space of an anthropomorphized public bench inspired by machine learning and speech interfaces for playful, social interactions with humans. It was also an urban prototype that presented an example of the smart, sensing, and disruptive urban machine-testing a working model at use in a public situation and understanding the nuances of disruption for people using public benches. Our findings endorsed the validity and possibilities of future urban machines as players and co-creators of places.

\subsection{Other Learnings and Constraints}

There is an underlying expectation that anthropomorphized benches are still meant for sitting, with any additional usage dependent on affordances created by incorporating urban technologies into the street furniture. Without any instructions or support from other features, a public bench simply redesigned with a speech interface lacks the intuitiveness and would be incomplete as a smart, sensing, and disruptive urban machine. The inputs and outputs of verbal speech are less obvious and invisible for users during interactions, which need to be directed, logical, and timely. With an anthropomorphic form and visibility of some in-built components (such as the digital displays and speakers), a secondary but familiar layer of physical affordance is added, differentiating the urban machine from ordinary public benches. As apparent with I Have Feelings Too, the inclusion of computer vision (or motion sensors) to track movement would also expand the depth of interactions beyond human voice and enable a more natural flow of playing from approach to sitting and conversing. Therefore, the public bench would know when someone arrives, dwells at the space, or leaves, which, in turn, determines when it should greet, be playful, and stop talking.

Besides interactivity between humans and machines, our case study also suggested opportunities for interactions among machines as part of playful experiences in public space. Since we were able to implement three anthropomorphic public benches in close proximity, the overlapping commentary from each bench also formed an incidental conversation between machines when the benches gave verbal responses about similar topics at the same time. Mentioning ice-cream from a food stall behind them or declaring their love/hate for people, the situatedness of the conversations resulted in serendipitous moments hinting that the benches might be gossiping or passing remarks about the people around them. From the perspective of a user, such occurrences are akin to being in the middle of a playful dialogue or comedic exchange. With elements similar to theatre improvisation (or improv), this scenario points to a possible future where the human could join a group of urban machines in a seemingly spontaneous yet collaborative effort to generate playful narratives of city life. Although it was not intended as part of our study, this form of interaction would also broaden the social dynamics around public benches to include a different form of co-creation.

Nevertheless, we acknowledge that the context of our case study does restrict our understanding of user behaviour and associated activities. The conditions of the public festival implied an inherent willingness and playful mindset of people to participate and interact with our prototype. In contrast to everyday experiences, the willingness of festival-goers to tolerate and enjoy disruption by the anthropomorphized public benches is much higher. Hence, our findings are centred on uncovering the types of actions and experiences that are divergent to the norms of public sitting and did not measure attractiveness and desire of use. Considering these constraints, I Have Feelings Too is only one example of what could be done for its specific urban situation, but at the same time, probes into the reactions of people to further an initial discussion on the future of this design space.

\subsection{Towards Urban Machines as Player and Co-Creator}

Through our analysis of case studies, we utilised the mapping of quadrants to position and communicate our concept-driven design as it illustrates the potential of urban machines developing playful personalities and portraying humanistic attributes. Representing a smart, sensing, and disruptive design, I Have Feelings Too advocates a complex use of technological means to facilitate playful and expressive experiences. It also seeks playability through adaptive content 


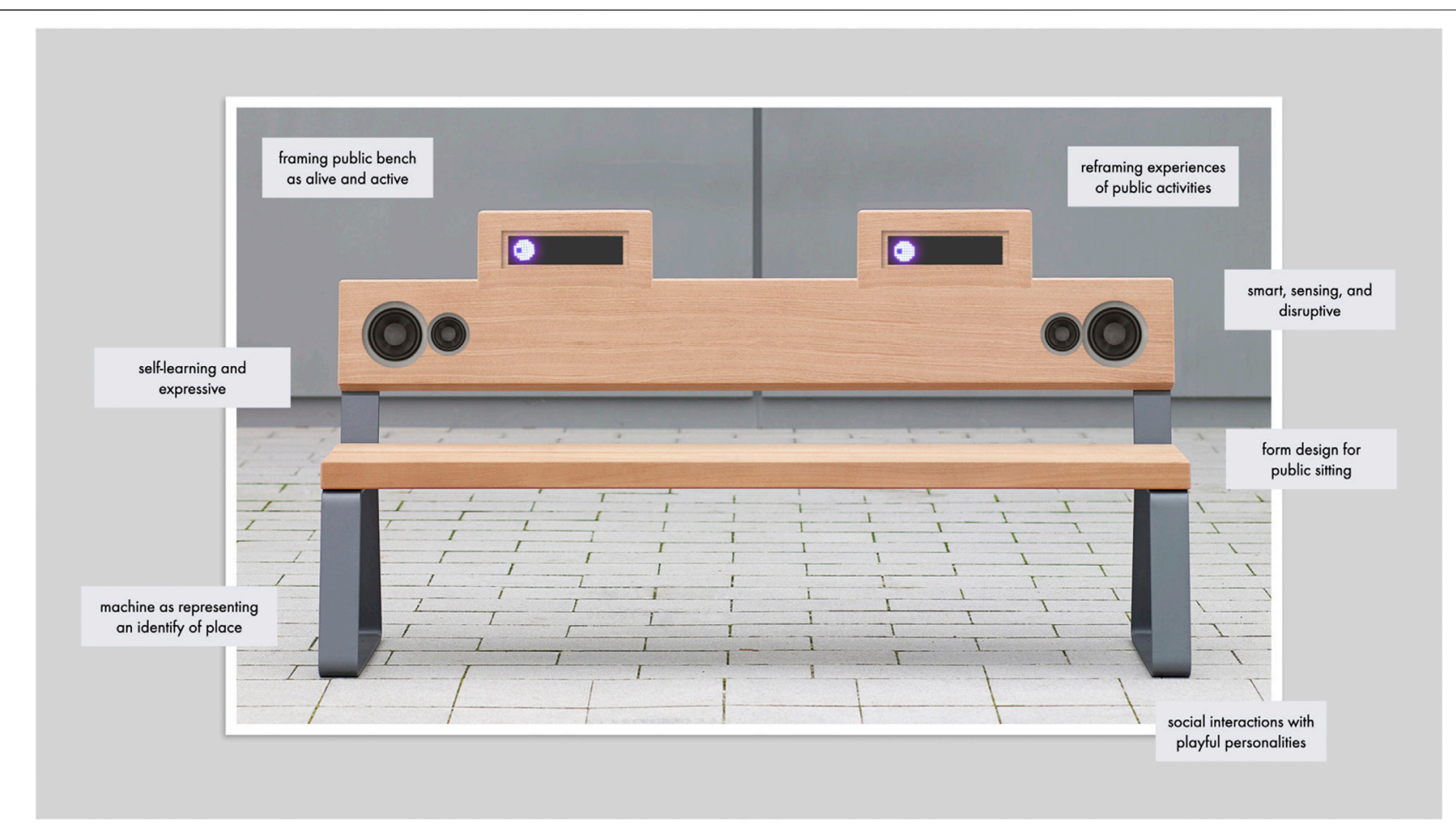

FIGURE 9 | An annotated portfolio (Gaver and Bowers, 2012) of the public bench envisioned as an anthropomorphized urban machine endowed with artificial intelligence. Original bench image [Public domain], via Architonic, https://www.architonic.com/en/product/westeifel-werke-campus-levis-bench/1235255.

changes and intricate interactivity with further potential for more advanced updates of its computerised system. In a possible world where the ideals of I Have Feelings Too are actualised, we speculate that leaps in the advancement of $\mathrm{AI}$, machine learning, and robotics would rapidly progress the evolution of street furniture into urban machines. Redesigned with an anthropomorphic form, the public bench retains the existing affordance of its street furniture type and still provides the basic function of sitting with its overall structure. However, it also redefines established norms of design to include speakers, motion sensors, and speech interfaces, thus drastically changing user attitudes toward the public bench by giving it human-like features such as voice, sight, and hearing. Challenging our acceptance and understanding of an intelligent, learning, and personified public bench, the concept is disruptive by nature with its aesthetics, functions, and introduction of unusual social interactions in cities (see Figure 9).

Exemplified by our urban prototype (as a speculative artefact), public benches designed as learning and expressive machines also cease to be part of the background setting in a city filled with common urban objects and pervasive digital screens. Instead, they stand out as talkative, strange, and even annoying at times. Like humans, the personality of each public bench is unique with developed likes and dislikes, which constantly evolves to the circumstances surrounding its location. Regardless, the concept outlined by I Have Feelings Too postulates all personified public benches as players of the smart and playable city. They are meant to be artificial companions of individuals and groups as playful entities of places. Predominately known for their capabilities to engage users in playful, social situations, the public benches would converse and play with humans and also encourage strangers to interact with one another while the street furniture serves as a mediator. Hence, the smart and playful public bench is no longer just a utility-it becomes an object of entertainment, a platform for expression, and a symbol of local culture.

Looking ahead beyond existing designs of public benches with dual functionalities of utility and play, I Have Feelings Too can also be envisioned as a future concept that positions urban machines to be co-creators of playful experiences in public spaces. From the perspective of placemaking with playful interactions, this notion of co-creation (Eggertsen Teder, 2019; Šuklje Erjavec and Ruchinskaya, 2019; Mengi, 2020) can be understood as a partnership or a collaboration between stakeholders with shared responsibilities in the process of making play. Since intelligent, learning, and personified public benches would be artificial, spatial entities that are representing the identity of places, they are also inevitably a "Playmaker" and a stakeholder of public space (see Figure 10). Learning from playing with humans while cultivating human-like features based on the changing landscape of its surrounding environment, urban machines will make play by automatically generating new personality traits, emotional expressions, and verbal responses for playful interactions. They may rewrite city 


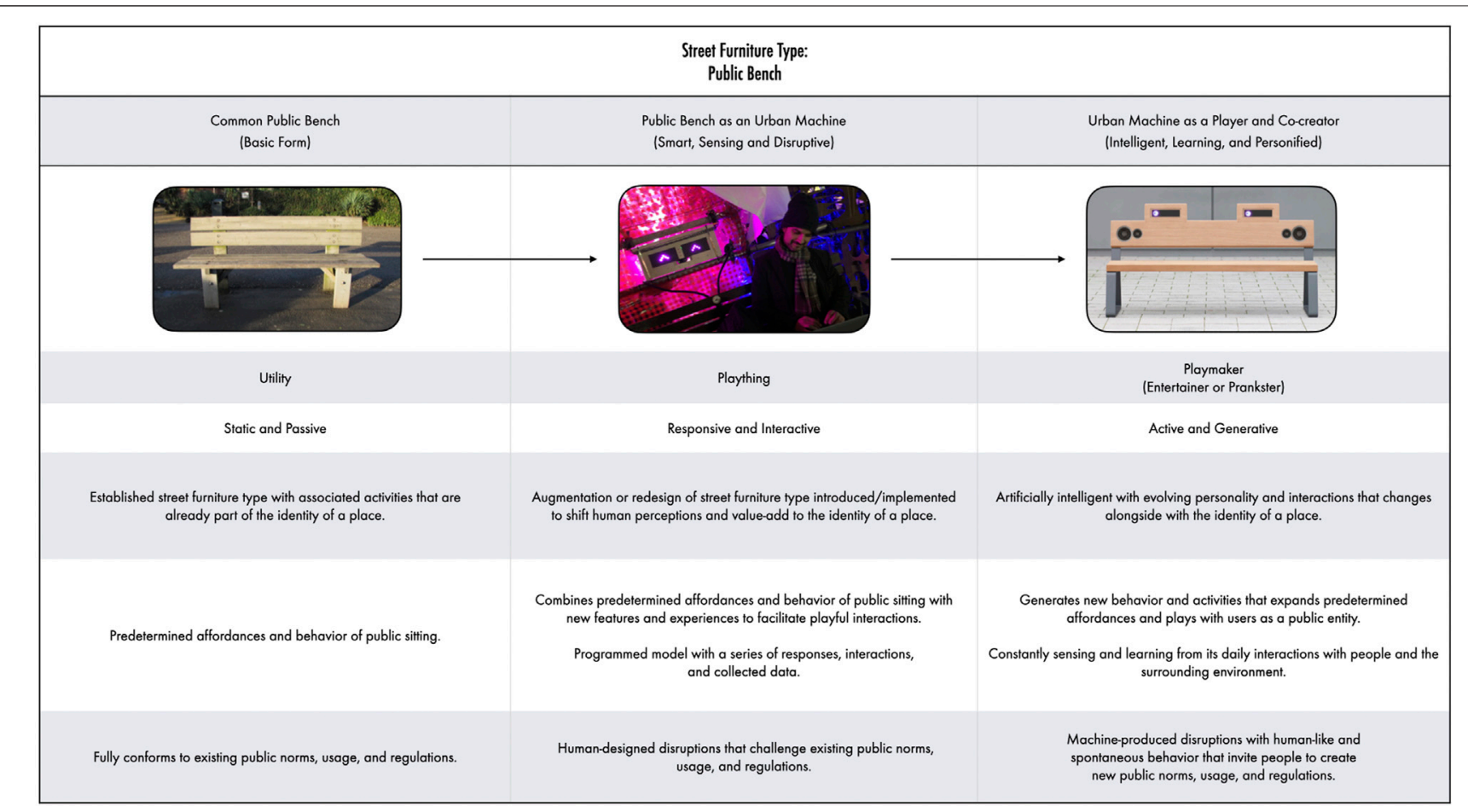

FIGURE $\mathbf{1 0}$ | Comparing key features in the evolution of the public bench into an urban machine representing as a player and co-creator.

stories, create new jokes, and try different pranks in order to expand their arsenal of playful activities. Alternatively, urban machines can also be programmed in ways that are not solely dependent on learning from how humans play. Beyond our concept-driven design with public benches, new genres have emerged with shape-changing interfaces and urban robots with examples like coMotion (Grönvall et al., 2014b) and Woodie (Hoggenmueller et al., 2020). Instead of us playing with them, these machines add playfulness to city life as spatial entities with their own behaviour in how they play humans and shape public situations.

As machine learning with AI progresses in the future of cities, the role of urban machines will shift from playthings for humans to active co-creators of play. Real-life urban machines for playful placemaking can develop localised personas and new narratives through their interactions with people and establish unique identities that are inherent to the overall atmosphere of a place. An urban machine can be supportive of existing urban practices and function as an entertainer to enliven an underutilised space by drawing crowds with performances. It can also be highly disruptive towards the mundane of social norms and transform into the neighbourhood prankster, pesky but memorable in its need to be the centre of attention via interactions with humans. With an appropriate fit of form, function, and meaning, the relationship between technology and cities is once again redefined, as the machine becomes the active agent molding public experiences to be personal and meaningful, changing a foreign space into a place of belonging.

\section{CONCLUSION}

In the context of the playable city, we sought to understand how the ordinary public bench could be repurposed and reframed as an urban machine for playful placemaking. Through a comparative study of design precedents and informed speculation, we analysed key examples of public benches that exhibited degrees of smartness and disruption through the lens of play. As smarter technology is embedded in public benches, more opportunities open up for technology-enabled playful transformations. In the examples we analysed, the intention of the designer was key to understanding how disruptive or conforming a specific design was, although the evolving urban context and user appropriation can also influence human perception and behaviour.

The notion of the urban machine is useful here to capture the growing agency of emerging technologies, in particular artificial intelligence. Our concept-driven prototype and speculative artefact, I Have Feelings Too, goes some way towards exploring a smart, sensing, and disruptive urban machine that is designed to be playful. Whilst not being a truly functioning AI, as a technology probe it gave us insight into how people might react and interact with a social group of anthropomorphic street furniture that communicates through emotional and verbal expressions.

Beyond the support of playing activities for humans, complex urban machines can be developed to display the playful nature inherent to sentient beings. As such, urban play designs are no longer limited to humans as primary players or activators of playful interactions. Instead, urban machines can act upon humans by being playful themselves to refresh novelty and 
inspire participation, thus expanding on their potential to partake an increasingly active role as future co-creators of play in the cities of tomorrow.

\section{ETHICS STATEMENT}

The studies involving human participants were reviewed and approved by The University of Sydney-Human Research Ethics Committee. Written informed consent to participate in this study was provided by the participant's legal guardian/next of kin. Written informed consent was obtained from the individual(s) for the publication of any potentially identifiable images or data included in this article.

\section{REFERENCES}

Alfrink, K. (2015). The Gameful City. The Gameful World. Cambridge, MA: The MIT Press, 527.

Allam, Z., and Dhunny, Z. A. (2019). On Big Data, Artificial Intelligence and Smart Cities. Cities. 89, 80-91. doi:10.1016/j.cities.2019.01.032

Auger, J. (2013). Speculative Design: Crafting the Speculation. Digital Creativity. 24, 11-35. doi:10.1080/14626268.2013.767276

Bekker, T., de Valk, L., and Eggen, B. (2014). A Toolkit for Designing Playful Interactions: The Four Lenses of Play. J. ambient intelligence smart environments. 6, 263-276. doi:10.3233/ais-140259

Boehner, K., Vertesi, J., Sengers, P., and Dourish, P. (2007). How HCI Interprets the Probes. New York, NY, USA: Association for Computing Machinery, 1077-1086.

Brignull, H., and Rogers, Y. (2003). "Enticing People to Interact with Large Public Displays in Public Spaces," in Proceedings of INTERACT (Brighton, UK), $17-24$.

Caillois, R. (2001). Man, Play, and Games. Urbana: University of Illinois Press.

Calder, K. E. (2016). Singapore : Smart City, Smart State. Washington, D.C: Brookings Institution Press.

Cardullo, P. (2021). Citizens in the 'smart City' : Participation, Co-production, Governance. Routledge Studies in Urbanism and the City. Abingdon, Oxon: Routledge.

Chew, L. (2020). "A Contemporary Way of Playing-Designing Interactive Urban Play for Playful Placemaking," in Companion Publication of the 2020 ACM Designing Interactive Systems Conference, 497-501.

Cid, F., Moreno, J., Bustos, P., and Núñez, P. (2014). Muecas: a Multi-Sensor Robotic Head for Affective Human Robot Interaction and Imitation. Sensors. 14, 7711-7737. doi:10.3390/s140507711

Coombs, G., Sade, G., and McNamara, A. (2018). Undesign: Critical Practices at the Intersection of Art and Design. Boca Raton, FL: Taylor \& Francis.

Cugurullo, F. (2021). Frankenstein Urbanism: Eco, Smart and Autonomous Cities, Artificial Intelligence and the End of the City. Abingdon, Oxon: Routledge.

Del Signore, M. (2018). Urban Machines: Public Space in a Digital Culture. Babel. Trento: ListLab.

Deleuze, G. (1987). A Thousand Plateaus : Capitalism and Schizophrenia. London: Athlone Press.

Der, R., and Martius, G. (2012). Ger ; Eng the Playful Machine: Theoretical Foundation and Practical Realization of Self-Organizing Robots. Berlin, Heidelberg: Springer-Verlag. 1. aufl. edn.

Dow, S., MacIntyre, B., Lee, J., Oezbek, C., Bolter, J. D., and Gandy, M. (2005). Wizard of $\mathrm{Oz}$ Support Throughout an Iterative Design Process. IEEE Pervasive Comput. 4, 18-26. doi:10.1109/mprv.2005.93

Dunne, A. (2013). Speculative Everything : Design, Fiction, and Social Dreaming. Cambridge, Massachusetts: The MIT Press.

Eberle, S. G. (2014). The Elements of Play: Toward a Philosophy and a Definition of Play. Am. J. play. 6, 214.

\section{AUTHOR CONTRIBUTIONS}

LC is the lead author, with LH and LL being the second and third co-authors, respectively.

\section{ACKNOWLEDGMENTS}

We would like to thank the Willoughby City Council and Design Lab at The University of Sydney for their support in the development and showcase of I Have Feelings Too during Vivid Sydney at Chatswood 2018. We were also very grateful to the journal editors and reviewers for their patience and feedback in the revision of our article.

Eggertsen Teder, M. (2019). Placemaking as Co-Creation - Professional Roles and Attitudes in Practice. CoDesign. 15, 289-307. doi:10.1080/15710882.2018.1472284 Fingas, J. (2016). Intel Unveils a Drone Made for Aerial Light Shows. Engadget.

Forlano, L., and Mathew, A. (2014). From Design Fiction to Design Friction: Speculative and Participatory Design of Values-Embedded Urban Technology. J. Urban Technology. 21, 7-24. doi:10.1080/ 10630732.2014.971525

Fredericks, J., Caldwell, G. A., and Tomitsch, M. (2016). "Middle-out Design," in Proceedings of the 28th Australian Conference on Computer-Human Interaction (New York, NY, USA: Association for Computing Machinery), 200-204. OzCHI '16. doi:10.1145/ 3010915.3010997

Fuchs, M. (2018). Subversive Gamification. Singapore: Springer Singapore, 181-191. doi:10.1007/978-981-10-1891-6_12

Gaver, B., and Bowers, J. (2012). Annotated Portfolios. Interactions. 19, 40-49. doi:10.1145/2212877.2212889

Gaver, W., Bowers, J., Boucher, A., Gellerson, H., Pennington, S., Schmidt, A., et al. (2004). "The Drift Table: Designing for Ludic Engagement," in CHI '04 Extended Abstracts on human factors in computing systems (ACM) (CHI EA '04), 885-900.

Gaver, W. (2015). Position Statement: Homo Ludens (Subspecies Politikos). The Gameful World. The MIT Press, 513.

Giuliani, M., Petrick, R. P. A., Foster, M. E., Gaschler, A., Isard, A., Pateraki, M., and Sigalas, M. (2013). "Comparing Task-Based and Socially Intelligent Behaviour in a Robot Bartender," in Proceedings of the 15th ACM on International Conference on Multimodal Interaction (New York, NY, USA: Association for Computing Machinery), 263-270. ICMI '13. doi:10.1145/ 2522848.2522869

Glas, R., Lammes, S., Raessens, J., de Lange, M., and de Vries, e. (2019). Imar. The Playful Citizen : Civic Engagement in a Mediatized Culture. Games and Play. Amsterdam: Amsterdam University Press.

Grönvall, E., Kinch, S., Petersen, M. G., and Rasmussen, M. (2014a). "Causing Commotion With a Shape-Changing Bench: Experiencing Shape-Changing Interfaces in Use," in Proceedings of the SIGCHI Conference on human factors in computing systems (ACM), 2559-2568.

Grönvall, E., Kinch, S., Petersen, M. G., and Rasmussen, M. K. (2014b). "Causing Commotion With a Shape-Changing Bench," in Proceedings of the SIGCHI Conference on Human Factors in Computing Systems (New York, NY, USA: Association for Computing Machinery), 2559-2568. CHI '14. doi:10.1145/ 2556288.2557360

Hård, M., and Misa, T. J. (2010). Urban Machinery: Inside Modern European Cities. Inside Technology. Cambridge, Mass: MIT Press. 1st mit press pbk. ed. edn.

Hespanhol, L. (2017). Media Architecture Compendium Digital Placemaking. Stuttgart, Germany: avedition.

Hoggenmueller, M., Hespanhol, L., and Tomitsch, M. (2020). "Stop and Smell the Chalk Flowers: A Robotic Probe for Investigating Urban Interaction With Physicalised Displays," in Proceedings of the 2020 CHI Conference on Human Factors in Computing Systems, 1-14. 
Huizinga, J. (1949). "Homo Ludens : a Study of the Play-Element in Culture. International Library of Sociology," in The Sociology of Culture (London: Routledge \& K. Paul), 3.

Hutchinson, H., Hansen, H., Roussel, N., Eiderbäck, B., Mackay, W., Westerlund, B., et al. (2003). "Technology Probes," in Proceedings of the SIGCHI Conference on Human Factors in Computing Systems (New York, NY, USA: Association for Computing Machinery), 17-24. doi:10.1145/ 642611.642616

Innocent, T. (2019). Citizens of Play: Revisiting the Relationship Between Playable and Smart Cities. Making Smart Cities More Playable. Singapore: Springer Singapore, Gaming Media and Social Effects, 25-49. doi:10.1007/978-981-139765-3_2

Innocent, T. (2016). "Play and Placemaking in Urban Art Environments," in Proceedings of the 3rd Conference on Media Architecture Biennale (New York, NY, USA: Association for Computing Machinery). doi:10.1145/ 2946803.2946805

Jacobs, J. (2016). The Death and Life of Great American Cities. New York, NY: Random House. Available at: https://books.google.com.au/books? id=hklmDQAAQBAJ

Kanniah, J. (2014). Practical Robot Design: Game Playing Robots. first edition. Boca Raton, FL: CRC Press, an imprint of Taylor and Francis.

Kim, S., and Choudhury, A. (2021). Exploring Older Adults' Perception and Use of Smart Speaker-Based Voice Assistants: A Longitudinal Study. Comput. Hum. Behav. 124, 106914. doi:10.1016/j.chb.2021.106914

Kirwan, C., and Zhiyong, F. (2020). Smart Cities and Artificial Intelligence: Convergent Systems for Planning, Design, and Operations. Smart Cities and Artificial Intelligence. San Diego: Elsevier.

Korsgaard, H., and Brynskov, M. (2014). "City Bug Report: Urban Prototyping as Participatory Process and Practice," in Proceedings of the 2nd Media Architecture Biennale Conference (ACM), 21-29.

Lee, J. M., Baek, J., and Ju, D. Y. (2018). Anthropomorphic Design: Emotional Perception for Deformable Object. Front. Psychol. 9, 1829. doi:10.3389/ fpsyg.2018.01829

Leorke, D., and Owens, e. (2020). Marcus. Games and Play in the Creative, Smart and Ecological City. Routledge Research in Sustainable Urbanism. London: RoutledgeTaylor Francis Group.

Ligthart, L. P., and Ramjee, e. (2017). Prasad. Breakthroughs in Smart City Implementation. Gistrup, Denmark: River Publishers Series in CommunicationsRiver Publishers.

Lim, S., Abdul Malek, J., Abdul Malek, J., Hussain, M. Y., and Tahir, Z. (2018). Citizen Participation in Building Citizen-Centric Smart Cities. Geografia. 14, 42-53. doi:10.17576/geo-2018-1404-04

Lucero, A., Karapanos, E., Arrasvuori, J., and Korhonen, H. (2014). Playful or Gameful? Interactions. 21, 34-39. doi:10.1145/2590973

Luostarinen, N. (2019). Ambiguity of (Traffic) Signs. The J. Play Adulthood. 1, 24-44.

Melson, G. F., Kahn, Jr., P. H., Jr, Beck, A., and Friedman, B. (2009). Robotic Pets in Human Lives: Implications for the Human-Animal Bond and for Human Relationships With Personified Technologies. J. Soc. Issues. 65, 545-567. doi:10.1111/j.1540-4560.2009.01613.x

Mengi, O. (2020). Creative Placemaking Revisited: Exploring Major Drivers for the Practice of Making and Co-Creation. Ijkbd. 11, 220-243. doi:10.1504/ ijkbd.2020.10035186

Morrison, A., Mitchell, P., and Brereton, M. (2007). "The Lens of Ludic Engagement: Evaluating Participation in Interactive Art Installations," in Proceedings of the 15th international conference on multimedia (ACM), 509-512.

Mosco, V. (2019). The Smart City in a Digital worldSocietyNow. first edition. Bingley: Emerald Publishing Limited.

Muller, L. (2013). Speculative Objects: Materialising Science Fiction. 19th International Symposium on Electronic Art.

Nagenborg, M., Stone, T., González Woge, M., and Vermaas, P. E. (2021). Technology and the City: Towards a Philosophy of Urban Technologies, Philosophy of Engineering and Technology, 6. Cham: Springer International Publishing AG.

Nagenborg, M. (2018). Urban Robotics and Responsible Urban Innovation. Ethics Inf. Technology. 22 (4), 344-355. doi:10.1007/s10676-018-9446-8
Nam, T., and Pardo, T. A. (2011). "Conceptualizing Smart City with Dimensions of Technology, People, and Institutions," in Proceedings of the 12th Annual International Digital Government Research Conference: Digital Government Innovation in Challenging Times (New York, NY, USA: Association for Computing Machinery), 282-291. doi:10.1145/ 2037556.2037602

Nassar, M. A., Luxford, L., Cole, P., Oatley, G., and Koutsakis, P. (2019). The Current and Future Role of Smart Street Furniture in Smart Cities. IEEE Commun. Mag. 57, 68-73. doi:10.1109/mcom.2019.1800979

[Dataset] Newstex (2020). Video Interview: Ai-Da, the World's First Ultra-realistic Robot Artist. London: Newstex.

Nijholt, A. (2020). Making Smart Cities More Playable Exploring Playable CitiesGaming Media and Social Effects. 1st ed. Singapore: Springer Singapore.

Nijholt, A. (2017). Towards Playful and Playable Cities. Singapore: Springer Singapore, 1-20. doi:10.1007/978-981-10-1962-3_1

[Dataset] Urban, Adj (2021). OED Online. Oxford University Press. Available at: www.oed.com/view/Entry/220386 (Accessed November 4, 2021).

Pelikan, H. R. M., Broth, M., and Keevallik, L. (2020). "'Are You Sad, Cozmo?"," in Proceedings of the 2020 ACM/IEEE International Conference on Human-Robot Interaction (New York, NY, USA: Association for Computing Machinery), 461-470. HRI '20. doi:10.1145/ 3319502.3374814

Poushneh, A. (2021). Humanizing Voice Assistant: The Impact of Voice Assistant Personality on Consumers' Attitudes and Behaviors. J. retailing consumer Serv. 58, 102283. doi:10.1016/j.jretconser.2020.102283

Prassler, E. E., Zöllner, M., Bischoff, R., Burgard, W., Haschke, R., Hägele, M., et al. (2012). Towards Service Robots for Everyday Environments : Recent Advances in Designing Service Robots for Complex Tasks in Everyday Environments. Springer Tracts Adv. Robotics 76, 526.

Rodriguez Bolívar, M. P., and Alcaide Munoz, L. (2019). E-Participation in Smart Cities: Technologies and Models of Governance for Citizen Engagement. Public Adm. Inf. Technology. 34. doi:10.1007/978-3-31989474-4

Salles, A., Evers, K., and Farisco, M. (2020). Anthropomorphism in Ai. AJOB Neurosci. 11, 88-95. doi:10.1080/21507740.2020.1740350

Shin, D.-H. (2009). Ubiquitous City: Urban Technologies, Urban Infrastructure and Urban Informatics. J. Inf. Sci. 35, 515-526. doi:10.1177/ 0165551509100832

Stokes, B., Baumann, K., Bar, F., and Caldwell, B. (2017). Creative Placemaking for Neighborhoods: Positioning a Game to Circulate Stories. International Communication Association Annual Conference (67th Annual)

Stokes, B., Bar, F., Baumann, K., Caldwell, B., and Schrock, A. (2021). Urban Furniture in Digital Placemaking: Adapting a Storytelling Payphone across los angeles. Convergence. 27, 711-726. doi:10.1177/ 1354856521999181

Stolterman, E., and Wiberg, M. (2010). Concept-Driven Interaction Design Research. Human-computer interaction. 25, 95-118. doi:10.1080/ 07370020903586696

Šuklje Erjavec, I., and Ruchinskaya, T. (2019). A Spotlight of Co-creation and Inclusiveness of Public Open Spaces. Cham: Springer International Publishing, 209-223. doi:10.1007/978-3-030-13417-4_17

Tekinbas, K. S., and Zimmerman, E. (2003). Rules of Play : Game Design Fundamentals. Cambridge, Mass: MIT Press.

Tomitsch, M., McArthur, I., Haeusler, M. H., and Foth, M. (2015). The Role of Digital Screens in Urban Life: New Opportunities for Placemaking. Citizen's Right to the Digital City. Singapore: Springer Singapore, 37-54. doi:10.1007/ 978-981-287-919-6_3

Turner, T. K. (2017). Robot sophia Will Change the World. Carlsbad, CA: University Wire.

Ullah, Z., Al-Turjman, F., Mostarda, L., and Gagliardi, R. (2020). Applications of Artificial Intelligence and Machine Learning in Smart Cities. Computer Commun. 154, 313-323. doi:10.1016/j.comcom.2020.02.069

Wakkary, R., Odom, W., Hauser, S., Hertz, G., and Lin, H. (2015). "Material Speculation: Actual Artifacts for Critical Inquiry," in Proceedings of The Fifth Decennial Aarhus Conference on Critical Alternatives, 97-108. doi:10.7146/ aahcc.vli1.21299 
Whyte, W. H. (1980). The Social Life of Small Urban Spaces. Washington, DC: Conservation Foundation.

Wong, R. Y., and Khovanskaya, V. (2018). Speculative Design in Hci: From Corporate Imaginations to Critical Orientations. New Dir. Third Wave Human-Computer Interaction. 2, 175-202. doi:10.1007/978-3-319-73374-6_10 Yarosh, S., Thompson, S., Watson, K., Chase, A., Senthilkumar, A., Yuan, Y., et al. (2018). "Children Asking Questions: Speech Interface Reformulations and Personification Preferences," in Proceedings of the 17th ACM Conference on interaction design and children (ACM), 300-312.

Conflict of Interest: The authors declare that the research was conducted in the absence of any commercial or financial relationships that could be construed as a potential conflict of interest.
Publisher's Note: All claims expressed in this article are solely those of the authors and do not necessarily represent those of their affiliated organizations, or those of the publisher, the editors, and the reviewers. Any product that may be evaluated in this article, or claim that may be made by its manufacturer, is not guaranteed or endorsed by the publisher.

Copyright (C) 2021 Chew, Hespanhol and Loke. This is an open-access article distributed under the terms of the Creative Commons Attribution License (CC $B Y$ ). The use, distribution or reproduction in other forums is permitted, provided the original author(s) and the copyright owner(s) are credited and that the original publication in this journal is cited, in accordance with accepted academic practice. No use, distribution or reproduction is permitted which does not comply with these terms. 


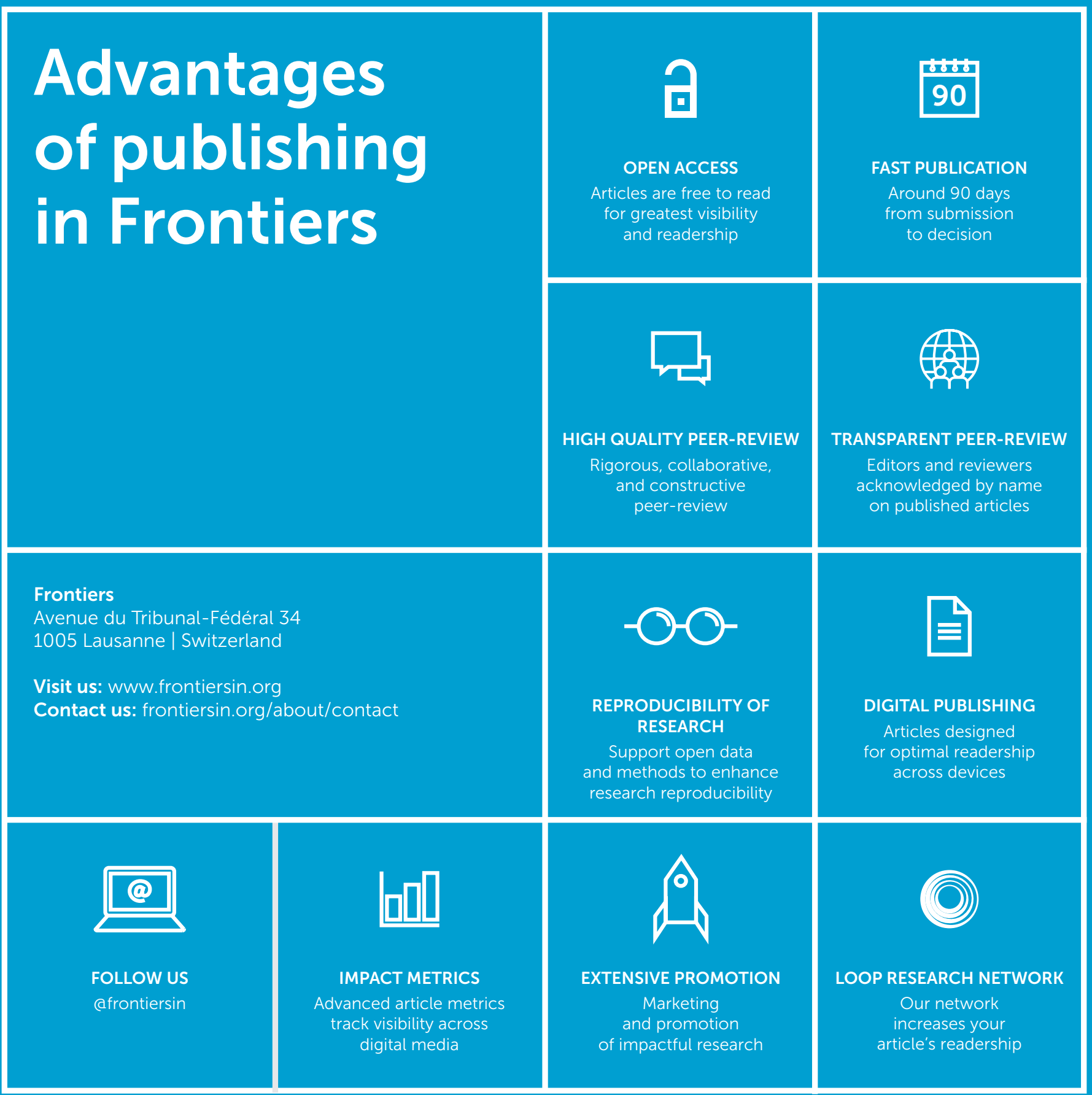

